\title{
Forgetfulness and cognitive aging : prevalence, characteristics, and determinants
}

Citation for published version (APA):

Ponds, R. W. H. M. (1998). Forgetfulness and cognitive aging : prevalence, characteristics, and determinants. [Doctoral Thesis, Maastricht University]. NeuroPsych Publishers. https://doi.org/10.26481/dis.19981210rp

Document status and date:

Published: 01/01/1998

DOI:

10.26481/dis.19981210rp

Document Version:

Publisher's PDF, also known as Version of record

\section{Please check the document version of this publication:}

- A submitted manuscript is the version of the article upon submission and before peer-review. There can be important differences between the submitted version and the official published version of record.

People interested in the research are advised to contact the author for the final version of the publication, or visit the DOI to the publisher's website.

- The final author version and the galley proof are versions of the publication after peer review.

- The final published version features the final layout of the paper including the volume, issue and page numbers.

Link to publication

\footnotetext{
General rights rights.

- You may freely distribute the URL identifying the publication in the public portal. please follow below link for the End User Agreement:

www.umlib.nl/taverne-license

Take down policy

If you believe that this document breaches copyright please contact us at:

repository@maastrichtuniversity.nl

providing details and we will investigate your claim.
}

Copyright and moral rights for the publications made accessible in the public portal are retained by the authors and/or other copyright owners and it is a condition of accessing publications that users recognise and abide by the legal requirements associated with these

- Users may download and print one copy of any publication from the public portal for the purpose of private study or research.

- You may not further distribute the material or use it for any profit-making activity or commercial gain

If the publication is distributed under the terms of Article $25 \mathrm{fa}$ of the Dutch Copyright Act, indicated by the "Taverne" license above, 


\section{Forgetfulness and cognitive aging}

Prevalence, characteristics, and determinants 
Forgetfulness and cognitive aging: Prevalence, characteristics, and determinants / Rudolf Wilhelmus Henricus Maria Ponds. - Maastricht: Neuropsych Publishers Maastricht. - Ill.

Thesis Mastrich University, - Witla ref. -

With summary in Dutch.

ISBN $\quad 90-75579-09-8$

NuGI 716743

Subject headings: menory - aging - health

Produchon: Datawyse I University Press Maastricht

Neuropsych Publishers is a nomprofit organization which aims at promoting the science of 'Brain and Behalwior' and improving the application of the products of this science in health care and education. Neuropsych Publisher accomplishes these aims by publishing books, dissertations and other products of scientific activity, by disseminating educational materials and publication of tests, assessment scales and other psychometric instruments in the field of Neuropsychology, Neuropsychiatry and other areas within the donain of Brain and Behavior.

\section{Postal address:}

Neuropsych Publishers

Department of Psychiatry and Neuropsychology

Masastricht University

P.O. Box 6.16

NL-6200 MD Maustricht

The Netherlands 


\section{Forgetfulness and cognitive aging}

Prevalence, characteristics, and determinants

\section{PROEFSCHRIFT}

ter verkrijging van de graad van doctor aan de Universiteit Maastricht, op gezag van de Rector Magnificus, Prof. dr. A. C. Nieuwenhuijzen Kruseman, volgens het besluit van het College van Decanen, in het openbaar te verdedigen op donderdag 10 december 1998 om 14.00 uur

door

Rudolf Wilhelmus Henricus Maria Ponds

geboren op 20 februari 1960 te Lievelde 
Prof. dr. J. Jolles

Beoordelingscommissie

Prof. dr. M.A. van den Hout (voorzitter)

Prof. dr. B.G. Deelman (Rijksuniversiteit Groningen)

Dr. M.M.A. Derix

Prof. dr. H.T. van der Molen (Open Universiteit, Heerlen)

Prof. dr. H.M. van Praag

The studies described in this thesis were carried out at the Maastricht Brain \& Behavior Institute of the Maastricht University (department of Psychiatry and Neuropsychology) and the University Hospital Manstricht. The first phase of the Maastricht Aging Study (MAAS) was supported by the Netherlands Programme for Research on Aging (NESTOR - Nederlands Stimuleringsprogramma Ouderenonderzoek).

Publication of this thesis was financially supported by: BAYER B.V., Bristol-Myers Squibb B.V., Ell Lilly Nederland B.V., Hoechst Marion Roussel B.V., Pfizer B.V., Sigma-Tau Ethifarma B.V., and UCB Pharma B.V. Furthermore, additional financial support for publication by the "Stichting Alzheimer Fonds' and the 'Internationale Stichting Alzheimer Onderzoek' is gratefully acknowledged. 


\section{Contents}

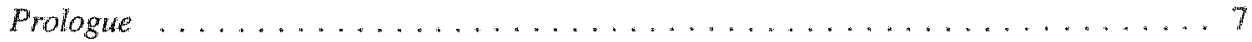

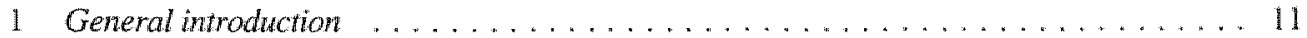

Introduction ............................... 11

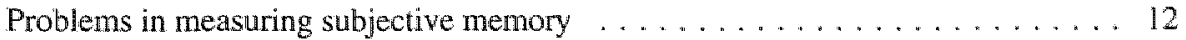

Metamemory: Different aspects of subjective memory . . . . . . . . . . . . 14

Memory self-efficacy: A mediating role in subjective memory in old age . . . . . 15

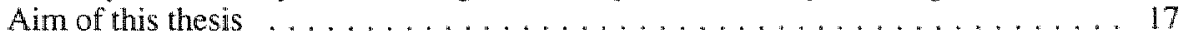

Outline of this thesis $\ldots \ldots \ldots \ldots \ldots \ldots \ldots \ldots$

2 Prevalence and covariates of subjective forgetfulness in a nomal population $\ldots \ldots \ldots$

Abstract . . . . . . . . . . . . . . . . . . . . . . . . . . 23

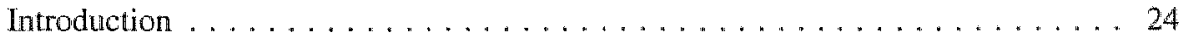

Method ................................... 25

Results ............................... 28

Discussion . . . . . . . . . . . . . . . . . . . . . . . 34

3 Age-related changes in subjective cognitive functioning ... . . . . . . . 37

Abstract . . . . . . . . . . . . . . . . . . . . . . . . . 37

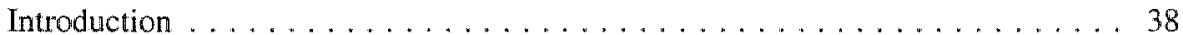

Method . . . . . . . . . . . . . . . . . . . . . . . . . . . . . 39

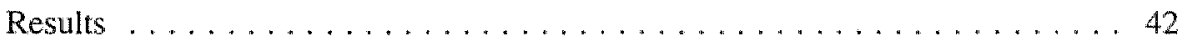

Discussion . . . . . . . . . . . . . . . . . . . . . . . 46

4 The Cognitive Failure Questionnaire: Factor structure, effects of age, sex, and education and the relation with cognitive performance and psychosocial variables $\ldots . .49$

Abstract . . . . . . . . . . . . . . . . . . . . . . . . . . . . . . 49

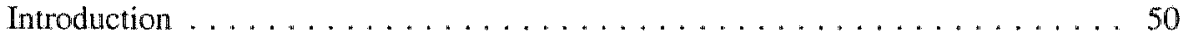

Method ................................ . . . 53

Results ............................. 56

Discussion . . . . . . . . . . . . . . . . . . . . . . 62

5 The abridged Dutch Metamemory in Adulthood (MIA) questionnaire:

Structure, and effects of age, sex, and education . . . . . . . . . . . . . 69

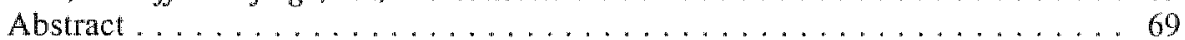

Introduction . . . . . . . . . . . . . . . . . . . . . 70

Method ..................................... 72

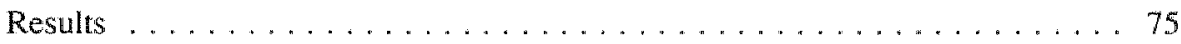

Discussion .................................... 84

6 Predictors of subjective memory as measured with the Metamemory in Adulhood

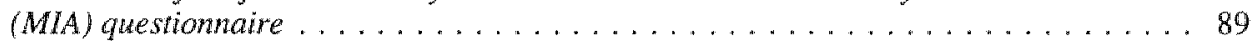

Abstract . . . . . . . . . . . . . . . . . . . . . 89

Introduction . . . . . . . . . . . . . . . . . . . . . . 90

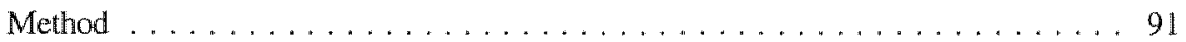

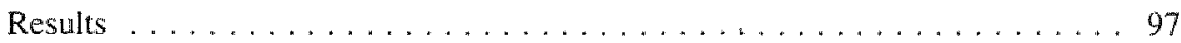

Discussion . . . . . . . . . . . . . . . . . . 101 
7 Psychosocial predictors of metamemory in middle-aged and old people . . . . . . 107

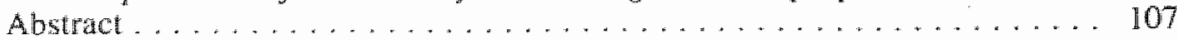

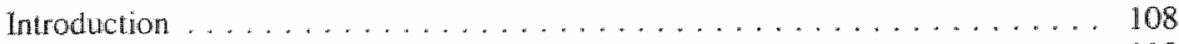

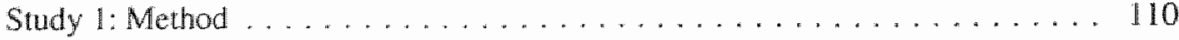

Study 1: Results ................................. 113

Study 2 Method ................................ 114

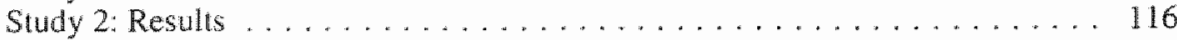

Discussion ............................... 118

8 Memory complaints in elderty people: The role of memory abilities, metamemory,

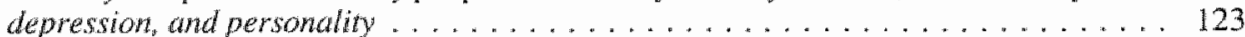

Abstract . . . . . . . . . . . . . . . . . . . . . . . . . . . . 123

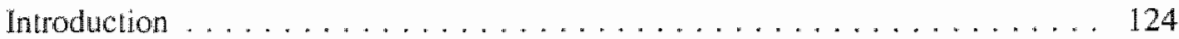

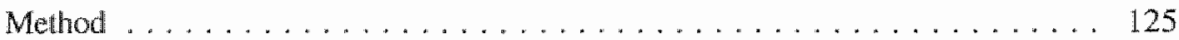

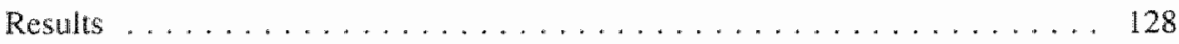

Discussion . . . . . . . . . . . . . . . . . . . . . 133

9 Relation between Memory Self-Efficacy, performance prediction, and performance feedback in elderly adults . . . . . . . . . . . . . . 139

Abstract . . . . . . . . . . . . . . . . . . . . . . . . . . . . . 139

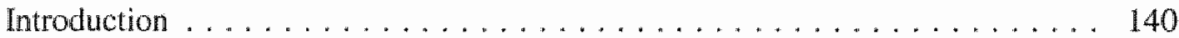

Method . . . . . . . . . . . . . . . . . . . . . . . . 143

Results . . . . . . . . . . . . . . . . . . . . . . . 148

Discussion ................................ 156

10 Concluding remarks . . . . . . . . . . . . . . . . . . . . . 161

Age-related changes in subjective memory: It depends on what and how you ask . 161

Characteristics of age-related differences in subjective memory . . . . . . . 162

Relation between objective and subjective memory . . . . . . . . . . . . 164

Subjective memory: Non-cognitive factors . . . . . . . . . . . . . 165

Memory self-efficacy and aging: A working model . . . . . . . . . . . 167

Designing memory training programs . . . . . . . . . . . . . . 168

Conclusion ................................. 169

Summary ............................. 171

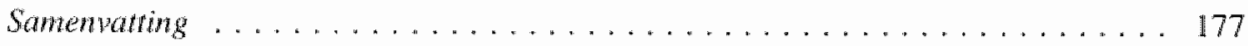

Dankwoond ................................. 183

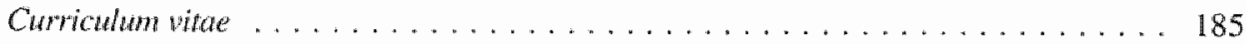

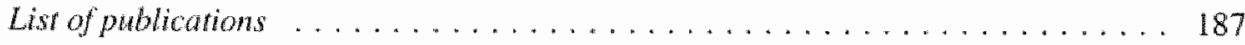




\section{Prologue}

Many elderly people have serious memory complaints which compromise their quality of life to such an extent that they seek professional help (Commissaris et al, 1996; Commissaris, Verthey, Ponds, Jolles \& Kok, 1994; Jolles, Verhey, Riedel \& Houx, 1995). In the last decade, many specialized memory clinics have opened to meet this need. In May 1986 the Maastrich Memory Chinc (MMC) of the University Hospital of Maastricht was opened (Verhey, 1993). The MMC is a facility for the diagnosis and treatment of memory problems or dementia, based on a multidisciplinary approach (psychiatry, neurology, and neuropsychology). It also serves as a research center for the study of memory disorders, with particular emphasis on the early stages of dementia. Up to now, almost 3000 patients have attended the MMC.

Approximately $15 \%$ of the, mostly, elderly patients who attend the MMC do not show any sign of abnormal cognitive functioning after extensive neuropsychological examination, despite the serious memory problems they report. Their memory problems are mostly related 10 psychological factors, such as fear of incipient dementia, low self-esteem, depressed mood, or a neurotic personality structure. The following two case reports may serve to illustrate this.

\section{Case $1^{a}$}

TM, a 70-year old musician, was referred to the Maastricht Memory Clinic of the University Hospital of Maastricht because of memory complaints. He was referred by his neurologist who had diagnosed mild Parkinson disease for which no treatment was yet considered. TM complained about forgetting names and detaills of recent and past events for a year, at which time one of his grandchildren died. There were no complaints about attention and concentration, wordfinding, reading, calculation, writing, or orientation. His memory problems did not interfere with his daily activities, which was confirmed by his wife, but he had an intense fear of forgetting things. Whenever he forgot something. TM got into panic despite reassurance from family members. This panic was associated with shorthess of breath. tachycardia, sweating, dizziness, and a sensation of pain in the chest. This panic remained until somebody prompted him about what he tried to remember. TM felt very embarrassed about his forgetfulness, especially when he forgot names, and eventually avoided situations in which he felt he might forget something. For example, he canceled his subscription to the newspaper and got rid of his television. After reading the newspaper or watching television, he could not resist rehearsing the information he had read or seen, which inewitably was. always incomplete. Moreover, he had forbidden his family to tell him names or to speak about events he might forget. He avoided going outside the house, because he might see and read the business names on trucks in the street and was afraid that he might not remenaber these names later in the day. He would wake up early in the morning and force himself to

a This case report has been published in: Verhey, F. R. I., Ponds, R, W. H. M., van der Lugl, P. J. M., \& Jolles, J. (1991). Een nieuw psychogeriatrisch syndroom: De vergeetfobie (A case of phobia about forgeting: A. new symdrome in the era of dementia). Medisch Copract, 46, 575-576. 
think about some person whose name the could not remember (e.g., the name of a famous American tapdancer in the $50 \mathrm{~s}$ ). He would then panic and wake up his wife to ask her the name (Fred Astaire). He also kept a very extensiwe diary of his dally activities, which he used to refer to it he could not clearly remember something at night. TM realized that his fear of forgetting was disproportionate and felt severely handicapped by his avoidance reactions. Nevertheless, he could not resist the thought that his forgetfulness might be a sign of denentia.

Psychiatric examination revealed mild symptoms of depression, secondary to the phobia of forgetting. On the Mini Mental State Examination he had a score of 29 out of 30 . The results of blood tests and a CT-scan of the brain were normal. There were no psychiatric problems before the present history. His family described him as a sensitive person. TM had been examined by a cardiologist 25 years ago for vague angina pectoris complaints and about 5 years ago a tentative diagnosis of $\mathrm{M}$. Bechterev was made by a rheumatologist. There were no other illnesses in the past and there was no Parkinsonism or dementia in the familly. Neuropsychollogical examination showed only a very slight cognitiwe impaiment with respect to the active reproduction of newly acquired verbal information (but normal recognition), and a slightly decreased rate of information processing. He was of average intelligence and his perceptual and language abilities were nomal.

The diagnosis was a simple phobia about forgetting with panic attacks, mild Parkinson syndrome, and wery mild cognitiwe disturbances, definitely not severe enough to warrant the diagnosis of dementia. The observed cognitive dysfunctions were probably related to the mildly depressed mood of the patient. Because follow-up data for this patient were not available of this patient, it cannot be ruled out that the cognitive dysfunctions might turn out to be the very early signs of subcortical dementia related to Parkinson disease. For now, it was clear that the disproportional fear of forgetting was in itself sufficient to sustain or even worsen actual forgetting.

Case 2

MM was a 60-year old women who was referred to the Maastricht Memory Clinic by her neurologist because of memory complaints. She had had these complaints for 7 years, but in the last 2 years she experienced far more hinder from them. She also complained about problems of concentration. She felt very embarrassed about her memory problems and stathed to avoid situations in which she would meet other people because she was afraid of making mistakes. Her memory problems did not interfere with her activities of daily living. She was afraid that her memory problems were the first signs of dlementia. She was diagnosed as having temporal epilepsy 9 years ago (focus left temporal lobe) for which she used antiapilepric medication (Tegretol). She had not had epilleptic insults since she started the medication. At the age of 50 , she suffered from a mild traumatic brain injury with a posttraumatic amnesia of several minutes.

Nenropsychiatric examination revealed mild symptoms of depression and anxiety. On the Mini Mental State Examination she had a score of 28 out of 30 . The results of blood tests were normal. There were no psychiatric problems before the present history. At the neuropsychological examination she was very anxious and nervous, especially during the memory tests. She repeatedly underestmated her performance. The test results showed that she had slight impairments with respect to the active reproduction of newly acquired verbal information (but normal recognition) and there was a heightened susceptibility to 
interference. Her performance on visuoconstructive tasks was below average, but still within the normal range. She was of average intelligence and her perceptual and language abilities were normal.

The diagnosis was very mild cognirive disturbances which could not be related to possible left hemisphere dysfunctions. Depressive complaints wero secondary to her anxiety about dementia. Theoretically, the cognitive disturbances could be retated to her mild brain trama in the past. She was reassured that there were no signs of dementia and it was decided to examine her again after 2 years.

At this 2-year follow-up, her memory complaints had increased. She was still very afraid of dementia, a fear which was strengthened by the recent death of her brother who had Alzheimer disease. Her avoidance behavior had increased and she planned to give up her volunteer actiwities at a women"s club in her village (club administration, organizing bustrips) because she expected she would make serious mistakes in the near future due to her memory problems. At neuropsychological examination she was again very anxious but her overall test performance was better than it was 2 years before and her performance on different memory tests was now within the normal range for her age, so that dementia could be excluded. It was concluded that her memory complaints were primarily due to stressful life events and reinforced by her intense fear of dementia, her strong attentional bias for (possible) memory failures, and her negative thoughts and expectations about her own memory functioning. She successfully participated in a short cognitive-behavioral treatment program ${ }^{\text {b }}$ that focussed on modifying her negative beliefs about her memory.

Not all elderly people who are concerned about their memory seek professional help. Moreover, the impact of their anxiety on their daily functioning or well-being might not be as pervasive as in the two examples given above. Nevertheless, many elderly people do have serious complaints about their memory. In cognitive aging research it is increasingly recognized that these memory complaints cannot simply be explained in terms of declining memory abilities: an individual's knowledge, beliefs, and affects about his or her memory seem to be more important determinants of perceived memory decline in old age than memory ability per se (e.g., Cavenaugh, 1996; Hultsch, Hertzog \& Dixon, 1987; Lovelace, 1990; Wilson \& Evans, 1996). This point is clearly illustrated by the two examples given above.

For this reason, the study of subjective memory and its determinants is one of the research goals of the Maastricht Aging Sfudy (MAAS), a large cross-sectional and longitudinal study into cognitive aging that started in 1991 at Maastricht University (Jolles, Houx, van Boxtel \& Ponds, 1995). The main research topic of MAAS concerns the study of the complex interrelations between age, biomedical factors (e.g., hypertension, diabetes), psychological factors (e.g., lifestyle, mood), sociodemographical factors (e.g., education, social support), and cognitive abilities, as measured with a broad array of cognitive tests (e.g, memory, mental speed, attention, intelligence). Whereas most studies on cognitive aging solely focus on age-related changes in objective cognitive functioning measured with standard clinical and laboratory cognitive tests, MAAS also assesses subjective memory functioning by making use of standard memory

b Ponds, R. W. H. M., Schmid, A. J. M, de Lugr, M., Lulofs, R., Verhey, F. R. J., Jolles, J. (1995). De angst on te vergeten: Behandeling wan functionele geheugenklachten (Fear of forgetting: Treatment of functional memory complaints. Tijdschrifu voor Psychiatrie, 37, 62-68. 
questionnaires and newly developed instruments. As such, MAAS aims to bridge the gap between findings from traditional laboratory memory research and findings on how people perceive their memory to function in dally life. The research described in this thesis is mainly based on cross-sectional data on subjective cognitive functioning collected in the course of MAAS.

\section{References}

Cavendugh, J. C. (1996). Memory self-efficacy as a moderator of memory change. In F. Blanchard-Fields \& T. H. Hess (Eds.). Perspectives on Cognitive Change in Adulthood and Aging (pp. 488-507). New York: McGrawHill Companies.

Commissaris, C. J. A. M., Jolles, J., Verhey, F. R. J., Ponds, R. W. H. M., Danoiseaux, V. G. M., \& Kok, G. J. (1996). Forgetfulness or dementia? Who is worried and why? European Joundal of Public Health, 6, 297-299.

Commissaris, C. J. A. M., Verhey, F. R. J., Ponds, R. W. H. M., Jolles, J., \& Kok, G. J. (190,4). Public educalion about nomal forgetfulness and dementia: Importance and effects. Patient Education and Counseling, 24, 109-115.

Hultsch, D. F., Hertzog, C., \& Dixon, R. A. (1987). Age differences in metamemory: Resolwing the inconsistencies. Canadian Journal of Psychology. 4l, 193-208.

Jolles, J., Houx, P. J., Boxtel, M. P. J. v., \& Ponds, R. W. H. M. (1995). Maasinicht Aging Study: Determinants of cognitive aging. Maastricht: Neuropsych Publishers.

Jolles, J., Verhey. F. R. J., Riedel, W. J., \& Houx, P. J. (1995). Cognitive impairment in elderly people: Predisposing factors and implications for experimental drug studies. Drags and Aging. 7, 459-479.

Lovelace, E. A. (1990). Aging and metacognitions concerning memory function. In E. A. Lovelace (Ed.), Aging and cognition: Mental processes, self awareness and interventions (pp. 157-188). Amsterdam, the Netherlands: Elsevier Science.

Verhey, F. R. J. (1993). Demenria depression and forgetfuiness: Clinical studies of the early diagnosis and the differential diagrosis of dementia. "Thesis. Maastricht: University Press Maastricht.

Wilson. R. S., \& Evans, D. A. (1996). How clearly do we see our memories. Soumal of the American Geriatric Society, 44, $93-94$ 


\section{General introduction}

\section{Introduction}

Many aspects of cognitive functioning have been shown to deteriorate with increasing age (Birren \& Schaie, 1990). This is certainly the case for memory, where older adults in general show a decrease in performance on a broad array of memory tests, especially when the acquisition of new information is required (Craik \& Jennings, 1992). Four major classes of hypotheses have been put forward to explain the nature of the memory impaiment in old age (e.g., Light, 1991): (1) failures in metamemory (e.g., deficient memory strategy use), (2) defective semantic encoding (e.g., less rich, extensive, and deep encoding of information), (3) failures of deliberate recollection (e.g. people of older age are more dependent on environmental support for netrieval, the retrieval support hypothesis), and (4) diminished processing resources (e.g., reduced attentional capacity, reduced working-memory capacity, or cognitive slowing). The age-related decline in memory functioning measured with memory tests seems to be rellected by older people's self-appraisal of their memory. For example, Cutler and Grams (1988) found that in a sample of almost 15,000 subjects aged 55 and older, $54 \%$ reported that they had had (some) difficulty in remembering things during the past year. This percentage systematically increased with age: from $45 \%$ in the age group 55 to 59 years to $62 \%$ in the age group of 85 years and older.

Research on memory and aging is mainly based on laboratory studies and the most frequently used tests are free recall, cued recall, and recognition memory for verbal information like words, sentences, and prose. Laboratory studies offer the opportunity for experimental manipulation within strictly controlled conditions, which is necessary to examine the mechanisms underlying age-associated memory decline. However, these studies do not tell us much about the memory functioning of elderly people in their natural, or nonlaboratory, environment (Hulicka, 1982). How for example, do memory problems affect the ability of older adults to cope with the demands of daily life? What constraints do the memory problems impose on their choice of activities? What strategies are used to adapt to memory impairment? For theoretical (e.g., what is the influence of memory beliefs or motivation on test performance) as well as practical reasons (e.g., the development of remedial interventions) it is important to combine information about memory function assessed with well-defined tests that have a sound theoretical basis ("objective" memory) with information about people's perceptions of their memory functioning in daily life ('subjective' memory).

In doing so, one of the most intriguing findings is that there is hardly any correlation between self-reported memory functioning or memory complaints and performance on memory tests (e.g., Gilewski \& Zelinski, 1986). The absence of a correlation between subjective and objective 
memory may in part be explained by methodological problems (e.g, memory tests lack ecological validity or the memory introspection paradox; see next paragraph). More important, however, is the notion that memory complaints or a perceived decline in memory functioning in old age is not primarily determined by actual memory ability or other memory-related cognitive skills (e.g., attention or speed of information processing), but is also determined by non-cognitive factors like specific demographic variables (e.g., educational level), personality traits (e.g, neuroticism), affective state (e.g, depression), health, environmental stress, social support, societal beliefs about memory and aging, memory self-efficacy beliefs, and worry about incipient dementia (e.g., Arbuckle, Gold, Andres, Schwartzman \& Chaikelson, 1992; Bandura, 1989; Bazargan \& Barbre, 1994; Bolla, Lindgren, Bonaccorsy \& Bleecker, 1991; Commissaris, Verhey, Ponds, Jolles \& Kok, 1994; Cutler \& Grams, 1988; Derouesnế et al., 1989; Hänninen et al., 1994; Poitrenaud, Malbezin \& Guez, 1989; Ponds \& Jolles, 1996; Ryan, 1992; Stevens, Kaplan, Ponds, Diederiks \& Jolles, in press). To put it simply, memory processes that underlie everyday memory functioning do not operate in isolation from personality and social processes (Hultsch, Hertzog, Dixon \& Davidson, 1988).

The fact that self-reported memory function largely seems to reflect individual differences in lifestyle, life-demands, social expectations, emotional states, and personality, and at best is only marginally related to actual memory ability, makes it a complex field of study. Moreover, memory self-repont questionnaires have severall serious methodological and logical limitations which will be described in the next paragraph.

\section{Problems in measuring subjective memory}

Subjective memory is usually measured with self-report questionnaires in which the respondent is asked about the frequency of daily memory failures (e.g, "how often do you forget names', how often do you have difficulties in finding words', "how often do you forget appointments', 'how often do you forget where you put something'), or in which they are asked to rate their competence in well-described daily memory tasks (e.g." "how good are you in remembering names', "how good are you in remembering appointments', "how good are you in remembering the content of a book or newspaper"). Comparison of the scores of older and younger people then may reveal possible age differences in everyday memory efficiency. There are, however, several methodological difficulties in the use of self-report questionnaires in cognitive aging research (Dixon, 1989; Rabbitt \& Abson, 1990; Rabbitt, Maylor, McInnes, Bent \& Moore, 1995).

\section{How to validate self-report memory questionnaires?}

It remains unclear how a person's subjective reports of his of her memory can be validated, because the ecological validity of most laboratory memory tests is generally very low (Kausler, 1989). Traditional memory tests are, in terms of everyday memory demands, highly artifucial. The material to be memorized (e.g., a list of 15 unrelated words) shows little or no resemblance to everyday memory tasks. Moreover, unlike real-life memory tasks, laboratory memory tasks are typically brief and do not require sustained effort and are administered under conditions of 
minimal distraction and stress. As memory tasks and memory questionnaires seem to measure different 'types' of memory, it is problematic to use memory tests to validate memory questionnaires.

Although the correlation between memory questionnaires and memory tests in general increases as the memory tests become more "ecologically valid", the correlation remains small. For example, Sunderland, Watts, Baddeley \& Harris (1986) found no correlation between a selfreport memory questionnaire and a test that measured paired-associate learning of words, but found a modest correlation (.37) with a sitory recall task, which is presumed to be a more ecologically valid memory task. In this context it is important to note that face validity is not the same as ecological validity, as is often assumed. A list-learning task with real items from a grocery store does not guarantee that you measure real everyday memory. What is important and what makes a test ecologically valid is in how far the test taps the same aspects of memory and the same memory processes as remembering does in daily life.

\section{Memory introspection paradox}

Many people, and especially those who are forgetful, have difficulty in objectively assessing their own daily memory failures. This is known in the literature as the memory introspection paradox (Hermann, 1982): people who are forgetful, forget what they forgot and so underreport their memory failures. Researchers have tried to tackle this problem by asking close relatives to rate the frequency of memory failures, under the assumption that this rating would be more reliable and "objective'. But again, this in general only leads to a relatively small increase, if any, in the correlation between subjective and objective memory (e.g., Sunderland et al., 1986).

\section{Domain specificity}

Many memory questionnaires are multidomain in the sense that they ask questions about a wide array of daily memory failures or scenarios. Usually, the answers to the different questions are summed to give an overall score. This approach may mask differences in the patterns of daily memory failures between individuals or age groups. It should be noted, however, that different panterns of memory lapses in individuals or age-groups do not necessarily imply differences in functional competence, but may simply reflect differences with which different groups encounter the specific memory scenarios described in the memory questionnaires because the groups have different lifestyles, social environment, and daily tasks. For example, women report more memory lapses related to shopping and housework than men, simply because they are more involved in these daily activities (Maylor, in Rabbitt et al. 1995).

\section{Different etiology of memory problems}

Memory questionnaires tell us something about the frequency of daily memory failures of different individuals or age groups, but usually do not provide information about why these failures occur. Daily memory failures may be caused by different underlying dysfunctional. cognitive processes or dajly circumstances. For example, difficulty in remembering names may be reported by both young and older adults, but the underlying problem in young adults may be that 
they meet too many new people in a short period of time, whereas older adults may have difficulty in the distinct encoding of even a few new names in memory.

\section{Reference point}

People cannot rate their memory function in absolute terms and can only make relative comparisons in terms of how well their memory copes with the particular (memory) demands of everyday life, or how good their memory is in comparison to that of people they know. Therefore, the reference point to which people compare their memory function is of considerable importance, especially in cognitive aging research. Older people may consider their memory as being 'normal' or 'good' given their present age, although their current memory functioning may have declined in retrospect ("adaptive" response). It is therefore important to ask for relative measures of reported memory abilities, so that people judge their current memory performance to their own past performance at some defined point in time. This, in general, gives more reliable information about possible changes in memory abilities than absolute measures (Hultsch, Hertzog \& Dixon, 1987).

\section{Societal beliefs}

There is a widespread conditioned belief in Western society that cognitiwe functioning will inevitably decline with age (Fingerman \& Perlmutter, 1994; Ryan, 1992; Ryan \& Kwong See, 1993). This may lead older people to overestimate the actual decline in memory functioning.

\section{Personality and mood}

Individual and age-group differences in subjective memory ratings may reflect low self-esteem and self-confidence rather than differences in memory competence. Individuals with higher scores for depressive mood, anxiety, and neuroticism usually report more memory problems, although they do not necessarily show evidence of objective memory decline or memory dysfunctioning in memory tests (e.g. Bolla et al., 1991; Derouesné et al., 1989; Hänninen et al., 1994). The administration of mood and personality questionnaires together with memory questionnaires, makes it possible to estimate the extent to which subjective memory ratings may be attributed to low self-esteem rather than to objective memory functioning.

\section{Metamemory: Different aspects of subjective memory}

As stated before, an individual's memory performance is not only determined by actual memory skills but also by knowledge of the memory demand characteristics of a situation and by a perception of the likely outcome of behavior in that situation (Hultsch et al., 1988). This self-knowledge and self-perception of memory have been labeled metamemory. Metamemory thereby represents one's knowledge, perceptions, and beliefs about the functioning, development, and capacities of (1) one"s own memory and (2) the human memory system (Dixon, 1989). 
Metamemory makes an essential distinction befween remembering and thinking about remembering.

Hultsch, Hertzog, Dixon, and Davidson (1988) defined four broad dimensions of metamemory: memory knowledge, memory monitoring, memory selfuefficacy, and memory-related affect. Memory knowledge reflects factual knowledge about memory tasks and memory processes (e.g., knowing that organizing the elements of a list of items improves recall or that recognition is more easy than active recall). Memory monitoring involves self-knowledge about one"s own memory use (e.g., use of memory strategies) and the current state of one's memory (e.g., knowing how accurate your memory is). Memory self-efficacy refers to one's sense of mastery of memory. It includes individual beliefs about memory abilities, strengths, and weaknesses (e.g.o one's belief in the degree to which memory functioning is amenable to self-control). Memory-related affect encompasses a variety of states that are generated by, or associated with, memory-demanding situations.

Metamemory thus encompasses different aspects of subjective memory that are relevant to our understanding of everyday memory functioning. The questionnaine that best covers the four dimensions of metamemory mentioned above, is the Metamemory in Adulhood (MA) questionnaire (Dixon, Hultsch \& Hertzog, 1988). The MIA is one of the most frequently used memory questionnaires in cognitive aging research. The MLA asks subjects to rate on a 5-point Likert scale 108 statements describing their own memory functioning and their general knowledge of memory processes. It consists of seven factors or subscales: Strategy (daily use of various internal and external memory strategies, Task (general knowledge of basic memory processes), Capacity (perceived memory capacity in a variety of daily memory tasks), Change (penceived change or decline in memory functioning), Anxiety (perceived feelings of stress and anxiety related to memory performance), Achievement (perceived importance of having a good memory and the motivation to perform well on everyday memory tasks), and finally Locus of Control (perceived sense of control over memory abilities). Research has shown robust effects of age on Capacity, Change, and Locus, and some inconsistent or only small effects of age on the other four scales (Dixon \& Hultsch, 1983; Hultsch et al., 1987; Hultsch et al., 1988).

\section{Memory self-efficacy: A mediating role in subjective memory}

Of the different dimensions of metamemory defined above, memory selfefficacy (MSE) is considered to be the most important moderator of changes in memory functioning with age (Berry \&. West, 1993; Lovelace, 1990; Welch \& West, 1995). The concept of MSE is based on the definition of self-efficacy of Bandura $(1977,1989)$, who defines self-efficacy as the degree of belief one has in his or her ability to mobilize the motivation, cognitive resources, and courses of action needed to exercise control over lask demands (e.g., memory tasks). People with a high sense of perceived self-efficacy within a given domain act, think and feel differently from those with low self-efficacy (Bandura, 1989). As Bandura wrote:

"... people who have a low sense of perceived self efficacy in a given domain ... have low aspirations and weak commitment to the goals that they choose to pursue. In taxing situations 
they dwell on their personal deficiencies, the formidableness of the task, and adverse consequences of failure. Such perturbing thinking further undermines their effort and analytic thinking by diverting attention from how best to execute activities to concerns over personal deficiencies and possible calamities. Failure experiences sap their motivation. They do not exert much cognitive effort in processing information and decrease their efforts and give up quickly in the face of difficulties. They are also slow to recover their sense of efficacy following failure or setbacks. Because they are prone to diagnose insufficient performance as deficient aptitude, it does not require all that much failure for them to lose fauth in their capabilities. They fall easy victims to stress and depression...

People who have high assurance in their capabilities approach difficult tasks as challenges to be mastered rather than as threats to be avoided. Such an affirmative orientation fosters interest and engrossing inwolvement in activities. They set themselves challenging goals and maintain strong commitment to them. They are active cognitive processors of information and. remain highy efficient in their analytic thinking in complex decision siuations. They heighten their efforts in the face of failures or setbacks. They ascribe failure to insufficient effort, which supports a success orientation. They quickly recover their sense of efficacy after failures or setbacks. They approach potential stressors or threats with assurance that they can exercise some control over them. Such an efficacious outlook enhances the level of cognitive functioning and performance accomplishments, reduces stress, and lowers vulnerability to depression" (p. 731).

Thus self-efficacy is not a passive belief about some future action, but a belief system that leads a person to behave in certain ways based on that belief. An individual's beliefs about his or her memory abilities play a crucial role in determining what he or she does when confronted with the task of remembering. These beliefs do not necessarily represent veridical estimates of that individual's potential memory capabilities, but do thave a substantial impact on determining which behaviors an individual will choose to engage in or how he or she will perform memory tasks. If memory self-efficacy beliefs are low, less effort (or inefficient allocation of effort) than necessary will be invested in memory tasks, which might lead to low memory performance. This in turn strengthens the subject's beliefs about his or her inadequate memory functioning. So, poor memory performance may become more a function of self-doubt than actual lack of ability.

Figure 1.1 shows a simplified model of selfefficacy, adapted from Berry and West (1993). It shows the four principal sources of self-efficacy information as postulated by Bandura (1977, 1989), which lead to a self-efficacy judgments within a given context. These self-efficacy judgments determine a variety of task-engagement behaviors. Mastery experience or previous performance accomplishments are presumed to be the most powerful source of information and are based on the results of past and present performance of a given activity. Vicarious observations rely on what other people of a relevant reference group are capable of doing. Social influences or social persuasions refer to what other people expect a person to be capable of doing. Finally, the state of emotional arousal (e.g., anxiety) within a given context provides information about personal competency. Self-efficay judgments affect task selection and the effort and persistence put into that specific activity or task, which ultimately determines task performance. The model is recursive: past performance influences future judgments of self-efficacy that, in turn, influence future performance.

When looking at the potential sources of memory self-efficacy in the elderly, it becomes clear why the elderly are vulnerable. Because of normal aging, they realize that their present everyday 


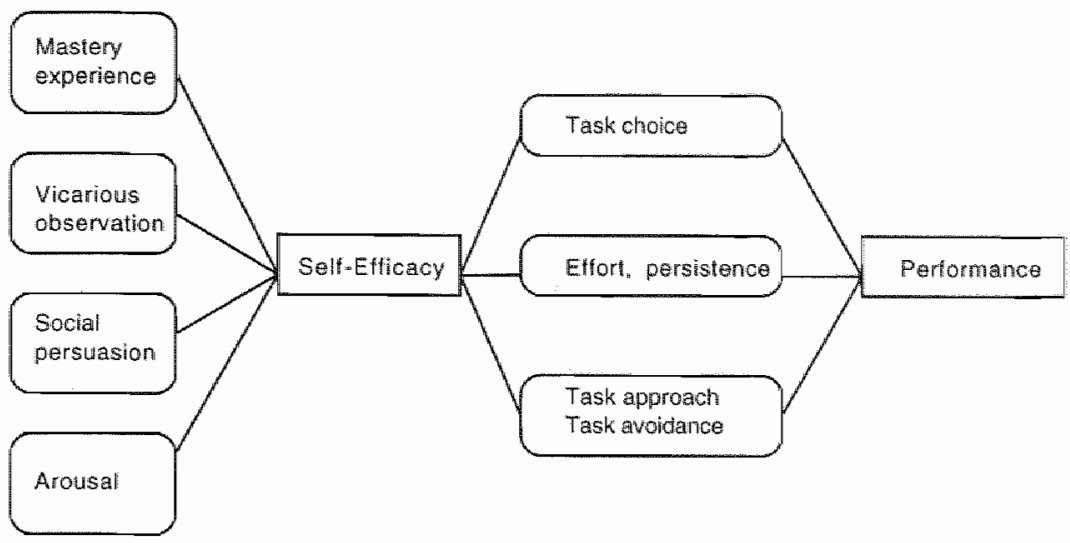

Figure 1.1 A model of the sources and effects of self-efficacy

memory is not as accurate as it was in the past, so their feeling of mastery is undermined. They see that other elderly people also have memory difficulties, so this is probably what can be expected in old age. Also, negative social stereotyping leads other people to tell them that they should not expect their memory to be as good as it used to be. Finally, elderly people may experience anxiety in memory demanding situations, and this anxiety may disrupt adequate memory functioning.

From the foregoing it is clear that the study of age-related changes in everyday memory functioning needs to incorporate the measurement of different aspects of metamemory, because an indiwidual's knowledge and beliefs about memory play an important role in detemining what tha person does when confronted with memory lasks in daily life.

\section{Aim of this thesis}

The main theme of this thesis is the study of age-related changes in subjective memory, focussing on the prevalence, characteristics, and possible determinants of everyday forgetfulness. Most of the reported studies are based on data from the Maastricht Aging Study (MAAS), a large cross-sectional and longitudinal study on normal cognitive aging including almost 2000 individuals covering the whole adult age range (Jolles, Houx, van Boxtel \& Ponds, 1995). MAAS investigates possible determinants of both objective and subjective cognitive functioning, with emphasis on memory. Since MAAS started in 1991, a substantial amount of data has been collected on different aspects of subjective memory. The measurement of subjective memory was considered to be important for several reasons: 
1. Adequate cognitive and memory functioning is essential for the autonomy and independence of older individuals in daily life. Age-associated decline in memory functioning, as measured with objective memory tests, is one of the most consistent findings in the literature on the psychology of aging. However, as stated above, there is usually a discrepancy between objective memory functioning and how people experience their memory in daily life: elderly people may have serious memory complaints but normal to even above normal memory performance and vice versa. In order to understand why some elderly people have difficulties. with everyday memory and others do not, information is needed about both objective and subjective memory function. For this reason, different aspects of subjective memory (e.g., individual memory-beliefs, memory-knowledge, perceived changes in memory functioning. the use of memory strategies) and their possible determinants (e.g., personality, mood, anxiety for dementia, health, social support) were studied in MAAS, in addition to assessment of memory function in traditional laboratory cognitive and memory tests.

2. A better understanding of the determinants of perceived memory decline or memory complaints in old age would enable us to design appropriate treatment and intervention programs. Many elderly people take part in memory training programs and courses that teach them to apply mnemonic devices and strategies (Verhaeghen, Marcoen \& Goossens, 1992). The implicit assumption in these training programs is that elderly people have some sort of memory deficit which can be compensated for by using specific memory strategies. It may be questioned whether this 'deficit-approach' is appropriate. Beliefs about memory competence and controllability are probably more important determinants of everyday memory failures in older age than inappropriate use of memory strategies, and modification of these beliefs in addition to teaching mnemonic strategies may enhance the effects of memory intervention programs (Dellefield \& McDougall, 1996; Floyd \& Scogin, 1997; Lachman, Weaver, Bandura, Elliott \& Lewkowicz, 1992).

3. The sudy of subjective memory may also be helpful in designing more sensitive and valid instruments for the measurement of subjective memory complaints. This is important for two reasons. First, such instruments may help the clinician to decide whether the memory complaints of elderly people are "benign' (e.g., secondary to depression) or "malign" (e.g." indicating the first phase of dementia). These instruments should not only provide information about the extent to which memory complaints are "above average", but should also offer the tools to examine the possible causes of the memory complaints (e.g., prodrome of dementia, anxiety for dementia, depression, everyday stress, low memory self-efficacy beliefs). Second, such instruments may be helpful in defining of what is called the 'gray area' or the borderline between normal and pathological aging or dementia (Jolles, Verhey, Riedel \& Houx, 1995). In the past decade, several attempts have been made to define the clinical and neuropsychological features of this borderline state because the dichotomous classification of older adults as being either 'normal" or 'demented' is thought to be inadequate (Rediess \& Caine, 1996). At present, four diagnostic concepts receive the most attention: Age-Associated Memory Impairment (AAMI; Larrabee, 1996), Age-Related Cognitive Decline (ARCD; APA, 1994). Mild Cognitive Impaiment (MCI; Smith et al., 1996), and Aging-Associated Cognitive Decline (AACD; Levy, 1994). In all these concepts, perceived subjective loss of memory 
function is one of the diagnostic criteria, but usually no mention is made of how this subjective loss of memory should be quantified, which complicates studies into the reliability and validity of these diagnostic concepts.

4. Some longitudinal population-based studies on cognitive aging have recently shown that subjective memory complaints in older age may be predictive of dementia, even when no objective signs of memory deterioration are found (e.g., Schmand, Jonker, Hooijer \& Lindeboom, 1996). Memory complaints may therefore reflect a real but subtle decline of memory, which cannot as yet be assessed with standard memory tests.

Several large-scale population-based studies on normal and abnormal cognitive aging are currently being performed in the Netherlands, in addition to the Mastricht Aging Study. The Longitudinal Aging Study Amsterdam (LASA) focusses on the autonomy and quality of life of older persons. This study is investigating the physical, cognitive, emotional, and social functioning of approximately 3000 adults aged 55 years and older (Deeg \& Westendorp-de Seriere, 1994). The Amsterdam Study of the Elderly (AMSTEL) is a two-phase population study of cognitive decline and dementia in approximately 4000 community dwelling elderly individuals aged 65 to 84 years (Hooijer, Dinkgreve, Jonker \& Lindeboom, 1992). The Rotterdam elderly study aims at the identification of factors related to chronic diseases, such as dementia, in a population aged 55 years and older (Horman, Grobbee, de Jong \& van den Ouweland, 1991). Objective and subjective memory and learning abilities in everyday life of older people are studied in depth at the University of Groningen by Deelman and colleagues (Berg, Brouwer, Deelman, Schmidt \& Sikken, 1998). MAAS has much in common with these studies, but is unique in that it covers the complete range of adult ages and includes a very broad and in-clepth evaluation of both objective and subjective cognitive functioning. To our knowledge, the studies reported in this thesis are the first in the Netherlands that have examined in detail (age-related) everyday memory functioning in the normal population on such a large scale (in total approximately 3,500 subjects) and over such a broad age range (25-85 years).

\section{Outline of this thesis}

The primary focus of chapters 2,3 , and 4 is on the prevalence and the correlates of self-reported everyday memory and cognitive problems in large population-based samples of people aged 24 to 86 years. Chapter 2 focusses on the prevalence of forgetfulness in relation to age, sex, educational level, affective state, and subjeciive health. We also looked at the possible causes of forgetfulness as reported by the respondents and made an inventory of the steps people took to improve their memory. Chapter 3 presents data on age-telated changes in self-evaluations of memory and related domains of cognitive functioning such as attention, mental speed, planning, and decision making. The key question was to what extent subjective age-related decline in memory is accompanied by perceived decline in other cognitive functions as well. Chapter 4 presents data on the differential effects of age, sex, and education on the Cognitive Failure Questionnaire (CFQ). The CFQ is an established 25-item self-report questionmaire that asks about every cognitive failures in memory, 
attention, perception and motor functioning. The factor structure and the relation between the CFQ scores and objective cognitive function and several psychosocial measures (subjective health, distress, life events, and worry of dementia) are also examined.

Chapter 5, 6, and 7 describe three stulles of metamemory as measured with the Metamemory in Adulhood (MIA) questionnaire. Chapter 5 describes a psychometric study of the factor structure, reliability, and discriminant validity of the complete and abridged translated Dutch MIA administered to a sample of almost 1900 normal and heal thy adults aged 24 to 86 years. Chapter 6 describes the relations between several subject background variables, cognitive measures (mental speed, episodic and semantic memory), psychosociall measures (distress "heallth locus of control, subjective health, and worry of dementia), and four subscales of the abridged Dutch MIA (Capacity, Change, Anxiety, and Locus). In this study, we analyzed the data for more than 1300 healthy adults aged 241083 years by using different hierarchical regression models. Chapter 7 describes the relation between a variety of psychosocial factors (health-related variables, affective state, personalicy, daily stress, and socia』 support) and scores on the MIA subscales Capacity, Change, and Anxiety. A group of 319 normal adults aged 40 to 90 years took part in the study. The number and variety of the psychosocial measures was greater than those used in the study reported in Chapter 6.

Chapter 8 describes the relations between memory complaints, memory performance, metamemory variables, personality, and affective state. To this end we compared a group of older people with explicit memory complaints (participants of a memory training program) with a group people of the same age, sex, and education, but without memory complaints.

The studies reported in the Chapters 2 to 7 are primarily based on correlational data. Chapter 9 describes an experimental study in which we examined the way in which memory self-efficacy beliefs influence future memory predictions and performance. We looked at the differential effects of positive and negative performance feedback on performance of a memory prediction task in older persons with high or low memory self-efficacy beliefs. We expected that alder people with low memory self-efficacy beliefs would have a strong attentional bias towards negative feedback, whereas those with high memory self-efficacy beliefs would focus their attention more on positive feedback.

Chapter 10 presents a general discussion of the various findings and conclusions of this thesis.

\section{References}

Arbukkle. T, Y., Gold, D. P. Andres, D., Schwartaman, A. \& Chakelson, J. (1992). "The role of psychosocial conhext, nge, and intelligence in memory performance of older man. Psychology and Aging, 7, 25-36.

Association Psychiatric Association (1994). Diagnostic and statistical monual of mental disorders (4thed.). Washington, D.C.: APA.

Bandura, A. (1977). Self-efficacy: toward a unifying theory of behaviora change. Pyychology Review, 84, $191-215$.

Bandata, A. (1989). Regulation of cognitive processes through perceived self-efficacy. Develophenral Psychology, $25.729-735$.

Bazargan. M., Batbre, A. R. (1994). The eftects of depression, health status, and stressful hife-events on sellreported memory problems among aged blacks. Mamational Jownal of Aging and Human Development, 38 , $351-362$.

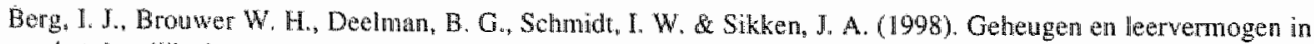
het dagelijks leven van ouderen. Tidschrif woor Gerontologie ex Geriatrie, 29, 130-140. 
Bery, I. M. \& West, R. L. (1993). Cognitive self-efficacy in relation to personal mastery and goal setting across the life span. Intemational Jommal of Behavioral Development, $16,351.379$.

Birren, Ji. E. Schaie, K.W. (1990). Handbook of the psychology of aging (third edrion). San Diego: Academic Press.

Bolla, K. I., Lindgren, K. N., Bonaccorsy, C. \& Bleecker, M. L. (1991). Mernory complaints in older adults. Fact or fiction? Archives of Neurology, 48,61-64.

Commissaris, C. J. A. M. Verhey, F. R. J., Ponds, R. W. H. M., Jolles, J., de Kak, G. J. (1994). Public education about normal forgetfulness, and dementa: Importance and eftects. Patient Edeucafion cond Cownseling, $24,109-115$.

Craik, F. I. M. \& Jennings, J. M. (1992). Human memory. In F. I. M. Craik \& T. A. Salthouse (Eds,), Handbook of aging and cognition. (pp. 51-110), Hillsdale: Lawrence Erlbaum.

Cutler, S. J. \& Girms, A. E. (1988). Correlates of self-reported everyday menory problems. Joumal of Gerontology: Social Sciences, 43, 82-90.

Deeg, D. J. H., \& Westendorp-de Seriere, M. (1994). The Longitudinal Aging Study Amsterdam: An overview, In D. J. H. Deeg \& M. Westendorp-de Seriere (Eds.), Automosny and well-being in the aging poputation (pp. 1-6). Amsterdam: VU University Press.

Dellefieid, K. S., \& McDougall, G. J. (1996). Increasing metamemory in older adults. Nursing Research, 45, 284m 290.

Derouesné, C., Alperovitch, A., Arvay, N., Migeon, P., Moulin, F., Vollant, M., Rapin, J. R. \& Le Poncin, M. 1989\%. Memory complaints in the elderly: A sudy of 367 communty-dwelling individuals from 50 to 80 years old. Archives of Gerontology and Geriarrics. Suppl. 1, 151-163.

Dixon, R. A. (1989). Questionaire research on metamemory and aging: issues of structure and function. In L. W. Poon, D. C. Rubin, \& B. A. Wilson (Eds.), Everyday cognition in adththood and late life (pp. 394-415). Cambridge: Cambridge Uniwersity Press.

Dixon, R. A., \& Hultsch, D. F. (1983). Structure and development of metamemory in adalithood. Joumal of Gerontology, 38, 682-688.

Dixon, R. A., Hultsch, D. F., \& Hertzog, C. (1988). The metanemory in adulthood (MlA) questionnaire. Psychopharmacology Bulletin, 24,671-688.

Fingerman, K. L., \& Perlmutter, M. (1994). Self-ratings of past, present, and future cognitive performance across adulthood. International Joumal of Aging and Human Development, 38, 363-382.

Floyd, M. \& Scogin, F. (1997). Effects of memory training on the subjective memory funtioning and mental health of older adults: A meta-anallysis. Psychology and Aging, 12, 150-161.

Gilewski, M. J., \& Zelinski, E. M. (1986). Questionnaire assessment of memory complaints. In L. W. Poon (Ed), Mandbook for clinical memory assessment of older adults (pp. 93-107). Washington: American Psychological Association.

Härninem, T., Reinikainen, K. J., Helkala, E, Koivisto, K., Mykkänen, L., Laaksso, M., Pyörälä, K., \& Riekkinen. P. J. (1994). Subjective memory conplains and personality traits in normal elderly subjacts. Iournal of the American Geriatric Sociery, 42, 1-4.

Hermann. D. J. (1982). Know thy memory: The use of questionnaires to assess and sudy menory. Psychological Bulletin, 92, 434-452.

Hofman, A., Grobbee, D. E., de Jong, P. T. V. M., \& wan den Ouweland, F. A. (1991). Determinants of disease and disability in the elderly: The Rotterdam elderly study. Europena Joural of Epidentology. 7, 403-422.

Hooijer, C., Dinkgreve. M. Jonker, C., \& Lindeboom, J. (1992). Short screening tests for dementia in the elderly population. A comparison between AMTS. MMSE, MSQ, and SPMSQ. International Journal of Geriatric Psychiatry: 7. 559-57!.

Hulicka, 1. M. (1982). Memory functioning in late adiulthood. In F. I. M. Craik \& S. Trehub (Eds.), Adwances in the stady of communication and affert: Aging and cognisive processes (volume 8) (pp. 331-351). New York: Plenum Press.

Hultsch, D. F., Hertzog, C., \& Dixon, R. A. (1987). Age differences in metamemory: resolwing the inconsistencies. Canadian Journal of Psychology, 41, 193.208.

Hultsch, D. F., Hertzog, C., Dixon, R. A., \& Dawidson, H. (1988). Memory self knowledge and self-ellicacy in the aged. In N. L. Lowe \& C. I. Brainerd (Eds.), Cognitive developmen in adulthoud: Progress in cogninive developmental research (pp. 65-92). New York: Springer-Verlag-

Jolles, J. Houx, F. J., van Boxtel, M. P. J., \& Ponds, R. W. H. M. (1995). Maastricht Aging Studiy: Determinants of cognitive aging. Maastricht: Neuropsych Publishers.

Jolles, J., Verhey, F. R. J., Riedel, W. J., \& Houx, P. J. (1995), Cognitive impairnent in elderly people: Predisposing factors and implications for experimental drug studies. Drugs and Aging, 7, 4594479. 
Kanster, D. H. (1989), Commenes on aging memory and its averyday operations. In $\mathbb{L}$. W. Poon, D. C. Rubin, R B. Wilson (Eds.), Everyday cognhion in adwhood and late life (pp. 483-495). Cambridge: Cambridge Uniwersity Press.

Lachman, M. E. Weaver, S. L., Bundura, M. Ellion. E., Lewkowicz, C. I. (1992). Inproving menory and contul beliefs ifrough cognithe testructuring and self-generated strategies. Jownal of Gerontology: Pychological Sciences, $47,293-299$.

Larrabe, G. J. (1996). Age-A.ssociated Menory Impaiment: Definition and psychometric chamacteristics. Aging, Newropsychology, and Cognition, $3,118131$.

Lewy, R. (1994). Aging-Associated Cognitive Decline. International Psychogeriatrics, 6.63-68.

Light, L. L. (1991). Mernory and aging; four hypotheses in search of data. Anwal rewiew of p.sychologyn $42,333-$ 376.

Lovelace, E. A. (1990). Aging and metacognitions concerning memory function. In E. A. Lovelace (Ed.), Aging and cognifion: Mental processes, self awctenes and whenentions (pp. 157-188). Ansterdam, the Netherlands: Elsevier Science.

Poinchaud, J., Mabbezin, M., \& Guez, D. (1989). Self-rating and psychometric assessment of age-related changes in memory among young elderly managers. Developmental Neuropsychology, 5, 285-294.

Ponds. R. W. H. M., \& Jolles, J. (1996). Memory complaints in elderly people: the role of memory abilities, metamemory, depression, and personality. Educathonal Gerontology, 22, 341-357.

Ratbobit, P., \& Abson, V. (1990). "Lost and Found'. some logical and methodological limitations of self-report questionnaines as tools to study cognitive ageing. Brifish Journal of Psychology, 81, 1-16.

Rabbiti, P. Maylor, E.. Mclinnes, L., Bent, N., \& Moore, B. (1995). What goods cam self-assessment questionnalites deliver for eogntive gerontology? Applied Cognitive Psychology, 9, \$127-S152.

$\mathbb{R}$ ediess, $\mathrm{S}_{n}$ \& Caine, E. (1996). Aging, cogrition, and DSM-IV. Aging, Neuropsychology, and Cognition, 3 105- 117 .

Ryan, E. B. (1992). Beliels about memory changes across the adult life span. Jowmal of Gerontog\%, 47, 41-46.

Ryan, E. B., \& Kwong See, S. (1993). Age-based beliefs about memory changes for self and athers across adulthood. Jounal af Cremontology: Psychological Sciences" 48, 199.201.

Schmand, B., Jonker, C., Hodijer, C., \& Lindeboom, I. (1996\%. Subjective memory complaints may announce dementia. Nemrology, 46, $121-125$.

Smith, G. E., Petersen, R. C., Parisi, J. E., Ivnik, R. J., Kokmen. E., Tangalos, E. G., \& Waring, S. (1996). Definition, course, and outcome of mild cognitive impaiment. Aging, Nestopsychology, and Cognition, 3 , $141-147$.

Stevens, F. C. F. Kaplan, C. D., Ponds, R. W. H. M. Diederiks, J. P. M. \& Jolles, J. (in press). How ageing and social factors affect memory. Age A A geing.

Sundertand, A., Watts, K., Baddeley, A. D. \& Harris, J. E. (1986). Subjective memory assessment and rest performance in elderly adults. Jommal of Geronology, 41, 376-384.

Wertheghen, P. Marcoen, A.n \& Goossens, L. (1992). Improving memory performance in the aged ihrough mnenonic trainting: a meta-analytic study. Psychology and Aging, 7, 242-251.

Wuth, D. C. \& West, R. L, (1995). Selfefficacy and mastery: Its application to issues of emvironmental control, cogrution, and aging. Developmental Review, 15, 150-171. 


\title{
Prevalence and covariates of subjective forgetfulness in a normal population* $^{*}$
}

\begin{abstract}
In this study we examined the prevalence and covariates of forgetfulness in a large sample of almost 2,000 subjects in the age range 24 to 86 years. Nearly $40 \%$ of the participants considered themselves to be forgetful. There was an systematic increase in the prevalence of forgetfulness with age, from $29 \%$ in the young age group to $52 \%$ in the oldest age group. Forgetfulness was not considered to be a serious problem in terms of perceived hindrance and worry by most subjects, independent of their age. Age, depression, and subjective health (especially complaints about vitality) acted as covariates of forgetfulness. Gender and education had no effect on the prevalence of forgetfulness. The younger adults ascribed their forgetfulness more to potentially reversible and manageable memory-extrinsic causes such as tension and emotional problems, whereas the older adults mentioned less manageable and more or less irreversible memory-intrinsic causes such as aging more often. Eleven percent of all forgetful people had considered looking for a treatment for their memory proplems, or had actually done so. In this group, education (37\%) and memory training ( $29 \%$ ) were the preferred interventions.
\end{abstract}

* Parts of this chapter have been published in:

Ponds, R. W. H. M., Conmissaris, C. I. A. M., Jolles, J. (1997). Prevalience and covariates of subjective forgetfulness in a normal population in the Netherlands. Insernational Journal of Aghg and Hunan Development, 45, 207-221.

Commissaris, C. J. A. M., Ponds, R. W. H. M. \& Jolles, J. (1998). Subjective forgetfulness in a normal Dutch population: Possibilities for health education and other interventions. Patien Education and Counseling. $34,25-32$. 


\section{Introduction}

Memory complaints are very common among middle-aged and older subjects. Cutler and Grams (1988) found that in a sample of almost 15,000 persons aged 55 and older, $54 \%$ reported that they had (some) difficuly in remembering things during the past year. This percentage systematically increased with age: from $45 \%$ in the age group 551059 years to $62 \%$ in the age group of 85 years and oider. Elderly people are often worried about their diminishing memory and the possibility that this memory decline may indicate incipient dementia (Commissaris, Verhey, Ponds, Jolles, \& Kok, 1994). They also believe they have Jess control over their memory functioning than younger people do (Hultsch, Herizog, \& Dixon, 1987). Moreover, older adults make more pessimistic attributions of their memory failures and ascribe memory problems more to more or less irrewersible causes such as poor memory ability or aging, whereas younger adults attribute their memory failures more to potentially manageable causes such as lack of effort or being too busy (Lachman, 1991; Lachman \& McArthur, 1986). Until now, little attention has been paid to the prevalence and characteristics of forgetfulness in young and middle-aged samples.

Although self-perceptions of memory may not be veridical estimates of actual memory skills or competence, they nevertheless may have a substantial impact on the behavior in everyday memory demanding situations. Low self-confidence for memory ability together with negative attribution patterns concerning potential causes of forgetfulness, may lead to decreased effort when trying to remember, avoidance of everyday tasks involving memory, and anxiety when memory is challenged; this leads to lower memory performance and in turn further strengthens the subjects' belief of his or her declining memory abilities (Bandura, 1989; Cavanaugh, 1989; Lachman, 1991; Lovelace, 1990).

Whether age differences are found in self-appraisal of memory depends on the type of questions being asked (Cavanaugh, 1987). Relative measures of memory abilities, in which people judge their present memory performance on the basis of their own past performance, consistently show that elderly people perceive more decline in their memory functioning than younger people. When absolute measures are used, in which people judge their present memory functioning either in terms of a global rating (from "good" to "bad") or present frequency of welldescribed everyday memory failures, age differences may be absent or only very small (Cavanaugh, 1987; Chaffin \& Hermann, 1983; Crook \& Larrabee, 1990; Jackson, Bogers, \& Kerstholt, 1988; McMillan, 1984), A possible explanation for these findings is that with absolute measures elderly subjects rate their present memory functioning according to what they expect to be normal for their ange. Consequently, such adaptive attitude would imply that elderly people do not perceive their memory loss as a serious problem for their daily functioning. This latter notion is supported by the absence of age differences in several studies that explicitly asked for the perceived hindrance or worry of everyday memory failures (Crook \& Larrabee, 1990; Gilewski. Zelinski, \& Schaie, 1990; Lovelace \& Marsh, 1985; Sunderland, Watts, Baddeley, \& Harris, 1986). Cavenaugh, Grady, and Perlmutter (1983), however, found that older adults were more concened about their everyday memory failures than younger subjects.

In this study we looked at the subjective evaluation of memory functioning in a large sample of almost 2,000 persons in the broad age range 241086 years. The study had several goals. First, we were interested in the prevalence of forgetfulness in relation to age and the impact this 
forgetulness had for everyday functioning. Subjects were asked if they considered themselves as being forgetful. When they replied affirmatively, they also rated the degree of bindrance and worry about their forgetfulness. It should be noticed that labeling oneself as forgetful is not the same as rating frequency of forgetting. People who frequently forget may not necessarily consider themselves as forgetful and vice versa. Labeling oneself as forgetful is more likely to depend upon the perceived discrepancy between a subject"s everyday memory functioning and his or her everyday memory demands (Cromwell, 1994). Forgetfulness may therefore be considered as a relative instead of a absolute measure of subjective memory functioning.

Second, we looked at several possible covariates of forgetfulness. On the basis of previous studies (e.g., Cutler \& Grams, 1988) we expected that female and lower educated subjects would describe themselves as being forgetful more often than male and higher educated subjects would. Several studies have also demonstrated a relation between self-appraisal of memory functioning and affective state (e.g., Bolla, Lindgren, Bonaccorsy, \& Bleecker, 1991) and health (e.g., Cutler \& Grams, 1988; Gilewski, et al., 1990). We expected that participants with more depressive complaints and participants who considered themselves as less healthy were more likely to consider themselves forgetful.

Third, we were interested in what forgetful participants thought was the most likely cause of their forgetfulness. On the basis of the experimental study of Lachman and McArthur (1986), we expected that younger persons would ascribe their forgetfulness more to potentially manageable and reversible memory-extrinsic causes (e.g. emotional problems), whereas older persons would mention less manageable and reversible memory-intrinsic causes (e.g. aging, health) more often.

Fourth, in order to be able to improve future interventions and health education activities in the field of dementia and forgetfuness, we gathered information about the people who had undertaken or who had considered undertaking action to improve their memory.

\section{Method}

\section{Participants and procedure}

This study was conducted as part of a large cross-sectional study into biological and psychological determinants of successful and pathological cognitive aging, which is part of a large research program into cognitive aging termed the Maastricht Aging Study (MAAS: Jolles, Houx, van Boxtel, \& Ponds, 1995). In the first phase of this cross-sectional study an extensive postal questionnaire on subjective cognitive functioning in rellation to age, health, and psychological factors was sent to 2,340 persons in the age range of $24-86$ years. The subjects were recruited from a register of patients of general practices in the region of Maastricht (Metsemakers, Höppener, Knottnerus, Kocken, \& Limonard, 1992). This register contains all relevant past and current medical morbidity as documented by the general practitioners. Persons with previous or current medical conditions with known impact on cognitive functioning were excluded. Exclusion criteria were overt cerebrovascular disease, chronic neurological pathology (e.g. dementia, epilepsy, parkinsonism), mental retardation, and major psychiatric disorders. Participant sampling was stratified by 13 discontinuous age classes ( 25 years $\pm 1,30$ years $\pm 1, \ldots$, 80 years $\pm 1,85$ 
years \pm 1$)$ and sex. A total of 3,921 persons were drawn from the register. After screening by th general practitioner, 187 persons were excluded because of current illness or psychosocia indications. The remaining 3,734 were invited by their practitioners to participate in the study 2,340 were willing to participate and received the postal questionnaire. In total 2,043 participant completed and retumed the postal questionnaire in good order.

Only subjects with complete data on the questions concerning forgetfuness were included i the study (see below). For this reason 72 were excluded, leaving a total number of 1,971 . Thes were divided in four age groups: young (age classes 25,30 , and 35 years), young middle-age $(40,45$, and 50 years), old middle-aged $(55,60$, and 65 years), and old $(70,75,80$, and 8 . years). Educational level was measured by a Dutch scoring system (de Bie, 1987) which consist of an 8-point scale, ranging from unfinished primary education (level 1) to university education (level 8). The mean age, gender, and educational level of the participants are presented in Tabl 2.1.

Table 2.1 Descriphye characteristics of the subjects in the study.

\begin{tabular}{|c|c|c|c|c|c|c|c|}
\hline & \multicolumn{2}{|c|}{$N$} & \multicolumn{2}{|c|}{ Age } & \multicolumn{2}{|c|}{ Educanion } & \multirow{2}{*}{$\frac{\operatorname{Sex}(M / F)}{\%}$} \\
\hline & $n$ & F) & $M$ & $S D$ & $M$ & $S D$ & \\
\hline Total group & 1971 & $(100)$ & 53.3 & 17.1 & 3.2 & 1.9 & $45 / 55$ \\
\hline Young & 479 & (24) & 31.4 & 4.0 & 4.3 & 1.8 & $42 / 58$ \\
\hline Young middle-age & 508 & (26) & 45.5 & 4.2 & 3.5 & 18 & $50 / 50$ \\
\hline Old middle age & 523 & (27) & 60.5 & 4.2 & 2.7 & 1.6 & $48 / 52$ \\
\hline Old & 461 & (23) & 76.5 & 5.2 & 2.5 & 1.8 & $42 / 58$ \\
\hline
\end{tabular}

Note. Data on educational level were mitssing for 40 subjects (young, 9 subjects; young middlemage, 7 ; old middleage, 8 ; old, 16).

The four groups were roughly equivalent in size, with a relative underrepresentation of the old group. There were also slightly more women than men in the sample, especially in the young and old groups. A significant decline in mean level of education was found from the youngest to the oldest age groups $(F(3,1930)=104.2, p<.001)$. Multiple range tests (Duncan, $p=.05$ ) showed that the groups were significantly different from each other, except for the old middle-aged and old groups.

\section{Measures}

Forgetfulness. The prevalence of forgetfulness was assessed with the question "Do you consider yourself as being forgetful?". Those that replied affirmatively also rated the degree of hindrance and worry about this forgetfulness on a 5-point scale. These scales ranged from "no hindrance at 
all" and "not worried at all" (score 1) to "wery much hindrance"" and "very much wortied" (scorte 5). Questionnaires with missing data on one or more of these three questions were excluded from the analyses.

Causes of forgetfuness. All participants who considered themselves forgetful were asked to indicate the possible cause (s) of their forgetfulness and lo rate its importance. They could choose from a prestructured list of nine causes, which was based on two previous studies on forgetfulness in the aged (Commissaris, Jolles, Verhey, Ponds, Damoiseaux, \& Kok, 1996; Ponds \& Jolles, 1996). They could also write down causes that were not in the list. Only the first and most important cause was analyzed in this study (one per person).

Affective state and subjective health. Feelings of depression were measured with the subscale Depression of the revised version of the Symptom Checklist (SCL-90: Derogatis, 1977; Dutch version: Arrindell \& Ettema, 1,986). The SCL-90 is a multidimensional self-report inventory of current psychopathology. Items are rated on a 5-point scale. The subscale depression contains 16 items which reflect symptoms of depression (score range 16-80). Subjective health was measured with the Dutch Inventory of Subjective Health (Dirken, 1987). The 21 -item version administered in this study probes health complaints of a somatic and psychosomatic nature. The score range is $0-21$.

Need for treatment and medication use. All participants were asked whether they use(d) medication that was not prescribed by a doctor in order to improve their memory or vitality (OTC: 'over-the-counter drugs'). Participants who described themselves as forgetful were asked if they ever had considered treatment for or getting information about their memory complaints and what kind of treatment or information they are (were) particularly interested in. Finally, they were asked if they would participate in a treatment with medication that possibly has a positive effect on the working of memory.

\section{Data analysis}

Chi-square tests and logistic regression analyses were used to look at the relation between age, gender, education, depression, and subjective health on the one hand and prevalence of forgetfulness and type of indicated causes on the other.

Four levels of age were used in the analyses of age effects; these four levels correspond with the age subsamples presented in Table 2.1. Educational level was compressed to three levels instead of eight: low level (educational levell 1 and 2), medium level (level 3 to 5 ), and high level (6 to 8). These three levels roughly correspond with primary education, junior vocational training, and senior vocational or academic training. The scores on the depression scale of the SCL-90 were compressed to three levels (low, medium, and high), based on the separate normative data for men and women (Arrindell \& Ettema, 1986). Data for depression were missing for 117 subjects. Approximately $47 \%$ of the remaining 1854 subjects had a low depression score, $32 \%$ had a medium score, and $21 \%$ had a high score. No normative data were available for the subjective health questionnaire, but the scores were compressed in three levels (low, medium, and high) on the basis of the accumulative frequency distribution of the scores for men and women separately. Each level of subjective health comprised approximately $33 \%$ of the subjects. Data for

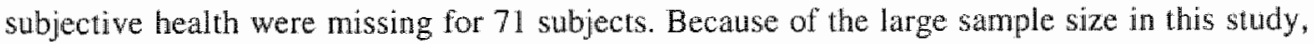
only probabilities of $1 \%$ or less were considered signiticant, unless reported otherwise. 


\section{Results}

Prenalence of forgetfulness, hindrance, and worry

From the total group of 1,971 participants, $764(38.8 \%)$ considered themselves as being forgetful. There was a significant increase in the prevalence of forgetfulness with age: young age group $29.4 \%$, young middle-aged group $33.9 \%$, old middle-aged group $40.7 \%$, old group. $51.6 \%\left(X^{2}(3)=55.7, p<.001\right)$. The prevalence of forgetfulness for each age group is shown in Figure 2.1 .

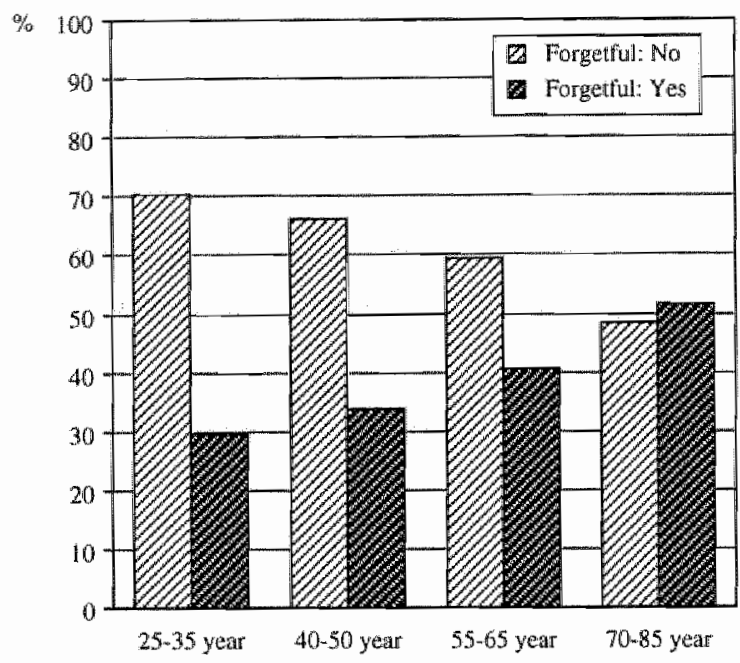

Figure 2.1 Reported forgevfulmess as a function of age $(n=1971)$

The degree of perceived hindrance and worry about the forgetfulness for each age-group is shown in Figure 2.2 and 2.3. There was a strong correlation between hindrance and worry $(r=$ $.57, p<.001)$. The correlations between age (continuous variable) and hindrance and worry were low: 10 for age and hindrance $(p=.005)$ and .08 for age and worry $(p=.029)$. Mean item scores on hindrance were $2.74(S D=0.87)$ for the young group, $2.94(S D=0.72)$ for the young middle-aged group, $2.91(S D=0.84)$ for the old middle-aged group, and $3.03(S D=0.82)$ for the old group. With respect to worry the mean item scores were $2.33(S D=0.89), 2.64(S D=$ $0.85), 2.66(S D=0.86)$, and $2.65(S D=1.01)$, respectively. A near significant age effect was found for hindrance $(F(3,763)=3,61, p=.013)$, whereas a significant age effect was found for worry $(F(3,763)=4.69, p=.003)$. Additional multiple comparison tests (Duncan with $p<.05$ ) revealed that only the youngest age group had a significantly lower mean score for worry than the other three age groups, who did not differ from each other. There were no effects of gender or education on hindrance and worry. 
The prevalence of forgetfuness was significantly related to the level of education (three levels: $X^{2}(2)=25.3, p<.001, n=1,931$ ), depression (three levels, $x^{2}(2)=118.7, p<.001, n=$ 1,854), and subjective health (three levels; $X^{2}(2)=188.8, p<.001, n=1,900$ ), but not to sex $\left(X^{2}(1)=1.73, p=.189, n=1,971\right.$. Forgettulness was more frequently reported in persons with lower education, higher depression scores, and higher scores on the subjective health questionnaire (less healthy).

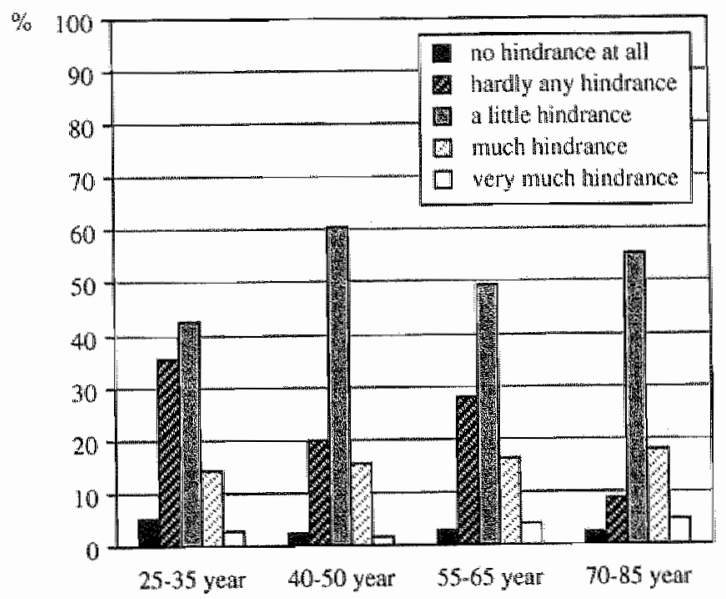

Figure 2.2 Perceined hindrance of forgetfulness in different age groups $(n=764)$

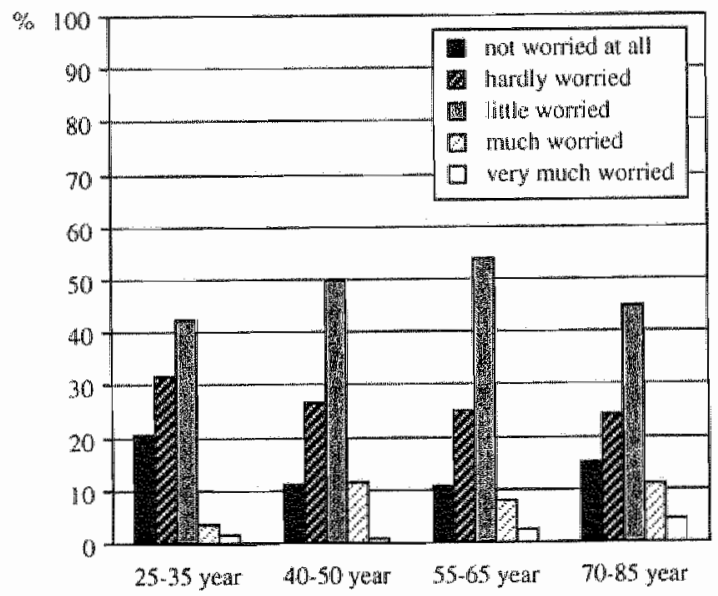

Figure 2.3 Perceived worry of forgeifulness in different age groups $(n=764)$ 
Age, gender, education, depression, and subjective health were not independent of each other. Correlational analyses with age, education, depression, and subjective health as continuous variables showed that age was significantly related to lower education $(r=-37)$, higher depression scores $(r=.06)$, and lower health $(r=.19)$; lower education was related to higher depression scores $(r=-16)$ and lower health $(r=-29)$; higher depression scores were related to lower health $(r=.54)$; and finally being female was related to a lower educationall level $(r=-13)$, higher depression scores $(r=.17)$ and lower health $(r=14)$. To examine the relative contribution of these wariables on the prevalence of torgetfulness, we performed an additional multiple logistic regression analysis with forgetuhess as dependent variable and age, gender, education, depression, and subjective health as independent variables. Only subjects with complete data on all the independent variables were included in the analysis $(n=1,774)$. The results of this analysis are shown in Table 2.2.

Table 2.2 kesults of the logistic regression analysts for the prediction of forgetfulness.

\begin{tabular}{|c|c|c|c|c|c|c|}
\hline \multirow{2}{*}{$\begin{array}{l}\text { Variable } \\
\text { Age }\end{array}$} & \multirow{2}{*}{$\begin{array}{l}\text { Descriplion } \\
4 \text { groups }\end{array}$} & \multicolumn{2}{|c|}{$\begin{array}{c}\text { Regression } \\
\text { coefficient (SE) }\end{array}$} & \multirow{2}{*}{$\frac{p}{.000}$} & \multicolumn{2}{|c|}{ Oddls ratio $(95 \% \mathrm{Cl})$} \\
\hline & & 0.194 & $(0.051)$ & & 1.21 & $(1.10$ to 1.34$)$ \\
\hline Sex & male $=1$ & 0.193 & $(0.107)$ & .072 & 1.21 & $(0.98$ to 1.50$)$ \\
\hline Edelecation & 3 lewels & 0.008 & $(0.076)$ & 918 & 1.01 & $(0.87101 .17)$ \\
\hline Depresston & 3 levels & 0.413 & $(0.073)$ & .000 & 1.51 & $(1.31$ to 1,74$)$ \\
\hline Subjective health & 3 levels & 0.643 & $(0.074)$ & .000 & 1.90 & $(1.65102 .20)$ \\
\hline Constant & & -3.346 & $(0.341)$ & & & \\
\hline
\end{tabular}

Note. Based on 1,774 participants, $S E=$ standard eror. $C l=$ confidence interval.

The likelithood of forgetfuness increased with older age, ligher scores for depression, and lower health ratings. Within this model, no effects of educational level or gender were found on the prevalence of forgetfuness. The effect of edncation previously found is probably because of the confounding effect of age, given the strong negative correlation between age and educational level.

\section{Additional analysis on subjective health}

Because of the strong relation between forgetfulness and subjective health, we performed additional analyses on the subjective health questionnaire to examine the possibility that certain complaints are more strongly related to forgetfulness than others. A principal component factor analysis yielded four factors accounting for $51 \%$ of the variance. The four factors could be labeled gastro-intestinal complaints (6 items; e.g. "Do you often have pain in your stomach"; wariance accounted for $28.1 \%$; Cronbach's alpha .83 ), vitality complaints (6 items; e.g., "Do you often feel 
tired"; variance accounted for 10.4\%; Cronbach's alpha .79), cardio-pulinonary complaints (4 ifems; e.g." "Do you often have pain in your chest or heart region"; variance accounted for $6.8 \%$ \% Cronbach's alpha .73), and locomotor complaints (5 items; eg. "Do you often have pain in your back"; variance accounted for $5.8 \%$; Cronbach's alpha .62). The scores of these four subscales of the subjective health questionnaire were compressed in three levels. Subjects with no complaints were assigned to the lowest level. The remaining subjects with one or more complaints on the subscales were assigned to the medium and highest level of complaints on the basis of the accumulative frequency distribution of the scores on each subscalle (with a cut-off point of approximately $50 \%$ ). The results of the logistic regression analysis with four subscales or clusters of subjective health complaints are shown in Table 2,3.

Table 2.3 Reswls of the logistic regression andysis for the prediction of forgerthess wh four chusters of subjective health complaints.

Variable:

Description

Regression
coefficient ( $S E$ )

coefficient $(S E)$
Odds tatio $(95 \% \mathrm{Cl})$

\begin{tabular}{|c|c|c|c|c|c|c|}
\hline Age & 4 groups & 0.217 & $(0.053)$ & .000 & 1.24 & $(1.12101 .38)$ \\
\hline Sex & male $=1$ & .0 .012 & $(0.111)$ & .917 & 0.99 & $(0.79101 .22)$ \\
\hline Education & 3 levels & 0.007 & $(0.077)$ & .930 & 1.01 & $(0.87101 .17)$ \\
\hline Depression & 3 levels & 0.304 & $(0.076)$ & .000 & 1.36 & $(1.17101 .57)$ \\
\hline SH - Vitalitya & 3 levels & 0.518 & $(0.077)$ & .000 & 1.68 & $(1.44$ to 1.95$)$ \\
\hline SH - Gastro-intestinal & 3 levels & 0.227 & $(0.070)$ & .001 & 1.25 & $(1.09101 .44)$ \\
\hline SH - Cardio-pulmonary & 3 levels & 0.107 & $(0.072)$ & .137 & 1.11 & $(0.97$ to 1.28$)$ \\
\hline SH - Locomotor & 3 levels & 0.149 & $(0.086)$ & .083 & 1.16 & $(0.98$ to 1.37$)$ \\
\hline Constant & & -3.497 & $(0.357)$ & & & \\
\hline
\end{tabular}

Note. Based on 1.774 participants. $S E=$ standard error. $C l=$ confidence interval.

$\approx \mathrm{SH}=$ subjective thealth.

Age and depression were again both related to forgetfulness, but from the subjective health questionnaire only the clusters gastro-intestinal and especially vitality complaints were related to the prevalence of forgetfulness.

\section{Causes of forgetfulness}

Table 2.4 shows the main causes of forgetfulness as mentioned by the forgetful persons in the four age-groups. More than a quarter of the persons could not think of a possible cause for their forgetfulness. Forgetfulness as a result of aging was mentioned most often, followed by tension or emotional problems, lack of interest, and concentration problems. The other causes in the list were only mentioned by very small percentages of the persons. Being too busy was relatively frequently mentioned by the youngest age-group $(8 \%)$. 
Table 2.4 Man crase of forgeringes anong the four age grouph

\begin{tabular}{|c|c|c|c|c|c|c|c|c|c|c|}
\hline & \multicolumn{2}{|c|}{$\begin{array}{c}\text { Total } \\
\text { group } \\
y=764\end{array}$} & \multicolumn{2}{|c|}{ Young } & \multicolumn{2}{|c|}{$\begin{array}{c}\text { Young } \\
\text { middle-age } \\
n=172\end{array}$} & \multicolumn{2}{|c|}{$\begin{array}{c}\text { old } \\
\text { middle-age } \\
m=213\end{array}$} & \multicolumn{2}{|c|}{$\begin{array}{c}\text { Old } \\
n=238\end{array}$} \\
\hline & $n$ & $\%$ & $n$ & 哭 & $n$ & $\%$ & $n$ & $\%$ & $n$ & $\%$ \\
\hline 1. Age & 259 & 33.9 & 3 & 2.1 & 39 & 22.7 & 37 & 36.2 & 140 & 58.8 \\
\hline 2. Unknown & 197 & 25.8 & 35 & 24.8 & 34 & 19.8 & 63 & 29.6 & 65 & 27.3 \\
\hline 3. Tersion/emotional problems & 93 & 12.2 & 29 & 20.6 & 22 & 12.8 & 26 & 12.2 & 16 & 6.7 \\
\hline 4. Lack of interest & 73 & 9.6 & 26 & 18.4 & 24 & 14.0 & 17 & 8.0 & 6 & 2.5 \\
\hline 5. Poor concentration & 63 & 8.2 & 24 & 17.0 & 28 & 16.3 & 10 & 4.7 & 1 & 0.4 \\
\hline 6. Health problems & 21 & 2.7 & 5 & 3.5 & 9 & 5.2 & 3 & 1.4 & 4 & 1.7 \\
\hline 7. Toobusy & 16 & 2.1 & 11 & 7.8 & 4 & 2.3 & 1 & 0.5 & - & - \\
\hline 8. Lack of mental exercise & 16 & 2.1 & 6 & 4.3 & 6 & 3.5 & 3 & 1.4 & 1 & 0.4 \\
\hline 9. Medication & 10 & 1.3 & - & - & - & - & 6 & 2.8 & 1 & 0.4 \\
\hline 10. Anesthesia & 6 & 0.8 & - & - & 2 & 1.2 & 3 & 1.4 & $\mathbb{1}$ & 0.4 \\
\hline 11. Always poor memory & 5 & 0.7 & 2 & 1.4 & - & - & 2 & 0.9 & 1 & 0.4 \\
\hline 11. Mental decline & 5 & 0.7 & -- & - & 1 & 0.6 & 2 & 0.9 & 2 & 0.8 \\
\hline & 764 & 1000 & 141 & 100 & 172 & 100 & 213 & 100 & 238 & 100 \\
\hline
\end{tabular}

Table 2.5 Main cause of forgerfulness and alabject characteristics.

Age Sex Educationa

$\begin{array}{lccr}\text { 1. Age } & \text { older } & \text { n.s. } & \text { lower } \\ \text { 2. Tensiontemotional problems } & \text { younger } & \text { female } & \text { n.s. } \\ \text { 3. Lack of interest } & \text { younger } & \text { n.s. } & \text { lower } \\ \text { 4. Poor concentration } & \text { younger } & \text { M.s. } & \text { n.s. }\end{array}$

\begin{tabular}{llll}
\hline 5. Menory-inirinsic causes & older & m.s. & lower \\
\hline
\end{tabular}

Note. $p<.01$.

$a_{n}=553$

To examine whether the indicated causes were related to differences in age, gender, and education, a series of chi-square tests were perfomed on the four most frequently mentioned 
causes. The number of persons who mentioned a certain cause was compared with the total number of persons who mentioned one of the other causes. Persons who did not give a cause for their forgetfulness $(n=197)$ were excluded from this analysis. They were not different in terms of age, gender, and education from those who did mention a cause. The remaining group that had indicated a certain cause consisted of 567 persons. The results are shown in Table 2.5.

Older and lower educated persons more often ascribed their forgetfulness to aging. Younger persons ascribed their forgetfulness more often to tension and emotional problems, lack of interesi, and poor concentration. Additionally, tension and emotional problems were more often mentioned by females, and lack of interest more often by lower educated persons.

In the next step of the analysis we examined possible effects of age, sex, and education with respect on the nature of the cause in tems of reversible and manageable memory-extrinsic causes (tension and emotional problems, poor concentration, lack of interest, lack of mental exercise, 100 busy) and less reversible and manageable memory-intrinsic causes (age, health problems, mental retardation, medication, anesthesia, always poor memory). As can be seen in Table 2.5, older persons and lower educated persons more often ascribed their forgetfulness to memory-intrinsic causes.

\section{Need for treatment and medication use}

All participants were asked whether they use(d) medication that was not prescribed by a doctor in order to improve their memory functioning or vitality. No information is available about the type of medication they use(d). Eleven percent of the total group had used this type of medication for at least one month, elderly persons more often than younger persons $(p<.01)$. No difference was found between men and woman nor between higher and lower educated subjects.

Eighty-six of the 764 participants who described themselves as forgetful $(11.3 \%)$ had considered looking for a treatment for or getting information about their memory complaints, or had actually done so. This indicates that most forgetful people do not feel need for treatment or information. Participants who had this need were more worried about their forgetfulness ( $p<$ $.001)$ and experienced more hindrance in daily life $(p<.001)$ than participants without this need. No differences were found between men and women. Persons with a higher level of education considered getting information or treatment more often than other subjects did $\left(X^{2}(1)=12,2, p<\right.$ .001 ). Table 2.6 presents the most important treatment or intervention preferences (more than one preference could be indicated). An educational or training program was preferred most often, followed by a consultation with the general practitioner of a specialist.

All participants who considered themselves as being forgetful were also asked it they were interested in participation in a treatment with medication that possibly has a positive effect on memory. Almost $47 \%$ of them were interested in a treatment with medication. They were more worried about their forgetfulness than those who were not interested in such treatment $(p<.001)$. They also experienced more hindrance in daily life $(p<.001)$ and they tended to be older $(p<$ $.01)$. Furthermore, men were more interested in a treatment with medication than women were. $\left(X^{2}(1)=7.7, p<.01\right)$. 
Table 2.6 Med for ireament and infonnation awnong the group of forgethil people $(n=86)$.

\begin{tabular}{lc}
\hline & \\
Education (e.g., a brochure or an information meeting) & $37 \%$ \\
A course or a training program & $29 \%$ \\
Consultation with a general practitionier or a specialist & $20 \%$ \\
Medication prescribed by a physician & $6 \%$ \\
Medication from a practitioner of complemeniary medicine & $4 \%$ \\
Over-the-counter medication to improve memory & $2 \%$ \\
Other & $2 \%$ \\
\hline
\end{tabular}

\section{Discussion}

Nearly $40 \%$ of the participants in this study considered themselves to be forgetful. There was a systematic increase in the prevalence of forgetfulness with age. In the oldest age group more than one half of the participants considered themselves as being forgetful. Perhaps the most interesting finding in our study is the relatively high prevalence rates of forgetfulness in the young and young middle-aged groups. Almost one third of these, according to gerontological criteria, young persons considered themselves forgetful. In line with the findings from other research (e.g., Sunderland et al., 1986), older persons did not experience more hindrance from their forgetfulness than younger forgetful persons. Perceived worry about forgetfulness seems to be largely age independent. Only forgetful persons in the youngest age group had a significantly lower mean score on worry compared to the other three groups. Overall, the frequency distributions of perceived worry and hindrance as shown in Figures 2.2 and 2.3 suggest that forgetfulness is not considered a serious problem by most of the participants, irrespective of their age. Approximately $80 \%$ of the forgetful persons in the different age groups experienced "no" to "little" hindrance from their forgetfulness and about $90 \%$ were "not" to only "little" worried about their forgetfulness.

Besides age, only depression and especially subjective health acted as covariates of forgetfulness. No effects were found for gender and education, which is in contrast to the findings of Cutler and Grams (1988). Subjective health was most strongly related to forgetfulness. Additional analyses showed that especially vitality complaints were related to higher prevalence rates of forgetfulness. It is interesting to note that these complaints correspond with the more physical symptoms of depression (e.g., tiredness, loss of appetite, sleeping problems). whereas the depression questionnaire used in this study focussed more on the typical mood symptoms of depression (e.g., feeling down, loss of interest). These dlata suggest that not health in general, but physical symptoms of depression or, more broadly, problems with vitality are related to everyday memory problems.

With increasing age, people ascribe their forgetfulness more often to less manageable and more or less irreversible memory-intrinsic causes, with aging being mentioned most often. These findings are in line with the experimentally based attribution study of Lachman and Mc Arthur 
(1986). This pessimistic atribution pattern is not only related to age, but also to a lower level of education. Younger persons more often mentioned manageable and reversible memory-extrinsic causes for their forgetfulness. The three mostly mentioned causes (tension and emotional problems, lack of interest, and poor concentration) may be interpreted as being related to affective state. The pessimistic attribution pattem of the elderly again underlines the importance of modifying negative beliefs about memory competence and controllability, when treatment of memory problems in the elderly is considered (Lachman, Weaver, Bandura, Elliott, \& Lewkowicz, 1992).

Only eleven percent of all forgetful persons were interested in some form of treatment or information. People who had this need experienced more hindrance in daily life and were more worried about their forgetfulness than the group without this need for information or treatment. No differences in age were found. Most persons were interested in training and education as a possible intervention to decrease their worries or to improve the functioning of their memory in daily life. Nevertheless, treatment of memory with medication seems to be quite attractive as $47 \%$ of all forgetful people were interested if they were offered a treatment with medication that possibly has a positive effect on the working of their memory.

In summary, although relatively high percentages of subjects from young to old age considered themselves forgetful, most of them did not perceive their forgetfulness as a serious problem in their daily functioning. We should, however, not disregard those subjects who experienced considerable hindrance from their forgetfulness and, perhaps of even more importance, were very worried about this forgetfulness. After all, this was the case for roughly one to two persons out of ten who considered themselves forgetful, which is rather substantial if considered from a more clinical point of view. Although not explicitly asked for in this study, the perceived forgeffulness by these subjects may have a detrimental effect on their quality of life.

\section{References}

Arrindell, W. A., \& Esttema, J. H. M. (1986). SCL-90. Een multidimensionele psychopathologie indicator (The SCL.90. A multidimensional instrument for the assessmen of prychopathology). Lisse, The Nethertands: Swets \& Zeillinger.

Bandura, A. (1989). Regulation of cognitive processes through perceived self-efficacy. Developwental Psychology. 25.729.735.

Bolla, K. I. Lindgren, K. N. Bonaccorsy, C., B Bleecker, M. L. (1991). Memory complaints in older adulis. Fact or fiction? Archives of Neurology, 48,61-64.

Cavanaugh. J. C. (1987). Age differences in adults' self-reports of memory ability: It depends on how and what you ask. Ime Fnational Journal of Aging and Human Developtrent, 24, 271-277.

Cavanaugh, I. C. (1989). The importance of awareness in memory aging. In L. W. Poon, D. C. Rubin, \& B. A. Wilson (Eds.), Everyday cognision in adulthood and late life (pp. 416-436). Cambridge: Cambridge University Press.

Cavanaugh, J. C., Grady, J. G., \& Permutter, M. (1983). Forgetting and use of memory aids in 20 to 70 year olds everyday life. Mnternational Jownal of Aging and Human Development, 17, 113-122.

Chaffin, R., \& Hermann, D. J. (1983). Self report of memory abilities by old and young adules. Hownan Lewaning, $2,17.28$.

Commissaris, C. J. A. M. Jolles, J, Verhey, F. R. J., Ponds, R. W. H. M., Damoiseaux, V. G. M. \& Kok, G. J. (1996). Forgefulness or dementia? Who is worried and why? European Joumal of Public Health, 6, 297-299.

Commissaris, C. J. A. M., Verhey, F. R. J., Ponds, R. W. H. M., Jolles, J., \& Kok, G. J. (1994). Public education about normal forgetfulness and dementia: Importance and effects. Patient Educarion and Cownseling, $24,109-115$. 
Cromwell. S. L. (1994). The subjective experience of forgetulness among elders. Qualitive Healdh Research" 4. $444-462$

Crook, T. H., \& Larrabee, G. J. (1990). A selffrating scale for evaluating memory in everyday life. Psychology and Aging, 5, 48-57.

Cuiler, S. J., \& Grams, A. E. (1988). Correlates of self-reported everyday memory problems. Joumal of Ge ponvology: Social Sciences; $43,82-90$.

de $\mathrm{B}$ ie, S. E. (1987). Standaarduragen 1987 . Voorstellen voor uniformering van vraagstellingen naar achtergrondkenmerken en intenvews (Toward a standardization of questions conceming demographic variables in population studies) (2nd ed.). Leiden: Leiden Uniwersity Press.

Derogatis, L. R. (1977). SCL-90: Administration, scoring and procedures manual-1 for the R(evised) version. Baltmore: Johns Hopkins School of Medicine, Clinical Psychometrics Research Unit.

Dirken, J. M. (1967). Het meten van stress in indastriele situaties (The measurenewt of stress in industrial situations). Groningen, The Netherlands: Wolters.

Gilewski, M. J., Zelinski, E. M., \& Schaie. K. W. (1990). The memory functioning questionnaire for assessmen: of memory complaints in adulthood and old age. Psychology and Aging, 5, 482-490.

Hultsch, D. F, Hertzog, C., \& Dixon, R. A. (1987). Age differences in metamemory: Resolving the incongistemcies. Canadian Jaumal of Psychology, 41, 193-208.

Jackson, J. L., Bogers, H., \& Kerstholt, J. (1988). Do memory aids aid the elderly in their day to day remembering? In M. M. Gruneberg, R. E. Morris, \& R. N. Sykes (Eds.). Practic aspects of memory: Current research and issues. Clinical and educarional implications (pp. 137.142). Chichester: John Wiley \& Sons.

Jolles, J., Houx, P. J., van Boxlel, M. P. I., \& Ponds, R. W. H. M. (1995). Maastricht Aging Snudy: Determinants of cognitive aging. Maastricht: Neuropsych Publishers.

Lachman, M. E. (1991). Perceived control over memory aging: Developmental and intervention perspectives. Jourpal of Social Mssues, $47,159-175$.

Lachman. M. E. B. McArthur, L. Z. (1986). Adulthood age differences in causal aitributions for cognitive, physical $I_{r}$ and social performance. Psychology and Aging, I, 127-132.

Lachman, M. E., Weaver, S. L., Bandura, M., Elliott, E., Lewkowicz, C. J. (1992). Improving memory and control beliefs through cognitive restructuring and self-generated strategies. Jountal of Gerontology: Psychological Sciences, 47, 293-299.

Lovelace, E. A. (1990). Aging and metacognitions concerning memory function. In E. A. Lovelace (Ed.), Aging and cognition: Mental processes, self awareness and interventions (pp. 157-188). North-Holland: Elsevier Science Publishers.

Lovelace, E. A., \& Marsh, G. R. (1985). Prediction and evaluation of memory performance by young and old adults. Joumal of Gerontology, 40, 192-197.

McMillan, T. M. (1984). Investigation of everyday memory in normal subjects using the subjecrive memory questionnaire (SMQ). Cortex, 20,333-347.

Metsemakers, J. F. M., Hoppener, P., Knottnerus, J. A., Kocken, R. J, J., \& Limonard, C. B. G. (1992) Computerized health information in the Netherlands: A registration network of family practices. British Journal of General Practice, $42,102 \times 106$.

Ponds, R. W. H. M. \& Jolles, J. (1996), Memory complaints in elderly people: The role of memory abilities, metamenory, depression, and personality. Edacational Gerosirology, 22, 341-357.

Sunderland, A., Watts, K., Baddeley, A. D., \& Harris, J. E. (1986). Subjective memory assessment and test pertormance in elderly adulis. Joumal of Gerontology, 4l, 376-384. 
Chapter 3

\title{
Age-related changes in subjective cognitive functioning*
}

\begin{abstract}
The main focus of this study was to examine age-related changes in self-evaluation of cognitive functioning in the domains of memory, attention, mental speed, planning, and decision making. Almost 2,000 persons in the age range 24 to 86 years rated their present cognitive functioning relative to three different reference points: compared to their age-mates, to their level 5 to 10 years ago, and to their level when they were 25 years. An age-stratified group of 420 participants also completed a series of cognitive tests. Age-related decline in subjective cognitive functioning started at the age of 50 and steadily increased afterwards. This decline was not restricted to memory, but also involved changes in attention, mental speed, planning and decision making. When participants compared their present cognitive functioning with that of their own age-group, no age effects were found. Subjective health and depression were both related to subjective decline in cognitive functioning. No relation was found between subjective and objective cognitive functioning.
\end{abstract}

* Ponds, R.W.H.M., van Boxtel, M.P.J., Jolles, I. (submitted) 


\section{Introduction}

Studies on the self-appraisal of memory in the aged population have almost consistently shown that aging is accompanied by a subjective decline in daily memory functioning (e.g., Cutler \& Grams, 1988). There is, however, no straightforward relation between selfreported memory functioning and memory performance. Correlations between subjective memory functioning, as measured with self-report questionnaires, and performance on memory tests are either absent or at best modest (Gillewski \& Zelinski, 1986). Yet, information on subjective memory functioning in aged people is of considerable importance. Although self-perceptions of memory functioning may not be veridical estimates of actual memory skills or competence, these perceptions may have a substantial impact on the behavior of elderly people in everyday memory demanding situations (Lovelace, 1990).

When reviewing the research on subjective cognitive functioning in the aged population, several shortconings may be pointed out. The question whether the subjective age-related changes in cognition are global or specific cannot be answered because most studies are focussed on memory only. Although a decline in memory functioning is probably the most prominent change when one grows older, other cognitive functions such as attention or problem-solwing are also vulnerable to aging. It would therefore be of interest to examine to what extent older subjects experience subjective decline in these other cognitive functions as well.

The finding that memory complaints or incidents of memory failure are more frequent among elderly subjects is typically found in studies where a young sample is compared with an old sample. Only few studies have examined changes in subjective cognitive functioning over the whole adult age range, which is necessary to answer questions concerning the age at which changes occur, and the speed at which they proceed. Several studies have shown that people already start to notice a decline in memory functioning in their early middle age and that this decline steadily increases in the following years (Fulicka, 1982; Hultsch, Hertzog, \& Dixon, 1987).

The reference point to which people compare their present memory functioning is also of considernble importance. Relative measures of reported memory abilities, where people judge their present memory performance relative to some defined point in their own past performance, seem to yield more information than absolute measures, in which people have to judge their present functioning in either terms of a global rating (from "good" to "bad") or present frequency of well-described menory failures. Rabbitt (1982), for example, asked subjects to complete a memory questionnaire twice, reporting their current level of memory functioning and their level when they were 30 years old. No correlation was found between two list learning tasks and the present level of reported memory abilities, whereas the correlations between the memory tests and the difference scores between the two levels were substantial. In the same line are the findings of Hultsch et al. (1987) with the Metamemory in Adulthood questionnaire: strong age effects were found on a scale in which subjects rate self-perceived decline in memory, whereas the age effects on a scale in which subjects rate their present memory capacity were rather small. Moreover, studies that showed no, or only small age-related differences in subjective memory functioning all used absolute instead of relative measures of memory (Cavanaugh, 1987; Chaffin \& Herrmann, 1983; Crook \& Larrabee, 1990; Jackson, Bogers, \& Kerstholt, 1988; McMillan, 1984). 
In this paper we report on the results of a study in which we examined self-report of cognitive functioning in the domains of memory, attention, mental speed, planning, and decision-making. Almost 2000 persons in the age range 24 to 86 years rated their present functioning relative to three reference points: to age-mates, to their level 5 to 10 years ago, and to their level when they were 25 years old. The primary research questions concemed the specificity of the subjective agerelated decline in cognition and the age at which the first dectine in cognitive functioning is noticed. We were also interested in the association between subjective cognitive functioning on the one hand and self-rating of depression and health on the other, as several studies have demonstrated a relation between self-appraisal of memony functioning and affective state (e.g., Bolla, Lindgren, Bonaccorsy, \& Bleecker, 1991) and self-appraisal and health (e.g., Cutler \& Grams, 1988). Finally, we looked at the relation between subjective and objective cognitive functioning in an age-stratified subsample of 420 subjects aged 25 to 80 years.

\section{Method}

\section{Participants and procedure}

This study was conducted as part of a large cross-sectional study into biological and psychological determinants of successful and pathological cognitive aging, which was part of a large research program on cognitive aging (Maastricht Aging Study - MAAS: Jolles; Houx, van Boxtel \& Ponds, 1995). In the first phase of this cross-sectional study an extensive postal questionnaire on subjective cognitive functioning in relation to age, health, and psychological factors was sentt to 2,340 subjects aged 24 to 86 years.

Participants were recruited from a register of patients of general practices in the region of Maastricht in the Netheriands (Metsemakers, Höppener, Knottnerus, Kocken, \& Limonard, 1992). This register contains all relevant past and curtent medical morbidity as documented by the general practitioners. Subjects with previous or actual medical conditions with known impact on cognitive or motor functions were excluded from the selection. Exclusion criteria were overt cerebrovascular disease, chronic neurological pathology (e.g., dementia, epilepsy, parkinsonism), mental retardation, and major psychiatric disorders. Subject sampling was stratified by 13 discontinuous age classes ( 25 years $\pm 1,30$ years, ... 85 years \pm 1 ) and sex. A total number of 3,921 persons were drawn from the register. After screening by the general practitioners, 187 were excluded because of present illness or psychosocial indications. The remaining 3,734 were invited by their practitioner to participate in the study; 2,340 were willing to participate and received the postal questionnaire. A total of 2,043 participants completed and returned the postal questionnaire in good order.

Due to missing data on the guestions concerning subjective cognilive functioning, 95 persons were excluded leaving a total number of 1,958 participants (see below). There were slightly more women ( $54 \%$ ) than men in the sample. The age range was 24 to 86 years with a mean age of 53,1 years. Educational level was measured by a Dutch scoring system (de Bir, 1987) which consists of a 8-point scale, ranging from unfinished primary education (level 1) to university education (level 8). Mean educational level was 3.2 for the total group, but increasing age was associated 
with a lower level of education.

In the second phase of the cross-sectional study, a subsample of 420 perons from the postal survey sample was selected and were administered a series of cognitive tests. There was a considerable time lag of 3 to 12 month between filling in the postal questionnaire and cognitive testing. Approximately one third of the participants was tested within 3 to 6 months, one third within 7 to 8 months, and one third between 9 and 12 months. The subsample was again stratified. for age (12 age classes, see above), sex, and two levels of occupational achievement, to control for the effects of relevant cognitive performance predictors. The age range was 24 to 82 years (mean age 51.2 years) and the mean educational level was 3.5. Fifty-one percent of the sample was of the male sex.

\section{Measures}

Subjective cognithe functioning. The subjects were asked to evaluate their present cognitive functioning by comparing it to that of people of their own age (Same age-scalle), by comparing it to their level of cognitive functioning 5-10 years ago (Recent past-scale), and by comparing their present level with that when they were 25 years old (Early adulthood-scale). In each scale eight identical questions were asked which covered several cognitive functions. Four questions were related to attentional functions (the ability to concentrate, sustained and divided aftention, and distractibility), two questions were related to decision-making and planning ("executive functions"; Lezak, 1995), one question focussed on memory, and one question concermed possible changes in mental speed. For example: "Compared to 5-10 years ago I find it ... to concentrate on things I see, hear, or read" (Recent past-scale: concentration). The subjects could rate possible changes on a 5-point scale ranging from much better or easier (score 1) to much worse or far more difficult (score 5); a score of 3 indicated no change or no difference. The subjects in the age-range of 2426 years did not fill in the Early adulthood-scale.

Missing data were handled in the following way. If only one of the eight questions of each scale was left blank, this question was assigned a score of 3 (the middle of the 5-point scale). Different number of persons still had missing data on one or more of the questions of each comparison scale (Early adulthood-scale: $n=178$; Same age-scale: $n=72$; Recent past-scale: $n=$ 48). We decided to include only those persons with complete data for the Recent-Past and the Same-age scale. As a result of this criterion, 85 persons ( $5 \%$ ) of the original group of 2,043 were excluded from further analysis. There were 127 persons aged 24 to 26 who were asked not to fill in the Early adulthood-scale. From the remaining group of $1,83 \rrbracket$ persons aged 29 to 86 years, 143 still had missing values for the Early Adulthood-scale, so that the number of persons for the Eanly adulthood-scale was 1688 .

Objective cognitive funcrioning. A set of neuropsychological tests was administered which tapped memory and memory-related functions, attention, mental speed, and complex information processing.

The Motor Choice Reaction Test is a computer test that evaluates reaction times as a function of the complexity of task requirements (Houx \& Jolles, 1993). The task used here combines response selection with stimulus-response incompatibility. The variables of interest are the time needed for decision making and the actual movement time. 
The Letter-Digit Modalities Test is a modification of the procedurally identical Symbol-Digit Modalities Test (Lezak, 1995). It is used as a measure of the speed of processing of general information, i.e., the test is supposed to draw upon several (cognitive) processes such as visual perception, aftention, and memory. The two variables of interest are the number of correctly coded letter-digit combinations in 90 seconds on an oral and written administration.

The Concept Shifting Test is derived from the well known Trail Making Test (Lezak, 1995), which is used to measure the ease of shifting between concepts. There are three task conditions: the subject has to cross out, in the proper order, 16 circles containing only digits ( 1 to 16 ; part $A$ ), letters (A to $\mathrm{P}$; part B), or both (1-A-2-B, etc.; part C). In the latter subtest, one has to shift between the concepts 'digits' and "letters'. The variables of interest are the times (sec) needed to complete each subtest.

The Siroop Color-Word Test (Lezak, 1995) is a test of selective attention and interference susceptibility. The test involves three cards displaying one hundred stimuli each: collor names, colored patches, and color names printed in incongruously colored ink. For the last card, the color of the ink has to be named instead of the color name. This task is particularly sensitive to interference. The variables of interest are the times (sec) needed to complete each card.

The Visual Verbal Leaming Test (Brand \& Jolles, 1985) is a computerized, visual version of the Auditory Verbal Learning Test (Lezak, 1995). A set of 15 frequently used monosyllabic: meaningful words is visually presented in a fixed order at a rate of one every two seconds in five consecutive trials. After each trial or presentation the subject is requested to recall as many words as possible with no restriction conceming the order of recall (immediate recall). Twenty minutes after the fifth presentation, the subject is again requested to recall as many words as he or she can remember (delayed recall). This test measures memory storage and retrieval of verbal information in episodic nemory.

In the Fluency task, the subject is asked to name as many different animals and professions as possible in one minute. This test measures strategy-driven retrieval from semantic memory. The variables of interest are the number of correctly named animals and professions.

The multiple choice version of the Benton Visual Retention Test (Lezak, 1995) was used to evaluate short-term memory in the visual modality. The variable of interest is the number of correctly identified visual figures.

Affective state and subjective health. Feelings of depression were measured with the subscale Depression of the revised version of the Symptom Checklist (SCL-90; Derogatis, 1977; Dutch version: Arrindell \& Ettema, 1986). The SCL-90 is a multidimensional self-report inventory of current psychopathology. Items are rated on a 5-point scale. The subscale depression contains 16 items which reflect symptoms of depression (score range 16-80). Subjective health was measured with the Dutch Inventory of Subjective Health (Dirken, 1967). The 21 -item version administered in this study probes health complaints of a somatic and psychosomatic nature. The score range is a-21.

\section{Data analysis}

Principal component analyses (PCA) were conducted on the three comparison scales to examine the coherence between the different cognitive functions that were tapped in the eight questions. 
Separate PCA were performed in a young and old sample to examine possible effects of age on the factor structure. In addition to the PCA, internal consistency estimates were calculated (Cronbach's alpha). Multiple regression analyses were conducted to examine the relation between age, sex, education, depression and subjective health and the scores on the three comparison scales. For each of the 15 cognitive test parameters $z$-scores were calculated based on the total population of tested subjects. Next, these $z$-scores were averaged to achieve an overall test performance score for each subject. Correlational analyses (zero-order, partial correlation) were performed to examine the relation between subjective and objective cognitive functioning. Because of the large sample sizes in this study, only probabilities of $1 \%$ or less were considered as significant, unless reported otherwise.

\section{Results}

\section{Factor structure}

A one-factor solution was found for all three comparison scales. This solution accounted for $46 \%$ of the variance in the Same age-scale (item loadings ranging from .44 to .77), 54\% of the variance

"able 3.1 Mean score and standard dewarions per comparison scale as a funcrion of age class.

\begin{tabular}{|c|c|c|c|c|c|c|c|c|}
\hline \multirow[b]{2}{*}{ Age class } & \multirow[b]{2}{*}{$n$} & \multicolumn{2}{|c|}{ Same age scale } & \multicolumn{2}{|c|}{ Recent past scale } & \multirow[b]{2}{*}{$n$} & \multicolumn{2}{|c|}{ Early aduthood scale } \\
\hline & & $M$ & $S D$ & $M$ & $S D$ & & $M$ & $S D$ \\
\hline 25 years & 127 & 2.71 & 0.56 & 2.50 & 0.63 & - & - & - \\
\hline 30 years & 161 & 2.86 & 0.45 & 2.77 & 0.57 & 152 & 2.82 & 0.46 \\
\hline 35 years & 195 & 2.81 & 0.47 & 2.81 & 0.50 & 1.87 & 2,80 & 0.46 \\
\hline 40 yean's & 173 & 2.82 & 0.50 & 2.92 & 0.50 & 162 & 2.86 & 0.60 \\
\hline 45 years & 175 & 2.83 & 0.43 & 3.01 & 0.46 & 166 & 2.98 & 0.56 \\
\hline 50 years & 161 & 2.80 & 0.52 & 3.16 & 0.43 & 148 & 3.14 & 0.58 \\
\hline 55 years & 173 & 2.74 & 0.49 & 3.14 & 0.46 & 157 & 3.12 & 0.57 \\
\hline 60 years & 181 & 281 & 0.57 & 3.24 & 0.43 & 167 & 3.38 & 0.56 \\
\hline 65 yenrs & 167 & 2.74 & 0.57 & 3.25 & 0.48 & 162 & 3.35 & 0.60 \\
\hline 70 years & 149 & 2.70 & 0.52 & 3.26 & $0.4 \|$ & 134 & 3.46 & 0.68 \\
\hline 75 years & 127 & 2.82 & 0.58 & 3.43 & 0.49 & 109 & 3.66 & 0.59 \\
\hline 80 years & 107 & 2.74 & 0.60 & 3.38 & 0.48 & 90 & 3.73 & 0.62 \\
\hline 85 years & 62 & 2.59 & 0.53 & 3.39 & 0.52 & 54 & 3.72 & 0.68 \\
\hline Total sample & 1958 & 2.78 & 0.52 & 3.06 & 0.56 & 1688 & 3.18 & 0.65 \\
\hline
\end{tabular}

Note. Minimum score is 1 (far more easy or better), maximum score is 5 (far more difficult or worse). 


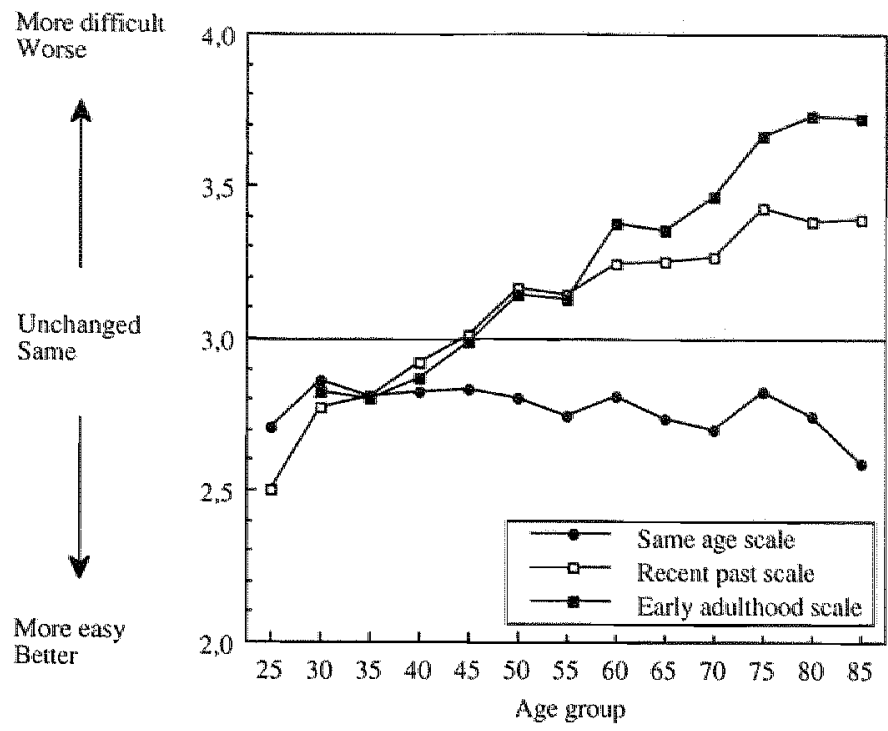

Figure 3.1 Subjective cognitive functioning as a function of age class

in the Recent past-scale (item loadings ranging from .49 10.80 ), and $56 \%$ of the variance in the Early adulthood-scale (item loadings ranging from .46 to .83 ). Internal consistency estimates for the Same age-scale, Recent past-scale, and the Early adulthood-scale were $.82, .87$, and .88 respectively. To control for possible age differences in the factor structure of the three comparison scales, PCA and reliability analyses were performed separately for a young (all subjects younger than 51 years, $n=992$, mean age 38.7 years) and old subsample (all subjects older than 54 years, $n=966$, mean age 67.9 years). Again, a one-factor solution was found for the three scales in both groups. In the young group, the one-factor solution accounted for $46 \%$ of the variance on the Same age-scale (Cronbach's alpha .82), 54\% on the Recent past-scale (alphil .88), and $52 \%$ on the Early adulthood-scale (alpha .87). In the old group, these percentages were $46 \%, 48 \%$, and $53 \%$ respectively, with Cronbach's alphas of $.82, .83$, and .86 . These findings suggest that the factor structure of the three comparison scales is invariant over age.

Effects of age, sex, education, depression and subjective health

On the basis of the results of the PCA, the eight questions of each comparison scale were combined into one comparison score. The mean scores for each scale for all the 13 age classes are presented in Table 3.1. The direction of the mean scores on the three comparison scales is shown in Figure 3.1. On the Same age-scale, the participants rated themselves as somewhat better than their "average" age-mates. However, when the participants had to rate their present cognitive functioning relative to their own past cognitive performance, an age-related decline became apparent. Subjective decline in cognitive functioning was already noticed at the age of 50 and increased steadily thereafter, although in absolute terms these changes were of a relatively small 
magnitude. As expected, this notion of decline was most prominent in the Early adulthood-scale. The younger groups (age classes 30,35 , and 40 years) judged their general cognitive functioning as being somewhat better than it was at the age of 25 years or 5-10 years ago. The steady increase in the decline was attenuated in the oldest age groups ( 80 and 85 years).

Multiple regression analyses were performed to examine the relation between the scores on the three comparison scales (dependent variables) and age, sex, education, depression, and subjective health (independent variables). All independent variables were entered and allowed to compete among themselwes (stepwise forward). The criterion to enter was a correlation between the dependent and independent variable with a significance level of $p<.05$. Missing values for the depression and the subjective health questionnaire were replaced by the age-corrected scale means from the total sample. Separate regression analyses were performed for the subgroup with complete data on all predictor variables and the total group where total scores on the depression and subjective health questionnaire were replaced by the sample mean. Both methods yielded identical results. Therefore, only the analyses for the total group are presented here. The correlations between the variables in the regression and the results of the regression analyses are shown in Table 3.2 and 3.3. As expected, age accounted for a considerable amount of variance on the Recent past-scale (19\%) and the Early adulthood-scale (22\%). Subjective health and depression accourted for an additional $6 \%$ and $2 \%$ on the Recent past-scale and $5 \%$ and $1 \%$ for the Early adulthood-scale. Higher age, lower health ratings, and higher depression scores were related to higher scores on the two scales, indicating more decline in subjective cognitive functioning. Only $10 \%$ of the variance on the Same age-scale was explained by the set of predictors. The most substantial contribution was found for subjective health $(6 \%)$, followed by only small contributions of depression ( $1 \%)$, age $(1 \%)$, education (1\%), and sex $(0.5 \%)$. Lower health ratings, higher depression scores, younger age, lower education, and being female were related to higher scores on the Same age-scale (lower cognitive functioning compared to age mates).

Table 32 Correlations betwesn the three scales of suljecrive cognitive fumctioning, age, education, sex, deptession. and subjective health.

\section{Sanne age}

2. Recentiast

3. Early adulthood

4. Age

5. Education

6. $\operatorname{Sex}$

7. Depression

8. Subjective thealth

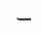$$
.44
$$$$
39
$$$$
-.06
$$$$
-14
$$$$
.13
$$$$
23
$$$$
25
$$

44
39
06
14
13
23
25

$.80 \quad-$

$.44 \quad .47$

$\begin{array}{lll}-.24 & -.23 & -.37\end{array}$

$.07 \quad .05 \quad .00 \quad \cdots 12$

$.27 \quad .23 \quad .06 \quad-.14$

$\begin{array}{llll}.33 & .30 & .19 & -.28\end{array}$

$\begin{array}{ll}.17 & - \\ .14 & .51\end{array}$

Nore. Based on 1958 subjects, except tor the Early Adulthood-scale $(n=1688)$. For all correlations: $p<.01$ (onetailed), except Early advilthood scale and $\operatorname{Sex}(p<.05)$, and Age and Sex (ns). 
Table 3.3 Multiple regression of age, sex, educarion, depression, and subjective health on the three scales af subjective cognithve functioning.

\begin{tabular}{|c|c|c|c|c|c|}
\hline Scale & Predictons & Berat & & $\mathrm{K}^{2}$ Change & $r$ \\
\hline \multirow[t]{6}{*}{ Same age } & Subjective healnh & .17 & & .062 & $128.7^{* * *}$ \\
\hline & Depression & .12 & & .013 & $27.5 * 2$ \\
\hline & Age & -.14 & & .011 & $22.8 *$ \\
\hline & Education & -.12 & & .013 & $28, f^{*}$ \\
\hline & Sex & .07 & & .004 & $9.5 *$ \\
\hline & & & $\mathbb{R}^{2}$ & .109 & \\
\hline
\end{tabular}

\begin{tabular}{|c|c|c|c|c|}
\hline \multirow[t]{3}{*}{ Recent past } & Agge & .40 & .193 & 466.5 \\
\hline & Subjective health & .18 & .064 & 169.4 ; \\
\hline & Depression & .15 & .016 & $42.8 *$ \\
\hline
\end{tabular}

Age

Subjective health

Depression
.47

23

.12
.218

.049

.010 $471.0^{\text {s. }}$

$112.8 * *$

24.2 **

\section{$R^{2} \quad .277$}

Note. Based on 1958 subjects, except for the Early Adulthood-scale $(n=1688)$. Beta = standardized regression coeffictent in the final model.

$p<.01 * 0<.001$.

\section{Relation between subjective and objective cognitue functioning}

Table 3.4 shows the correlations between the subjective cognitive scales, age, education, sex, subjective health, depression and overall test performance. As expected, the strongest correlations with test performance were found for age and education. Higher age and lower education were associated with lower overall test performance. There were significant negative zero-order correlations between the overall testperformance and the Recent past-scale and Early adulthoodscale: more subjective decline was related to lower test performance. However, after controlling for the effects of age, education, sex, subjective health, and depression (partial correlation), the correlations dropped to zero or near zero $(.00$ for the Recent past-scale, 01 for the Early adulthood-scale, and -.08 for the Same age-scale). 


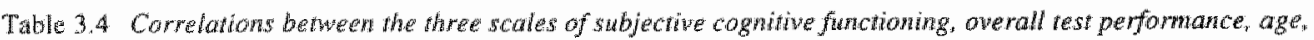
education, sex. subjective health, and depression.

$\begin{array}{lllllllll}1 & 2 & 3 & 4 & 5 & 6 & 7 & 8 & 9\end{array}$

1. Same age

2. Recent past

3. Early adulthood

4. Age

5. Education

6. sex

7. Subjective health

8. Depression

9. Testperfommance

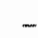

\begin{tabular}{|c|c|c|c|c|c|c|c|}
\hline $.32 *$ & - & & & & & & \\
\hline $32 *$ & 80 & - & & & & & \\
\hline-.03 & $.50^{* * *}$ & $.48 *$ & - & & & & \\
\hline-.03 & $-23^{-25}$ & $\times 18^{* \ldots \%}$ & $-.38 *$ & - & & & \\
\hline .20 & 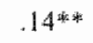 & $.09^{x / 2}$ & .05 & -.05 & - & & \\
\hline .25 杫 & 31 & .24 梅 & $.177^{2}$ & $-.24 *$ & $.20^{\text {承级 }}$ & - & \\
\hline $20^{* * * *}$ & $.22 *$ & 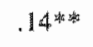 & .05 &.$- \| 1 *$ & -.20 & $.46^{*}$ & - \\
\hline-.05 & -.37 承 & $-33^{\text {电和 }}$ & $-.69^{*}$ *脉 & -.54 舟 & .08 & $-24 x$ & 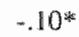 \\
\hline
\end{tabular}

Note. Based on 420 subjects, except for the Early Adulthood-scale $(n=353)$.

$* p<.05 * p<.01$ (onewailed).

\section{Discussion}

This study mainly focussed on the self-report of cognitive abilities in a large sample of normal and healthy persons covering a broad age range from young to very old. The main findings can be summarized as follows.

The results of the factor and reliability analyses suggest that the perceived change or decline in memory functioning with age is accompanied by a perceived change in attentional and executive functions as well. Cognitive aging, at least in the subjective domain, seems to be rather global in nature.

A decline in subjective cognitive functioning is already noticed at middle age (50 years) and steaclily increases thereafter. This is in contrast with the general societal belief that the age-related decline in cognitive skills, especially memory, appears in the senium, i.e. after the age boundary of 65 years. At least as interesting is the finding that persons in the age range 25 to 40 years, believed that their present cognitive functioning was better than it was 5 to 10 years before. Although in an absolute sense, this perceived difference was small, it suggest that the 'optimum' of subjective cognitive functioning occurs between 30 and 40 years instead between 20 and 30 years as one might have expected. The steady increase in perceived decline in cognitive functioning was attenuated in the oldest age groups ( 80 and 85 years), which might be explained as a "healthy survivor" effect. It is also possible that these elderly subjects were counting their blessings.

The question whether age differences are found in the self-report of cognitive functioning strongly depends on the type of comparison subjects have to make. Age differences in perceived cognitive functioning were only found when the subjects had to rate their present functioning in 
comparison to their functioning in the past. These effects were, as expected, strongest when the reference point was defined as 25 years. Only a very small age effect (less than $1 \%$ of explained variance) was found when subjects had to rate their present cognitive functioning to that of their age-mates. Overall, our participants rated themselves as somewhat better than their "average" agemate, a phenomenon that is well known in social comparison studies as illusory superiority (Hoorens, 1993).

The perceived decline in cognitive functioning was more marked in the subjects with higher depression scores and lower ratings of subjective health, which is in line with previous studies on subjective memory. These effect modifications of subjective health and depression may in part be due to a general tendency to complain. The present data, however, do nol allow to verify this possibility. Lower education was also related to a greater perceived decline. A similar relation was found by Arbuckle, Gold, and Andres (1986) and Cutler and Grams (1988). Gender either had no, or only a marginal effect on subjective cognitive functioning.

As in many other studies, no correlation was found between subjective reports of cognitive functioning and actual performance on cognitive tests. The considerable time lag between the subjective reports and the administration of the cognitive tests, however, seriously limits the validity of this finding. No information is available on the stability of the subjective reports on cognitive functioning, subjective health, and depression. Moreover, we cannot rule out the possibility that changes (decline) in cognitive functioning have occurred during this time period, especially in the older subjects.

Some studies have failed to show age differences on memory questionnaires that used absolute instead of relative measures of present memory functioning. To explain these findings, it has been suggested that with absolute measures, elderly subjects rate their present memory functioning to what they expect to be normal for their age (Cavanaugh, 1987; Huliseh et al., 1987). The absence of age differences on our scale, in which the participants were explicitly asked to rate their present cognitive functioning compared to that of their age-mates, supports such an explanation. In other words, elderly people seem to have an adaptive attitude in their appraisal of cognitive functioning. This, however, does not necessarily imply that older subjects are satisfted about their cognitive functioning. After all, they still notice a decline in cognitive functioning. Thus, although their cognitive functioning may be at an expected lewel, it still may give rise to specific cognition-related problems in everyday life.

\section{References}

Arbuckle, T. Y., Gold, D., \& Andres, D. (1986). Cognitive functioning of older people in refation to social and personality variables. Journal of Psychology and Aging, 1, 55-62.

Arrindell, W. A., \& Entema, J. H. M. (1986). SCL-90. Een mulridimensionete psychopathologie indicator (The SCL-90. A wutidimensional insmument for the assessment of psychopathology). Lisse, The Netherlands: Swets \& Zeitlinger.

Bolla, K. I., Lindgren, K. N., Bonaccorsy, C., Be Blecker, M. L. (1991). Memory complaints in older adults. Fact or fiction? Archives of Nertology, 48,61-64.

Brand, $\mathrm{N}_{\text {, }}$ \& Jolles, J. (1985). Learning and retreival rate of words presented auditorily and wisually. The Joumal of General Psychology, 112, 201-210.

Cavanaugh. J. C. (1987). Age differences in adults self-reports of memory ability: In depends on how and what you ask International Jaumal of Aging and Human Development, 24, 271-277. 
Chaffin, R. Herman, D. J, (1983). Self report of memory abilites by old and young adulls. Human Laarning. $2,17-28$

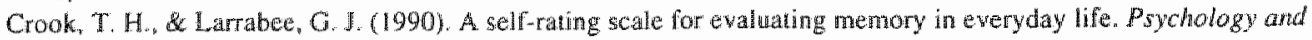
Aging, $5,48.57$.

Cutler. S. I. \& Crams, A. E. (1988). Correlates of self-reported everyday memory problems. Journal of Gerontology: Sactal Sciences, $43,82-90$.

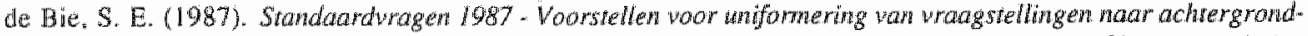
kenmerken en inerviews Toward a standardization of questions conceming demagraphic variables in population shudies) (2nd ad.). Leiden: Lejden Lniversity Press.

Derogatis, L. R. (1977). SCL-90: Adwinistration, scoring and procedures manual-1 for the R(evised) wersion. Baltimore: Johns Hopkins School of Medicine, Clinical Psychometrics Research Unit.

Dirken, J.M. (1967). Het weten var stress in industriale situaties the measurement of stress in industrial situations \% Groningen, The Netherlands: Wolters.

Gilewski, M. J., Zelinski, E. M. (1986). Questionnaire assessment of memory complaints. In L. W. Poon (Ed.). Handbook for clinical memory assessment of older adutrs (pp. 93-107). Washington. American. Psychological Association.

Hoorens, $W$. (1993). Selfenhancement and superiority biases in sociall comparison. In W. Stroebe \& Hewstone (Eds.), European Review of Social Psychology, Vohme 4 (pp. 113m39) Chicester. John Wiley \& Sors Ltd.

Honx, P. I., \& Jollew, I. (1993). Age-related decline of psychowotor speed: Erfects of age, brain health, sex, and education. Perceptual and Motor skils, 76, 195-211.

Hulicka, II. M. (1982). Memory functioning in late aduhthood. In F. I. M. Craik \& S. Trehub (Eds.), Advances in the study of conmunication and affect. Aging and cognitive processes, Volwne 8 (pp. $331-35$ ). New York: plenum Press.

Hultsch, D. F., Herlzog, C., \& Dixon, R. A. (1987), Age difterences in metamemory: Resolvirng the inconsistencies. Canadian Journat of Psychology, 41, 193-208.

Jackson, J. L., Bogers, H., \& Kerstholt, J. (1988). Do memory aids aid the elderly in their day to day remenbering" In M. M. Gruneberg. R. E. Morris, \& R. N. Sykes (Eds.), Practic aspects of memary: carrent research and issues: Climical and educational implicanons (pp. 137-142). Chichester: John Wiley \& Sons.

Jolles, J."Houx, P.J., van Boxtel, M.P.J., Ponds, R.W.H.M. (Eds.) (1995). Maastrich Aging Sindy: Determinants of cognitive aging. Mastricht: Neuropsych Publishers.

Lezak, M. D. (1995). Newropsychological Assessmen (3rd edition). New York: Oxford University Press.

Lovelace, E. A. (1990). Aging and metacognitions concerning memory function. In E. A. Lovelace (Ed.), Aging ard cognition: mental processes, self awareness and interventions (pp. 157-188). North-Holland: Elsevier Science Publisllers.

McMillan, T. M. (1984). Investigation of everyday mamory in nomal subjects asing the subjective nemory questionnaire (SMQ). Cortex, 20,333-347.

Metsemakers, J. F. M. Hoppener, P., Knotmerus, J. A., Koeken, R. J. J. \& Limonard, C. B . G. (1992). Compliturized the th information in the Netherlands: a registration netwotk of family practices. British Joumal of Genertal Practice. $42,102-106$.

Rabbitt, P. (1982). Dewelopment of methods to measure changes in activites of daily living in the elderly. In $S$. Corkin, K. L. Davis, 1. H. Growdon, E. Usdin, R. J. Wurtman (Eds.), Alzedmers disease: A report of progress, Agimg, Volune 19 (pp, 127,131). Now York: Raven Press. 


\title{
The Cognitive Failure Questionnaire: Factor structure, effects of age, sex, and education and the relation with cognitive performance and psychosocial variables*
}

\begin{abstract}
This study was designed to examine the factor structure of the Cognitive Failure Questionnaire (CFQ), effects of age, sex and education on CFQ, and the relation between the CFQ and objective cognitive functioning and psychosocial measures in a large sample of the normal adult population. Factor analyses on the 25 items of the CFQ suggested that a one-factor solution could fit the data well. A four-factor solution was found for a limited set of 17 items. These four factors were termed 'Absent-mindedness', "Absent-mindedness in social interactions', 'Names and Words', and 'Orientation'. Different age groups showed very similar profiles of scores (both in absolute and relative frequency) across individual $C F Q$ items. Effects of sex and education were found on the overall CFQ score but these effects were negligibly small. No substantial relations were found between cognitive performance measures and scores on the overall CFQ or CFQ subscales. Psychological distress, worry about dementia, and subjective health were reliable predictors of CFQ scores.
\end{abstract}

* Ponds, R.W.H.M., Rozendagl, N., Jolles, J. (submitted) 


\section{Introduction}

The Cognitive Failures Questionnare (CFQ), developed by Broadbent and colleagues (Broadbent, Cooper FizGerald \& Parkes, 1982), is a 25-item self-repon questionnaire that measures failures in perception, memory, attention, and motor functioning. The original aim of the CFQ was to measure individual differences in cognituve efficiency or competence. As such, it is a potentially interesting instrument to study age-related changes in (subjective) cognitive functioning, but relatively little research has been published on its use in aging research. Our main goal was to examine the relation between age and the CFQ in a wery large cross.mectional sample of 1358 persons aged 23 to 83 years.

The CFQ has a high test-retest reliability (Broadbent et al., 1982; Merckelbach, Muris, Nijman \& de Jong, 1996). CFQ scores are not related to intelligence or educational level (Broadbent et al., 1982; Pollina, Greene, Tunick \& Puckett, 1992; Rabbitt \& Abson, 1990) and two studies reported that $\mathrm{CFQ}$ scores are related to sex, with females having significantly higher scores (Hood, MacLachlan \& Fisher, 1987; Pollina et al., 1992). Like most measures of subjective memory or subjective cognitive functioning, the CFQ does not show a reliable or robust correlation with objective measures of cognitive abilities (e.g., Rabbitt \& Abson, 1990). Positive correlations have consistently been found between CFQ scores and scores for measures of neuroticism, anxiety, depression, and psychiatric problems like obsessionality or phobia (Broadbent, Broadbent \& Jones, 1986; Broadbent et al., 1982; Hood et al., 1987; Houston, 1989; Matthews \& Wells, 1988; Merckelbach et al., 1996; Pollina et al., 1992). In explaining these findings, Broadbent and others have suggested that the CFQ reflects vulnerability to stress (Broadbent et al., 1986; Broadbent et al., 1982; Matthews \& Wells, 1988; Reason, 1988; Reason, 1993). People with high CFQ scores are less able to develop adequate coping strategies, possibly due to a less effective management of attentional resources, when confronted with stressful situations. As a consequence, they may develop neurotic and depressive complaints. For example, nurses with high CFQ scores reported more psychiatric symptoms when working on a stressful ward, but not when working on a less stressful ward (Parkes, in Broadbent, 1982). An altemative, and more straightorward explanation, would be that psychiatric and neurotic symptoms "consume" cognitive and attentional resources, thereby producing everyday cognitive failures (Merckelbach et al., 1996).

Relatively few studies have focussed on possible effects of age on the CFQ. Because aging is clearly associated with a decline in cognitive functioning concerning memory, speed, and attentional lasks, one might expect an age-related increase in daily cognitive failures. However, this is not the case. For example, Rabbit, Maylor, Mclnnes, Bent \& Moore (1995) found a nearly identical pattern ol average scores on the iterns of the CFQ for a group of 475 young students and 3509 people aged 50 years and older. On most items the older subjects reported even fewer lapses, though this was not statistically significant. The older subjects had higher scores on four items, with there being a significant difference in scores for item 22 (tip of the tongue" experiences). Rabbit and Abson (1990) found a small and negative correlation ( -12 ) between CFQ score and age in a sample of 442 subjects aged 50 to 85 years. When the sample was split into four age groups (aged 50 to 59 years, 60 to 69 years, 70 to 79 years, and 80 years and older), the only significant difference between groups was between individuals younger and older 
than 60 years, with the younger group having higher CFQ ratings. A similar negative conelation (-19) between age and CFQ score was found by Rabbitt and Abson (1991) in a sample of 312 individuals aged 50 to 79 years. Kramer, Humphrey, Larish, Logan \& Strayer (1994) found no age differences on overal $\|$ CFQ rating in a sample of 32 young adults (age range $18-28$ years) and in sample of 30 old adults. When age differences were examined per item, the older persons reported a significantly higher incidence of 'tip of the tongue' experiences, whereas the younger persons reported a significantly higher incidence of daydreaming (iten 19). Studies that used self-report questionnaires that, like the $\mathrm{CFQ}$, ask for the absolute frequency of daily cognitive or memory failures, also report either no or only very weak effects of age (Cavanaugh, 1987; Crook \& Larrabee, 1990; Devolder \& Pressley, 1991; Reason, 1993).

Reason (1993) offers two hypotheses for the counter-intuitive finding that daily cognitive failures do not increase with age (and sometimes even decline), assuming that the self-report of cognitive failures comesponds to actual cognitive performance. The activity hypothesis states that elderly subjects encounter fewer opportunities for cognitive failures due to a less taxing and less active lifestyle. The compensation hypothesis states that elderly persons are well aware of their diminishing cognitive abilities and compensate for this in daily life by using cognitive aids (e.g., external memory aids) or by increasing their attentional focus in daily routine activities, which might result in fewer cognitive enrors.

Although still open to debate, most studies thus far suggest that the CFQ is unifactorial, measuring one general cognitive failure factor (Broadbent et al., 1982; Larson, Alderton, Neideffer \& Underhill, 1997; Matthews, Coyle \& Craig, 1990; Merckelbach et al, 1996). However, some studies suggest that the CFQ is multifactorial. Pollina el al. (1992), using a sample 387 students, were able to extract five factors. Matthews et al. (1990), using different procedures for extracting the number of factors, found a one-, twom, seven-, and a nine-factor solution in another sample of 475 students. Maylor (Rabbitt et al., 1995) used the same procedure as Mattews et al, in a very large sample of persons older than 50 years and found a five-factor solution. Finally, Larson et al. (1997) came up with a three factor solution in a sample of 2,379 American Navy recruits. All studies reported seem to yield at least one common factor, being the processing of peoples names. The discrepancies in the factor structure in these studies, may in part be due to the highly heterogeneous samples used (e.g., college sudents, elderly, navy recruits), the small number of people in some of the samples, and the different statistical procedures used.

Our sample was not only wery large (1358 persons, equal male/female tatio), but the subjects' ages also covered the whole adult age range, which makes it an excellent sample to investigate the dimensionality of the CFQ. We were interested whether the CFQ had an age-invariant factor structure in addition to one general factor. Four general questions were added to the CFQ. focussing on the possible increase in cognitive failures in the past 5 years, and the perceived degree of hinder, worry, and annoyance about these failures. We examined the differential effects of age, sex, and education on the CFQ scores and looked at the relation between CFQ scores and indices of cognitive performance (episodic and semantic memory, speed and attention) as well as psychosocial measures (distress, subjective health, life events and worry about dementia). Prewious research has shown that boh subjective health and worry about dementia are predictors of complaints about forgetfulness or low subjective memory ratings (Commissaris, Verhey, Ponds, Jolles \& Kok, 1994; Ponds, Commissaris \& Jolles, 1997; Ponds \& Jolles, 1996). 
Table 4. Demographic characteristics and means (M) and standard dewiatons (SD) for we wanables whe srudy by age group.

\begin{tabular}{|c|c|c|c|c|c|c|c|c|c|c|}
\hline & \multicolumn{2}{|c|}{ All subjects } & \multicolumn{2}{|c|}{ Young } & \multicolumn{2}{|c|}{$\begin{array}{l}\text { Young } \\
\text { midde-aged }\end{array}$} & \multicolumn{2}{|c|}{$\begin{array}{c}\text { Old } \\
\text { muddle-aged }\end{array}$} & \multicolumn{2}{|c|}{ Old } \\
\hline$N$ & \multicolumn{2}{|c|}{1358} & \multicolumn{2}{|c|}{351} & \multicolumn{2}{|c|}{365} & \multicolumn{2}{|c|}{357} & \multicolumn{2}{|c|}{285} \\
\hline \multirow[t]{2}{*}{ Men/women } & \multicolumn{2}{|c|}{6861672} & \multicolumn{2}{|c|}{$177 / 174$} & \multicolumn{2}{|c|}{$180 / 185$} & \multicolumn{2}{|c|}{$183 / 174$} & \multicolumn{2}{|c|}{$146 / 139$} \\
\hline & $M$ & $S D$ & $M$ & $S D$ & $M$ & $S D$ & $M$ & $S D$ & $M$ & $S D$ \\
\hline Age & 51.4 & 16.3 & 30.5 & 4.3 & 45.5 & 4.1 & 60.4 & 4.2 & 73.8 & 3.4 \\
\hline Education & 3.6 & 1.9 & 4.6 & 1.7 & 3.9 & 1.8 & 3.0 & 1.7 & 3.0 & 1.9 \\
\hline
\end{tabular}

\section{CFQ neasures}

\begin{tabular}{|c|c|c|c|c|c|c|c|c|c|c|}
\hline Total score & 31.8 & $\mathbb{i} 1 . \|$ & 30.6 & 10.4 & 32.8 & 11.2 & 32.6 & 10.7 & 31.1 & 1.9 \\
\hline Absent-mindedness & 7.7 & 3.6 & 7.1 & 3.4 & 7.8 & 3.6 & 8.0 & 3.5 & 8.2 & 3.9 \\
\hline Social interactions & 5.7 & 2.4 & 5.9 & 2.4 & 6.0 & 2.4 & 5.6 & 2.3 & 5.0 & 2.4 \\
\hline Names and words & 5.6 & 2.1 & 4.9 & 2.1 & 5.6 & 2.1 & 5.9 & 2.1 & 5.9 & 2.2 \\
\hline Orientation & 3.0 & 1.9 & 2.8 & 1.8 & 3.1 & 11.9 & 3.1 & 1.8 & 2.8 & 2.0 \\
\hline Increase & 1.7 & 0.8 & 1.4 & 0.7 & 1.7 & 0.8 & 1.9 & 0.7 & 1.9 & 0.8 \\
\hline Flinder & 2.0 & 0.8 & 1.9 & 0.8 & 2.0 & 0.9 & 2.1 & 0.8 & 2.1 & 0.9 \\
\hline Worry & 1.8 & 0.9 & 1.6 & 0.7 & 1.9 & 0.9 & 2.0 & 0.9 & 1.9 & 0.9 \\
\hline Annoyance & 1.9 & 0.9 & 1.8 & 0.8 & 1.9 & 1.0 & 1.9 & 0.9 & 1.9 & 0.9 \\
\hline
\end{tabular}

\section{Pychosacial weastores}

\begin{tabular}{|c|c|c|c|c|c|c|c|c|c|}
\hline Subjoctive bealth & 5.0 & 4.2 & 3.9 & 3.4 & 5.0 & 4.4 & 5.7 & 4.3 & 5.4 \\
\hline Distress & 33.1 & 9.6 & 33.5 & 10.4 & 32.5 & 9.3 & 34.1 & 10.5 & 32.3 \\
\hline Luje ovents & 1.0 & 1.1 & 1.3 & 1.2 & 1.0 & 1.1 & 0.9 & 0.9 & 0.7 \\
\hline Worry dementia & 2.0 & 0.9 & 1.7 & 0.8 & 2.0 & 0.9 & 2.2 & 0.9 & 20 \\
\hline
\end{tabular}

Cogminite measures

\begin{tabular}{|c|c|c|c|c|c|c|c|c|c|c|}
\hline Cognitive speed & 000 & 0.83 & 0.61 & 0.49 & 0.18 & 0.73 & -0.26 & 0.67 & -0.84 & 0.80 \\
\hline Episodic memory & 00.0 & 0.89 & 0.50 & 0.64 & 0.21 & 0.89 & -0.09 & 0.78 & -0.73 & 0.98 \\
\hline Semantic memory & 00.0 & 0.90 & 0.34 & 0.81 & 0.30 & 0.59 & .0 .19 & 0.88 & -0.45 & .80 \\
\hline
\end{tabular}

Note. Cognitive conpound meastres were calculated on population-bosed Z-transformed test variables (population mean $=0, S D=1 \%$. 


\section{Method}

\section{Paricipants and procedure}

The study was part of a larger research progran on determinants of normal cognitive aging, the Maastricht Aging Study (MAAS; Jolles, Houx, van Boxtel \& Ponds, 1995). Participants were recruited from the Registration Network Family Practices (RNH; Metsemakers, Höppener, Knotherus, Kocken \& Limonard, 1992). This register contains the background characteristics and past and current medical morbidity of 60,000 patients in 15 general practices in the region of Maastricht. All selected participants were personally inwited by their family doctor to take part in MAAS. Individuals with previous or current medical conditions with known impact on cognitive andyor motor functions were excluded. Exclusion criteria were overt cerebrovascular disease, chronic neurological pathology (e.g., dementia, epilepsy, parkinsonism), mental retardation, and major psychiatric disorders. MAAS started in March 1993 with four successive cross-sectional panel studies which lasted through December 1995. Each of these panel studies had the same methodology with respect to sample frame, inclusion of participants, stratification criteria, and basic measurements. The last three panel studies of MAAS were combined in the current study.

Participants were stratified for age (12 discontinuous age classes, ranging from $25 \pm 1$ year, $30 \pm 1$ year, to $80 \pm 1$ year), sex, and level of general ability (two levels, based on the achievement in professional life), in order to control these background variables, which may themselves affect cognitive functioning. Educational level was measured by a Dutch scoring system (de Bie, 1987) which consists of an 8-point scale, ranging from unfinished primary education (level 1) to university education (level 8). Thirty-nine persons were excluded from the original group of 1397 participants because of missing data for one or more of the main variables in the study. This group, consisting of 14 men and 25 women, had a higher mean age (68 year) and had a lower education (level 2.1) than the remaining group of 1358 individuals. Demographic characteristics are presented in Table 4.1. The participants were divided into four age groups: young (age classes 25,30 , and 35 years), young middle-aged ( 40,45 , and 50 years), old middle-aged (age classes 55,60 , and 65 years), and old (70,75, and 80 years). The total sample consisted of 660 men and 656 women, with a mean age of 51.4 years. The women/men ratio for each age group was largely equivalent. The mean level of education declined from the youngest to the oldest age group, $F(3$, $1354)=62.7, p<.001$, and allgroups, except for the old middle-aged and old groups, were significantly different from each other (Duncan's multiple range test, $p=.05$ ).

\section{Measures and procedure}

All participants filled in a postal questionnaire pertaining to socioeconomic background medical $^{2}$ history, subjective cognitive functioning, and psychological well-being.

Cognitive Failure Questionnaire (CFQ). The participants completed a slightly modified version of the Dutch translation (Merckelbach et al., 1996) of the original CFQ of Broadbent (Broadbent et al., 1982). The CFQ consists of 25 items measuring the frequency of everyday cognitive failures or lapses. These concern failures of memory, attention, action, and perception. Participants 
indicate on a 5 -point scale how often they usually experience each particular cognitive failure. The description of the anchorpoints of the scale were "never' (score $=0$ ), "very rarely' (1), "occasionally" (2), "quite often" (3), and "wery often" (4). Total possible CFQ score ranged from 0 10 100, with higher scores indicating more cognitive fallures. In addition, all participants (except those who had reported no cognitive failures at all) indicated on a 5 -point scale if they had experienced an increase in these cognitive failures in the past 5 years (termed Increase, ranging from "no increase", score 1, to 'very strong increase", score 5), and how hindered they were in their daily life by these cognitive failures (Hinder, ranging from "no hindrance at all", score 1 , to "very much hindrance", score 5), how worried they were about these cognitive failures (Worry, ranging from "not worried at all", score 1, to "very much worried, score 5), and finally how annoying they found these cognitive failures (Annoyance, ranging from "not annoying at all, score 1 , to 'very much annoying', score 5).

Psychosocial mecusures. Four psychosocial measures were used in this study: Psychological distres.s, subjective thealth, worry about dementia, and recent life events.

Psychological distress. Feelings of depression and anxiety were measured with the subscales Depression and Anxiety of the revised version of the Symptom Checklist (SCL-90, Derogatis, 1977; Dutch version, Arrindell \& Etrema, 1986,. The SCL-90 is a multidimensional self-report inventory of current psychopathology. Items are rated on a 5-point scale. The subscale Anxiety consists of 10 items and measures feelings of generalized anxiety (score range 5-50). The subscale Depression contains 16 items which reflect symptoms of depression (score range 16-80). Because the two scales were highly intercorrelated in the present sample $(r=.77)$, they were combined into one distress score (items of both scales were summed). Higher scores indicate more distress.

Subjective health. Subjective health was measured with the VOEG ("Vragenlijst Omtrent Evaren Gezondheid" - Inventory of Subjective Health), which was originally developed by Dirken (1967). It has been used in several large Dutch surveys to measure subjective health status. The 21 -item version administered in this study probes health complaints of a somatic and psychosomatic nature. Scores may range form 0 to 21 . Higher scores indicate more complaints.

Wory about dementia. Participants could indicate on a 5-point scale their worry about becoming demented, ranging from "not worried at all" (score 1) to "very much worried" (score 5).

Life events. Participants could indicate if they had experienced important life events in the past 12 months. A list of 15 life events was presented and there was the possibility to describe life events that were not on the list. Examples of life events on the list were death of a loved one, moving, marriage or divorce, being victim of a crime, and severe illness.

Cognitive performance. The participants underwent an extensive neuropsychological examination 3-4 weeks after they had complleted the postal questionnaire. Performance tests were used to assess the cognitive domains of memory and simple and complex information processing.

Letter-Digit Substiturion Test. (LDST) This test is a modification of the procedurally identical Symbol-Digit Modalities Test (Lezak, 1995). It is used as a measure of the speed of processing of general information, i.e., the test is supposed to draw upon several (cognitive) processes such as visual perception, attention, and memory. Subjects were instructed to copy numbers in cells 
indexed by alter. The letter refers to nine letter/number combinations at the top of the fom. The wariables of interest are the number of correctly coded letter-digit combinations in 90 seconds under two conditions. In the first condition, participants fill in the digits corresponding to the letters with a pencil (written version). In the second condition, they say the digits aloud and the examiner records their answers (oral version).

Cancept Shifting Test (CST; Houx \& Jolles, 1994). This test is derived from the Trail Making Test (Lezak, 1995), which is used to measure the ease of shifting between concepts. "There are three task conditions: the subject has to cross out, in the proper order, 16 circles containing only digits (1 to 16; part $A$ ), letters ( $A$ to $P$; part B), or both ( $1-A-2-B$, etc; part $C$ ). In the latter subtest, the subject has to shift between the concepts 'digits" and "letters'. The variables of interest are the times needed to complete each subtest.

Stroop Color-Word Test (SCWT; Lezak, 1995). The Stroop test is a test for selective attention and interference susceptibility. The test involves three cards displaying hundred stimuli each: color mames (Card I), colored patches (Card II), and color names printed in incongruously colored ink (Card III). For the last card, the color of the ink has to be named instead of the color name. Performance of this task is especially susceptible to interference. The variables of interest are the times needed to complete each card.

The Visual Verbal Learning Test (VVLT; Brand \& Jolles, 1985). The VVLT is a computerized, visual version of the Auditory Verbal Learning Test (Lezak, 1995). A set of 15 frequently used monosyllabic meaningful words is visually presented in a fixed order at a rate of one every 2 seconds in five consecutive trials. After each trial or presentation the subject is requested to recall as many words as possible with no restriction concerning the order of recall (immediate recall). Twenty minutes after the fifth presentation, the subject is again requested to recall as many words as he or she can remember (delayed recall). After the delayed recall, recognition is tested in which the subject has to recognize the 15 words of the test, which are mixed with 15 new words. The variables of interest are the total number of correctly remembered words over trials 1-5 (immediate recall), the maximum number of words in trials $1-5$, the number of words remembered on delayed recall, and the number of correctly recognized words at delayed recognition. This test measures memory storage and retrieval of verbal information in episodic memory.

Fluency. In the fluency task, the subject is asked to name as many different items from a particular category (animals or professions) as possible in 60 seconds. "This test measures strategy-driven retrieval from semantic memory. The variables of interest are the number of correctly named animals or professions.

\section{Data reduction}

On the basis of the results of factor analysis in earlier research (Ponds, this thesis, chapter 6), we grouped the test scores into three compound performance indices: Episodic Memory (including the total, maximal, delayed recall, and recognition scores of the VVLT), Semantic Memory (including Fluency animals and Fluency professions), and Speed (including part A, B, and C from the CST, Card I, II, and III from the SCWT and the scores of the oral and written version of the LDST). The compound score was the average $Z$-score for the test scores that were included in the componind performance index. The signs of the test scores of the Speed compound index were 
inverted so that for all three compound performance indices a positive score reflects above average performance and a negative score reflects below average performance

\section{Statistical analysis}

We used exploratory factor analysis (principal component analysis) and confirmatory factor analyses (LISREL, Joreskog \& Sörbom, 1996) to examine the possible factorial structure of the CFQ. In addition, we calculated internal consistency estimates (Cronbach's alpha). We used analyses of variance to assess the effects of age, sex, and education on the CFQ. Because of the large sample size, only probatilities of $1 \%$ or less, were considered significant. Multiple hierarchical regression analyses were carried out to test the predictive value of the demographic variables, test performance, and the psychosocial measures for scores on the CFQ. The level of significance for a predictor wariable for entering into the regression model was $p<.01$, taking the large sample size into consideration.

\section{Results}

\section{Factor structure}

The initial exploratory factor anallysis (principal components with varimax rotation) revealed a five-factor solution, with one strong first factor. Eigenvalues for the five factors were $6.9,1.4$, $1.2,1.2$, and 1.1 with a corresponding amount of variance accounted for of $27.5 \%, 5.6 \%, 5.0 \%$, $4.7 \%$, and $4.2 \%$ (in total $47 \%$ ). When we repeated the factor analysis, allowing one factor to be extracted, item factor loadings ranged from 34 to .62 , suggesting that one general cognitive failure factor provided a good fit of the data. Cronbach's alpha for this one factor solution of the CFQ was .88. As we were interested in finding multiple factors on the CFQ subscales in addition to one general factor, and the five factor solution did account for almost $20 \%$ extra variance above the one-factor solution of the CFQ, we performed an additional analysis on the first five-factor solution. As there was no a priori reason to assume orthogonality of factors, the five-factor solution was rotated using the direct ablimin criterion. Inspection of the factor pattern matrices of the oblique solution, focussing on the highest loading items, showed that some meaningful interpretation could be given of four scales. For example, the first factor referred to a general absent-mindedness, with items like 'forget why you went from one part of the house to the other' (item 2) and 'forget whether you have turned off a light or a fire or locked the door' (item 6). The second factor referred to absent-mindedness in a social context (e.g., item 19, "daydreaming when you ought to be listening to something'). The third and fifth factors referred to problems in name finding (e.g., item 20, 'forget people's names') and orientation (e.g., "confuse left and right when giving directions') respectively. The fourth factor could not be clearly interpreted. Eight items had substantial item factor loadings on two or more factors. This was especially the case with the items of the fourth factor. Not surprisingly, these eight items were also the items with the weakest loading on their own factor. We decided to eliminate these items, and conducted a new factor analysis (principal component with oblique rotation) on the remaining 17 items. Now four factors 
were clearly identified. The first seven-item factor was termed Absen-mindedness (items 2,6 , $16,17,18,23$ and 24 ; item factor loadings ranging from 42 to $68 ; 28.8 \%$ variance accounted for; Cronbach's alpha. 76). The second four-item factor was termed Social Interactions as the items referred to cognitive failures in social interactions (items 8, 9, 10, and 19; item factor loadings $.55-.72$; variance $7.7 \%$; Cronbach's alpha .63 ). The third factor consisted of three items and was termed Names and Words as it referred to difficulties in finding names and words (items 7.20, and 22; item factor loadings $59-.82$; variance $6.9 \%$; Cronbach"s alpha .64). The fourth factor was termed Orientation as all three items referred to difficulties in way finding (items 3,4 , and 12; item factor loadings .57 - .76; variance $6.4 \%$; Cronbach's alpha .59). In addition, we performed a confirmatory factor analysis (CFA) with the LISREL 8 program (Joreskog \& Sorbom, 1996) as a formal test for the four factor solution on the $17 \mathrm{CFQ}$ items. The ratio chi-square test was significant, $X^{2}(113, n=1,358)=460,28, p<.001$, which was expected given the large sample size. The Non-Normed fit index (NNFI), which is less influenced by sample size, was 91 , which indicates a moderate but acceptable model fit. We carried out a multi-sample analysis with LISREL as a formal test of the age-invariance of the four factor solution. The total sample was divided into a young group (age $<52$ years, $n=716$ ) and an old group (age $>54$ years, $n=642$ ), and the covariance matrices of the CFQ items of each group were used as input. In multi-sample analysis, the chi-square is a measure of fit of the model in both groups. In the model specified, factor loadings, factor correlations, and error variances were equal for the two groups, which is a very constrained model. This resulted in a moderata, but again acceptable model fit: $X^{2}(266, n=1,358)=710.45, p<.001 ; N N F I=.91$. The contribution to the overall chi-square of the young group was 299.61 (42\%), the old group contributed 410.83 ( $58 \%$ ). The four factor solution, seemed to be largely invariant over age.

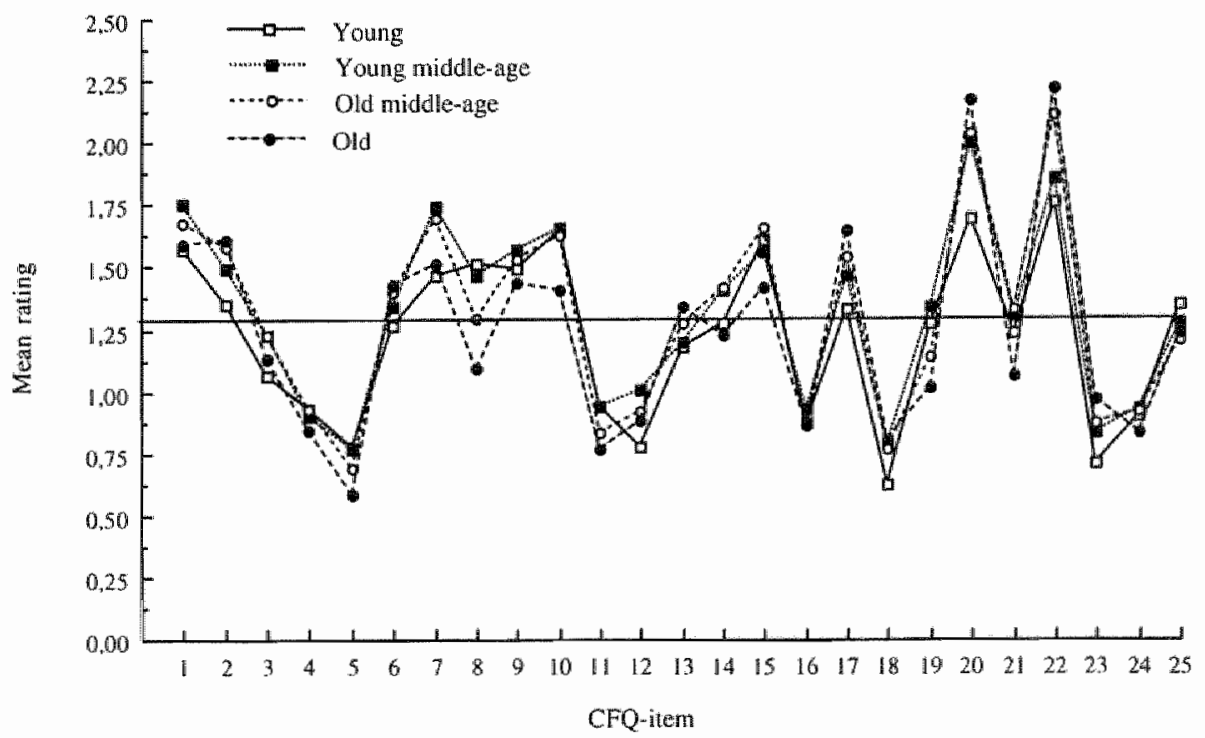

Figure 4.1 Mean ratings for the 25 items of the Cagnitive Failure Questiontaire of the 4 age groups and the overall irem mean 


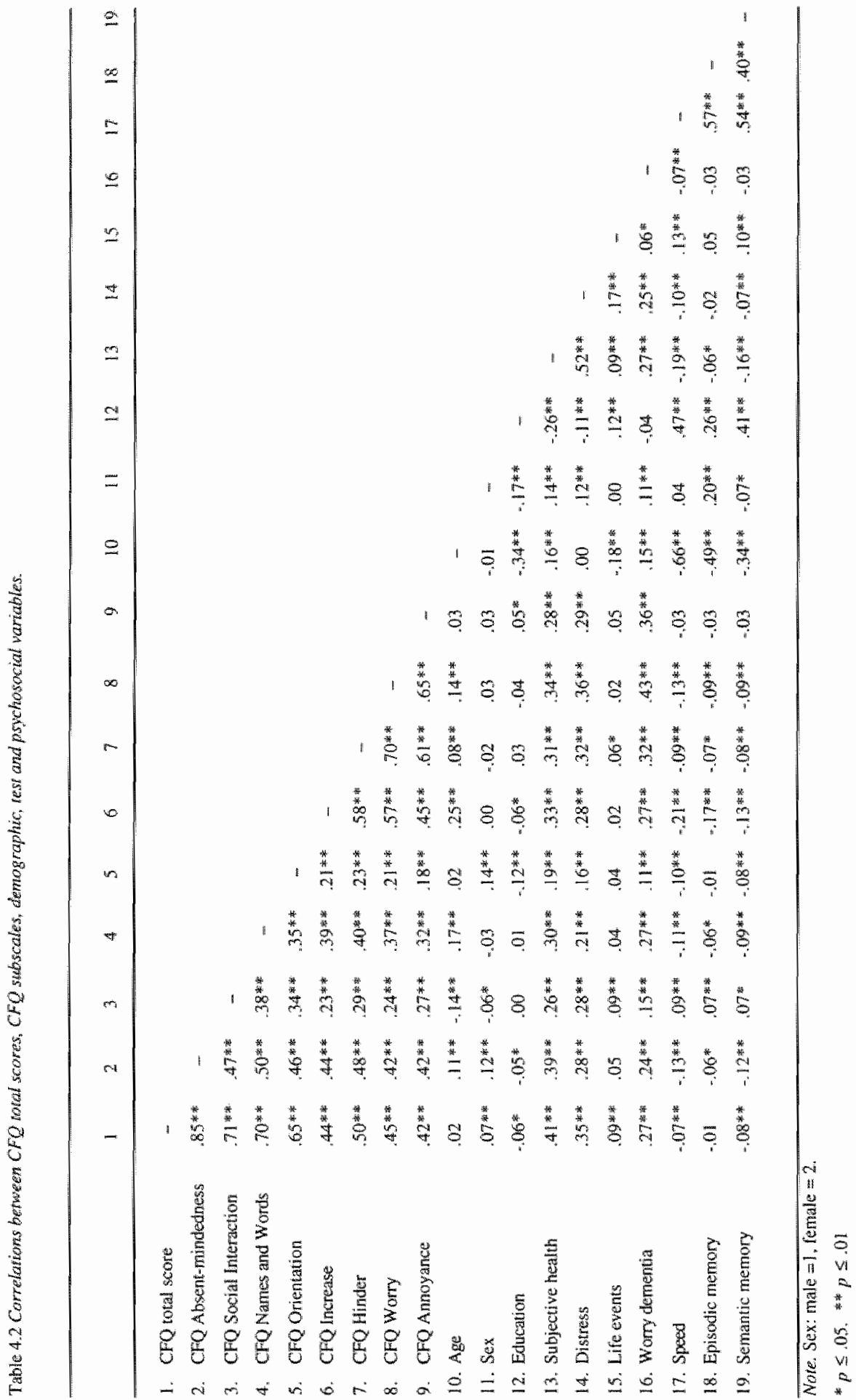




\section{Effects of age, sex and education}

Figure 4. 1 shows the mean ratings for the 25 items of the CFQ of the four age groups. The overall item mean was 1.27 , which indicates a relative low overall frequency of cognitive failures, between "very rarely" and "occasionally'. Lowest frequencies were obtained for item 5 (bumping into people), item 18 (accidently throwing away things), and item 23 (forgetting what you came to the shops to buy). Highest frequencies were found for item 20 (forgetting people's names) and item 22 (difficullies in word finding). The four age groups showed very similar score patterns across the items. Significant age differences were found for item 8 (saying something that afterwards might be taken as insulting, significantly more frequent in the young and young middle-aged group than in the other two age groups), item 20 (the youngest age group had significantly less difficulty in name finding than the older groups), and item 22 (problems in word finding were reported significantly more frequently by the old middle-aged group and the old group than by the younger groups).

CFQ total score. In Table 4. I the mean CFQ total score and the mean scores of the four subscales are presented for the total sample and the four age groups. We carried ont an analysis of variance (ANOVA) with the CFQ total score and the four subscales as dependent variables and age, sex, and educational. level as independent variables. Age had four levells corresponding to the four age groups presented in Table 4.1. Educational level was compressed to three levels instead of eight: low level (educational level 1 and 2), medium level (level 3 to 5), and high level (6 to 8). These levels roughly correspond with primary education, junior" vocational training, and senior vocational or academic training.

The 4 (age) $\times 2$ (sex) $\times 3$ (educational level) ANOVA on the CFQ total score revealed main effects for education, $F(2,1334)=6.53, p=.002$, and $\operatorname{sex}, F(1,1334)=7.49, p=.006$. Follow-up multiple comparison tests (Duncan, $p<.01$ ) showed that the group with the lowest educational level had the highest CFQ total scores (mean score $=33.1$ ). The groups with the medium and high educational levels had mean CFQ total scores of 30.7 and 31.9 respectively. Women had higher CFQ total scores than men (mean scores of 31.0 and 32.6). Because the sample size in this study is very large, it is important to examine the magnitude of the effects by looking at the amount of variance explained. The effects of education and sex were very small, accounting for less than $0.5 \%$ of the variance. Age did not have a main effect, and there were no interaction effects.

CFQ subscales. Main effects of age, education, and sex were found on CFQ Absentmindedness. Older age led to higher $\operatorname{scores}_{,} F(3,1334)=3.97, p=.008$ (youngest group was significantly different from the three older age groups; amount of variance explained by age was $1.2 \%$ ). Lower education also gave higher scores, $F(2,1334)=4.75, p=.009$ (the group with the lowest educational level had a significantly higher mean score than the groups with a medium or high level of education; amount of vartiance explained less than $0.5 \%$ ). Women had higher scores than men, $F(1,1334)=24.8, p<.001$ (variance explained $1.5 \%$ ). No interaction effects were found. A main effect of age was found on CFQ Social interaction, $F(3,1334)=12.7, p<.001$. The oldest age group had a significantly lower mean score than the younger age groups. The amount of variance explained was $2 \%$. Age was also the only variable to affect CFQ Names and Words, $F(3,1334)=11.4, p<.001$ (the youngest age group had a significantly lower mean score than the three older age groups; amount of variance explained $3 \%$ ). Education and sex bad 
an effect on the CFQ ortentation. Lower education led to higher scores, $F(2,1334)=5.16, p=$ 006 (the Jow level group had a significantly higher score than the medium and high level groups; amount of variance accounted for $1.4 \%)$. Women had higher scores than men, $F(1,1334)=$ $16.34, p<.001$ (amount of variance accounted for $2 \%$ ).

CF $Q$ additional questions. Main effects of age, but not education and sex, were found on two of the four additional CFQ questions: Increase and Worry. Older participants reported a greater increase in cognitive fallures, $F(3,1323)=25.08, p<.001$ (all groups were significanly different from each other, except for the old middle-aged and old groups; amount of variance accounted for $6 \%$ ). The older groups were also slightly more worried about these cognitive failures, $F(3,1323)=11.37, p<.001$ (youngest group had a significantly lower mean score than the three older age groups; amount of variance accounted for $2 \%$ ). No effects of age, sex, and education were found for Hinder and Annoyance.

\section{Regression analyses}

Table 4.2 shows the zero-order correlations between the different CFQ measures, the compound test scores, and the psychosocial measures. Correlations between CFQ measures and the three compound test scores were very low or event absent, whereas substantial correlations were found between the $\mathrm{CFQ}$ measures and subjective health, distress, and worry of dementia. These three psychological measures were highly intercorrelated, which in part may be explained by the common variance these variables shared with age, sex, and education.

Because we wanted to examine the effects of test performance and psychosocial measures independently of the possible interacting variables of age, sex, and educational level, we performed multiple hierarchical regression analyses. In Step 1, age, sex, and educational level were entered in the model, in Step 2 the three cognitive compound scores, and in Step 3 the four psychosocial measures. To control for possible differential effects of the predictor variables as a function of age, we tested interactions of age with all the predictor variables by entering this block of nine interactions as a final step. We did not find any contribution of these interactions. Table 4.3 shows the results of the regression analyses on the different CFQ measures.

Age, sex, and education contributed relatively little to the overall amount of variance explained for the different CFQ measures, as the analyses of variance already had shown. Effects of age were only found on the first three CFQ subscales, indicating that increasing age was associated with higher scores on CFQ Absentmindedness and CFQ Names and Words and lower scores on CFQ Social Interactions. Although no age effects were found on the CFQ total score, indicating that the frequency of cognitive failures was invariant over age, the older participants reported an increase in these cognitive failures in the past 5 years (CFQ Increase) and were more worried about these cognitive failures (CFQ Worry). A small contribution of sex (more frequent failures reported by women) was found on the CFQ Absent-mindedness and CFQ Orientation (1\%-2\%). Education contributed to CFQ Orientation only $(1 \%$, more frequent failures in lower educated participants). The contribution of the cognitive performance indices to the variance on the $\mathrm{CFQ}$ measures was either absent or very small. Semantic memory and speed accounted for no more than $0.7 \%$ of the variance in the CFQ total score and CFQ Absent-mindedness, respectively.

Best predictors for the CFQ scores were the psychosocial measures subjective health, worry of dementia, and distress, but not life events. Subjective health was the strongest predictor of the 
Table 4.3 Stepwise hierarchical nuthiple regression of subject background variables, test perfomance and we psychosocial measures on the $\mathrm{CFQ}$.

CFQ Beta FChange $p \quad R^{2}$ Change Cumulative $R^{2}$

CFQ Toral Score

Semantic memory

-.02
28

Subjective health

.28

Distress

.17

Worry dementia

.14

$\begin{array}{rr}9.2 & .003 \\ 268.5 & .000 \\ 46.8 & .000 \\ 31.6 & .000\end{array}$

.007

.007

.165

.172

.028

.200

.018

.218

CFQ Absent-mindedness

Sex

Age

Speed

Subjective healuth

Worry dementia

Distress

CFQ Social interactions

Age

Subjective health

Distress

Worry dementia

CFQ Names and words

Age

Subjective health

Worry dementia

\section{CFQ Orientation}

Sex

Education

Subjective health

Disiress

CFQ Increase

Age
Subjective health
Worry dementia
Distress

Age

.000

.030

.138

.20
.18
.16
.15

$\begin{array}{rr}90.7 & .000 \\ 140.3 & .000 \\ 45.9 & .000 \\ 26.9 & .000\end{array}$

$.016 \quad .196$


Table 4.3 Stepwise hievarchtol multiple regression of subject background variables, test performance and the prychosocial measures on the CFQ (continued).

CFQ Beta $\quad F$ Change $P \quad R^{2}$ Change Cumulative $R^{2}$

\section{CFQ Hinder}

$\begin{array}{lrrrrr}\text { Age } & .02 & 8.7 & .003 & .006 & .006 \\ \text { Distress } & .18 & 150.8 & .000 & .100 & .106 \\ \text { Worry dementia } & .23 & 90.8 & .000 & .057 & .163 \\ \text { Subjective health } & .15 & 25.6 & .000 & .016 & .179\end{array}$

\section{CFQ Worry}

Age

$$
07
$$

26.9

.000

.020

Worry of dementia

Disuress

Subjective health

\section{CFQ Annoyance}

Worry of dementia

Subjective heath

Nore. Bet $a=$ slandardized regression coefficients in the final model.

different measures of the CFQ. It accounted for almost $17 \%$ of the variance in CFQ total score and 8-13\% on the first three CFQ subscales; its contribution to the variance in CFQ Orientation subscale was relatively small (approximately $3 \%$ ). Poorer subjective health was strongly related to higher frequencies of cognitive failures. Being worried about dementia and greater distress also were related to higher CFQ total scores. The contribution of the psychosocial measures to the variance on the CFQ subscales was mixed. Scores on CFQ Increase were again best predicted by subjective health, followed by worry of dementia and distress. The other three additional $\mathrm{CFQ}$ questions (Hinder, Worry, and Annoyance) were best predicted by distress and worny about dementia.

\section{Discussion}

This study was designed to examine the factor structure of the CFQ, effects of age, sex and education, and the relation between the CFQ and objective cognitive functioning and psychosocial measures in a large sample of the normal adult population.

Factor analyses, using all 25 items suggested that a one-factor solution could fit the data well, 
corresponding with the findings of most other factor analytic studies reported to date. This 'general cognitive failure' factor accounted for $27.5 \%$ of the wariance with item factor loadings ranging from 34 to .62 . The internal consistency estimate was high (.88). We performed an additional factor analysis because the one-factor solution left a substantial amount of common factor variance unaccounted for. After elimination of eight items we identified a four-factor solution. We applied this solution to the data for a young and an old sample, showing that this four-factor solution appeared to be invariant over age. The four factors had moderate internal consistency estimates (ranging from 59 to .76 ) despite the limited number of factor items. "Whe first factor, termed 'Absent-mindedness', contained failures of retrospective memory and of inappropriate attentional focus and seems to correspond best with the "Retrospective memory" factor of Maylor (in Rabbitt et al., 1995) and the "Absent-mindedness" factor of Mattews et al. (1990). The second factor, termed "Absent-mindedness in social interactions", included problems of impulse control as well as inappropriate attentional control when listening to other people. It corresponds in part with the 'Interpersonal intelligence' factor of Pollina er al. (1992). Two of the three items of the 'Names and Words' factor typically represented problems in retrieval from semantic memory (forgetting names and "tip of the tongue" experience). This factor has consistently been found in almost every other factor analytic study of the CFQ. The fourth factor 'Orientation' has not yet been found in other studies, although it emerged as a very robust factor in all the different factor analyses we conducted.

The different age groups showed very similar score profiles (both in absolute and relative frequency) across individual CFQ items. The profiles were almost identical to those found by Maylor (in Rabbitt et al., 1995) when she compared a young student sample with a very large sample of older adults. Two conclusions may be drawn from this similarity of profiles with age. First, the similarity of the relative frequency of cognitive failures with age suggests that there are no marked overall differences in the frequencies with which young and old people encounter particular scenarios in their everyday lives as tapped by the CFQ questions. This does not support the activity hypothesis forwarded by Reason (1993), which states that elderly people engage in fewer or other cognitively demanding tasks in daily life. Second, the similarity in the absolute freguencies between the four age groups does not support a specific age-related pattern of functional incompetence with respect to daily cognitive performance. In addition, formal testing for age differences on the overall CFQ score did not reveal significant age differences. Reason (1993) suggests that this may be due to the fact that elderly people are more willing to compensate for their diminishing cognitive abilities (compensation hypothesis). He suggest two possible mechanisms. As older people might interpret daily cognitive failure more as harbinger of their cognitive decline, they "invest a greater degree of custodial attention in the performance of routhe activities, and, in consequence, make fewer absentminded errors" (p. 4.11). However, we did not find that the elderly participants were more hindered, worried, or amnoyed about their daily cognitive failures (though a small age effect was found for worry), which would support this anxiety variant of the compensation hypothesis. Another possibility is that elderly people try to compensate by using more memory aids. This, however, is not in line with our findings in a comparative sample of almost 1900 persons aged 24 to 86 years, which showed that there were no marked differences in use of internal and external memory strategies in young and older persons (Ponds \& Jolles, 1996). Another explanation for the absence of age differences in absolute measures of cognitive failures is the possibility that older individuals adjust their rating of 
frequency of daly cognitive failures to what they expect to be nomal for their age. We do have sone support for this explanation. Although our elderly participants did not report more cognitive fatures than the younger participants, they did indicate that the incidence of these failures bad increased over the past 5 years.

We found effects of sex and education on the overall CFQ score, but these effects were negligibly small, confirming the findings of other studies that there is no relation between gender and intelligence and overall CFQ ratings. Effects of age, sex, education were more apparent (but still small) on some of the subscales of the CFQ. The older participants reported more problems in name and word finding and general absent-mindedness, but this was not a smooth age-related effect, as it was caused only by lower scores of the youngest age group. In social interaction, the oldest age group reported fewer failures, suggesting a better control of social skills or, alternatively, the frequency of social interactions is reduced in older age. Problems in orientation were reported more frequently reported by persons of lower education and by women. In sum, the four subscales of the CFQ provided an indication that there are some differences in functional competence that is not found in the analysis of the overall CFQ scores, but it also shows that these differences are tather small.

We did not find a substantial relation between the cognitive performance measures and scores on the overall CFQ or CFQ subscales. Rabbiut et al. $(1990,1995)$ pointed out several methodological and logical problems that might account for this generally found lack of correlation between self-report cognitive questionnaires and cognitive performance. We will not reconsider all these problems, but focus on the problem of domain specificity. Rabbitt argues that both cognitive tasks and items of cognitive questionnaires may be highly domain specific, each tapping quite different skills or cognitive processes. As a consequence, correlations may only be found between an item or a subset of itens that require the same cognitive skills as are required in specific cognitive performance task. For this reason, we had expected to find a relation between the measure Speed performance and the CFQ measure Absent-mindedness as both measures seem to have a strong attentional component in common. However, even scores on the CFQ Names and Words, which can be considered as a typical measure of semantic memory, were not correlated with the Semantic memory performance measure.

Life events were not correlated with CFQ scores, most likely due to the low incidence of life events and the small range of variance. CFQ scores were best predicted by psychological distress, worry about dementia, and most strongly by subjective health. There are several explanations for this relation. First, people with higher scores for these variables, especially those with lower health ratings, actually do have lower cognitive abilities and for this reason suffer from more cognitive lapses in daily life. However, our findings do not support this explanation. Correlations between these wariables and the cognitive performance measures were in general low, ranging from .03 to .19 , and .02 to. 12 when age, sex, and education were partialled out. Second, il could be that these people indicate a higher incidence of daily cognitive failures because they are more inclined to complain in general because of a neurotic personality. Several studies have shown strong correlations between CFQ scores and measures of neuroticism (e.g., Rabbitt et al., 1995). We cannot rule out this possibility, as our data set did not include a measure of neuroticism. Merkelbach et al. (1996), however, still found a significant association between CFQ and anxiety symptoms after they partialled out the infuence of neuroticism. This leaves open a third explanation, which is that people who are distressed, preoccupied about dementia, and who have 
a poor general health, are, because of that, more prone to attentional disnuptions in cognitively demanding everyday situations.

\section{References}

Arrindell, W. A. E Etterna, J. H. M. (1986). SCL-90. Een wnultimensionele psychopashologie indicator (The SCL-90. A multidimensional instrument for the assessment of psychopathology. Lisse. The Netherlands: Swets \& Zeithinger.

Broadbent, D. E., Broadbent, M. H. P., \& Jones, J. L. (1986). Performance correlates of selfreported cognitive failure and of obsessionality. British Journat of Clinical Psychology, 25, 285-299.

Broadbent, D. E. Cooper, P. F., FitzGerald, P., \& Parkes, K. R. (1982). The Cognitive Failure Questionnaire (CFO) and its correllates. British Journal of Clinical Psychology, 21, 1-16.

Cavanaugh, J.C. (1987). Age differences in adults" self-reports of memory ability: Ii depends on how and what you ask. International Joumal of Aging and Haman Development, 24, 271-277.

Commissaris, C. J. A. M., Verhey, F. R. J., Ponds, R. W. H. M., Jolles, J., \& Kok, G. J. (1994). Public educalion about normal forgetfulness and dementia: importance and effects. Patient Educavon and Counseling. 24. $109-115$,

Crook, T, H., \& Larrabee, G. J. (1990). A self-rating scalle for evaluating memory in everyday life. Psychology and Aging, 5, 48-57.

de Bie, S. E. (1987). Standaardvragen 1987 - Voorstellen voor umiformering van wragasiellingen nadr achtergrond. kenmerken en interyiews (Toward a standardization of questions concerning demographic wariables in population studies). (2nd ed.). Leiden, the Netherlands: Leiden University Press.

Brand, $\mathbb{N}_{\text {. }}$ Jolles, J. (1985). Learning and retreival rate of words presented auditorily and visually. The Jowmal of General Psychology. 112, 201-210.

Derogatis, L. R. (1977). SCL-90: Admimistration, scoring and pracedures manual-l for the R(evised) version. Baltimore: Johns Hopkins School of Medicine, Clinical Psychometrics Research Unit.

Devolder, P. A., \& Pressley, M. (1991). Memory complaints in younger and older adults. Applied Cognitive Psychology, 5, 443-454.

Dirken, J. M. (1967). Het meten van stress in industriele situaties (The meassurenent of siress in industrial situations. Groningen, The Netherlands: Wolters.

Hood, B. M., MacLachlan, M., \& Fisher, S. (1987). The relationship between cognitive failures, psychoneurotic symptoms and sex. Acta Psychiarrica Scandinavica, 76, 33-35.

Houston, D. M. (1989). The relationship between cognitive failure and self-focuses attention. British Jomrnat of Clinical Psychology, 28, 85-86.

Houx, P. J., \& Jolles, J. (1994). Vutnerability factors for age related cognitive decline. In R. L. Isaacson \& K. F. Jenssen (Eds.y, The vulnerable brain and environmental risk (pp. 25-41). New York: Plenum Press.

Jolles, J., Houx, P. J., van Boxtel, M. P. J., \& Ponds, R. W. H. M. (1995). Maastrich Aging Shudy: Determinants of cognitive aging. Maastricht. Neuropsych Publishers.

Joreskog. K. Gi, \& Sörbom, D. (1996). LISREL 8: User's reference guide. Chicago. Scientific Sofiware International.

Kramer, A. F., Humphrey, D. G., Larish, J. F., Logan, G. D. \& Strayer, D. L. (1994), Aging and inhbition: Beyond a unitary view of inhibitory processing in atention. Psychology and Aging, 9, 491-512,

Larson, G. W., Alderton, D. L., Neideffer, M., \& Underhill, E. (1997). Further evidence on dimensionality and correlates of the Cognitive Failures Questionnaire. Brifish Journal of Psychology, 88, 29-38.

Lezak, M. D. (1995). Neuropsychological Assessment. (Mrd edition). New York: Oxtord University Press.

Matthews, G., Coyle, K., Craig, A. (1990). Multiple factors of cognitive failure and their relationships with stress vulnerability. Joumal of Psychoparhology and Behavioral Assessment, 12, 49-65.

Mathews, G., \& Wells, A. (1988). Relationsinips between anxiety, self-consciousness, and cognitive failure. Cogninion and Emotion. 2, 123-132.

Merckelbach, H., Muris, P., Nijman, H., \& de Jong. P. (1996). Self-reported cogmitive failures and neurotic sympiomatology. Personality and Individual Differences; $20,715-724$.

Metsemakers, J. F. M., Höppener, P., Knotmerus, J. A., Kocken, R. J. J., \& Limonard, C. B. G. (1992). Computerized health intormation in the Netherlands: A registration network of family praclices. British Journal of General Practice, 42, 102-106. 
Pollina, L. K., Greene, A. L.. Tunick. R. H. \& Pucket. J. M. (1992). Dimensions of everyday memory in young: adulthood. British Jounthal of Pyschology, 83, 305-321.

Ponds, R. W. H. M. Commissaris, K. J. A. M., \& Jolles, J, (1997). Prevalence and covariates of subjective forgetfulness in a nomal population. finemational Joumat of Aging and Human Development, 45, 207-22I.

Ponds, R. W. H. M. \& Jolles, J. (1996). The abridged Dutch Metamemory in Adulthood (MIA) questionnaire: Structure, and effects of age, sex, and education. Psychology and Aging. 11. 324-332.

Ponds, R. W. H. M (Chapter 6). Predictors of subjective memory as measured with the Metamemory in Adulthood (MLA) questionnaire (this thesis).

Rabbitt. P. \& Abson, V. (1990). 'Lost and Found': Some logical and methodological limitations of self-report questionnaires as tools to study cogritiwe ageing. British Journal of Psychology, 81, $1-16$.

Rabbit, P.y Abson, V. (1991). Do older people know how good they are? British Joumal of Psychology, 82, 137-151.

Rabbitt, P., Maylor, E., Mclnnes, L., Bent, N., \& Moore, B. (1995). What goods can selfoassessment questionnaires deliver for cognitive gerontology? Applied Cognirive Psychology, 9, S127-5152.

Reason, J. (1988). Siress and cognitive failure. In S. Fisher \& J. Reason (Eds.), Hondbook of hife stress, cognition and health (pp. 405-421). New York: John Wiley \& Sons.

Reason, J. (1993). Self-report questionnaires in cognitive psychology: have they deliwered the goods? In A. Baddeley \& L. Weiskrantz (Eds.), Attenton. Selection, awareness, and control. A tribure to Donald Broadbent (pp. 406-423). Oxford: Oxford University Press. 
Appendix

Ttems of the CFQ questionnaire and the CFQ subscales

1. Do you read something and find you haven't been thinking about it and must read it again?

A 2. Do you find you forget why you went from one part of the house to the other?

D 3. Do you fail to notice signposts on the road?

D 4. Do you find you confuse right and left when giving directions?

5. Do you bump into people?

A 6. Do you find you forget whether you've turned off a light or a fire or locked the door?

C 7. Do you fail to listen to people's names when you are meeting them?

B 8. Do you say something and realize afterwards that is might be taken as insulting?

$\mathrm{B}$ 9. Do you fail to hear people speaking to you when you are doing something else?

B 10 . Do you lose your temper and regret it?

11. Do you leave important letters unanswered for days?

D 12. Do you find you forget which way to turn on a road you know well but rarely use?

13. Do you fail to see what you want in a supermarket (although it's there)?

14. Do you find yourself suddenly wondering whether you have used a word correctly?

15. Do you have trouble making up your mind?

A 16. Do you find you forget appointments?

A 17. Do you forget where you put something like a newspaper or a book?

A 18. Do you find you accidentally throw away the thing you want to keep and keep what you meant to throw away - as in the example of throwing away the matchbox and putting the used match in your pocket?

B 19. Do you daydream when you ought to be listening to something?

C 20. Do you find you forget people's names?

21. Do you start doing one thing at home and get distracted into doing something else (unintentionally)?

C 22. Do you find you can't quite remember something although it" son the tip of your tongue"?

A 23. Do you find you forget what you came to the shops to buy?

A 24. Do you drop things?

25. Do you find you can't think of anything to say?

$A=C F Q$ Absent-mindedness

$\mathrm{B}=\mathrm{CFQ}$ Social interactions

$\mathrm{C}=\mathrm{CFQ}$ Names and words

$\mathrm{D}=\mathrm{CFQ}$ Orientation 

Chapter 5

\title{
The abridged Dutch Metamemory in Adulthood (MIA) questionnaire: Structure, and effects of age, sex, and education ${ }^{*}$
}

\begin{abstract}
This study presents data on the factor structure, reliability and discriminant validity of the Metamemory in Adulthood (MIA) questionnaire in a Dutch sample of 1,899 normal and healthy respondents aged 24 to 86 years. The factor structure of the Dutch MIA corresponded with that of the original MIA. The Strategy scale could be divided into two subscales: external and internal memory strategies. The number of items of the MIA could be reduced by $34 \%$ without loss of the factor structure or lowering of the internal consistency of the subscales. Data on the relation of the abridged MIA with age, sex, education, depression, anxiety, and subjective health are presented. The study supports the cross-national use of the MIA as a research and clinical instrument for the evaluation of subjective memory functioning.
\end{abstract}

* A slightly shoriened version of this chapter has been published in:

Ponds, R. W. H. M., \& Jolles, J. (1996). The abridged Dutch Metamemory in Adulthood (MIA) questionnaire: Structure, and effects of age, sex, and education. Psychology \& Aging. 11, 324-332. 


\section{Introduction}

Most research on memory and aging has shown that memory complaints are more frequent among older and middla-aged adults than among younger adults (e.g., Cutler \& Grams, 1988). There is also ample evidence of an age-related decline in memory performance, especially when new information has to be acquired (Craik \& Jennings, 1992). There is, however, no straightforward relation between memory complaints and memory performance; correlations between complaints and test performance are either absent or low (Gilewski \& Zelinski, 1986). This finding has led to the notion that memory complaints and memory performance in elderly people are not solely determined by actual memory abilities or skills, but are also related to contextual factors such as demographic variables (for instance education), health, and psychological and social variables such as personality traits, affective state, environmental stress, or social support (Arbuckle, Gold, Andres, Schwartzman, \& Chaikelson, 1992). There is also growing interest in the possible mediating role of self-knowledge and self-belief in one's own memory functioning, termed metamemory, in age-related changes in memory performance on the one hand and in age-related memory complaints and concern on the other (Light, 1991; Lovelace, 1990). Although self-perceptions of memory may not be veridical estimates of actual memory skills or competence, they newertheless may have a substantial impact on the behavior in everyday memory demanding situations. Low self-confidence for memory ability may lead to decreased effort when trying to remember, avoidance of everyday tasks involving memory, and anxiety when memory is challenged; this leads to lower memory performance and in turn further strengthens the subjects" belief of his or her declining memory abilities (Bandura, 1989). Therefore, detailed information about memory self-beliefs is of considerable importance when studying memory in the aged.

Metamemory is not considered to be a unitary concept. Hultsch, Herzog, Dixon and Davidson (1988) defined four broad dimensions of metamemory: memory knowledge (factual knowledge about memory tasks and memory processes), memory monitoring (sel-knowledge about current memory use, contents, and states), memory-related affect (affective states generated by or associated with memory-demanding situations), and memory self-efficacy (beliefs about memory abilities, strengths, and weaknesses). Although numerous self-report questionnaires have been developed to measure metamemory (Dixon, 1989; Gilewski \& Zellinski, 1986; Zelinski \& Gilewski, 1988), only wo seem to cover most of these dimensions: the Memory Functioning Questionnaire (MFQ) of Gilewski, Zelinski, and Schaie (1990) and the Metamemory in Adulthood (MIA) questionnaire of Dixon, Hultsch, and Hertzog (1988). Both instruments are frequently used in aging research, despite their considerable length.

The MIA asks respondents to rate on a 5-point Likert scale 108 statements describing their own memory functioning and their general knowledge of memory processes. The questionnaire consists of seven factors or subscales. These are reported use of various memory strategies (Strategy), knowledge of basic memory processes (Task), perceived memory capacity (Capacity), perceived change in memory functioning (Change), perceived feelings of stress and anxiety related to memory performance (Anxiety), perceived importance of having a good memory and performing well on memory tasks (Achievement), and perceived sense of control over memory (Locus). Studies with multiple samples have shown high internal reliabilities for the seven

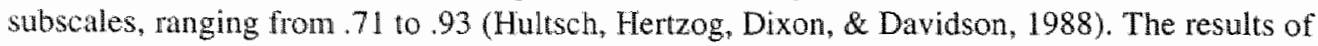


the first factor analysis of the MIA suggested, however, that the Strategy subscale could be divided into two factors despite its high internal reliability (Dixon \& Hultsch. 1983). One factor could be labeled internal memory strategies (e.g., imagery), whereas the other could be labeled as external memory strategies (e.g., writing down appointments). This subdivision might be of importance, given the suggestion of Hultsch. Hertzog, and Dixon (1987) that younger adults may be more likely to rely on internal memory strategies, whereas older adults may tely more on external strategies.

Correlations of the MIA subscales with instruments measuring mood, personality, and locus of control are low, which supports the discriminant validity of the MA (Dixon, et al., 1988). Only the MLA subscale anxiety is related to trait anxiety and related affective states. Thus fau, no data are reported on test-retest reliability.

Data from three studies which comprise a total of six different samples all covering broad age ranges from young (18-20 years) to old (over 80 years), showed robust age differences for MIA Change, Capacity, and Locus (Cavanatugh \& Poon, 1989; Dixon \& Hultsch, 1983; Hultsch, et al., 1987). Older respondents consider that they have less memory capacicy than younger respondents, perceive more decline in their memory functioning, and consider that they have less control over their memory. Age had little or no relation to Task, Achievement, and Anxiety. Conflicting results were found for the MIA subscale Strategy. In the study of Cavanaugh and Poon (1989), the young respondents reported a more frequent use of memory strategies than the old respondents, whereas in the Victoria subsample of Hultsch, Hertzog and Dixon (1987) the opposite was found. Sex differences were examined only in the study of Hultsch, Hertzog, and Dixon (1987). In both the Victoria and Annwille samples, women reported greater anxiety in memory-demanding situations (MLA Anxiety) and reported more use of memory strategies (MIA Strategy) than did men. Thus far, no data are available on the possible effects of education on the MIA.

In this study we report on our findings obtained with the Dutch version of the MIA in a sample of more than 2,000 subjects ranging in age from 24 to 86 years. The MIA was chosen because the available psychometric data on reliability and walidity support the use of this instrument for clinical and experimental purposes. Several issues were addressed in this crossmational replication study. Our first interest was in seeing in how far the factor structure of the MIA would be recovered in the Dutch translation. A related issue concerned the possible division of the Strategy scale into two separate subscales: internal and extemal memory strategies. One of our main goals in the study was to reduce the number of items in the MLA without having it lose its factor structure. This would make the MIA a more feasible instrument for large scale population studies. We were specially interested in the test-retest reliability of the MIA, given the fact that no data are available on this subject. We studied discriminant validity by correlating the MIA subscales with measures of anxiety, depression, and subjective health. Effects of age, sex, and education on the MIA were also examined. Finally, we compared palterns of self-appraisal of memory as measured by the MIA in a young group of participants and in an old group of participants who were very concerned about their memory. From a clinical perspective, we were interested in possible age differences in self-report of memory in these two groups, although we could not tell from the present data set in how far their experienced memory dysfunctioning was related to an actual decrease in memory skills. 


\section{Method}

\section{Participants and procedure}

This study was conducted as part of a large cross-sectional study of biological and psychological deteminants of successful and pathological cognitive aging, which in turn is part of a large research program on cognitive aging, the Maastricht Aging Study (MAAS; Jolles, Houx, van Boxtel, \& Ponds, 1995). In the first phase of this cross-sectional study an extensive postal questionnaire on subjective cognitive functioning in relation to age, health, and psychological factors was sent to 2,340 participants in the age range of 24-86 years. This postal questionnaire included a Dutch translation of the Metamemory in Adulthood (MTA) questionnaire.

Participants were recruited from a register of patients of general practices in the region of Maastricht, the Netherlands (Metsemakers, Höppener, Knottnerus, Kocken, \& Limonard 1992). This register contains all relevant past and current medical morbidity as documented by the general practitioners. Those with previous or current medical conditions with known impact on cognitive and/or motor functions were excluded from the selection. Exclusion criteria were overt cerebrovascular disease, chronic neurological pathology (e.g., dementia, epilepsy, parkinsonism), mental retardation, and major psychiatric disorders. Participant sampling was stratified by 13 discontinuous age classes ( 25 years $\pm 1,30$ years $\pm 1,35$ years $\pm 1, \ldots, 80$ years $\pm 1,85$ years \pm 1) and sex. A total of $392 \|$ participants were drawn from the register. After screening by the general practitioner, 187 were excluded because of current illness or psychosocial indications. The remaining 3,734 participants were invited by their practitioners to participate in the study; 2,340 were willing to participate and received the postal questionnaire. In total 2,043 respondents completed and returned the postal questionnalre in good order.

Only respondents with complete data on the MIA subscales were included in the study. For this reason 144 respondents were excluded, which left a total number of 1,899 participants. They were divided into four age groups: young (age classes 25,30 , and 35 years), young middle-aged $(40,45$, and 50 years), old middle-aged $(55,60$, and 65 years) and old $(70,75,80$, and 85 years). Educational level was measured by a Dutch scoring system (de Bie, 1987) which consists of an 8-point scale, ranging from unfinished primary education (level 1) to university education (level 8). The mean age, sex, and educational level of the subjects are presented in Table 5.1.

The four groups were roughly equivalent in size, with a relative underrepresentation of the old group (22\%). There were also slightly more women than men, especially in the young and old groups. A significant decline in mean level of education was found from the youngest to the oldest age group $(F(3,1834)=97.4, p<.001)$. Duncan's multiple range tests $(p=.05)$ showed that the groups were significantly different from each other, except for the old middle-aged and old groups.

The test-retest reliability of the MIA was studied in an additional longitudinal research project on cognitive aging and health (Houx \& Jolles, 1994). All participants came for their first follow-up 5 years after initial testing. In order to assess test-retest stability, the MIA was completed twice, with an interval of 4 weeks, by a subsample of 48 participants (27 men, 21 women). They were all healthy community dwelling individuals with a mean age of 67 years (range $23-87$ years). 
Table 5.1 Descriprive characteristics of the subjects in the study.

\begin{tabular}{|c|c|c|c|c|c|c|}
\hline & \multirow{2}{*}{$\frac{N}{n(\%)}$} & \multicolumn{2}{|c|}{ Age } & \multicolumn{2}{|c|}{ Education } & \multirow{2}{*}{$\frac{\operatorname{Sex}(M / F)}{\%}$} \\
\hline & & $M$ & $S D$ & $M$ & $S D$ & \\
\hline Total group & $1899(100)$ & 52.0 & 16.9 & 3.3 & 1.9 & $46 / 54$ \\
\hline Young & $476 \quad(25)$ & 30.6 & 4.1 & 4.3 & 1.8 & $41 / 59$ \\
\hline Young middle-aged & 501 (26) & 44.8 & 4.2 & 3.6 & 1.8 & $50 / 50$ \\
\hline Old middlia aged & $513 \quad(27)$ & 59.8 & 4.1 & 2.7 & 1.7 & $49 / 51$ \\
\hline Old & $409 \quad(22)$ & 75.6 & 5.2 & 2.5 & 1.9 & $44 / 56$ \\
\hline
\end{tabular}

Note. Data on educational level were missing for 61 subjects (young, 15 subjects; young middne-aged, 13; old middle-aged, 13; old, 20).

\section{Measures}

MIA. The Metamemory in Adulthood (MIA) questionmaire published by Dixon, Hultsch, and Hertzog (1988) was translated into Dutch and used in this study. In the original MIIA, the Strategy questions are mixed with the items of the other subscales. We changed the order of the MIA questions by putting all the Strategy questions together at the end of the questionnaire. This was done for participants' convenience, because the type of question and the response format of the Strategy items are different from the items of the other subscales.

Missing data on the MIA were handled in the following way. The first step involved removing all participants who had left blank $5 \%$ or more of the MIA questions ( 6 or more questions). This very stringent criterion was used because this was the first psychometric analysis of the Dutch MIA, and we wanted to analyze only complete or near complete questionnaires. A total number of 144 respondents $(7 \%$ ) were removed from the sample on the basis of this criterion; most of them were in the two oldest age groups (young age group, 2\%; young middle-aged group, $3 \%$; old middle-iged group, 6\%; old age group, 17\%). Next, we checked, for each subscale, whether at least $80 \%$ of the items were correctly filled in, following the guidelines given by Hertzog, Hultsch, and Dixon (1989). This was the case for all participants. The remaining questions with missing values were assigned a score of 3 (the middle of the 5-point scale).

Affective state, subjective health, and forgetfulness. Feelings of depression and anxiety were measured with the subscales. Depression and Anxiety of the revised version of the Symptom Checklist (SCL-90: Derogatis, 1977; Dutch version: Arrindell \& Ettema, 1986). The SCL-90 is a mutidimensional self-report inventory of current psychopathology. Items are rated on a 5-point scale. The subscale Anxiety consists of 10 items and measures feelings of generalized anxiecy (score range 5-50). The subscale depression contains 16 items which reflect symptoms of depression (score range 16-80). The VOEG ('Vragenlijst Omtrent Evaren Gezondheid' Inventory of Subjective Health) was originally developed by Dirken (1967). It is used in several large Dutch surveys to measure subjective health status. The 21 -ttem version administered in this 
study probes heath complaints of a somatic and psychosomatic nature. The score range is $0-21$. The incidence of forgetfuness was assessed with the question "Do you consider yourself as being forgetful?". Participants who replied affirmatively also rated their worry about this forgetfulness on a 5 -point scale. This scale ranged from "not worried" (score 1) 10 "very worried" (score 5).

\section{Data malysis}

For the psychomentic analysis of the Dutch MA, we performed confirmatory factor analyses (CFAs) on the basis of "perfectly congruent weights" (Ten Berge, 1986), using the software program PECON (Enzmann, 1993). This method determines the recoverability of components or factors from an original sudy in a replication study after rotation to perfect congruence. For this purpose, the scale configuration of the MIA was represented by means of a matrix of components weights in which the items were either 0 or 1 . The factor structure of the original and the Dutch MIA are thus equal by definition and have the same interpretation. What is of interest now is to what extent the set of factors that were good summarizers for the original MIA, is able to summarize the variables of the Dutch MIA in the same way. The recoverability of the factors in a new data set (in this case the Dutch MIA) can be determined in several ways. First, one can compare the amount of variance explained in the original data set with the amount of variance explained in the new data set. However, data for the explained amount of variance in the original MIA are not available from the present literature. Second, the amount of variance explained in the CFA can be compared with the amount of variance explained by a separate Principal Component Analysis (PCA). If the amount of variance explained by CFA is comparable to that explained by PCA, the information in the data set is summarized well by the clefined factor structure. Third, because the factor configuration in both the original and the Dutch MIA are equal by definition, one can also check the comparability of the two questionnaires by looking at the degree of correspondence of the inter correlations between the factors and the them loadings of both questionnaites.

The Strategy subscale was analyzed separately, because we suspected that this scale in fact consists of two scales. Moreover, separate analysis is also more appropriate given the specific phrasing of the questions of this scale as weli as its different response format compared to the other MIA subscales.

One of our main goals in this study was to reduce the number of items in the Dutch MIA without loss of its factor structure. For this purpose a new series of PECON analyses were performed on the total sample. Items with loadings of less than .50 on their own factor or with high loadings on other factors were dropped from the list. A high loading on another factor was defined as an item loading that was less than. 15 below the loading of the intended factor. To test the reliability of the shortening of the MLA, the same analyses were repeated for two split-half subsamples and a young and old subsample to see whether the same items would be eliminated as in the total sample.

To evaluate possible age differences in the factor structure of the abridged MIA, we repeated PECON analyses in a young, a middle-aged and an old subsample. The covariance matrices for the summed responses to the eight scales of the abridged MIA for the three age groups were analyzed with the LISREL 7 program (Joreskong \& Sörbom, 1989). However, with large sample sizes, the chi-square statistic may be significant even when the differences between the observed 
and the estimated covariance matrices are small. A goodness-of-fit index that is less infuenced by the sample size and that was used here, is the Bentler-Bonnett normed fit index, which reflects the proportion of information in the covariance matrix that is accounted for by the model (Bollen, 1990). A fit index above 9 is assumed to indicate reasonable fit.

In addition to the CFAs, internal consistency estimates were calculated (Cronbach"s alpha). The test-retest stability was assessed with Pearson correlation coefficients. We conducted regression analyses to look at the relation between depression, anxiety, and subjective health and the scores on the MIA subscales, after controlling for the effects of age, sex, and ecucation. We used multivariate and follow-up univariate analyses of variance to assess the effects of age, sex and education on the MIA. Because the sample size in this study was very large, only probabilities of $1 \%$ or less were considered significant (unless reported otherwise).

\section{Results}

\section{Factor structure}

The results of the CFA and reliability analyses of the 108 -item version of the Dutch MTA are summarized in Table 5.2 and 5.3.

Table 5.2 Summary of the confirmatony factor analysis and reliability analyses of the 108-item version of the Metamemory in Adulthood questionnaire.

\begin{tabular}{|c|c|c|c|c|}
\hline Mia subscale & $\begin{array}{l}\text { No. of } \\
\text { items }\end{array}$ & $\begin{array}{l}\text { Range factor } \\
\text { loadings }\end{array}$ & $\begin{array}{l}\% \text { of variance } \\
\text { explaineda }\end{array}$ & $\begin{array}{l}\text { Cronbach"s } \\
\text { Alpha }\end{array}$ \\
\hline
\end{tabular}

$\begin{array}{lcccc}\text { Task } & 16 & .20-.68 & 5.39 & .81 \\ \text { Capacity } & 17 & .39-.67 & 6.45 & .85 \\ \text { Change } & 18 & .17-.78 & 7.84 & .91 \\ \text { Anxiety } & 14 & .46-.71 & 7.19 & .87 \\ \text { Achievement } & 16 & .27-.59 & 4.45 & .74 \\ \text { Locus } & 9 & .33-.66 & 3.61 & .69 \\ \text { All scales } & 90 & - & 34.93 & -\end{array}$

$\begin{array}{lcccc}\text { Strategy } & 18 & - & - & .85 \\ \text { Strategy-ex } & 9 & .51-.76 & 18.31 & .77 \\ \text { Strategy-in } & 9 & .34-.73 & 22.22 & .84 \\ \text { Both scales } & 18 & - & 40.53 & -\end{array}$

Note. Based on 1899 subjects. The Strategy subscale was analyzed separately. Strategy-ex = external strategies: Strategy-in = internal strategies.

a Unique variance (corrected for the correlations between the factors). 
The amount of variance explained by the six factors conjointly in the CFA was 34.9\%, which was comparable to the $37.7 \%$ that a six factor PCA accounted for. Internal consistency estimates (Cronbach's alpha) tanged from 69 for Locus to 91 for Change and were almost identical to the internil consistency estimates reported by Dixon, Hultsch, Hertzog, and Davidson (1988). The pattern of factor intercorrelations. (Table 5.3) was nearly identical to that reported by Hertzog, Hulsch and Dixon (1989), with the highest correlations between Capacity, Change, Anxiety, and Locus.

Table 5.3 Coritations among the seven original scales of the 108-item version af the Metamemory in Adulihood questromaire and the rwo sieparate Strategy sicales.

\begin{tabular}{llllllllll} 
MIN subscale & 1 & 2 & 3 & 4 & 5 & 6 & 7 & 8 & 9 \\
\hline
\end{tabular}

1. Task

2. Capacity

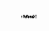

3. Change

$.10 \quad-$

4. Anxiety

$-.21 \quad .65$

5. Achievement

.20

. .46

$-$

6. Locus

.24

$\begin{array}{ll}.09 & -.20\end{array}$

$-.01$

.43

.43

7. Sitralegy

.27

$-.18$

$-.29$

.23

$-.21$

.30

$-.09$

$-.29$

$$
.31
$$

.27

.27 34

$-38$

9. Strategy-in

$.30 \quad-.09$

$.27 \quad .26$

$\begin{array}{rrc}.19 & - & \\ .22 & -.01 & - \\ .11 & -.06 & .86 \\ .26 & .05 & .86\end{array}$
$-$ $.49 \quad-$

Note. Based on 1899 subjects. Strategy-ex = external strategies; Strategy-in = internal strategies.

A high internal consistency was also found for Strategy (Cronbach's alpha .85). Yet, the separate CFA for Strategy clearly showed that the scale could be divided into two factors, each with nine items corresponding to internal and external memory strategies. The amount of variance explained by these two strategy factors conjointly in the CFA was $40.5 \%$, whereas a two factor PCA accounted for $41.3 \%$. The correlation between both factors was relatively high (.49), but was still low enough to suggest that the two factors accounted for different parcels of variance.

\section{Abridgenent of the MIA}

Additional CFAs based on the total sample of 1899 participants revealed that a substantial number of items (34 items or $31 \%$ ) on the MLA could be eliminated without loss of its factor structure. The numbers of items eliminated per subscale were six for Task (38\%), five for Capacity (29\%), eight for Change (44\%), two for Anxiety (17\%), nine for Achievement (56\%), two for Locus (22\%), and one for both Strategy subscales (11\%). The results of the CFA and reliability analyses are summarized in Tables 5.4 and 5.5 . 


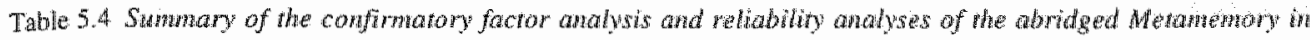
Aduhhood questionuare.

\begin{tabular}{|c|c|c|c|c|}
\hline MIA subscale & $\begin{array}{l}\text { No. of } \\
\text { inems }\end{array}$ & $\begin{array}{l}\text { Range factor } \\
\text { loadlings }\end{array}$ & $\begin{array}{l}\text { Of of wariance } \\
\text { explatined }\end{array}$ & $\begin{array}{l}\text { Cronbach"s } \\
\text { Alplua }\end{array}$ \\
\hline
\end{tabular}

$\begin{array}{lcccc}\text { Task } & 10 & .54-.71 & 6.93 & .82 \\ \text { Capacity } & 12 & .52-.68 & 8.01 & .84 \\ \text { Change } & 10 & .62-.81 & 9.63 & .91 \\ \text { Anxiety } & 12 & .54-.71 & 8.73 & .87 \\ \text { Achievement } & 7 & .53-.69 & 5.24 & .73 \\ \text { Locus } & 7 & .50-.73 & 4.99 & .75 \\ \text { All scales } & 58 & - & 43.42 & -\end{array}$

$\begin{array}{lcccc}\text { Strategy } & 16 & - & - & .85 \\ \text { Strategy ex } & 8 & .51-.75 & 20.27 & .77 \\ \text { Strategy } & 8 & .52-.77 & 23.61 & .84 \\ \text { Both scales } & 16 & - & 43.88 & -\end{array}$

Nore. Based on 1899 subjects. Strategy-ex = external strategies; Strategy-in = internal strategies.

"Unique variance (corrected for the correlations between the factors).

The amount of variance explained in the CFA by the first six factors increased to $43.3 \%$. A six-factor PCA on the same data set accounted for an almost equal amount of variance (44.4\%). Both strategy subscales accounted for $43.9 \%$ of the wariance, which was also comparable with the 44.3\% that a two-factor PCA accounted for. Factor loadings of the items ranged from .50 to .81. Although the number of items of some scales was substantially reduced, the internal consistency estimates remained high or even increased and were comparable with those of the original subscales. The pattern of intercorrelations between the factors or subscales of the shortened version of the MLA was comparable with the pattem in the original 108 -item version of the MIA (Table 5.5). Only the correlations between the Change, Capacity, Anxiety, and Locus subscales were slightly lower, which can be explained by the fact that most of the items from these scales were eliminated because they had high loadings on one or more of the other three subscales.

We performed additional analyses to verify the reliability of the abridgement of the MIA. CAFs were repeated in four subsamples: a young subsample (aged $24-51$ years, $n=977$, mean age $=37.9$ years), an old subsample (aged $54-86$ years, $n=922$, mean age $=66.8$ years), and wo subsamples that were created by a random split of the total sample (first group: $n=949$, mean age $=51.6$ years, $48 \%$ men; second group: $n=950$, mean age $=52.4$ years, $45 \%$ men). In each subsample we checked which items would be dropped from the list according to the item selection criteria that were used for the total sample. When we allowed for some fluctuation around the item selection criteria (.48 and .52 for the .50 criterion; 13 and .17 for the criterion of difference 
Table 5.5 Correkations among the eight subscales of the abridged Metanemory in Adulhood questionnaire.

\begin{tabular}{|c|c|c|c|c|c|c|c|c|c|}
\hline Mia subscale & 1 & 2 & 3 & 4 & 5 & 6 & 7 & 8 & 9 \\
\hline 1. Task & - & & & & & & & & \\
\hline 2. Capacity & -.08 & - & & & & & & & \\
\hline 3. Change & -.25 & .52 & - & & & & & & \\
\hline 4. Anxiety & .24 & -.32 & -.61 & - & & & & & \\
\hline 5. Achievement & .26 & .14 &. .27 & .35 & - & & & & \\
\hline 6. Locus & .04 & .28 & .15 & -.06 & .31 & - & & & \\
\hline 7. Sirategy & .27 & -.16 & -.28 & .29 & .17 & .06 & - & & \\
\hline 8. Stualegy-ex & .18 & -.22 & .28 & .25 & .08 & .01 & .86 & - & \\
\hline 9. Strategy-in & .28 & -.05 & -.20 & .25 & .21 & .12 & .83 & .44 & - \\
\hline
\end{tabular}

Note. Based on 1899 subjects. Strategy-ex $=$ external strategies; Strategy-in $=$ internal strategies.

between item factor loadings), the same 34 eliminated items in the total sample would now be dropped from the list in both the young and old subsample and in the first and second split-half group. These results support the reliability and age invariance of the item reduction that was based on the total sample.

\section{Age patterns in the factor structure}

To control for possible age differences in the factor structure of the abridged MIA, we performed the same CFA and reliability analyses separately for three age groups. For this purpose the total sample was divided into a young subsample (24-41 years, $n=643$ ), a middle-aged subsample (44-61 years, $n=687$ ), and an old subsample (64-86 years, $n=569)$. Table 5.6 shows that the mean item loadings, the amount of variance explained by each factor, and the internal consistency estimates were very similar in the three age groups. Table 5.7 presents the intercorrelations between the factors or subscales for the three age groups. In the oldest age group the correlations between Capacity and Locus and Change and Locus appeared to be higher than those in the other two age groups, whereas the correlations between Task and the factors Change, Anxiety and Achievement were lower in the young age group than in the other groups. Yet, the pattern of interconelations were wery similar for the three age groups.

In addition, we perfomed a LISREL analysis of the covariance matrices of the eight scales of the abridged MAA for the three age groups (model: equal factor covariance matrices). The goodness-of-fit index (GFI) was .962 for the young subsample, 988 for the middle-aged subsample, and .956 for the old subsample, whereas the overall adjusted $G F I$ was .955 . The likelihood ratio chi-square test was significant $\left(X^{2}(72)=249.41, p<.001, n=1,899\right)$ which is likely due to the large sample size. The Bentler-Bonnett normed fit index, which is less influenced by the sample size, was 930 . These data further suggest that the factor structure of the abridged MLA is invariant over age. 
Table 5.6. Summary of the confimaton factor analysis and reliability analysin of the abridged Metamemory in Aduthood questionnaire for the young, middle-aged and otd subscanples.

\begin{tabular}{|c|c|c|c|c|c|c|c|c|c|}
\hline \multirow[b]{2}{*}{ MA subseale } & \multicolumn{3}{|c|}{ Mean factor loading } & \multicolumn{3}{|c|}{ \%o of variance explained } & \multicolumn{3}{|c|}{ Cronbach's alpha } \\
\hline & $\mathrm{Y}$ & M & 0 & Y & M & 0 & $x$ & $\mathrm{M}$ & 0 \\
\hline Task & .61 & .61 & .63 & 7.05 & 6.83 & 7.23 & .82 & .81 & .82 \\
\hline Capacity & .59 & .61 & .62 & 7.33 & 8.13 & 8.35 & .82 & .85 & .85 \\
\hline Change & .69 & .71 & .71 & 8.52 & 8.87 & 9.06 & .87 & .89 & 89 \\
\hline Anxiety & .61 & .65 & .64 & 7.91 & 8.85 & 8.57 & .84 & .87 & .86 \\
\hline Achievement & .60 & .62 & .59 & 4.89 & 5.26 & 4.85 & $.7 \|$ & .72 & .68 \\
\hline Locus & .65 & .63 & .61 & 5.40 & 5.11 & $4.9 \rrbracket$ & .78 & .76 & .72 \\
\hline All scales & - & - & - & 41.10 & 44.05 & 4.3 .97 & - & - & - \\
\hline
\end{tabular}

$\begin{array}{lccccccccc}\text { Strategy-ex } & .64 & .63 & .63 & 20.34 & 20.40 & 20.64 & .77 & .78 & .78 \\ \text { Strategy-in } & .65 & .69 & .70 & 21.94 & 24.39 & 24.63 & .81 & .85 & .85 \\ \text { Both scales } & - & - & - & 42.28 & 44.80 & 45.27 & - & - & -\end{array}$

Nore. Based on 1899 subjects. $Y=$ young subsample; $M=$ middle-aged subsample; old subsample. Strategy-ex = external strategies; Strategy-in = internal strategies.

\section{Test-retest stability}

The test-retest correlations for the abridged MIA were derived from a scoring of those items that were administered in the context of the entire 108 -item instrument. The stability coefficients were satisfactory for both the 108-item instrument (range $=.79$ to .86 ) and the abridged version (range $=.72$ to .85 ), except for the Task subscale for which correlations of .58 and .50 were found for the 108-item instrument and the abridged MIA, respectively.

\section{Discriminant validity}

Age, sex, and educational level all correlated with subjective health, depression, and anxiety, although the strength of these correlations was generally low (ranging from .05 to .29). Because we wanted to examine the effects of subjective health, anxiety, and depression on the MIA subscales independently of the interacting variables of age, sex, and educational level, we performed a multiple hierarchical regression analysis. Only participants with complete data on all variables were included in the analysis $(n=1,720)$. In step 1 age, sex, and educational lewel were entered in the regression model, and in step 2 subjective health, depression, and anxiety were entered. Anxiety and depression either had no contribution or accounted for only very small amounts of variance in most subscales. Only in the Anxiety subscale of the MIA did anxiety account for $3 \%$ of the variance. More substantial contributions were found for subjective health on 


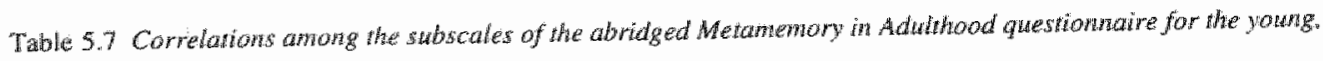
midde-aged and old subsamplex.

\begin{tabular}{|c|c|c|c|c|c|c|c|c|}
\hline \multirow[b]{2}{*}{ MAA subscale } & \multicolumn{8}{|c|}{ Young subsample $(n=643)$} \\
\hline & 1 & 2 & 3 & 4 & $\xi$ & 6 & 7 & 8 \\
\hline 1. Task & - & & & & & & & \\
\hline 2. Capacily & -.09 & - & & & & & & \\
\hline 3. Change &.$- \|$ & .50 & - & & & & & \\
\hline 4. Anxiely & .13 & -.36 & -.51 & - & & & & \\
\hline 5. Achievemerst & .17 & .17 & -.06 & .23 & - & & & \\
\hline 6. Locus & .07 & .19 & .06 & -.06 & .37 & - & & \\
\hline 7. Strategy-ex & .15 & -.28 & -.32 & .29 & .05 & .02 & - & \\
\hline 8. Strategy-in & .25 & -.12 & -.27 & .28 & .15 & 111 & .38 & - \\
\hline
\end{tabular}

Middlewaged subsample $(h=687)$

MAs subscale $\quad$\begin{tabular}{lllllll}
1 & 2 & 3 & 4 & 5 & 6 & 7 \\
\hline
\end{tabular}

1. Task

2. Capacity

$-.15$

3. Change

$-.31$

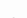

4. Anxiety

5. Achievement

$.28 \quad-.31$

$.25 \quad .15$

6. Locus

.02

.24

$-.59$

$\begin{array}{ll}16 & -.59 \\ -.28\end{array}$

7. Suategy-ex

8. Strategy in

19

$-.24$

.09

$\begin{array}{ccc}.37 & - & \\ .01 & .35 & - \\ .26 & .07 & -.05 \\ .25 & .25 & .15\end{array}$

$-.05 \quad-.21$

$\begin{array}{rr}.31 & .26 \\ -.21 & .25\end{array}$

.15 .45

\section{Old subsample $(n=569)$}

\section{MLA subscale}

12

34

56

6

78

1. Tusk

2. Capacily

$\begin{array}{rr}-0 & \\ .02 & - \\ -.33 & .56 \\ .31 & .22 \\ .37 & .25 \\ .05 & .4 \\ .18 & -.11 \\ .27 & .02\end{array}$

3. Change

4. Auxioty

5. Achievenemt

6. Loc 19

8. Strateg $y-d x$

9. Strategy-in

.27

.56
. .22
.25
.41
-.14
.02

-.62
-.12
.31
-.27
.12

$\begin{array}{rr}- & \\ .29 & - \\ -.14 & .28 \\ .22 & .12 \\ .20 & .21\end{array}$

-

$-.12$

.20

.21

.09

49

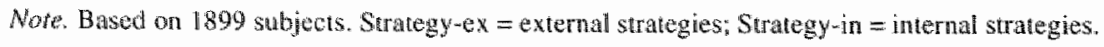


Capacity (5\%), Change (8\%) and Anxiety (12\%) subscales. Lower health ratings were related to lower ratings of memory capacity, a greater subjective decline of memory, and more subjective anxiety about memory performance.

\section{Effects of age, sex, and education}

A multivariate analysis of variance (MANOVA) was conducted with the eight subscales of the abridged MLA as dependent variables and age, sex, and educational level as independent variables. Age had four levels corresponding to the age subsamples presented in Table 5.1. Educational level was compressed to three levels instead of eight: low (educational levels 1 and 2), medium (levels 3 to 5), and high (levels 6 to 8 ). These levels roughly correspond with primary education , junior vocationall training, and senior vocational or academic training.

The 4 (age) $\times 2$ (sex) $\times 3$ (education) MANOVA on the eight subscales of the MIA revealed significant overall effects of age $(F(24,5239)=20.33, p<.001), \operatorname{sex}(F(8,1806)=16.96, p<$ $.001)$, and education $(F(16,3612)=18.09, p<.001)$. There were no interaction effects.

Table 5.8 Mean item score per subscale of the abridged Metamemory in Adulthood Quesrionnaire as a function of age.

\begin{tabular}{|c|c|c|c|c|c|c|c|c|c|}
\hline \multirow[b]{2}{*}{ MLA subscale } & \multirow[b]{2}{*}{$R^{2}$} & \multicolumn{2}{|c|}{ Young } & \multicolumn{2}{|c|}{$\begin{array}{l}\text { Young } \\
\text { middlle-aged } \\
n=488\end{array}$} & \multicolumn{2}{|c|}{$\begin{array}{l}\quad \text { Old } \\
\text { middle-aged } \\
n=500\end{array}$} & \multicolumn{2}{|c|}{$\begin{array}{l}\text { Old } \\
n=388\end{array}$} \\
\hline & & $M$ & $S D$ & $M$ & $S D$ & $M$ & $S D$ & $M$ & $S D$ \\
\hline Task & .002 & 3.80 & 0.56 & 3.83 & 0.55 & 3.85 & 0.56 & 3.88 & 0.58 \\
\hline Capacity & .024 & 3.30 & 0.58 & 3.16 & 0.63 & 3.13 & 0.63 & 3.01 & 0.68 \\
\hline Change & .220 & 3.79 & 0.62 & 3.38 & 0.77 & 3.00 & 0.79 & 2.69 & 0.84 \\
\hline Anxiety & .061 & 2.55 & 0.65 & 2.74 & 0.71 & 2.88 & 0.73 & 3.05 & 0.75 \\
\hline Achievement & .082 & 3.60 & 0.57 & 3.70 & 0.58 & 3.95 & 0.59 & 4.04 & 0.52 \\
\hline Locus & .001 & 3.26 & 0.58 & 3.29 & 0.59 & 3.29 & 0.60 & 3.18 & 0.62 \\
\hline Strategy-ex & .002 & 3.32 & 0.73 & 3.35 & 0.80 & 3.31 & 0.80 & 3.45 & 0.86 \\
\hline Strategy-in & .003 & 3.44 & 0.68 & 3.52 & 0.72 & 3.55 & 0.74 & 3.53 & 0.78 \\
\hline
\end{tabular}

Note. Strategy-ex = external strategies; Strategy-in = internal strategies.

Follow-up univariate $F$-tests showed significant age differences on all subscales of the MIA, except for Task and Locus. We performed additional multiple comparison tests $(p<.01)$ to see which of the group means were significantly different from each other. Mean item scores on the factors for the total sample and the four age groups are shown in Table 5.8. Older adults reported less menory capacity (Capacity: $F(3,1813)=12.54, p<.001$; young and old groups differed significantly from the other groups), more decline in memory (Change: $F(3,1813)=128.60, p<$ 
.001 ; significant differences between all age groups), and more feelings of anxiety about everyday memory tasks (Anxiety, $F(3,1813)=18.70, p<.001$; significant differences between all age groups). Older adults were also more motivated to achieve woll in everyday memory tasks (Achievement: $F(3,1813)=32.30, p<.001$; significant differences between all age groups, except for the old middle-aged and old group) and used memory strategies more often (Strategy-in: $F(3,1813)=6.65, p<.001$; only significant difference between the young and old middle-aged group with $p<.05$; Strategy-ex: $F(3,1813)=4.56, p=.003$; significant difference between the old middle-aged and old groups with $p<.05$ ). In terms of the amount of variance explained, the effects of age on both Strategy subscales and Capacity were very small (less than $1 \%$ and $2 \%$, respectively). The effects Cound on Anxiety, Achievement, and especially Change were more substantial: age accounted for $6 \%, 8 \%$, and $22 \%$ of the variance, respectively. A comparison between the reported use of strategies for each strategy scale revealed a significantly higher overill use of internal strategies compared with external strategies ( $t$-test, $p<001$ ). This was the case in each of the four age groups $(p<.05)$.

Univariate analysis showed sex differences on four MIA subscales. Male participants had lower scores on Capacity $(F(1,1813)=9.22, p=.002)$ and both Strategy subscales (Strategy-in: $F(1,1813)=13.00, p<.001 ;$ Strategy-ex: $F(1,1813)=53.04, p<.001)$, whereas female participants had higher scores for Anxiery $(F(1,1813)=23.46, p<.001)$. The sex effects were small in terms of the variance accounted for: Anxiety, 2\%; Strategy-in, 1\%; Strategy-ex, 3\%; and Capacily, $1 \%$.

Effects of educational level were found on six subscales. A lower level of education was related to higher scores on Anxiety $(f(2,1813)=48.04, p<.001$; significant differences between all three groups) and Achievement $(F(2,1813)=29.667, p<.001$; significant differences between all three groups), but to lower scores on Task $(F(2,1813)=6.21, p=.002$; significant difference between the high-and low-level groups) and on both Strategy subscales (Strategy-in: $F(2,1813)=16.89, p<.001$ : the low level group differed significantly from the other two groups; Strategy-ex: $F(2,1813)=19.61, p<.001$ : the high level group differed significantly from the other two groups). Participants with a lower education level also noticed more decline in memory (Change: $F(2,1813)=4.84, p=.008$; significant differences between all three groups). The effects of educational level were substantial for Change (4\% variance explained). Achievenent (7\%), and Anxiety (9\%), but very small for the other three scales (less than $1 \%$ ).

\section{Differences on the MA between forgerfut and nonforgetful young and older subjects}

The total sample of 1899 participants was divided into a young subsample (age 24-51 years) and an old subsample (age $54-86$ years). Twenty-six participants in the young subsample and 51 in the old subsample considered themselves forgetful and were (very) worried about their forgetfulness. The young subsample had a mean age of 41 years $(S D=8.5$ ), and a rinean educational level of $2.7(S D=1.3)$, and consisted of 12 men and 14 women. The old subsample had a mean age of 69 years $(S D=8.7)$, and a mean educational level of $2.3(S D=1.6)$, and consisted of 21 men and 30 women. Both groups were perfectly matched with nonforgetful participants on age, education, and sex. Scores on the SCL depression and anxiety scales as well as the VOEG subjective health scale were significantly higher (1-test, $p<.001$ ) for the forgetful 
participants (young: depression 34.6, anxiety 21.2 and subjective health 12.4 ; old: depression 32.0 , anxiety 19.3 and subjective heath 11.2 ) compared to the scores of the nonforgetfu participants (young: depression 20.6, anxiety 13.0 and subjective health 5.2 ; old: depression 21.2 , anxiety 12.6 and subjective health 5.7 ). The scores on the depression and anxiety scales of the old and young forgetful participants corresponded with the highest ranges of a norm group of healthy subjects; those of the nonforgetful participants corresponded with the mean scores of the norm group (Arrindell \& Ettema, 1986).

Table 5.9 shows the mean item scores of the abridged MIA subscales for the four groups. A multivariate analysis (MANOVA) was perfomed on the eight subscales of the MIA, with group (old vs,young) and forgetfulness (yes or no) as independent variables and the scores on the SCL90 anxiety and depression subscales and the VOEG subjective health scale as covariates. A significant overall effect was found for forgetfulness $(F(8,140)=12.75, p<.001)$ and group $(F$ $(8,140)=5.16, p<.001)$. Follow-up univariate $F$-tests $(p<.05)$ revealed significant differences on nearly every subscale of the MIA for the forgetful and nonforgetful groups, except for the Task and Locus subscales. The strongest differences were found for Capacity, Change and Anxiety. Forgetful participants reported a far lower memory capacity, a greater decline in memory functioning, and higher anxiety related to memory performance. They were also more motivated to achieve well in everyday memory situations and used memory strategies more often. Follow-up univariate $F$-tests for the young and old groups showed significant differences on Change and Achievement. Older participants reported a greater decline in their memory functioning and had a higher level of motivation to achieve well in memory. The group $x$ forgetfulness interaction was not significant, which indicates that there were no age-specific differences on the MIA between forgetful and nonforgetful young and old participants.

Table 5.9 Mean irem score per subscale of the abridged Metamemory in Adulthond questionnaire for nonforgerfut and forgerful young and old subjects.

\begin{tabular}{|c|c|c|c|c|c|c|c|c|}
\hline \multirow[b]{2}{*}{ MA subscale } & \multicolumn{2}{|c|}{$\begin{array}{c}\text { Young } \\
\text { nonforgetful } \\
n=26\end{array}$} & \multicolumn{2}{|c|}{$\begin{array}{l}\text { Young } \\
\text { forgetful } \\
r=26\end{array}$} & \multicolumn{2}{|c|}{$\begin{array}{l}\text { Old } \\
\text { nonlorgatul } \\
n=51\end{array}$} & \multicolumn{2}{|c|}{$\begin{array}{c}\text { Old } \\
\text { forgentul } \\
n=51\end{array}$} \\
\hline & $M$ & $S D$ & $M$ & $S D$ & $M$ & $S D$ & $M$ & $S D$ \\
\hline Task & 3.88 & 0.37 & 3.87 & 0.57 & 3.62 & 0.54 & 3.90 & 0.54 \\
\hline Capacity & 3.28 & 0.50 & 2.47 & 0.68 & 3.45 & 0.55 & 2.34 & 0.71 \\
\hline Change & 3.56 & 0.58 & 2.41 & 0.78 & 3.27 & 0.67 & 1.78 & 0.60 \\
\hline Anxiety & 2.69 & 0.60 & 3.60 & 0.76 & 2.71 & 0.66 & 3.88 & 0.63 \\
\hline Achievement & 3.63 & 0.60 & 4.18 & 0.45 & 3.95 & 0.55 & 4.27 & 0.40 \\
\hline Locus & 3.31 & 0.43 & 3.26 & 0.53 & 3.37 & 0.54 & 3.00 & 0.74 \\
\hline Surategy-ex & 3.06 & 0.95 & 3.72 & 0.74 & 3.26 & 0.82 & 3.70 & 0.78 \\
\hline Strategy-in & 3.24 & 0.83 & 4.08 & 0.59 & 3.38 & 0.84 & 3.73 & 0.78 \\
\hline
\end{tabular}

Note. Strategymex = external strategies; Strategy-in = internal strategies. 


\section{Discussion}

The first goal of the present study was to investigate the correspondence between the original 108-item MIA and its Dutch version. The results of the factor analyses showed that the dimensional or factor structure of the Dutch MIA was similar to that of the original MIA. The analyses also supported a further subdivision of the Strategy scale into two subscales: internal and external memory strategies. A second godl of the study was to examine the possibility to reduce the length of the MIA, which would make the instrument easier to use in large-scale population studies. It appeared that almost one third of the items could be eliminated from the list without loss of the original factor structure. The internal consistency of the abridged subscales remained high, despite the substantial reduction in the number of items in some of the scales. Additional factor and reliability analyses with the abridged version of the MIA in three age groups showed that the factor structure was invariant over age. The test-retest stability of the complete MIA as well as that of the abridged MIA were satisfactory. Only the subscale Task had a low testretest stability, which is possibly due to the mostly long and complex statements that are used in the items of this scale. The discriminant validity of the MIA was supported by the fact that almost no relation was found between depression and anxiety and the MIA when we controlled for the possible confounding variables of age, sex, and education. The only substantial relation found was between the SCL anxiety score and MIA Anxiety, which corresponds with the findings of Hultsch, Hertzog, Dixon and Davidson (1988). Subjective health accounted for substantial amounts of variance in the MIA subscales Capacity, Change, and Anxiety. Other studies also found a relation between subjective health and subjective memory ratings (Arbuckle, Gold, \& Andres, 1986; Cutler \& Grams, 1988; Gillewski, et al., 1990). These findings suggest that health problems have a negative effect on memory functioning. However, caution is needed before any definite conclusions can be drawn. It is not clear from the present data set whether the subjective health ratings of the participants rellect actual health status, and whether a perceived decline in memory capacity reflects an actual decrease in memory functioning.

Age effects were found on five of the seven subscales of the MIA: Capacity, Change, Anxiety, Achievement, and Strategy. Previous studies did not show (or only very small) age effects on the Anxity and Achievement scales, whereas the effects in this study were substantial in terms of the amount of variance explained. Moreover, the differences among the four age groups on these two scales were all significant, except for the old middle-aged and old age groups on the Achievement scale. The age effects on the Capacity and Strategy subscales were small in terms of the amount of explained variance. Compared with younger adults, older adults see themselves as having less memory capacily. They also notice a considerable decline in memory functioning over the years, experience greater anxiety in everyday memory-demanding situations, report a higher level of motivation to achieve well in memory, and use memory strategies more often.

On the Capacity scale, the youngest and oldest age groups differed significantly from the remaining groups; no difference was found between the two middle-aged groups. This rather small age effect on the Capacity scale contrasts with the large age effect on the Change scale. If the elderly participants experienced a substantial decline in memory functioning over the past years, why did they not report a larger decrease in memory capacity than they did? A possible explanation for this is given by Hultsch, Hertzog, and Dixon (1987), who suggest that because of 
the phrasing of the questions, participants may rate their memory functioning on the Change scale relative to their own past memory performance, whereas on the Capacity scale the rating of memory functioning was adjusted to what they expected to be nomal for their age. It seems that the question whether age differences are found in self-report of memory functioning depends on the type of comparison subjects have to make, which was already pointed out by Cavenatigh (1987). Hultsch and colleagues also suggest that the elderly would not perceive this decrease in memory functioning as a problem. This, however is not in line with the age effects found on the Anxiety and Achievement scales in this study. Althougth the decline in memory performance is probably perceived as a normal aging phenomenon by the elderly participants, it nevertheless causes them greater anxiety and an increased desire not to fail in everyday memory-demanding situations.

It is puzzling why we did not find an age effect on the Locus scale, whereas all three studies with the MIA mentioned before found a consistent and reliable age effect on the Locus scale. We only found an effect in the sample of 51 forgetful older adults. There is no good reason to believe that elderly Dutch experience more personal control over their memory functioning than the elderly American people. It is possible that the content validity of this scale has changed as a result of the translation, despite the fact that the psychometric properties of the scale corresponded with those of the American version.

The age effects on the two Strategy scales were very small. Moreover, between-groups comparisons did not reveal a steady increase in strategy use over the four age groups. The suggestion of Dixon and Hultsch (1983) that elderly persons rely more on external strategies, whereas younger persons use internal strategies more often, was not supported by our findings. Several studies have also found a strong age-independent preference for using external memory strategies versus internal memory strategies (Cavanaugh, Grady, \& Perlmutter, 1983; Lovelace \& Twohig, 1990). In the present study the opposite was found, with a more frequent use of internal strategies over external strategies, independent of age.

There appear to be few and only small sex differences on the MIA. Women reported making more use of (external) strategies and higher levels of anxiety in memory-demanding situations than men, whereas men had lower memory capacity ratings. These findings are in line with the research of Hultsch, Hertzog, and Dixon (1987) and further support the notion than sex differences do not play an important role with regard to the MIA.

To date, no data are available about the possible effects of education on the MIA. We found education to have effects on five subscales, especially Change, Anxiety, and Achievement. Given that there was a significant decrease in mean educational level with increasing age, it is important to notice that these effects were independent of age, as is shown by the absence of an interaction between age and education. A lower level of education was strongly associated with greater subjective decline in memory and, probably as a result of this, greater anxiety in memory-demanding situations and a higher level of motivation to achieve well on every memory tasks. The effects found on Task and both Strategy subscales indicate that a higher level of education is related to more general knowledge about memory and more use of strategies. These effects were, however, small in terms of their explained amount of variance.

A comparison between subsamples of participants who considered themselves forgetful and who were (very) worried about this forgetfulness and groups of subjects who did not consider themselves forgetful showed that forgetful participants were far more anxious and depressed. 
They also considered themselves less healthy. There were no age-specific differences on the MIA between forgetful and non-forgetful young and old participants. However, in their self-appraisal of memory the forgetful participants especially reported a far lower memory capacity, a greater memory decline, and higher anxiety related to memory. Although we do not have information about the actual memory skills of the forgetful participants, these findings are important when treatment of memory problems is considered. Such treatment should not only explain the relation between affective state and experienced memory problems, but should also focus on modifying negative beliefs about memory competence (Cavanaugh \& Green, 1990; Lachman, Weaver, Bandura, Elliott, \& Lewkowicz, 1992).

In sum, the present study supports the cross-national use of the MIA as a multidimensional research and clinical instrument for measuring the self-appraisal of memory. A substantial shortening of the MIA seems to be warranted and would make the questionnaire more practical for large scale population research.

\section{References}

Arbuckle, T. Y., Gold, D., \& Andres, D. (1986). Cognitive functioning of older people in relation to social and personalify variables. Jound of Psychology and Aging, 1, 55-62.

Arbuckle, T. Y., Gold, D. P., Andres, D., Schwartzman, A., \& Chaikelson, J. (1992). The role of psychosocial context, age, and intelligence in memory performance of older man. Pychology and Aging. 7, 25-36.

Arrindell, W. A., \& Eittema, J. H. M. (1986), SCL-90. Een multidimensionele psychoparhologie indicator (The SCL.90. A multidimensional instrumen far the assessment of psychoparhology). Lisse, The Netherlands: Swets Zeillinger. Bandura, A. (1989). Regulation of cognitive processes through perceived self-efficacy. Developmental Psychology,
25,729-735.

Bollen, K. A. (1990). Overall fit in covariance structure models: two types of sample size effects. Psychological Bullesin, 107, 256-259.

Cavanaugh, J. C. (1987). Age differences in adults' self-reports of memory ability: It depends on how and what you ask. Inemational Journal of Aging and Hwman Development, 24, 271-277.

Cavanaugh, J. C., Grady, J. G., \& Perlmutter, M. (1983). Forgetting and use of memory aids in 20 to 70 year olds everyday life. Imternational Joumat of Aging and Human Dewelopment, 17, 113-122.

Cavaraugh, J. C. \& Green, E. E (1990). I believe, therefore I can self-efficacy beliefs in memory aging. In E. A Lovelaco (Ed.), Aging and cognition: mental processes, selfawateness and inerventions (pp. 189-229). Amsterdam, the Netherlands: Elsevier Science.

Cavanaugh, J. C.. \& Poon, L. W. (1989). Metamemorial predictors of memory performance in young and older adults. Psychology and Aging, 4, 365-368.

Craik, F. I. M. \& Jennings, J. M. (1992). Human memory. In F. I. M. Craik \& T. A. Salthouse (Eds.), Handbrok of aging and oognition (pp. 51-110). Hillsdale: Lawrence Erlbaum.

Cutter. S. J., Grams, A. E. (1988). Conrelates of selfreported everyday memory problems. Journat of Gerontology: Social Sciences, 43,82-90.

de Bie. S. E. (1987). Siandadrdwagen 1987 . Voorstellen woor wriformering van vradgstellingen naar achtergrond. kenmerken en interwiews (Toward a standardization of questions concerwing demographic variables in population studies) (2nd ed.). Leiden, the Netherlands: Leiden University Press.

Derogatis, L. R. (1977). SCL-90: Administration, scoring and procedures mamal-l for the R(evised) version. Baltimore: Johns Hopkins School of Medicine, Clinical Psychometrics Research Unit.

Dirken, J. M. (1967). Het weten van stress in industriete situaties (The measkremen of stress in industrial situarionsi). Groningen, The Neherlands: Woters.

Dixon, R. A. (1989). Questionnaire research on metamenory and aging: Issues of structure and function. In L.W. Poon, D. C. Rubin, \&. B. A. Wilson (Eds.). Everyday cognition in adidthood and late life (pp. 394-415).
Cambridge: Cambridge University Press.

Dixon, R. A., \& Hultseh, D. F. (1983). Structure and devellopment of metamemory in adulthood. Journal of
Gerontology, 38, 682-688. 
Dixon, R. A., Hultsch, D. F., \& Hertzog, C. (1988). The metamemory in adulthood MA) questionnaire. Psychophamacology Bulleth, 24, 671-688.

Enzmantin D. (1993). PECON 20 (PErfect CONgruence). Berlin: Sozialpädagogisohes Institut Berlin.

Gilewski, M. J., \& Zelinski, E. M. (1986). Questionnaire assessment of memory complatints. In L. W. Poon (Ed. Handbook for clinical memory assessmen of older adults (pp. 93-107). Washington: American Psychological Association.

Gilewski, M. J., Zelinski, E. M. \& Schaie, K. W. (1990). The memory functioning questionmaire for assessmem of memory complaints in adulthood and old age. Psychology and Aging. 5, 482-490.

Hertzog, C. Hultseh, D. F, \& Dixon, R. A. (1989). Evidence for the convergent validity of two self-repor metamemory questionnaires. Developmental Psychology, 25, 687-700.

Houx, P. J., \&olles, J. (1994). Vulnerability factors for age-related cognitive deeline. In R. L. Isacson \& K. F. Jenssen (Eds.), The walnerable brain and environmental risk (pp. 25-41). New York: Plenum Press.

Hultsch, D. $F_{n}$. Hertzog, C., \& Dixon, R. A. (1987). Age differences in metamemory: Resolving the inconsistencies. Canadian Jownal of Psychology, 41, 193-208.

Hultsch, D. F., Hertzog, C. Dixon, R.A., \& Davidson, H. (1988), Memory self-knowledge and selfeefficacy in the aged. In N. L. Lowe \& C. J. Brainerd (Eds.), Cognitive developmen in adulthood: Progress in cogninive developmental research (pp. 65-92). New York: Springer-Verlag.

Jolles, I., Houx, P.J., van Boxtel, M.P.J., \& Ponds, R.W.H.M. (1995). Maastricht Agung Study. Deteminants of cogritive aging. Maastricht, the Netherlands: Neuropsych Publishers.

Jöreskog, K. G., Sörbom, D. (1989). LISREL 7. A guide to the progran and applications. Chicago: SPSS Inc.

Lachman, M. E., Weaver, S. L., Bandura, M., Elliott, E., \& Lewkowicz, C. I. (1992). Improving memory and control beliefs through cognitive restrueturing and self-generated strategies. Journal of Gerontology: Psychological Sciences, 47, 293-299.

Light, L. L. (1991). Memory and aging: Four hypotheses in search of data. Annual Review of Psychology, 42 , $333-376$.

Lovelace, E. A. (1990). Aging and metacognitions concerning memory function. In E. A. Lovelace (Ed.). Agüng and cognition: Mental processes, self awareness and interventions (pp. 157-188). North-Holland: Elsevier Science Publishers.

Lovelace, E. A., \& Twohig, P. T. (1990). Healthy older adults' perceptions of their memory functioning and use of mnemonics. Bulletin of Psychononic Society, 28, 115-118.

Metsemakers, J. F. M., Höppener, P., Knotnerus, J. A., Kocken, R. J. J., \& Limonard, C. B. G. (1992). Computerized health information in the Netherlands: A registration network of family practices. British Jowrval of General Practice, 42, 102-106.

Ten Berge, J. M. F. (1986). Rotation to perfect congruence and the cross-validation of components weights across populations. Multivariate Behavioral Research, 2l, 41-64.

Zelinski, E. M., \& Gilweski. M.J. (1988). Assessment of memory complaints by rating scales and questionnaires. Pyschophamarology Bulletin. 24, 523.529. 



\title{
Predictors of subjective memory as measured with the Metamemory in Adulthood (MIA) questionnaire*
}

\begin{abstract}
In the present study several determinants of subjective memory were assessed in a large cross-sectional study involving more than 1300 healthy adults aged 24 to 83 years. Subjective memory was measured by using four subscales of the abridged Dutch Metamemory in Adulthood (MIA) questionnaire: Capacity, Change, Anxiety, and Locus of Control. Different hierarchical regression models (with the MIA subscales as dependent variables) were compared in which the order of entry of the predictor variables was systematically changed. There were three blocks of predictor variables: subject background variables (age, sex, and education), cognitive compound measures (episodic memory, semantic memory, and speed), and psychological measures (distress, subjective health, worry of dementia, and health locus of control). Our findings suggested that self-evaluation of different aspects of subjective memory functioning is predicted mainly by psychological measures that reflect different aspect of competence (e.g., health) and well-being (e.g., distress). Age uniquely contributed to perceived change in subjective memory and perceived memory capacity. Neither actual memory ability nor basic cognitive processes, such as speed and attention, were related to self-appraisal of daily memory functioning.
\end{abstract}

* Ponds, R.W.H.M., Rozendaal, N., Jolles, J. (submitted) 


\section{Introduction}

There are numerous studies that focus on the relationship between subjective memory and objective memory. Althougt aging is clearly associated with a decline in perfomance on most memory tasks, and most older adults report a decline in their subjective memory functioning, cross-sectional correlations of self-reported memory functioning and mernory performance on either Jaboratory or standard clinical memory tests are lacking or at best modest (McDonald. Miszczak. Hertzog \& Hultsch, 1995; Ponds \& Jolles, 1996b; Srith, Petersen, Ivnik, Malec \& Tangalos, 1996; Zelinski, Gilewski \& Anthony-Bergstone, 1990; Zelinski, Gilewski \& Shaie, 1993).

It is often argued that this absence of a relation between subjective and objective memory is in part related to shortcomings of the measurement instruments used (Rabbitt \& Abson, 1990; Rabbitt, Maylor, McInnes, Bent \& Moore, 1995; Zelinski \& Gilewski, 1988). Laboratory memory tasks lack ecological validity and do not share the characteristics of everyday demands on memory. Another problem is that individuals with poor memories may "forget that they forgot" and therefore underestimate their daily memory failures when completing memory questionnaires.

Another explanation for the discrepancy between objective memory and subjective memory is that they are mediated by different sets of variables and that they have a rather small set of mediating variables in common. Age may be one such common variable. However, age may give rise to spurious correlations because its effects are based on two unrelated processes, namely the normal age-related decline in memory performance and the decline in memory reported by older adults that is based on, for example, the wideheld societal belief that memory declines with age (implicit theory of memory and aging" - McFarland, Ross \& Giltrow, 1992; McDonald-Miszczak et al., 1995). If self-appraisal of memory is not bused on actual memory ability, the correlation will disappear or will be substantially lower if age is partialled from both variables.

Memory performance not only depends on memory processes but also on other, more basic cognitive processes, like attention or speed of information processing, and intellectual variables, like reasoning or wocibulary. Individual and age-related differences in memory may be in part explained by differences in these more elementary cognitive processes (Hultsch, Hertzog \& Dixon, 1990; Taylor, Miller \& Tinklenberg, 1992; Zelinski et al., 1993). Ratings of subjective memory may be influenced more by personality traits, affective state, subjective health, societal beliefs about memory and aging, and memory self-efficacy beliefs. For example, elderly people with memory complaints have far higher scores on scales for neuroticism (Ponds \& Jolles, 1996b) or hypochondrid (Haininen et al, 1994) than elderly people without such memory complaints. Several studies have shown that lower subjective memory ratings or the presence of memory complaints is strongly associated with depressed mood or psychological distress (e.g., Bolla, Lindgren, Bonaccorsy \& Bleecker, 1991; Derouesné et al., 1989; Smith et a1., 1996) as well as lower subjective health (e.g., Cutler \& Grams, 1988). The influence of societal beliefs about memory and aging was demonstrated by Ryan and Kwong See (1993). They showed that individuals anticipated decline in memory when asked to rate their expected memory capacity and change at older age on the Capacity and Change subscales of the Metamemory in Adulthood (MIA) questionnaire (Dixon, Hultsch \& Hertzog, 1988). Finally, memory self-efficacy or personal belief in one's own memory ability influences subjective ratings of daily memory 
functioning (Cavanaugh \& Green, 1990; Cavenaugh, 1996).

We have recently found that health locus of control is also associated witl subjective memory as measured with the MA (Stevens, Kaplan, Ponds, Diederiks \& Jolles, submitted). People with an internal locus of health control had a larger perceived memory capacity and people with an extemal health locus of control were more anxious about their memory. We also found that worry of dementia was a strong predictor of complaints about forgetfuness or low subjective memory ratings (Commisaris, Ponds \& Jolles, in press; Commissaris, Verhey, Ponds, Jolles \& Kok, 1994).

We assessed several determinants of subjective memory in a large cross-sectional study inwolving more than 1300 healthy adults in the broad age range of 24 to 83 years. Different aspects of subjective memory were measured using four subscales of the abridged Dutch Metamemory in Adulthood questionnaire (Ponds \& Jolles, 1996a). These were perceived memory capacity (Capacity), perceived change or decline in memory functioning (Change), perceived anxiely in relation to memory performance (Anxiety), and perceived control over memory (Locus of Control). Although weak correllations have been found between these MIA subscales and performance on memory tasks (e.g., Dixon, 1989; Hertzog, Dixon \& Hultsch, 1990; Luszcz, 1993), we expected that the age-related variation in the scores on these scales would be mainly determined by psychological variables (distress, subjective health, worry of dementia, and health locus of control) and subject background variables (age, sex, and education). Episodic and semantic memory tasks and tasks that measure speed of information processing and attention were used as cognitive performance measures. We were especially interested in the possibility that basic cognitive processes, like speed and attention, might be more directly linked to daily memory functioning and failure than the typical laboratory memory tasks, because a reduced speed of information processing is assumed to have a broad impact on encoding and retrieval processes (Salthouse, 1988; Taylor, Miller \& Tinklenberg, 1992).

As we expected most of our predictor variables to be highly correlated, we compared different hierarchical regression models in which the order of entry of the predictor variables was systematically changed. This approach, which we adopted from a study by Zelinski, Gilewski, and Shaie (1993), allowed us to determine the relative or 'unique' contribution of each of the predictor variables to the amount of wariance explained.

\section{Method}

\section{Participants}

The study was part of a larger research program on determinants of normal cognitive aging, the Mastricht Aging Study (MAAS; Jolles, Houx, van Boxtel \& Ponds, 1995). Participants were recruited from the Registration Network Family Practices (RNH; Metsemakers, Höppener, Knottnerus, Kocken \& Limonard, 1992). This register contains the background characteristics and past and current medical morbidity of 60,000 patients in 15 general practices in the region of Mastricht. All selected participants were personally invited by their family doctor to take part in MAAS. Individuals with previous or current medical conditions with known impact on cognitive 
and/or motor functions were excluded. Exchusion criteria were overt cerebrovascular disease, chronic neurological pathology (e.g., dementia, epilepsy, parkinsonism), mental retardation, and major psychiatric disorders. MAAS started in March 1993 with four successive cross sectional panel studies which lasted through December 1995. Eact panel study had the same methodology with respect to sample frame, subjects inclusion, stratification criteria, and basic measurements. The last three panel studies of MAAS were used and combined in the current study.

Participants were stratified for age ( 12 discontinuous age classes, ranging from $25 \pm 1$ years, $30 \pm 1$ years, $1080 \pm 1$ years), sex, and level of general ability (two levels, based on the achievement in professional life) in order to control for these background variables which themselves may affect cognitive functioning. Educational level was measured by a Dutch scoring system (de Bie, 1987) which consists of an 8-point scale, ranging from unfinished primary eduction (level 1) to university education (level 8). Eighty-one people were excluded from the ariginal group of 1397 participants because of missing data on one or more of the main variables in the study. The remaining 1316 individuals consisted of 660 men and 656 women. The mean age was 51 years (range 24 to 83 years) and the mean level of education was 3.7 (range 1 to 8 ). Increasing age was associated with a lower level of education $(r=-.34, p<.000)$. The 81 participants (40 men and 41 women) who were excluded from the study due to missing data were older (mean age 64 years) and lower educated (mean level 2.4) than the remaining participants in the study.

\section{Measures and procedure}

Questionnaire measures. All participants filled in a postal questionnaire pertaining to socioeconomic background, medical history, subjective cognitive functioning, and psychological well-being. The following measures were taken from the questionnaire.

Subjective memory. Four scales of the abridged Dutch Metamemory in Adulthood (MIA) questionnaire (Ponds \& Jolles, 1996a) were used to evaluate subjective memory functioning. The Capacity scale has 12 items and higher scores indicate more memory capacity. The Change scale has 10 items and higher scores indicate less decline or more stability in memory functioning. Higher scores on the 12-item Anxiety scale reflect more feelings of stress and anxiety in relation to memory performance. Higher scores on the 7-item Locus of Control scale indicate more control over memory.

Psychological distress. Feelings of depression and anxiety were measured with the subscales Depression and Anxiety of the revised version of the Symptom Checklist (SCL-90: Derogatis, 1977; Dutch version: Arrindell \& Ettema, 1986). The SCL-90 is a multidimensional self-report inventory of current psychopathology. Items are rated on a 5-point scale. The subscale Anxiety consists of 10 items and measures feelings of generalized anxiety (score range 5-50). The subscale depression contains 16 items which reflect symptoms of depression (score range 16-80). Because the two scales were highly interconelated $(r=.76)$, they were combined into one distress score (items of both seales were summed). Higher scores indicate more distress.

Subjective health. Subjective health was measured with the VOEG ("Vragenlijst Omtrent Evaren Gezondheid' - Inventory of Subjective Health), which was originally developed by Dirken (1967). It has been used in several large surveys in the Netherlands to measure subjective liealth status. The 21 -item version administered in this study probes health complaints of a somatic and 
psychosomatic nature. The score range is 0-21. Higher scores indicate more complaints.

Health locus of control. Nine items of the original three dimensional 18 -item Health Locus of Control instrument (Wallston \& Walston, 1981) were selected for the postal questionnaire. For" each dimension three items were taken, based on a Dutch validation study of Halfens (1985). The three dimensions or subscales, each with a score range of 3 to 15 , were Internal orientation (e.g., "My health is mainly determined by what I do myself"; $\mathbb{1}=$ strongly disagree, 5 = strongly agree; higher scores indicate a more internal orientation), Chance or Fatalism orientation (e.g. "My health is mainly a question of good genes and luck"; higher scores indicate stronger chance orientation), and Physician or Powerful Others orientation (e.g., "Doctors determine my health": higher scores indicate stronger orientation towards physicians).

Worry about dementia. Participants could indicate on a 5-point scale how worried they were about becoming demented in the future, ranging from "not worried at all" (score 1) to "very much worried" (score 5).

Cognitive performance measures. Participants underwent an extensive neuropsychological examination 3-4 weeks after they had completed the postal questionnaire. Neuropsychological tests were used to assess the cognitive domains of menory and simple and complex information processing.

Letter-Digit Substitution Test. (LDST) This test is a modification of the procedurally identical Symbol-Digit Modalities Test (Lezak, 1995). It is used as a measure of the speed of processing of general information, i.e., the test is supposed to draw upon several (cognitive) processes such as visual perception, attention, and memory. Participants are instructed to copy numbers in cells indexed by a letter. The letter refers to nine letter/number combinations at the top of the form. The variables of interest are the number of correctly coded letter-digit combinations made in 90 seconds under two conditions. In the first condition, participants fill in the digits corresponding to the letters with a pencil (written version). In the second condition, they have to say the digits aloud and the examiner records their answers (oral version).

Concept Shifting Test (CST; Houx \& Jolles, 1994). This test is derived from the Trail Making Test (Lezak, 1995), which is used to measure the ease of shifting between concepts. There are three task conditions: the participant has to cross out, in the proper order, 16 circles containing only digits ( 1 to 16; part $A$ ), letters ( $A$ to $P$; part $B$ ), or both ( $1-A-2-B$, etc; part $C$ ). In the latter subtest, participants have to shift between the concepts 'digits' and 'letters'. The variables of interest are the times needed to complete each subtest.

Siroop Color-Word Test (SCWT; Lezak, 1995). The Stroop test is a test for selective attention and interference susceptibility. The test involves three cards displaying hundred stimuli each: color names (Card I), colored patches (Card II), and color names printed in incongruously colored ink (Card III). For the last card, the color of the ink has to be named instead of the color name. Performance of this task is especially susceptible to interference. The wariables of interest are the times needed to complete each card.

The Visual Verbal Learning Test (VVLT; Brand \& Jolles, 1985). The VVLT is a computerized, visual version of the Auditory Verbal Learning Test (Lezak, 1995). A set of 15 frequently used monosyllabic meaningful words is visually presented in a fixed order at a rate of one every 2 seconds in five consecutive trials. After each trial or presentation the participant is requested to recall as many words as possible with no restriction concerning the order of recall 
(immediate recall). Twenty minutes after the fifth presentation, the participant is again requested to recall as many words as he or she car remember (delayed recall). After the delayed recall, recognition is tested in which the participant has to recognize the 15 words of the test, which are mixed with 15 new words. The variables of interest are the total number of correctly remembered words over trials 1-5 (immediate recall), the naximum number of words in trials 1-5, the number of words remembered on delayed recall, and the number of correctly recognized words at delayed recognition. This test measures memory storage and retrievall of verbal information in episodic memory.

Fluency. In the fluency task, the participant is asked to name as many different animals or professions as possible in 60 seconds. This test measures strategy-driven retrieval from semantic memory. The variables of interest are the number of correctly named animals or professions.

\section{Data reduction}

To reduce the number of dependent test variables, we performed a factor analysis (principal components analysis - PCA - with oblique rotation) on the data for the total study sample (Eigenvalue $>1$ ). The PCA suggested a robust three-factor solution, which accounted for $73 \%$ of the variance. All variables of the CST, the SCWT, and the LDST loaded on one factor (factor lloadings ranging from .76 10 .87). Because these tests basically measure speed of simple and more complex information processing, we termed this factor Speed. All variables of the VVLT loaded strongly on the second factor (factor loadings ranging from .81 to.91), which we termed Episodic Memory because this test measures the encoding and retrieval of new inliormation. Both fluency tasks (animals and professions) loaded on the third factor (factor loadings .85 and .93 respectively), which we termed Semantic Memory.

To control for possible age differences in this factor structure, the same PCA was repeated in a young subsample (24-52 years, $n=689)$ and an old subsample $(54-83$ years, $n=583)$. In both subsamples a four-factor solution was found. The Speed factor split up into a factor including all three SCWT variables and a factor including the variables of the CST and the LDST. A PCA for the total group, allowing four factors to be extracted, also revealed a fourth Stroop factor (Eigenvalue .88).

Based on these results, we performed a confirmatory factor anallysis (CFA) with the LISREL 8 program (Joreskog \& Sorbom, 1996) to decide which of the two factor structures (three or four factors) would best summarize the data set. The three-factor model (Speed, Episodic Memory, and Semantic Memory) fitted the data well, when we allowed the three error terms of the SCWT and the two error tems of the LDST to correlate. The ratio chi-square test was significant, $X^{2}$ $(70, N=1.272)=291.50, p<.001$, which was expected given the large sample size, but the Non-Normed fit index (NNFI), which is less influenced by sample size was .98 , which indicates a good model fit. As expected, the four-factor model (Speed factor consisting of the LDST and the CST, SCWT factor consisting of the three SCWT measures, Episodic Memory, and Semantic Memory) also gave a good model fit, when we allowed two error terms of the LDST to correlate: $X^{2}(70, N=1,272)=436.17, p<.001 ; N N F I=.97$. The value of the chi-square, however, was higher for the four-factor model. The model also indicated that a substantially better fit would be found if two of the three SCWT variables (Card II and III) were also to load on the Speed factor. Furthermore, there was a substantional correlation between the Speed and Stroop factor (.78). 
Taking parsimony into account, we decided that the three-factor solution was preferable to the four factor solution.

A multi-sample analysis with LISREL was conducted with the young and old subsample as a formal test of the age-invariance of the three-factor solution for the test data. In the multi-sample analysis for which the covariance matrices of the test variables of each group were used as input, the chi-square is a measure of fit of all models in all subsamples. In the first model specified, factor loadings, factor correlations, and error wariances were equal for the wo subsamples, which resulted in a weak model fit: $X^{2}(175, N=1,272)=1285,9, p<.001 ; N N F I=.90$. In a second, less constrained model, the error variances were allowed to be different for both subsamples, retaining the invariance of the factor correlations and factor loadings. This resulted in a good model fit with a substantially lower chi-square: $X^{2}(161, N=1,272)=578.3, p<.001 ; N N F I=$ 96. The contribution to the chi-square of the young subsample was $265.9(46 \%)$, the old subsample contributed $312.4(54 \%)$. These findings indicate that the three-factor structure of the test scores was invariant over age.

On the basis of the findings of the factor analyses, the test scores were clustered in three compound performance indices: Episodic Memory (including the total, maximal, and delayed recall, and the recognition scores of the VVLT), Semantic Memory (including Fluency animals and Fluency professions), and Speed (including part A, B, and C from the CST, Card I, II, and III from the SCWT, and the scores of the oral and written versions of the LDST). The compound score was the average $Z$-score for the test scores that were included in the compound performance index. The signs of the test scores of the Speed compound index were inverted so that for all threa compound performance indices a positive score reflects above average performance and a negative score reflects below average performance.

\section{Statistical analysis}

We performed multiple hierarchical regression analyses with the four separate MIA subscales as dependent variables and the demographic or subject background wariables (Block 1: age, sex, and education), the cognitive compound scores (Block 2: Episodic Memory. Semmnic Memory, and Speed), and the psychological variables (Block 3: distress, subjective health, three subscales of the Health Locus of Control scale, and worry about dementia) as independent variables of predictors. We entered the three blocks of predictors in different sequences, to look at the relative contributions of each set of predictors (especially the demographic variables) when entered early or late in the regression. In the first regression model (model 1) the order of entry was blocks 1-2-3. In model 2 the order of entry was blocks $2-3-1$ and in model 3 blocks $3-2-1$. Because of the large sample size, we set the level of significance for a predictor variable for entering into the regression model at $p<.01$. To control for possible differential effects of the predictor variatles as a function of age (e.g., stronger influence of worry of dementia at especially old age), we tested interactions of age with all the predictor warables by entering this block of 11 interactions last within each model. We did not find any contribution of these interactions. 


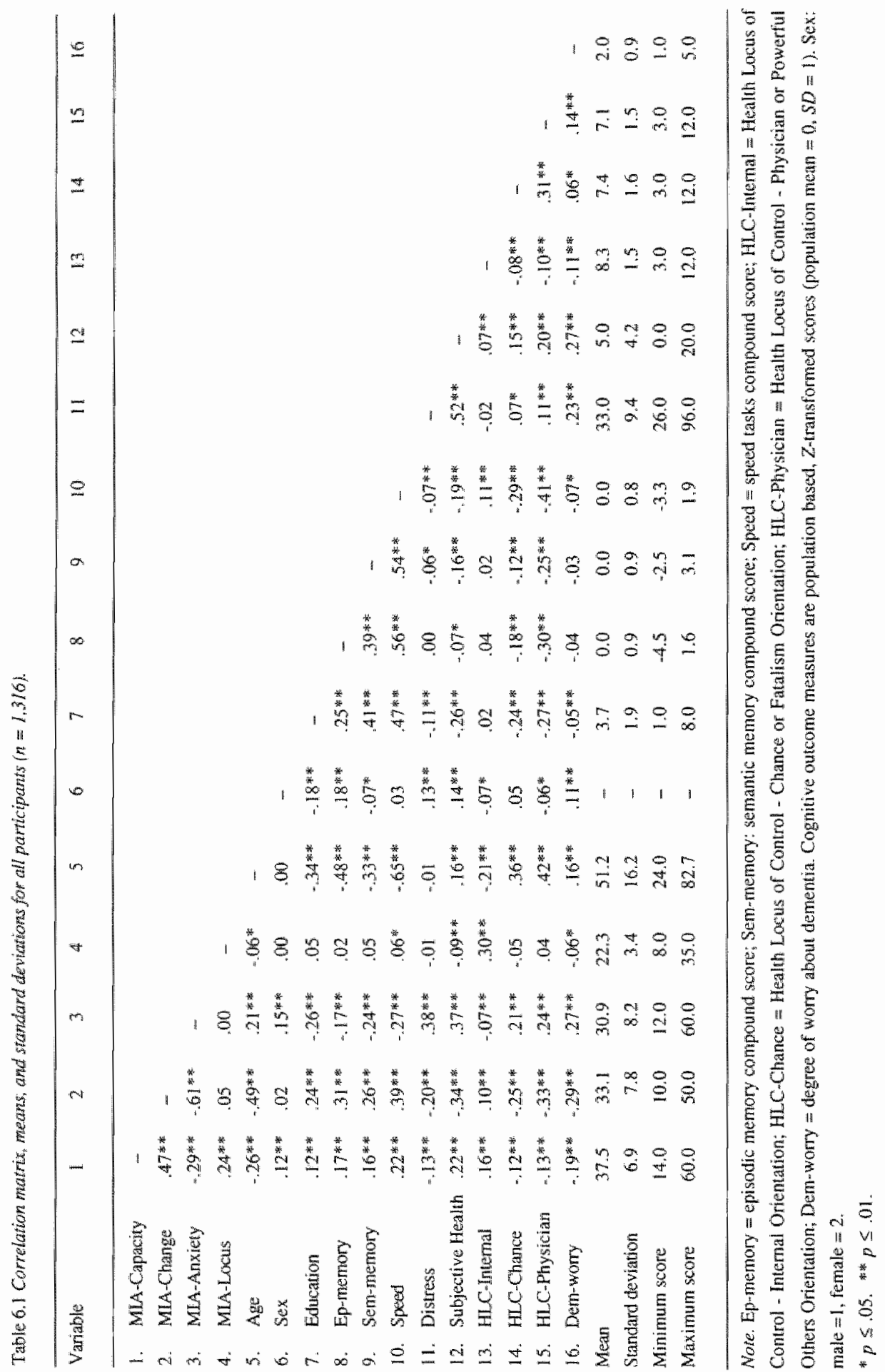




\section{Results}

\section{Correlations}

Table 6.1 shows the zero-order correlations between all the variables and their maans, standard deviations, and minimum and maximum values in the sample. In accordance with the findings of Ponds and Jolles (1996a), the MA subscales Capacity, Change, and Anxiety were significantly correlated, whereas the MIA Locus of Control subscale correlated with the MIA Capacity scale only. The correlation between Anxiety and Change was very high, $r=-.61$, indicating that a high subjective decline in memory was strongly associated with more anxiery about memory. Almost every predictor variable was significantly correlated with the MlA subscales Capacity, Change, and Anxiety. This may be because both the MIA subscales and the predictor variables shared a large part of their variance with age. Age correlated highly with the three MLA subscales and all predictor variables, except distress. Older age was associated with less memory capacity, greater decline in memory performance, more feelings of anxiety about everyday memory tasks, poorer performance on all cognitive tests, more health complaints, a lower internal control orientation towards heallth, and more worry about dementia.

\section{Regression analyses}

MIA Capacity. The overall amount of variance in MIA-Capacity explained by the three models was 15\% (Table 6.2). Significant predictor variables in all three models were age, sex, subjective health, worry about dementia, and control orientation towards health. Age made a substantial contribution when entered in the model first $(7 \%)$, but this percentage dropped to $1 \%$ when age was entered later. The contribution of sex ranged from $2 \%$ to $3 \%$. Older age was associated with lower memory capacity, especially among the male participants. Subjective health, worty about dementia, and health locus of control orientation were not only reliable predictors in all three the models, but their contribution to the amount of variance explained was more or less constant, ranging form $3 \%$ to $5 \%$ for subjective health, $2 \%$ for worry about dementia, and $1 \%$ to $2 \%$ for health locus of control orientation. Lower scores for memory capacity were related to more subjective health complaints, more worry about dementia, and lower internal health locus of control orientation. Speed accounted for $5 \%$ of the variance when the cognitive compound scores were entered in the model first, and $2 \%$ when the psychological variables were eniered first and the cognitive performance variables second. When age was entered first, no contribution of Speed was found, suggesting that the common variance of Speed and MIA Capacity was mainly shared with age. The contribution of the wo memory compound scores in Models 1 and 3 was very low and did not reach $1 \%$.

MiA Change. Table 6.3 shows the results of the regression analysis for MIA Change. Because the predictor variables entered in all three regression models were nearly identical the final amount of wariance explained by each model was equal $(35 \%)$. Of the demographic variables, only age made a substantial contribution to the variance in all three models, with older age being associated with more subjective memory decline. When the demographic variables were entered first, age 
Thble 6.2 Siepwise hierarchical multipte regression of subject background variables on MA Capacity.

\begin{tabular}{|c|c|c|c|c|c|c|}
\hline \multicolumn{2}{|c|}{ MA Capacity } & \multirow{2}{*}{$\frac{\text { Beta }}{-.17}$} & \multirow{2}{*}{$\begin{array}{c}\text { FChange } \\
96.9\end{array}$} & \multirow{2}{*}{$\frac{p}{.000}$} & \multirow{2}{*}{$\begin{array}{c}R^{2} \text { Change } \\
.068\end{array}$} & \multirow{2}{*}{ Cumulative $R$} \\
\hline Modell & Age & & & & & \\
\hline & $\operatorname{sex}$ & .17 & 21.0 & .000 & .015 & .083 \\
\hline & Sem-mermory & .08 & 9.5 & .002 & .007 & .090 \\
\hline & Subjective Health &. .16 & 54.0 & .000 & .036 & .126 \\
\hline & Dem-worry & -.13 & 25.8 & .000 & .017 & .143 \\
\hline & HLC-Internal & .11 & 16.7 & .000 & .011 & .154 \\
\hline \multirow[t]{6}{*}{ Model 2} & speed & .06 & 64.4 & .000 & .047 & .047 \\
\hline & Subjective Heallith &. .16 & 47.2 & .000 & .033 & .080 \\
\hline & Dem-worry & -.13 & 26.8 & .000 & .018 & .098 \\
\hline & HLC-Intenal & .10 & 19.0 & .000 & .013 & .111 \\
\hline & Sex & .16 & 39.8 & .000 & .026 & .137 \\
\hline & Age & -.15 & 19.6 & .000 & .013 & .150 \\
\hline \multirow[t]{8}{*}{ Model 3} & Subjectiwe Health & -.16 & 66.2 & .000 & .048 & .048 \\
\hline & HLC-Linternal & .11 & 28.5 & .000 & .020 & .068 \\
\hline & Dem-worry & -.13 & 23.0 & .000 & .016 & .084 \\
\hline & HLC-Chance &. .02 & 8.3 & .004 & .006 & .090 \\
\hline & Speed & .05 & 32.9 & .000 & .022 & .112 \\
\hline & Ep-memory & .03 & 7.9 & .005 & .005 & 118 \\
\hline & Sek & .16 & 35.2 & .000 & .023 & .141 \\
\hline & Age & -.14 & 15.5 & .000 & .010 & .151 \\
\hline
\end{tabular}

Note. Ep-niemory = episodic memory compound score; Sent-memory: semantic memory compound score: Speed = speed tasks compound score; HLC-Internat = Health Locus of Control - Internal orientation: HLC-Chance = Health Loets of Control - Chance or Fatalism Orientation; Dem-worry = degree of worry about dementia. Beta = standardized regression coefficient in the final model.

accounted for $24 \%$ of the variance. When the demographic variables were entered last (Models 2 and 3), age still accounted for $5 \%$ of the variance. The contribution of the cognitive compound scores was largely mediated by age. Contributions of Speed and Episodic Memory were found in Model 2 (15\% and $1 \%$ respectively) and Model $3(5 \%$ and $1 \%$ ) when both variables were entered before age. When the demographic variables were entered first in Model 1 , only a very small contribution was found for Semantic memory $(<1 \%)$. Subjective health and worry about 
Table 6.3 Stepwise hierarchical maltiple regression of subject background woriables on MIA Chonge.

\begin{tabular}{|c|c|c|c|c|c|c|}
\hline \multicolumn{2}{|c|}{ MIA Change } & \multirow{2}{*}{$\begin{array}{l}\text { Beta } \\
-.36\end{array}$} & \multirow{2}{*}{$\begin{array}{c}F \text { Change } \\
408.2\end{array}$} & \multirow{2}{*}{$\begin{array}{c}p \\
.000\end{array}$} & \multirow{2}{*}{$\begin{array}{c}R^{2} \text { Chothge } \\
.237\end{array}$} & \multirow{2}{*}{$\begin{array}{c}\text { Cunnulofine } \mathrm{k}^{2} \\
237\end{array}$} \\
\hline Modtel! & Age & & & & & \\
\hline & Education & -.01 & 10.1 & .002 & .006 & .243 \\
\hline & Sem-memory & .08 & 12.1 & .007 & .007 & .250 \\
\hline & Subjective Health & -.21 & 116.3 & .000 & .061 & .311 \\
\hline & Dem-wory & -.16 & 48.7 & .000 & .025 & .336 \\
\hline & HLC-Pysician & .09 & 13.5 & .000 & .007 & 342 \\
\hline \multirow[t]{7}{*}{ Madel 2} & Speed & .04 & 229.9 & .000 & .149 & .149 \\
\hline & Ep-memory & .08 & 20.0 & .000 & .013 & .162 \\
\hline & Subjective Flealch & -.21 & 130.4 & .000 & .076 & .237 \\
\hline & Dem-worry & -.16 & 69.0 & .000 & .038 & .276 \\
\hline & HLC-Physician &. .07 & 26.5 & .000 & .014 & .290 \\
\hline & HLC-Chance & -.05 & 14.9 & .000 & .008 & .298 \\
\hline & Age & -.31 & 90.4 & .000 & .049 & .347 \\
\hline \multirow[t]{7}{*}{ Model 3} & Subjective Health & -.21 & 168.9 & .000 & 114 & .114 \\
\hline & HLC-Physician & -.07 & 112.4 & .000 & .070 & .184 \\
\hline & Demaworry &. .16 & 54.8 & .000 & .033 & .217 \\
\hline & HLC-Chance & -.05 & 30.3 & .000 & .018 & .234 \\
\hline & Speed & .04 & 95.8 & .000 & .052 & .286 \\
\hline & Ep-memory & .08 & 21.6 & .000 & .012 & .298 \\
\hline & Age & -.31 & 97.4 & .000 & .049 & .347 \\
\hline
\end{tabular}

Note. Epwmemory = episodic memory compound score; Sem-memory: semantic memory compound score, Speed = speed tasks compound score; HLC-Chance $=$ Health Locus of Control - Chatrce or Fatalism Orientation: HLCPhysician $=$ Health Locus of Control - Pysician or Powerful Others Orientation; Dem-wory $=$ degree of worry about dementia. Beta $=$ standardized regression coefficient in the linal model.

dementia made significant contributions in all three models. Amount of variance explained by subjective health ranged from $6 \%$ to $11 \%$, that for worry about dementia ranged from $3 \%$ to $4 \%$, with lower subjective health and more worry about dementia leading to a greater perceived decline in subjective memory. Two of the three Health Locus of Control subscales, Chance orientation and orientation towards Physician, also seemed to be mediated mainly by age. These variables 


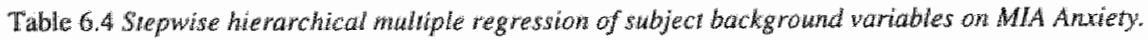

\begin{tabular}{|c|c|c|c|c|c|c|}
\hline \multicolumn{2}{|c|}{ MIA Ansiety } & \multirow{2}{*}{$\begin{array}{l}\text { Beta } \\
. .06\end{array}$} & \multirow{2}{*}{ FChange } & \multirow{2}{*}{$\begin{array}{c}p \\
.000\end{array}$} & \multirow{2}{*}{$\begin{array}{c}\mathbb{R}^{2} \text { Change } \\
.066\end{array}$} & \multirow{2}{*}{ Cumulative $R^{2}$} \\
\hline Madel/ & Education & & & & & \\
\hline & Age & .00 & 23.8 & .000 & .017 & .083 \\
\hline & $\operatorname{sex}$ & .07 & 19.9 & .000 & .014 & .097 \\
\hline & Sped & -.08 & 22.3 & .000 & .015 & .112 \\
\hline & Sem-memory &,- 09 & 8.7 & .003 & .006 & .118 \\
\hline & Distress & $.2 \$$ & 2033 & .000 & .119 & .236 \\
\hline & Dent-worry & .15 & 44.1 & .000 & .025 & .261 \\
\hline & Subjective Healnh & .11 & 17.4 & .000 & .010 & .271 \\
\hline & HLC-Chance & .09 & 15.0 & .000 & .008 & .279 \\
\hline & HLC.Pysician & .08 & 7.8 & .005 & .004 & .284 \\
\hline \multirow[t]{8}{*}{ Model 2} & Speed & -.10 & 100.6 & .000 & .071 & .071 \\
\hline & Sem-memory & -.11 & 17.9 & .000 & .013 & .084 \\
\hline & Distress & .25 & 218.0 & .000 & .131 & $.2 \Downarrow 4$ \\
\hline & Dern-worry & .14 & 53.0 & .000 & .031 & .245 \\
\hline & Subjective Health & .12 & 25.0 & .000 & .014 & .259 \\
\hline & HLC-Chance & .09 & 20.3 & .000 & .011 & .270 \\
\hline & HLC-Physician & .08 & 8.9 & .003 & .004 & .274 \\
\hline & $\operatorname{sex}$ & .08 & 12.1 & .000 & .007 & .281 \\
\hline \multirow[t]{8}{*}{ Model 3} & Distress & .25 & 225.7 & .000 & .147 & .147 \\
\hline & HLC-Physician & .07 & 66.4 & .000 & .041 & .188 \\
\hline & Den-worry & .14 & 44.8 & .000 & .027 & .214 \\
\hline & Subjective Health & .12 & 32.4 & .000 & .019 & .233 \\
\hline & MLC-Chance & .09 & 21.4 & .000 & .012 & .246 \\
\hline & Sem-memory & -.11 & 41.6 & .000 & .023 & .269 \\
\hline & Speed & -.10 & 9.7 & .002 & .005 & .274 \\
\hline & $\operatorname{sex}$ & .08 & 12.1 & .000 & .007 & .281 \\
\hline
\end{tabular}

Note. Semmethory: semantic memory compound score; Speed = speed tasks compound score; HLC-Chance = Health Locus of Contro - Chance or Fatalism Orientation; HLC-Physician $=$ Health Locus of Control - Pysician or Powerful Others Orientation; Dem-worry $=$ degree of worry about dementia. Beta $=$ standardized regression coefticients in the final model. 
contributed to the variance in Models 2 and 3, but not in Model 1 when age was entered frrst. Physician orientation contributed less than $1 \%$ to the variance.

MIA Anxiety. The amount of variance explained for MLA Anxiety was $28 \%$ in all three models (Table 6.4). Distress, subjective health, and worry about dementia were the best predictors in all the models: Distress explained between $12 \%$ and $15 \%$ of the variance, subjective health between $1 \%$ and $2 \%$, and worry about dementia about $3 \%$. Participants with high scores for Distress. more worry about dementia, and lower subjective health, thad higher anxiety scores. The effects of the subjects background variables in Model 1 disappeared when the effects of the psychological and cognitive compound variables were partialled out in the Models 2 and 3. Sex explained less than $1 \%$ in the last two models. Both Speed and Semantic memory accounted for a substantial amount of variance (in total $8.4 \%$ ) when entered first (Model 2), but this was reduced when the subject background variables were entered first (Model $1,2.1 \%$ ) and, to a lesser extent, when the psychological variables were entered first (Model 3, 2.8\%). Lower scores on Speed and Semantic Memory were associated with higher scores on Anxiety.

MIA Locus. The correlation matrix in Table 6.1 shows that only the subscale Internal orientation of the Health Locus of Control scalle was strongly correlated with the MIA Locus scale. The regression analyses showed that Internal orientation was the onlly strong predictor in all three models, accounting for $9 \%$ of the variance. A low internal health locus of control orientation was associated with low memory control as well. In all three models Physician orientation and subjective bealth explained a wery small amount of the variance $(0.5 \%$ and $0.7 \%$, respectively).

\section{Discussion}

Our findings show that there are multiple predictors for three of the four subscales of the MLA questionnaire. The amount of variance explained was substantial for Change (35\%) and Anxiety $(28 \%)$, and modest for Capacity (15\%). Charging the order of entry of the predictor variables shed some light on the unique contribution of each of the predictor variables.

As we expected, the psychological measures and especially subjective health and worry about dementia were strong predictor variables, whereas the contribution of the cognitive performance variables was very small. Lower subjective memory ratings in terms of memory capacity, change or anxiety, were related to lower subjective health, more worry about dementia, and lower health locus of control. For the MIA Anxiety scale, more distress was related to greater anxiety about memory. The common variance of the cognitive performance variables with the scores on MIA subscales was mainly shared with age and to a lesser extent with sex and eclucational level. If these subject background variables were entered first, the contribution of the cognitive performance measures was almost negligible. The contribution of semantic memory was less than $1 \%$ for all three subscales. Only Speed accounted for more than $1 \%$ on the subscale Anxisty. These findings support the notion that subjective memory in a normal population is not, or only marginally, based on actual cognitive ability.

When the effect of the performance variables and psychological measures were partialled out, 
age and sex still accounted for significan part of the variance in scores for Capacity and Change. Aithough women had higher scores for Capacity, they also had higher scores for Anxiety, which is in line with the findings of earlier studies (e.g. Ponds \& Jolles, 1996a). Age uniquely contributed to Capacity and especially Change. Age accounted for almost $5 \%$ of the wariance in the Change scores when the effects of test performance and the psychological measures were partialled out. This provides some support for the "implicit theory of memory and aging" (McFarland, Ross \& Giltrow, 1992), which states that the general beliefs individuals hold about changes in memory with aging strongly influence self-ratings of daily memory functioning. These behefs are that age is inevitably accompanied by a decline in memory functioning and this decline can hardly be influenced by skill training or effort (McDonald-Miszczak et al., 1995). In this case, the decline in memory functioning reported by older adults is not based on their actual memory performance but on the societal belief that memory inevitably declines in old age. The unique contribution of age to the variation in scores for the Capacity scale was much smaller (1\%). The zero-onder correlation between age and Capacily was also much smaller than that for age and Change (-.26 and -.49 , respectively). As Hultsch, Herzog, and Dixon (1987) argued, this is probably dwe do the different anchorpoint of the two scales. On the Change scale subjects are asked to rate their present memory compared to that in the past, whereas on the Capacity scale subjects probably adjust their rating of memory to what they expect to be normall for their age.

The psychological variables were the best predictors of subjective memory. This was especially the case for subjective health, worry of dementia, and health locus of control. Distress was strong predictor of Anxiety in all three regression models. Anxiety about memory seems to be most directly related to general anxiety and depressive complaints (remember that the distress variable was a composite score of both complaints of depression and anxiety). This is consistent with the findings of studies of the discrimant validity of MIA that showed that of all the MIA subscales, Anxiety was most strongly related to trait anxiety and depressed mood (Dixon et al., 1988). Smith et al. (1996) recently showed, in people older than 55 years, that emotional status, which was measured by the overall score on the Symptom Checklist -90 , contributed $20 \%$ to the variance of the General Frequency of Forgetting scale of the Memory Functioning Questionnaire of Gillewski et al. (1990). This seems to be in contrast with our finding that psychological distress was not telated to memory capacity or change. However, the different psychological measures used in our study were highly correlated and therefore do have a substantial sharing of variance (distress, subjective health and worry about dementia). In an earlier study we found that people who considered thenselves forgetful also reported more health problems on the same health questionnaire we used in this study (Ponds, Commissaris \& Jolles, 1997). These were mostly vitality problems that correspond with the more physical problems of depression (e.g., tiredness, sleep problems;. Moreover, Watson and Pennebaker (1989) argued that self-reported heath measures are affected by a trait-like tendency to be more anxious and distressed. It seems therefore likely that distress does play a role in the overall ratings of memory capacity and memory change, but this effect is reflected already in the higher scores for especially subjective health.

Presuming that subjective health reflects objective health status, than there are several possibla explanations of why health influences subjective memory ratings. As stated before, poor health may influence the affective state or induce depressive complaints (of course depressive complaints may also lead to poor health), and these depressive complaints may lead to an increase in memory failnues in everyday life. Though we recognize this possible overlap between distress and 
subjective health, our data also show that subjective health has a wique contribution that is not shared with distress. Another explanation is that health problems directly affect cognitive functioning, leading to a decline in daily memory functioning. Howevar, this is not strongly supported by the low zero-order correlations between subjective health and episodic memory $(-.07)$, semantic memory $(-.16)$, and speed $(-.19)$. When subject variables (age, sex, and education) were partialled out these correlations even decreased to $.01,-.04$, and -.04 respectively, confirming the finding of Zelinski af al (1990) that health status is not related to memory performance. A third explanation is that poor health may induce a more general lowered self-perceived competence, which in turn affects ratings of memory competence. The relation between health locus of control and memory ratings could also be explained in this way. A feeling of being in control may lead to stronger feelings of competence and vice versa. People who feel in control of their own health (either reflected in a higher score on the Internal orientation scalle, or lower scores on the Chance and Physician scale) have more positive memory ratings. They report higher subjective memory capacity, less memory change, and less memory anxiety.

Worry about dementia was a significant predictor of Capacity, Change, and Anxiety. The amount of variance explained by this predictor was stable in all regression models tested, underlining its unique contribution. We have also found a strong relation between worry of dementia and forgetfulness in samples that included relatively young subjects as well (Commissaris et al., 1994; 1996). Worry about dementia may be based on actual decline in memory functioning, but usually there is no decline or a very minor decline and people's worries about dementia are therefore unsubstantiated. But being worried about dementia may increase daily memory failures because it interteres with normal memory functioning and creates a strong attentional bias to memory failures and a misinterpretation of normal everyday memory failures. This itself may strengthen worry about dementia, leading to a vicious circle.

Hardly any of the predictor variables correlated with the Locus subscale of the MIA. Even age did not correlate whereas most studies with the MLA have found a consistent and reliable age effect. In our psychometric study of the Dutch MLA (Ponds \& Jolles, 1996a), we also did not find age effects on the Locus scale and the scale even did not differentiate between a forgetful and nonforgetful group. It is possible that the content validity of the scale has changed as a result of translation, despite the fact that its psychometric properties closelly corresponded to those of the original MIA. For now, we conclude that the Locus subscale probably taps only sone general health locus of control perceptions.

In sum, our findings suggest that self-evaluation of different aspects of subjective memory functioning is predicted mainly by psychological measures that reflect different aspect of competence (e.g., thealth) and well-being (e.g., distress). Age uniquely contributed to perceived change in subjective memory and perceived memory capacity, giving some support to the implicit theory of memory and aging. As found in many other studies, actual memory ability, nor basic cognitive processes like speed and attention, were related to self-appraisal of daily memory functioning. These conclusions are of course limited by the cross-sectional nature of the study. Follow-up studies of the present sample are in progress and will provide us with information about the causal relation between the predictor variables and subjective memory. 


\section{References}

Arrindell, W. A., E Eltema, J.H. M. (1986). SCL-90. Een multidimensionele psychopathalogie indicator (The SCL-90. A multidimensional instrument for the assessment of psychopahology). Lisse, The Netherlands: Swets zeillinger.

Bolla, K. I.., Lindgren, K. N., Bonaccorsy, C. \& Bleecker, M. L. (1991). Memory complaints in older adults. Fact or tiction? Archives of Neurology, $48,61.64$.

Brand, N., \&o Jolles, J. (1985). Learning and retreiwal rate of words presemted auditorily and visually. The Journal of Genchal Psychology, 112, 201-210.

Cavanagh, J. C., Oreen, E. E. (1990). I believe, therefore I can: Self-efficacy beliefs in memory aging. In E. A. Lovelace (Ed.), Aging and cognition: mental processes, self-awareness and interventions (pp. 189-229). Amsterdam, the Netherlands: Elsevier Science.

Cavenaugh, J. C. (1996). Memory self efficacy as a moderator of memory change. In F. Blanchard-Fields \& T. H. Hess (Eds.), Perspectives on Cognitive Change in Adulthood and Aging (pp. 488-507). New York: The MeGraw-Hill Compagnies.

Commisaris, C. J. A. M., Ponds, R. W. H. M. \& Jolles, J. (1998). Subjective forgetfulness in a normal Dutch population: possibilities for health education and other interventions. Patient Education and Counseling, 34. $25-32$.

Commissaris, C. J. A. M., Jolles, J., Verhey, F. R. J., Ponds, R. W. H. M., Damoiseaux, V. G. M. \& Kok, G. J. (1996). Forgetfulness or dementia? Who is worried and why? European Joumal of Public Heallh, 6, 297.299.

Commissaris, C. J. A. M., Verhey, F. R, J., Ponds, R. W. H. M., Jolles, J., \& Kok, G. J. (1994). Public education about nomal forgeffulyess and dementia: importance and effects. Patient Education and Counseling. 24. $109-115$.

Cutler, S. J., Grans, A. E. (1988). Correlates of self-reported everyday memory problems. Journal of Gerontology: Social Sciences, $43,82-90$.

de Bie "S. E. (1987). Standaardwragen 1987 . Voorstellen voor wniformering wan wragstellingen naar achfergrondkermerken en interviews (Toward a standardization of questions concerning demographic wariables in popalation studies). (2nd ed.). Leiden, the Netherlands: Leiden University Press.

Derogatis, L. R. (1977). SCL-90: Administration, scoring and proceduses manual-4 for the R(evised wersion. Bathmore: Johris Hopkins School of Medicine, Clinical Psychometrics Research Unit.

Derouesne, C., Alperovitch, A., Arvay, N., Migeon, P., Moulin, F., Vollant, M., Rapin, J. R., \& Le Poncin, M. (1989). Memory complainis in the elderly: a study of 367 community-dwelling individuals fron 50 to 80 years old. Archives of Gerontology and Geriatrics, Suppl. 1, 151-163.

Dirken. J. M. (1967). Het meten van stress in industriele situaties (The measuremen of stress in industrial situations. Groningen, The Netherlands: Wolters.

Dixon. $\mathbb{R}$. A. (1989), Questionnaire research on metamemory and aging: Issues of structure and function. In $\mathbb{L}$. W. Poon, D. C. Rubin, \& B. A. Wilson (Eds.), Everyday cognirion in addathood and late life (pp. 394-415). Cunnbridge: Cambridge Universily Press.

Dixom, R. A. Hultsch, D. F., \& Hertzog, C. (1988). The metamemory in adulthood (MIA) questionnaire. Psychophamacology Buletin, 24.671.688.

Gilewski, M. J., Zelinski, E. M.; Schate, K. W. (1990). The memory functioning questionnaire for assessment of memory complaints in adulthood and old age. Psychology and Aging. 5, 482-490.

Halnons, R. J. G. (1985). Low of Control. Beheersorientatie in relatie tot ziekse en gezondheidsgedrag (Locts of Control. Ortentation in relation to illness and health behavior. Maastricht: Rijksuniversiteit Limburg Press.

Hännimen, T., Reinikanen, K. J., Helkala, E. Koivisto, K., Mykkänen, L., Laakso, M., Pyörïlï, K., \& Rickkinen, P. J. (1994). Subjecive memory complaints and personality traits in normal elderly subjects. Sowmal of the American Geriarics Society, $42,11-4$.

Hertzog, C., Dixon, R, A., \& Hultsch, D. F. (1990). Relationships between metamemory, menory predictions, and mentmory task performance in adults. Psychology and Aging $5,215-227$.

Houx, P. J. \& Jolles, J. (1994). Vulnerability factors for age-related cognitive decline. In R. L. Isacson \& $K$. F. Jenssin (Eds.), The watherable brain and environmental risk (pp. 25-41). New York: Plenum Press.

Hutlsch, D. F. Henzog, C. \& Dixon, R. A. (1987). Age differences in metamemory: Resolwing the inconsistencies. Canadian Journat of Psychology, 41, 193-208.

Hultsch, D. F., Hertzog, C., \& Dixon, R. A. (1990). Ability correlates of memory performance in adulthood and Aging. Psychology and Aging, 5, 356-368.

Jolles, J. Houx, P. J., van Boxtel, M. P. J., Ponds, R. W. H. M. 1995). Maastricht Aging Srudy. Deteminants of cognitive aging. Maastricht: Meuropsych Publishers. 
Jöreskog, K. G., \& Sörbom, D. (1996). LUSREL 8: User's reference gude. Chicago: Scientific Software International.

Lezakik, M. D. (1995). Neuropsychological Assessment. (Third edition). New York: Oxford University Press.

Luszcz, M. A. (1993). When knowing is not enongh: the role of memory beliefs in prose recall of older and younger adults. Australian Psychologist, 28, 16-20.

McDonald-Miszezak, L., Hertzog, C., \& Hultsch, D. F. (1995). Stability and acciracy of metamemory in adulthood and aging: $\mathrm{A}$ longitudinal analysis. Psychology and Aging. 10, 553-564

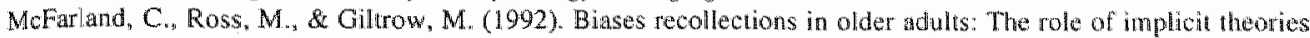
of aging. Journal of Personality and Social Pyschology, 62,837.850.

Metsemakers, J. F. M., Höppener, P., Knotmerus, J. A., Kocken, R. J. J., \& Limonard, C. B. G. (1992). Computerized health information in the Nethendands: a registration network of family practices. British Joumal of General Practice, 42, 102-106.

Ponds, R. W. H. M. Commissaris, K. J. A. M. \& Jolles, J. (1997). Prewalence and cowariates of subjective forgetfulness in a normal population. International Journal of Aging and Human Dewelopmest, 45, 207-221.

Ponds, R. W. H. M., \& Jolles, J. (1996a). The abridged Dutch Metamemory in Adulthood (MIA) questionnaire: structure, and effects of age, sex, and education. Psychology and Aging, 11, 324-332.

Ponds, R. W. H. M., \& Jolles, J. (1996b). Memory complaints in elderly people: the role of memory abilities, metamemory, depression, and personality. Educational Gerontology, 22, 341-357.

Rabbitt, P., \& Abson, V. (1990). 'Lost and Found': Some logical and methodological limitations of self-repont questionnaires as tools to study cognitive ageing. Brivish Joumal of Psychology, 81, 1-16.

Rabbitt, P., Maylor, E., McInnes, L., Bent, N., \& Moore, B. (1995). What goods can self-assessment questionnaires deliver for cognitive gerontology? Applied Cognitive Psychology, 9. S127-S152.

Ryan, E. B., \& Kwong See, S. (1993). Age-based beliefs about memory changes for self and others across adulthood. Joumal of Gerontology: Psychological Sciences, 48, 199-201.

Salthouse, "T.A. (1988). Resoure-reduction interpretations of cognitive aging. Developmental Review, $8,238-272$.

Snith, G. E., Petersen, R. C., Ivnik, R. J., Malec, J. F., Tangalos, E. G. (1996). Subjective memory complaints, psychological distress, and longitudinal change in objective memory performance. Psychology and Aging, $11,272-279$.

Stewens, F. C. F., Kaplan, C. D., Ponds, R. W. H. M. Diederiks, J. P. M. \& Jolles, J. (in press). How agcing and social factors affect memory. Age \& Ageing.

Taylor, J. L., Miller, T. P., \& Tinklenberg, I. R. (1992). Correlates of memory decline: A 4-year longitudinal siudy of older adults with memory complaints. Psychology and Aging, 7, 185-193.

Wallston, K. A., \& Wallston, B. S. (1981). Health Locus of Control scales. In H. M. Lefcourt (Ed.), Research with the Locus of Control corsstruct (Volume l: Assessment methods). New York: Academic Press.

Watson, D., \& Penmebaker, I. W. (1989). Health complaints, stress, and distress: Exploring the centrall role of negative affectivity. Psychological Review, 96, 234-254.

Zelinski, E. M., \& Gilewski. M. J. (1988). Assessment of memory complaints by rating scales and questionnaires. Pycophamacology Bulletu, 24,523-529.

Zelinski, E. M., Gülewski, M. J., \& Anthony-Bergstone, C. R. (1990). Memory Functioning Questionnaire: concurrent validity with menory performance and self-reponted menory failures. Prychology and Aging. 5 , $388-399$.

Zelinski, E. M. Gilewski, M. J., \& Staje, K. W. (1993). Individual differences in cross-sectional and 3-year

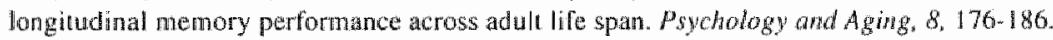





\title{
Psychosocial predictors of metamemory in middle-aged and old people $^{*}$
}

\begin{abstract}
The present study examined the relation between psychosocial factors and subjective and objective memory functioning in a group of 319 normal community-dwelling adults aged 40 to 90 years. Subjective memory was measured with three subscales of the Metamemory in Adulthood questionnaire (Capacity, Change, and Anxiety). Participants completed a postal questionnaire which included questions about subjective memory and a variety of psychosocial measures (demographic and health variables, affective state, personality traits, daily stress, and social support). Lower memory capacity was related to a less active coping style, higher educational Jevel, more subjective health complaints, and less social support. Higher ratings of memory decline were associated with greater neuroticism, older age, higher education, a less active coping style, and more subjective health complaints. Memory anxiety was related to greater neuroticism and a less active coping style. A group with low subjective memory $(n=27)$ and a group with high subjective memory $(n=31)$ were selected from the questionnaire sample to evaluate the relation between objective and subjective memory. No differences were found between the two groups on neuropsychological tests that focused on memory, speed, and attention. However, the oldest people in the low subjective memory group had a significantly lower performance on a episodic memory test than the oldest people in the high subjective memory group. The main conclusion of this study is that subjective memory is primarily related to psychosocial variables and is not based on actual memory or cognitive abilities.
\end{abstract}

* Ponds, R. W. H. M. Jolles, I. (submitted) 


\section{Introduction}

Many elderly people complain about their diminishing memory. It has long been assumed that these complaints reflect an age-related decline in memory abilities, as shown with a wide variety of memory tests. However, correlations between self-assessed memory ratings and performance on memory tests are either absent or low, which suggests that self-appraisal of memory is not a reflection of actual memory abilities (Gilewski \& Zelinski, 1986). It is now increasingly recognized that, besides age, a broad array of contextual variables should be taken into account to gain a fuller understanding of age-related differences in objective and subjective memory and cognitive functioning (Arbuckle, Gold, Andres, Schwartzman \& Chaikelson, 1992; Hultsch \& Dixon, 1990; Lawton, 1986). These contextual variables are assumed to be mediators of uge related changes in memory functioning and include demographic and health variables (e.g.s education, subjectiwe health), psychological wariables (e.g., mood, personality, locus of control), and social variables (e.g., environmental stress, social support). For example, Arbuckle, Gold and Andres (1986) found that education and the tendency to attribute desirable personality characteristics to oneself were predictors of both objective and subjective memory measures, with education being the most powerful predictor for both. Additionally, different sets of explanatory variables were found for the objective measures of memory (intellectual activity, extraversion, netroticism, and age) and for the subjective measures of memory (sex, health, interaction sex and finances).

A number of studies have explicitly looked at the relation between contextual variables and objective and subjective memory functioning. In general, these studies reported no association or only a weak association between objective and subjective memory measures, with lower subjective memory ratings being related to affective measures such as greater depression and anxiety (e.g., Bolla, Lindgren, Bonaccorsy \& Bleecker, 1991), poor subjective health (e.g., Herzog \& Rodgers, 1989), negative stereotypes of aging and a poor social network (Derouesné et al., 1989), personality traits such as greater neuroticism (Poitrenaud, Malbezin \& Guez, 1989), a makked tendency toward somatic complaining (Hännimen et al., 1994), and stressful life-events (Bazargan \& Barbre, 1994).

The present study was primarily designed to examine the relation between subjective nemory functioning, as measured with three subscales of the Metamemory in Adulthood (MIA) questionnaire (Dixon, Hultsch \& Hertzog, 1988), and a broad variety of psychosocial variables in a sample of middle-aged and old community dwelling subjects. The three MIA-subscales used were perceived nemory capacity (MIA-Capacity), perceived change or decline in general memory functioning (MLA-Change), and perceived anxiety in relation to memory performance (MIA Anxiety). Despite the fact that the MIA is one of the most frequently used metamemory questionnaires in aging research, relatively few studies have examined age-related changes in MIA scones from a broader contextual perspective.

Consistent age differences have been reported for the Capacity, Change, and Anxiety subscales, with the largest differences being found for Change (Hultsch. Hertzog \& Dixon, 1987). Sex and education had relatively little effect: women reported greater anxiety on the Anxiety subscale, and lower education was related to greater memory anxiety and more perceived memory decline (Hultsch et al., 1987; Ponds \& Jolles, 1996a). In general, weak correlations are 
found between the MIA subscales and memory task performance (e.g., Dixon \& Hultsch, 1983; Hertzog, Dixon \& Hultsch, 1990; Luszcz, 1993). Hultsch el al. (1988) report zeromonder cortelations between MIA scores and a variety of questionnaires measuring personality, locus of control, and affective state. They found that the MA subscales Capacity and Change generally showed low to modest correlations with measures of anxiety, depression, and well-being. The MIA subscale anxiety showed the highest correlations with neuroticism, depression, and well-being. Hultsch et al. concluded that a person's self-appraisal of memory, as measured by the MIA, is not simply a re-expression of basic personality dimensions. Ponds and Jolles (1996a) found that lower health ratings were related to lower ratings of memory capacity, a greater subjective decline of memory, and more subjective anxiety about memory performance, after controlling for the effects of age, sex, education, anxiety, and depressive mood. In a recent study, we examined the relation between metamemory, as measured with the MIA-subscales Capacity, Change, and Anxiety, and lifestyles in a sample of 497 people aged 25 to 80 years (Stevens, Kaplan, Ponds, Diederiks \& Jolles, in press). We found that an active lifestyle, frequent contact with friends and family, and a better health status were related to higher rating of memory capacity and lower ratings of memory anxiety. In another study with a sample of 1673 people aged 24 tot 85, we found coping ability, defined as the ability to stand up to the everyday demands of work, family, and life circumstances, to be the best predictor of perceived memory capacity. Higher scores on coping ability were related to higher scores on MIA-Capacity, independent of age (Evers et al., 1998).

In this paper we report our findings from two successive studies into the relation between the Capacity, Change, and Anxiety subscales of the MIA, psychosocial measures and objective cognitive functioning. In the first study, regression analyses were used to examine which demographic and psychosocial variables were predictors of subjective memory, as measured with the MIA subscales, in a sample of 319 people aged 40 to 90 years. The psyclosocial measures included were neuroticism, depressive mood, rigidity, extraversion, active coping style, subjective health, social support, and environmental stress. Based on the findings in the cognitive aging literature, we expected that better subjective memory functioning would be associated with less neuroticism, less depressed mood, fewer health complaints, lower environmental stress. more social support, and greater active coping abilities. As greater flexibility appears to be associated with generally better cognitive functioning over the adult age range (Gold \& Arbuckle, 1990), we expected a negative influence of rigidity on subjective memory functioning. Greater extraversion was expected to be positively associated with subjective memory, as greater sociability would lead to more social activities and to more opportunities to seek help in problem situations which could lead to stress reduction (Gold \& Arbuckle, 1990). In the second study, a variety of memory and cognitive tests were used to compare a group of 27 individuals with severe memory complaints and low scores on MIA-Capacity and MIA-Change, and high seores on MIA-Anxiety with a group of 31 individuals with no memory complaints and high scores MIA-Capacity and MIA-Change, and low scores on MIA-Anxiety. These groups were selected from the sample of the first study. 


\section{Study 1}

In the first study we examined which demographic and psychosocial variables were predictors of subjective memory, as measured with the MIA subscales, in a sample of 319 persons aged 40 to 90 years.

\section{Method}

\section{Participants and procedure}

Participants were recruited from a pool of mainly middle-aged and old community-dwelling people who had participated in an earlier study on the quality and effectiveness of an information brochure about normal forgetfulness and dementia (Commissaris et al., 1996). In this study, people could order a free information brochure about normal aging and dementia. In total 537 individuals participated in this study and had ordered the brochure. Almost $90 \%$ of them were, to some extent, worried about their forgetfulness and $70 \%$ were worried about incipient dementia. A total of 459 individuals of this study sample agreed to participate in future studies at our

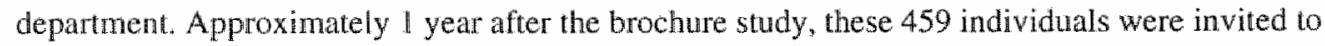
participate in the current study. They were all sent a postal questionnaire which included questions about subjective cognitive functioning and which assessed a number of psychosocial measures (see below). In total 319 persons (response $70 \%$ ) aged between 40 and 90 years completed and returned the postal questionnaire in good order and had complete data on the three Metamemory in Adulthood questionnaire subscales that were used as dependent variables in this study. Educational level was measured with a Dutch scoring system (de Bie, 1987) which consists of an 8-point scale, ranging from unfinished primary education (level 1) to university education (llevel 8). The mean age, sex, and educational level of the participants are presented in Table 7.1. The overall mean level of education was high compared to the educational level of the older groups in a large-scale population study we performed in the same region of the Netherlands (Ponds \& Jolles, 1996a). About 32\% were highly educated (senior vocational or academic training), 50\% had secondary education (junior vocational training), and $18 \%$ had only primary education. There were slightly more women $(n=175,55 \%)$ than men $(n=144,45 \%)$ in the sample.

\section{Measures of subjective memory}

"Two measures of subjective memory were taken. First, participants could indicate their degree of forgetfuiness on a 4-point scale ranging from "not at all" (score 1), "mildly" (2), "moderately" (3), to "severely" (4). Subjects also rated the degree of hindrance and worry about their forgetfulness on a 5-point scale, ranging from "no hindrance at all" and "not worried at all" (score 1) to "very much hindrance" and "very much worried" (score 5). Second, three subscales of the (non-abridged) Dutch Metamemory in Adulthood (MIA) questionnaire (Ponds \& Jolles, $1996 a$ ) were administered: MIA-Capacity, MIA-Change, and MLA-Anxiety. The MIA-Capacity scale has 
17 items and higher scores indicate more perceived memory capacity. The MIA-Change scale has 18 items and higher scores indicate less perceived decline or more stability in memory functioning. Higher scores on the 14-item MIA-Anxiely scale reflect more feelings of stress and anxiety in relation to memory performance.

\section{Psychosocial measures}

Neuroricism and extraversion were assessed with the Dutch Ansterdam Biographical questionnaire (de Wilde, 1970). The neuroticism scale consists of 30 items, in which the subject indicates the presence of psychoneurotic complaints. The extraversion scale consists of 21 items that measure especially social extraversion. Higher scores indicate greater neuroticism and (social) extraversion.

Rigidity was measured with the Rigidity subscale of the Dutch Personality Questionnaire (Luteijn, Starren \& van Dijk, 1985). This scale consists of 25 statements describing llexibility in daily customs and problem solving. Higher scores indicate greater rigidity.

Coping style was mexsured with the subscale 'Active Problem solving' ( 7 items) of the Dutch Utrecht Coping List (Schreurs, van de Willege, Tellegen \& Brosschot, 1987) which consists of statements describing a direct and rational approach towards problem situations. Higher scores indicate more active problem solving.

Depression was measured with the subscale Depression of the revised version of the Symptom Checklist (SCL-90: Derogatis, 1977; Dutch version: Arrindell \& Ettema, 1986). The depression scale contains 16 items which reflect symptoms of depression. Higher scores indicate more depressive complaints.

Subjective health was measured with the Dutch Inventory of Subjective Health (Dirken, 1967). This questionnaire consists of 21 items that probe possible health complaints. Higher scores indicate more health complaints.

Loneliness or subjective social isolation was assessed with the Loneliness Scale (de JongGierveld \& van Tilburg, 1991), which consists of 11 items measuring level of satisfaction of subjects with their social support network. Higher scores indicate greater loneliness.

Envirommental stress was assessed with the Dutch Everyday Problem Checklist (Vingerhoets \& van Tilburg, 1994), which consists of 1.14 items measuring daily hassles and chronic stressors encountered during the past 2 months (Daily hassles frequency; higher scores indicate more daily hassles).

\section{Daia analysis}

Multiple regression analyses were performed to examine the relation between scores on the three MLA-subscales (dependent variables) and the psychosocial variables (independent variables). Age, sex, and education were entered first into the equation. The three demographic variables (age, sex, and education) and the eight psychosocial variables were entered stepwise forward and were allowed to compete among themselves. The criterion to enter was a correlation between the dependent and independent variable with a significance level of $p<.05$. 


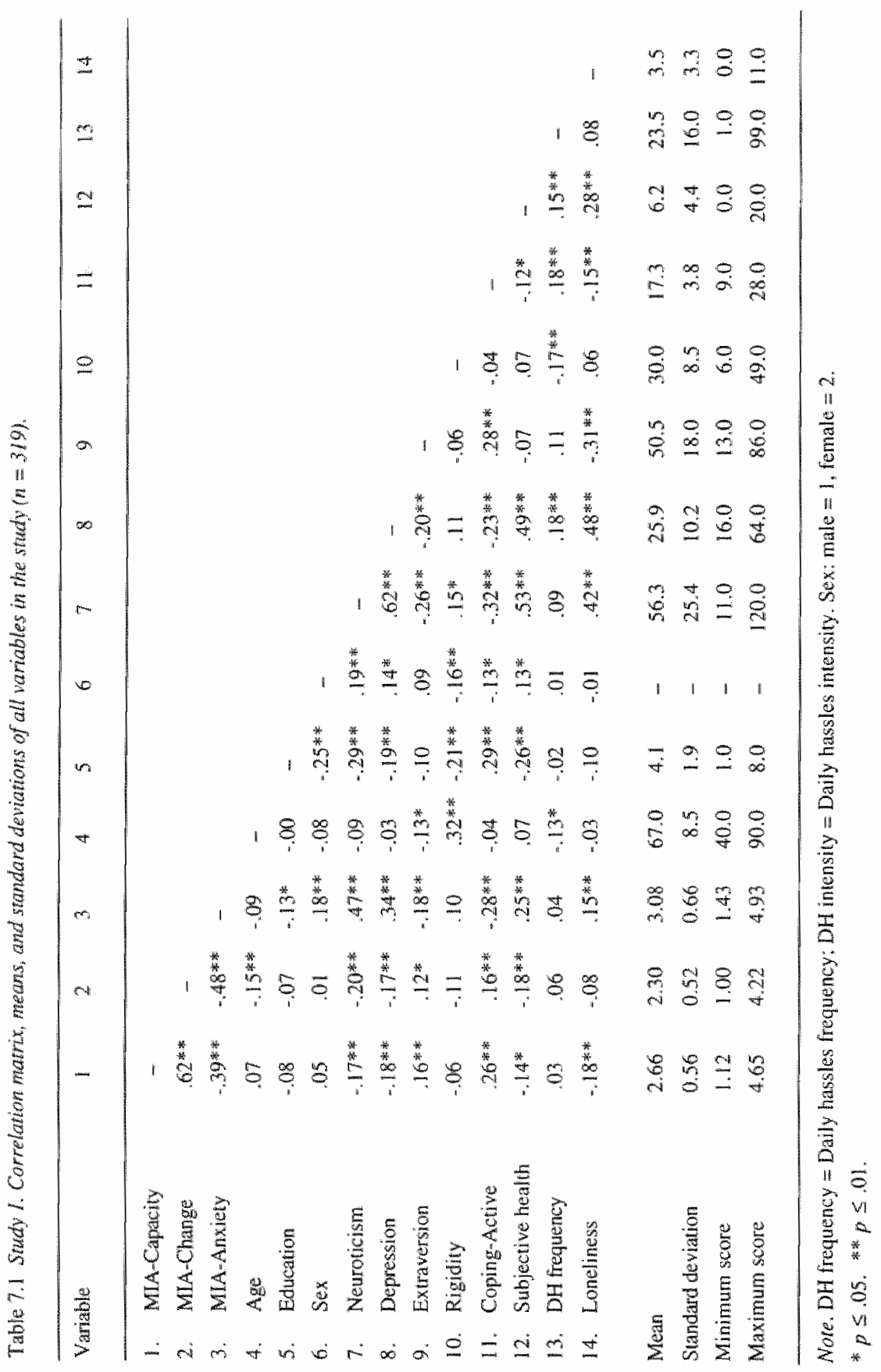




\section{Results}

In response to the question to what degree participants considered themselves as being forgetful $4.7 \%$ of the subjects answered "not at all", $56.1 \%$ "mildly", $32.6 \%$ "moderately" and $6.6 \%$ "severely". Table 7.1 shows zero-order correlations, the means and standard deviations for all the variables in the study. Age-corrected nomative data were avalable for most of the psychosocial measures used, except for the subjective health and daily hassles questionnaires. Overall, the mean scores on the different psychosocial measures corresponded with the mean score range of the norm group. Comparison of the mean item scores on the three MIA-scales with the mean item scores of a large normal age-stratified sample (Ponds \& Jolles, 1996a) showed that the present sample had lower scores on Capacity (indicating less perceived memory capacity) and Change (indicating more perceived decline), and higher scores on Anxiety (indicating more perceived memory-related anxiety). Significant zero-order correlations were found between the MIA subscales and most of the psychosocial variables, except for rigidity and daily hassles frequency. As expected, most psychosocial measures showed substantial intercorrelations. This was especially the case for neuroticism, depression, active coping style, and subjective health. Table 7.2 show the results of the regression analysis for each of the three MIA subscales.

Table 7.2 Study 1. Multiple regression for the three MIA-subscales.

\begin{tabular}{|c|c|c|c|c|c|}
\hline MA-subscale & Predictors & Beta & F Change & $R^{2}$ Change & Cumulative $R^{2}$ \\
\hline \multirow[t]{4}{*}{ MIA-Capacity } & Coping Active & .29 & $23.09^{\text {\% }}$ & .068 & .068 \\
\hline & Education & -.21 & 9.55 & .027 & .095 \\
\hline & Subjective health & -.13 & 8,29 :* & .024 & .119 \\
\hline & Loneliness &. .12 & $4.43 *$ & .012 & 131 \\
\hline \multirow[t]{5}{*}{ MIA-Change } & Neuroticism & -.14 & $12.73 * *$ & .039 & .039 \\
\hline & Age & -.17 & $9.52 * *$ & .028 & .067 \\
\hline & Education & -.19 & $6.54 *$ & .019 & .086 \\
\hline & Coping-Active & .15 & $5.37 \%$ & .015 & .101 \\
\hline & Subjective health &. .14 & $5.05^{*}$ & .014 & .115 \\
\hline \multirow[t]{2}{*}{ MIA-Anxiety } & Neuroticism & .42 & $89.65 *$ & .220 & .220 \\
\hline & Coping-Active & -.14 & $7.20^{* * *}$ & .017 & .237 \\
\hline
\end{tabular}

Note. Betas standardized regression coefficient in the final model.

$* p<.05 * p<.01$

MLA-Capacity. The owerall amount of vartance explained was $13 \%$. Significant predictors were an active coping style, education, subjective heath, and loneliness, which accounted for $7 \%$, 
$3 \%, 2 \%$, and $1 \%$ of the variance respectively. A less active coping style, higher education, lower subjective health, and less sociall support were related to lower perceived memory capacity.

MA. Change. The overall amount of variance explained was $12 \%$, with neuroticism $(4 \%)$, age $(3 \%)$, education $(2 \%)$, coping style $(2 \%)$, and subjective health (1\%) being reliable predictors. More perceived decline (or less stability) in memory functioning was associated with greater neuroticism, older age, higher education, a less active coping style, and more subjective health complaints.

MA-Anxiety. The overall amount of variance explained was $24 \%$. As expected, neuroticism made a very substantial contribution to the variance $(22 \%)$. Coping style accounted for an additional $2 \%$ of the variance. Higher memory anxiety was related to higher neuroticism and a less. actiwe coping style.

\section{Study 2}

In the second study, groups with high and low subjective memory ratings were compared by using a broad range of cognitive tests. The rationale behind this approach of comparing extreme groups was that if there is a relation between perceived subjective memory and objective memory and cognitive functioning, this should be reflected in significant performance differences between these two 'extreme' groups. Because reduced speed of information processing and reduced attentional resources are assumed to have a broad impact on encoding and retrieval processes (Salthouse, 1988; Taylor, Miller \& Tinklenberg, 1992), both memory tasks and tasks that measure speed of information processing and attention were used as cognitive performance measures.

\section{Method}

\section{Participants and procedure.}

Fifty-eight people from the first study sample were invited to participate in the second study. They were selected on the basis of their response to the question about forgetfulness. A low subjective memory group ( $n=27$ ) was formed from participants who considered themselves as being seriously forgetful (the response to the question about forgetfuness being either "severely" or "moderately" forgetful; the response to perceived hindrance and worry being "very much" or "much"). Purticipants who did not consider themselves forgetful or only to a small extent (the response to the question about forgetfulness being either "not al all" or "mildly" forgetful; the response to perceived hindrance and worry being "no" or "bardly") formed the high subjective memory group $(n=31)$. Both groups were matched for age, sex, and educational level as far as possible. Although the selection of the two groups was not based on extreme scores on the three MLA-subscales that were used in the first study, it proved that both groups, as expected, showed more or less extreme differences in scores for the MIA-subscales as well. We transformed the 
scores for the MLA-subscales of all participants in the first study into deciles. The mean scores for the MIA-Capacity, MIA-Change, and MA-Anxiety subscales of the low subjective memory group corresponded with the third, second, and ninth deciles of the Ma-subscales score distributions of the total group in the first study. In the high subjective memory group, the mean scores for the MA-Capacity, MLA-Change, and MLA-Anxiety subscales corresponded with the ninth, ninth, and third deciles, respectively. The Mini-Mental State Examination (Folstein, Folstein \& McHugh, 1975) was used to exclude those individuals who were possibly in an early stage of dementia, using a cut-off score of $23 / 24$.

Table 7.3 Shady 2. Descriptine characterisfics of the high and low subjective memory gromps

$\begin{array}{cc}\text { High subjective } & \text { Low subjective } \\ \text { memory group } & \text { memory group } \\ n=31 & n=27 \\ (16 \text { males }) & (12 \text { males })\end{array}$

\begin{tabular}{|c|c|c|c|c|c|}
\hline Variable & $M$ & $S D$ & $M$ & $S D$ & $p^{1}$ \\
\hline Age & 67.26 & 9.09 & 68.37 & 7.112 & $n s$ \\
\hline Education & 4.45 & 1.65 & 3.07 & 1.57 & .002 \\
\hline Forgetfulness & 1.67 & 0.48 & 3.33 & 0.48 & .000 \\
\hline Hindrance & 1.61 & 0.56 & 4.00 & 0.48 & .000 \\
\hline Worry & 1.42 & 0.56 & 4.26 & 0.47 & .000 \\
\hline MA-Capacily & 3.11 & 0.40 & 2.25 & 0.39 & .000 \\
\hline MIA-Change & 2.82 & 0.49 & 1.87 & 0.38 & .000 \\
\hline MIA-Ankiety & 2.59 & 0.54 & 3.64 & 0.67 & .000 \\
\hline MMSE & 28.19 & 1.56 & 27.81 & 1.76 & $n$ \\
\hline
\end{tabular}

Nore MMSE = Mini-Mental State Examination.

1 T-test.

Table 7.3 shows the demographic characteristics, mean MMSE scores, ratings for the questions on forgetfulness, and scores for the MIA subscales of the low and high subjective memory groups. The groups were almost perfectly matched for age. However, the mean educational level of the high subjective memory group was significantly higher than that of the low subjective memory group. There were fewer men in the low subjective memory group, but this difference in male/female ratio was not significant $\left(X^{2}(1)=0.297, p=.586\right)$. No differences were found for the mean MMSE scores and none of the participants had scores below the cut-off score of 23/24. All participants were tested at home. During this wisit a set of cognitive tests was administered that took approximately 45 minutes to complete. Participants were paid for their participation. 


\section{Measures of cognitive functioning}

Letter-Digit Modalities Test. This test is a modification of the procedurally identical Symbol-Digit Modalities Test (Lezak, 1995). It is used as a measure of the speed of processing of general information, i.e., the test is supposed to draw upon several (cognitive) processes such as visual perception, attention, and memory. The variable of interest is the number of correctly coded letter-digit combinations in 90 seconds.

Concept Shiffing Test (Houx \& Jolles, 1994). This test is derived from the Trail Making Test (Lezak, 1995), which is tised to measure the ease of shifting between concepts. There are three task conditions: the subject has to cross out, in the proper order, 16 circles containing only digits (1 to 16; part A), letters (A to P; part B), or both (1-A-2-B, etc; part C). In the latter subtest, subjects have to shift between the concepts 'digits" and 'letters'. The variable of interest is the time (seconds) needed to complete each subtest.

Stroop Color-Word Test (Lezak, 1995). The Stroop test is a test for selective attention and interference susceptibility. The test involves three cards displaying hundred stimuli each: color names, colored patches, and color names printed in incongruously colored ink. For the last card, the color of the ink has to be named instead of the color name. Performance of this task is especially susceptible to interference. The variable of interest is the time (seconds) needed to complete each card.

The Auditory Verbal Leaming Test (Lezak, 1995). The AVLT consists of 15 monosyllabic meaningful words which are presented to the participants five times. After each trial or presentation the participant is requested to recall as many words as possible with no restriction concerning the order of recall (immediate recall). Twenty minutes after the fifth presentation, the participant is again requested to recall as many words as he or she can remember (delayed recall). After the delayed recall, recognition is tested by asking the participant to identify the 15 words of the test, which are now mixed with 15 new words. The variables of interest are the total number of correctly remembered words over trials $1-5$ (immediate recall), the maximum number of words in trials $1-5$, the number of words remembered on delayed recall, and the number of correctly recognized words at delayed recognition. This test measures memory storage and retrieval of verbal information in episodic memory.

Fluency. In the fluency task, the participant is asked to name as many different animals as possible in 1 minute. This test measures strategy-driven retrieval from semantic memory. The variable of interest is the number of correctly named animals.

\section{Results}

Table 7.4 gives the mean scores for the psychosocial measures and the cognitive tests of the low and high subjective memory groups. Two multiwariate analyses of variance (MANOVA) with education as covariate were conducted with group as independent variable (two levels: forgetful and non-forgetful) and the test variables and the psychosocial measures as independent variables.

The low subjective memory group in general needed more time to complete the concept shifting task and had lower scores for the Letter-Digit Modalities test and both memory tasks. 
Table 7.4 Study 2. Means and standord deviations for the test and pasychosocial wariables in the fhigh and low subjective memory groups.

\begin{tabular}{|c|c|c|c|c|c|c|}
\hline & \multicolumn{2}{|c|}{$\begin{array}{l}\text { High subjective } \\
\text { memory group } \\
\quad(n=31)\end{array}$} & \multicolumn{2}{|c|}{$\begin{array}{l}\text { Low subjechive } \\
\text { memory group } \\
\quad(n=27)\end{array}$} & \multirow[b]{2}{*}{$F^{l}$} & \multirow[b]{2}{*}{$p$} \\
\hline & $M$ & $S D$ & $M$ & $S D$ & & \\
\hline \multicolumn{7}{|l|}{ Testuariables } \\
\hline Letter-Digit Modalities & 31.2 & 6.0 & 26.4 & 5.5 & 3.23 & .078 \\
\hline Concept Shifting Test $A$ & 24.11 & 5.3 & 28.3 & 7.6 & 4.22 & .045 \\
\hline Concept Shifting Test B & 27.1 & 6.6 & 32,9 & 11.4 & 2.15 & .149 \\
\hline Concept Shifting Test C & 36.8 & 11.3 & 46.3 & 18.8 & 2.76 & .102 \\
\hline Stroop Card I & 46.8 & 6.9 & 49.1 & 10.9 & 0.04 & .845 \\
\hline Stroop Card II & 63.0 & 12.3 & 65.5 & 15.8 & 0.03 & .957 \\
\hline Stroop Card ILI & 116.5 & 37.3 & 114.5 & 39.1 & 0.45 & .507 \\
\hline AVLT recall trial 1-5 & 50.4 & 9.1 & 43.3 & 11.1 & 3.40 & .071 \\
\hline AVLT delayed recall & 10.0 & 3.1 & 8.0 & 3.2 & 3.73 & .058 \\
\hline AVLT recognition & 28.8 & 1.5 & 27.8 & 2.4 & 2.03 & .160 \\
\hline Fluency & 23.0 & 6.4 & 22.2 & 5.4 & 0.06 & .812 \\
\hline \multicolumn{7}{|l|}{ Psychosocial variables } \\
\hline Neuroticism & 44.3 & 22.7 & 73,4 & 28.9 & 10.55 & .002 \\
\hline Depression & 21.0 & 7.7 & 32.4 & 14.3 & 8.62 & .005 \\
\hline Extraversion & 50.7 & 13.6 & 43.4 & 17.9 & 2.49 & .120 \\
\hline Rigidity & 29.2 & 8.6 & 31.9 & 8.3 & 0.18 & .674 \\
\hline Coping-Active & 18.6 & 3.6 & 14.7 & 3.6 & 11.69 & .001 \\
\hline Subjective health & 4.2 & 3.4 & 8.4 & 5.0 & 7.67 & .008 \\
\hline Daily hassles frequency & 22.5 & 17.2 & 22.0 & 17.3 & 0.08 & .776 \\
\hline Loneliness & 2.8 & 2.9 & 4.0 & 3.8 & 0.61 & .437 \\
\hline
\end{tabular}

Note. AVLT = Auditory Verbal Learning Test.

1. Follow-up uniwariate $F$-test $(d f=1,55)$ with edication as covariate.

There was however no significant overall group effect when education was taken as covariate ( $F$ $(11,45)=1.34, p=.235)$. Additional univariate F-tests revealed that on the A-part of the concept shifting task, the low subjective memory group needed significantly more time than the high subjective memory group. To examine the possibility that the differences in the performance of cognitive tests were due to especially the older participants, an additional two-way MANOVA was performed with education as covariate, in which the low and high subjective memory groups were divided into 'young' and 'old' groups ('young' low subjective memory group: $n=12$, mean age 
61.9 years; "old" low subjective memory group: $n=15$, mean age 73.5 years; "young" high subject ve memory group: $n=16$, mean age 60.6 years; "old' high subjective memory group: $n=$ 15. mean age 74.4 years). A significant overall effect of age was found (young/old) $(F(11,43)=$ $2.64, p=.011)$, with the younger subjects having significanty better scores $(p<.05)$ than the older subjects on all test variables, except for fuency and the variables of the Auditory Verbal Learning Test. There was no significant overall effect of group (high and low subjective memory) $(F(11,43)=1.17, p=335)$. There was a significant age $x$ group interaction $(F(11,43)=2.55$, $p=.014 \%$. In general, the old low subjective memory group had the lowest test performance. Univariate F-tests showed that this interaction effect was significant for the total immediate recall of trials $1-5$ and the delayed recall trial of the Auditory Verbal Learning Test.

A significant overall effect was found for the psychosocial measures $(F(8,48)=2.63, p=$ .018). Follow-up univariate $F$-tests showed significant group differences on four of the eight psychosocial measures. The low subjective memory group had significantly higher scores for neuroticism, depression, and subjective health (indicating lower subjective health) and a significantly lower score for active coping style than the high subjective memory group. The mean scores for depression and neuroticism of the low subjective memory group were within the wper range of the scores of the nom group, whereas those of the high subjective memory group were in the mean score range. The mean score for active coping style of the low subjective memory group was in the lower range of the norm group.

\section{Discussion}

The findings of the two studies suggest that subjective memory functioning is more closely related to psychosocial variables than to actual memory abilities. Lower memory capacity was related to a less active coping style, higher education, more subjective health complaints, and less social support. Subjective memory decline was associated with greater neuroticism, older age, higher educwion, a less active coping style, and more subjective health complaints. Memory anxiety was related to greater neuroticism and a less active coping style. No differences in cognitive functioning were found between a selected high and low subjective memory group when we controlled tor the differences in educational level between the two groups.

Before discussing the findings in more detail, it is important to point out certain limitations of the study. First, it stould be noted that the sample in this study is only partly representative for the nomal population. As mentioned before, the level of educarion of the participants was relatively high. Moreover, the participants in general had somewhat lower ratings for subjective memory, as expressed on the MIA subscales, than the nomal population. This is not surprising because this sample was selected from a larger sample of subjects who had participated on a voluntary basis in a study on the effectiveness of an information brochure on normal aging and dementia 1 year earher. Their interest in that study was most likely based on concern about their diminishing memory. For this reason, the "range' of the perceived quality of subjective memory is to some extent restricted in the present sample compared to that of the normal population in the sense that it included relatively few people with high subjective memory ratings. It is possiblle that because of this limitation, predictors in the present study that were not significant (e.g., daily hassles, 
rigidity, extraversion) might have been reliable predictors if the sumple had included more people with high subjective memory ratings.

Second, the multivariate regression analysis we used had the advantage that only the strongest predictors would be identified because all independent variables were allowed to compete anong themselves, but the disadvantage that, because of the intercorrelations beween the independent variables, potential relations between weaker variables and the independent variables may have been obscured. Also, independent variables that are strongly correlated with the independent variable may not emerge as predictor variables because they are strongly intercorrelated with another independent variable that has already been entered into the regression model. This might explain why depression, which was strongly correlated with neuroticism, subjective health, and loneliness, did not emerge as a predictor variable despite the fact that numerous studies have shown a relation between depression and measures of subjective memory (e.g., Bolla et al. 1991).

The overall amount of variance explained by the set of psychosocial variables of the three MIA-subscales was rather small. This underlines the notion of Hultsch et al. (1988) that self-appraisal of memory, as measured by the MIA, is not simply a re-expression of basic personality dimensions, although a substantial part of the variance on the MIA-Anxiety subscale is clearly associated with neuroticism. However, some interesting relations were found. In line with earlier studies (Evers et al., in press; Ponds \& Jolles, 1996a; Stevens et al., submitted), people with an active coping style, a better health, and more social support, were more likely to perceive themselves as having a good memory capacity. Moreover, greater stability or less decline in memory functioning was more likely if a person was younger, had a better health, and had a more active coping style. Greater neuroticism was related to more perceived decline in memory functioning, which suggest that the perception that memory is diminishing may in part be due to a neurotic personality (Hänninen et al., 1994; Poitrenaud et al., 1989; Ponds \& Jolles, 1996b). In the present sample, higher education was associated with less memory capacity and more decline in memory functioning. This is in contrast with our findings in a large-scale population study (Ponds \& Jolles, 1996a), where we found that lower education was associated with more perceived memory decline. A possible explanation for this is that the participants in the present study were more concerned about their memory functioning, as we explained before. We found earlier that the educational level of elderly people who were seeking help for their memory problems by either participating in a memory training program (Ponds \& Jolles, 1996a) or by visiting a memory clinic (Ponds et al., 1995) was above average. This suggest that subjective memory may be higher in better educated persons, but at the same time the higher educated person is more likely to worry about his or her diminishing memory at older age.

No differences in cognitive functioning were found between the high and low subjective memory groups, although, overall, the low subjective memory group had somewhat lower test scores than the high subjective memory group. This overall poorer performance of the low subjective memory group could be mainly ascribed to their lower educational level. Thus the main conclusion must be that subjective memory is not related to objective memory of cognitive abilities. However, an interesting age $x$ group interaction was found when the groups were split into an old and a young subsample, showing that the older low subjective memory group had a poorer overall performance, especially for the list-learning or episodic memory task, than the younger low subjective memory group. This suggests that there may be a direct relation between 
objective and subjective memory in people in the oldest age, which was also found recently in studies of Jonker, Launer, Hooiler \& Lindeboom (1996) and Schofield et al. (1997). The group differences with respect to the contextual variables mainly reflected, as expected, the findings of the mulliple regression analyses. From a more clinical perspective, however, it is important 10 note that the neuroticism and depression scores were at the upper limits of the nomal range.

Despite the absence of a clear relation between measures of objective and subjective memory in this study, self-assessment of memory is important for at least two reasons. Firstly, it is possible that subjective memory complaints do reflect very subtle real changes in memory which cannot yet be detected with memory or cognitive tests. These complaints may announce the development of dementia (Schmand, Jonker, Geerlings \& Lindeboom, 1997; Schmand, Jonker, Hooijer \& Lindeboom, 1996\%. Secondly, measurement of subjective memory provides us with attitudinal information about an individual."s memory self-beliefs. These self-perceptions of memory may have a substantial impact on the behavior of elderly people in everyday memory-demanding situations, despite the fact that these perceptions are not veridical estimates of actual memory skills or competence (Lovelace, 1990). Findings similar to ours could be used to develop memory intervention programs for the elderly. For example, the relation between neuroticism and subjectiwe memory decline suggests that low subjective memory may at least in part be due to a more-or-less personality-related owerconcern about normal changes in memory functioning in old age, for which reassurance might be given by providing proper information about normal age-related forgetfulness.

At a practical level, the present findings underline the notion of Rabbitt and Abson (1990) that subjective memory measures should be administered together with measures of personality. In this way, it can be estimated in how far age differences in self-report of memory are attributable to poor self-regard or to actual age differences in memory functioning.

\section{References}

Arbuckle, T. Y., Gold, D., \& Andres, D. (1986). Cognitive functioning of older people in relation to social and personality variables. Joumal of psychology and aging, 1,55.62.

Arbuckle, T. Y., Gold, D. P., Andres, D., Schwartzman, A., \& Chaikelson, J. (1992). The role of psychosocial context, atge, and iatelligence in memory performance of older man. Psychology and Aging. 7, 25-36.

Arrindell, W. A. \& Ellema, J. H. M. (1986). SCL-90. Een multidimensionele prychopathologie indicator (The SCL 90 . A mulidimensional instrument for the assessment of psychopathology. Lisse. The Netherlands: Swets \& Zeillinger.

Bazargan, M., \& Barbre. A. R. (1994). The effecis of depression, health status, and stressful life-events on selfreported memory problems among aged blacks. Intemational Journal of Aging and Homan Development. 38 , $351-362$

Bolla, K. I., Lindgren, K. N., Bonuccorsy, C., Bleecker, M. L. (1991). Memory complaints in older adults. Fact or fiction? Archives of Neurology, 48, 61-64.

Commissaris, C. J. A. M., Jolles, J., Verhey, F. R. J., Ponds, R. W. H. M., Damoiseaux, V. G. M., Kok, G. J. (1996). Forgedfulness or dementia? Who is worried and why? Europecan Joumal of Public Health, 6, 297-299.

de $\mathrm{B}$ ie, $\mathrm{S}$. E. (1987). Standaardwragen 1987- Voorstellen wor whiformering van vracgstellingen naat achtergrondkennerken en interviews (Toward a standardization of quesrions conceming demographic variables in population studies). (2nd ed.). Leiden, the Netherlands: Leiden University Press.

de Jong-Gierveld, J., \& van Tilburg. T. (1991). Mantal of the Loneliness Scale. Amsterdan: Department of Social Research Methodology, Vrije Universiteit Ansterdan.

de Wilde. G. \&. S. (1970). Neurotische labiliteit gemeten volgens de vragenlijstmethode-Neurotic instability measured with the questionnatre method. (second edition). Amsterdarn: F. van Rossen. 


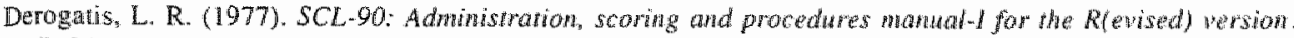
Ballimore: Johns Hopkins School of Medicine, Cinical Psychomentios Research Unit.

Derouesne, C., Aperowith, A., Arway, N. Migeon, P., Moulin, F., Vollam, M., Rapin, J. R., \& Le Poricin, M. (1989). Memory complain in the elderly: a siddy of 367 community-dwelling individuals front 50 to 80 years old. Archives of Gerontology and Geriatrics, Suppl. 1, $151-163$.

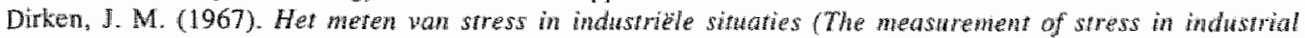
whorions. Groningen. The Nethenlands: Wolters.

Dixon. R. A., \& Hultsch, D. F. (1983). Metamemory and memory for text relationships in aduthood. Jowmal of Geromology, $38,689-694$.

Dixon, R. A., Hultsch, D. F., Hertzog, C. (1988). The metamemory in adulthood (MLA) questionnaire. Psychopharmacology Bulletin, 24,671-688.

Evers, S. M. A. A., Stewens, F. C. J., Diederiks, J. P. M., Ponds, R. W. H. M., Drop, M. J., Metsennkers, J. F. M., \& Jolles, J. (1998). Age-related differences in cognition: lifestyle, perceived lyeath shatus, and sociodemographic factors. European Joumal of Pablic Healh, $8,133-139$.

Folstein, M. F, Folsteim, S. E., \& McHugh, P. R. (1975). Mini-mental State: a practical method for grading the cognitive state of patients for the clinician. Jountal of Psychiotric Research, 12, 189-198.

Gilewski, M. J., \& Zelinski, E. M. (1986). Questionnaire assessnent of memory complaints. In L. W. Poon (Ed.). Handboak for climical memory assessment of older adwh (pp. 93-107). Washington: American Psychological Association.

Gold, D. P., A Arbuckle, T. Y. (1990). Interactions between personality and cognition and their implications for theories of aging. In E. A. Lovelace (Ed.), Aging and cognition: Menal processes, self awareness and inferventions (pp. 351-377). Amsterdam, the Netherlands: Elsevier Science.

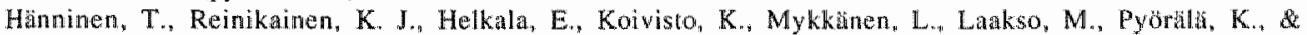
Riekkinen, P. J. (1994). Subjective memory complaints and personality traits in normal elderly subjects. Journal of the American Geriatrics Society, $42, \|-4$.

Herbog, C., Dixon, R. A., \& Hultsch, D. F. (1990), Relationships between metamemory, memory predictions, and memory task pertormance in adults. Psychology and Aging, 5, 215-227.

Herzog, A. R., Rodgers, W. L. (1989). Age differences in memoty performance and memory ratings as measured in a sample survey. Psychology and Aging, 4, 173-182.

Houx, P. J, \& Jolles, J. (1994). Vulnerability factors for age-telated cognitive decline. In R. L. Isancson \& K. IF. Jenssen (Eds.), The wulnerable brain and environmental risk (pp. 25-41). New York: Plenum Press.

Huilsch, D. F., \& Dixon, R. A. (1990), Learning and memory in aging. In J. E. Birren \& J. W. Schaie (Eds.), Handbook of the psycholagy of aging (pp. 258-274). San Dilego: Academic Press.

Hultsch, D. F., Herizog, C., Dixon, R. A. (1987). Age differences in metarnemory: Resolving the inconsistencies. Canadian journal of psychology: 41, 193-208.

Hulisch, D. F., Hertzog, C., Dixon, R. A., \& Davidson, H. (1988). Memory self-knowledge and self-efficacy in the aged. In N. L. Lowe \& C. I. Brainend (Eds,), Cogntine development in adwithocd: Progress in cognitive developmental research (pp. 65-92). New York: Springer-Wurlag.

Jonker, C., Launer, L. J., Hooijer, C. \& Lindeboom, 1. (1996). Memory complaints and memory impaiment in older individuals. Joumal of the American Gervaric Sociefy, 44, 44-49.

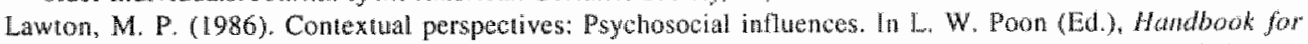
clinical nemory assesment of older adults (pp.93-107). Washington. American Psychological Association.

Lazak M. D. (1995). Newropsychological Assesshen. (Third edition ed.). New York: Ox Ford University Press.

Lovelace, E. A. (1990). Aging and metacognitions conerning memory function. In E. A. Lovelace (Ed.). Aging and cognition: mental processes, self awareness and interventiont (pp. 157-188). Anstardam, tha Nather ands: Elsevier Sctence.

Luszoz. M. A. (1993). When knowing is not enough: the role of memory beliefs in prose recall of older and younger adults. Australian Psychologist, $28,16-20$.

Lutejn, F, Starren, J., a wan Dijk, H. (1985). Hawdleiding bij de NPV - Manual for the NPV. North-Holland: Swets Zeitlinger.

Poitrenaud, J., Mabezin, M., \& Guez, D. (1989). Self-rating and psychometric assessment of age-related changes in memory among young-elderly managers. Developmental Neuropsychology, $5,285-294$.

Ponds, R. W. H. M., \& Jolles, J. (1996a). The abridged Dutch Metamemory in Adulthood (MLA) questionnaire: Structure, and effects of age, sex, and education. Psychology and Aging. $1,324-332$.

Ponds, R. W. H. M., Jolles, J. (1996b). Menory complaints in elderly peopte: The role of memory abilities, metamemory, depression, and personality. Educarional Cenontalkgy, 22, 341-357. 
Fonds, R. W. H. M. Sehridt, A. J. H., de Lugi, M. Lulofs, R., Verhey, F. R. J. \& Jolles, J. (1995), De angst on te vergeten: Behandeling van functinele geheugenklachen (The fea of forgeting: Trestment of functional

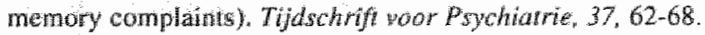

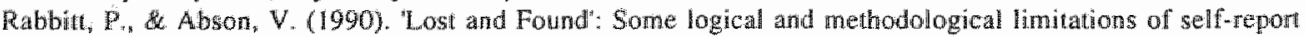
questionmaires as loolg to study cognitive angeng. British Hownal of Psychology, 81, 1\%. 16.

Salthouse, T. A. (1988). Resoure-reduction interpretations of cogniwye aging. Developmentol Revew, 8,238-272.

Schmand, B., Jonker, C., Geerlings, M. L. \& Lindeboom. J. (1997). Subjective memory complaints in the elderly: Rutiotion with depresswe symptoms and future dementa. British Joumal of Psyctiatry, $170,1-4$.

Sebrind, B., Jonker, C.. Hooijer, $C$, \& Windeboom, J. (1996). Subjective memory complaints may announce dementia, Nemology, $46,121-125$.

Schotield, P. W., Marder, K, Dooneief, O. Jacobs, D. M., Sano, M. \& Siern, Y. (1997). Association of subjective memory complaints whith subsequent cognitive decline in communty-dwelling elderly individuals whit baseline cognitive imparment. American journal of Psychiarry, 154, 609.615.

Schneurs, P. J. G., van de Willege, G., Tellegen, B., Brosschot, J. F. (1987). De Utrechse Copirg Lijst (UCL) - Khe Utrecht Coping List. Lisse: Swets \& Zeitlinger.

Stevens, F, C. J., Kaplan, C., Ponds, R. W. H. M. Diederiks, J. P. M, \& Jolles, J. (n press). Metamemory and active lifestyles. Age d Agking.

Taylor. J. La Miller, T. P. R Thiklenberg, J.R. (1992). Correlates of memory decline: A 4-year longitudinal study of older adults with memory complaints. Psychology and Aging, 7, $185-193$.

Vingerhoets; A. J. J. M., \& van Tiburg. M. A. L. (1994). Aledaagse Problemen Lijst - Everyday Problem Checklist. Lisse: Swets Test Servicas. 


\title{
Memory complaints in elderly people: The role of memory abilities, metamemory, depression, and personality ${ }^{*}$
}

\begin{abstract}
This study examined the relation between memory complaints, memory performance, and metamemory variables by comparing a group of elderly participants $(n=50)$ with memory complaints with a group of participants without memory complaints $(n=52)$. The groups were matched for age, sex, and education; mean age was 63 years. Data were also collected for personality variables (anxiety, neuroticism) and affective state. Metamemory was measured with the Metamemory in Adulthood (MIA) questionnaire. The memory tests used were the Auditory Verbal Learning Test, the Rivermead Behavioral Memory test, and two category fluency tasks. Significant group differences were found on all subscales of the MIA (except Locus) and for verbal fluency and depression. Logistic regression analysis with depression, memory performance, and the MIA as independent variables showed that only the memory self-efficacy factor of the MIA (subscales Capacity, Change and Anxiety) could discriminate between the groups. Furthermore, those in the memory complaints group had higher scores for neuroticism than those in the no-complaints group, whereas no differences were found with respect to the trait anxiety. The findings suggest that concern and complaints about memory in old age reflect memory self-efficacy beliefs rather than declining memory abilities.
\end{abstract}

* This chapter has been published in:

Ponds, R.W.H.M., \&olles, J. (1996) Educational Gerontalogy, 22, 341-357. 


\section{Introduction}

Menory complaints are very common among middle-aged and older adults. A study involving almost 15,000 participants aged 55 and older indicated that more than $15 \%$ reported having had frequent trouble remembering things in the past year, and almost $40 \%$ indicated that they sometimes had trouble remembering things (Cutler \& Grams, 1988). It is generally assumed that these complaints reflect an age-related decline in memory abilities, as many studies have shown that older adults show a decrease in performance on memory tests compared to younger adults, especially when the acquisition of new information is required (Craik \& Jennings, 1992). If memory complaints are primarily determined by memory abilities, there should be a close relation between memory complaints and memory performance: Elderly persons with memory complaints should have greater deficits in memory performance than elderly persons without memory complaints. Scogin, Storandt, \& Lott (1985) compared a group of elderly participants with memory complaints (who thad subscribed for a memory training) with a group of participants without complaints by using three memory recall tasks and two clinical memory tests (Digit Span forward of the WAIS-R and the Benton Visual Retention Test - BVRT). The only difference between the two groups, as assessed with 11 memory measures, was on the BVRT. Their conclusion that self-evaluation of memory is not systematically related to objective measures of memory performance is supported by the general finding that correlations between complaints, as measured by memory questionnaires, and performance on memory tests are mostly lacking or only modest (Gilewski \& Zelinski, 1986).

It is often argued that this absence of clear correlations may be due to shortcomings of the psychometric tests used. For example, the ecological validity of most memory tests is low. Traditional memory tests are, in terms of everyday memory, highly artificial. The material that has to be memorized as well as the way in which the material is presented to the subject shows little or no resemblance to everyday memory tasks, whereas memory questionnaires explicitly focus on problems in everyday memory situations (Kausler, 1989). Furthermore, many people, and especially those who are forgetful, have difficulty in objectively assessing their own daily memory failures.

Although these measurement problems contribute to the lack of a straightforward relation between memory complaints and memory performance, it is increasingly recognized that memory complaints and memory performance in elderly people are not solely determined by actual memory abilities or skills, but are also related to personality variables such as introversion or neuroticism (Gold \& Arbuckle, 1990), depressive mood (Bolla, Lindgren, Bonaccorsy, \& Bleecker, 1991), level of social and intellectual daily activities (Arbuckle, Gold, \& Andres, 1986), and knowledge and perceptions about one's own memory. These self-perceptions are termed metamemory (Huitsch, Hertzog, Dixon, \& Davidson, 1988).

An important aspect of metamemory is memory self-efficacy, an individual's belief in his or her memory abilities, strengths, and weaknesses. Athough these efficacy beliefs are not necessarily veridical estimates of actual memory abilities, they may have a strong influence on the way people use their memory in everyday situations (Bandura, 1989; Lovelace, 1990). If these beliefs are strongly negative, they may easily lead to a self-fulfilling prophecy. For example, negative self-efficacy beliefs may create a strong attentional bias towards everyday forgetfulness. 
As the result of low expectations about successful memory perfomance, a person may decide not to engage in memory-demanding situations or to decrease his or her effort expended on everyday memory tasks. This in turn may lead to an increased awareness of memory failune and strengthen the negative memory self-efficacy beliefs.

In this study we examined the relation between memory complaints, memory performance, and metamemory wariables by contrasting a group of elderly participants with explicit memory complaints with a control group of elderly participants without memory complaints. Elderly people with memory complaints were selected from a pool of subjects who had registered for a memory training program. In addition to memory assessment, data were collected about personality traits (trait anxiety, neuroticism), mood, and background variables related to daily intellectual and social activities (e.g., reading books). It was axpected that group differences would be found on most measures, with the memory-complain group having lower memory self-efficacy beliefs, higher scores for anxiety and neuroticism, nore depressive symptoms, and a life-style that could be viewed as less cognitively challenging than the control group. No group differences were expected with respect to memory performance. The group with memory complaints is referred to as the high-complaint group, whereas the control group is referred to as the low-complaint group.

\section{Method}

\section{Panticipants}

Seventy-four participants who had responded to a newspaper adwertisement recruiting alder adults with memory complaints for a memory training program, were invited to participate in the study. Fufty-six training participants were willing to participate. They were matched for age, sex, and educational level with 56 control participants who were recruited from an existing pool of healthy volunteers. The Mini-Mental State questionnaire was used to exclucle subjects who were possibly in an early stage of dementia, using a cutoff score of $\leq 23$ (Folstein, Folstein, \& McHugh, 1975). Three training participants scored below this cutoff score and were excluded from the study (MMSE scores of 23,23, and 21). Furthermore, four control participants and three training participants were excluded because too many data were missing on the metamemory questionnaire (see Measures).

The remaining group of 50 training participants had a mean age of 63.1 years $(S D=8.7)$ and included 35 women and 15 men. Educational level was measured by a Dutch scoring system developed by Verhage (Verhage, 1964), which consists of a 7-poini scale, ranging from unfinished primary education (level 1) to university education (level 7). The mean educational level of the training group was $4.4(S D=1.2)$. The control group of 52 participants ( 37 women and 15 men) had a mean age of 63.5 years $(S D=10.2)$ and a mean educational level of $4.4(S D=$ 1.3). 
Mecisures

Memory selfassesment. Three memory questionnaires were used: the Metamemory in Adulthood (MIA) Questionnaire (Dixon, Hultsch \& Hertzog, 1988), the Memory Assessment Clinics Self-Raring Scale (MAC-S), and the Memory Assessment Clinics Rating Scale for Family Members and Others (MAC-F) (Winterling, Crook, Salama, \& Gobert, 1986).

The MA is one of the most widely used metamemory questionnaires. Participants are asked to rate on a 5-point Likert scale 108 statements describing their own memory functioning and their general knowledge of memory processes. The MLA consists of 7 subscales: Strategy (use of memory strategies to improve memory perfomance), Task (knowledge of basic memory processes), Capacity (beliets about personal memory capacity), Change (perceived change in memory functioning): Anxiety (feelings of stress and anxiety related to memory performance), Achievement (personal motivation to perform well in memory situations), and Locus (perceived sense of control over memory abilities). Hertzog. Hultsch and Dixon (1989) found evidence for a higher order factor called Memory Self-Efficacy (MSE) consisting of the subscales Capacity, Change, Anxiety. The MSE factor is thought to reflect beliefs about personal competence in various memory situations. Respondents who had not filled in $5 \%$ or more of the MIA questions ( 6 or more questions) were excluded from the study. Remaining missing values on MIA questions were replaced by repondents" mean subscale item score.

In this study only the Frequency of Occurrence subscales of the MAC questionmaires were used. The Frequency scale consists of 24 items. On the MAC-S Frequency scale participants indicated on a 5 -point Likert scale how often specific memory problems occurred (e.g." "fail to recognize people who recognize you"). Responses ranged from "very often" (1) to "very rarely" (5). On the MAC-F' Frequency scale a close relative of the participant was asked to rate the occurrence of the same specific memory problems for that participant. Missing values (if fewer than 2) were replaced by participants" mean item score. Both questionnaires also included four globall itens. In these items participants (or a close relative in the case of the MAC-F) were asked, using a 5-point Likert scale, to describe their memory compared to that of others (Comparison with others: runge "very poor" to "very good"), to describe their memory as compared to the best it had ever been (Comparison with optimum: "much worse" to "much better"), to describe the speed of remembering as compared to the best it had ever been (Speed of remembering" "much slower" to "much faster"), and finally to describe their concern about their memory (Concern about memory: "very seriously concerned" to "hot concerned").

Memory performance. Three memory tests were used to assess menory performance: a modified version of the Auditory Verbal Learning Test (AVLT; Lezak, 1983), which measures encoding and retrieval of verbal information, the Rivermead Behavioral Memory Test (RBMT; Wilson, Cockburn, Baddeley, 1985), which measures everyday memory, and wo verbal category fluency tasks, which measures retrieval from semantic memory (Lezak, 1983).

The AVLT consists of 15 monosyllabic meaningful words which are presented to the subject five times. After each presentation the participant is requested to recall as many words as possible with no restriction concerning the order of recall (immediate recall). Twenty minutes after the fifth presentation, the participant is again requested to recall as many words as he or she can remember (delayed recall). The variables of interest were the total number of correctly remembened words 
over trials $1-5$ (immediate recall, maximum score 75 ) and the number of words remembered on delayed recall (maximum score 15 ).

The RBMT was developed to bridge the gap between strictly experimental and more naturalistic measures of memory, and is considered to have more ecological validity than standard memory tests. The test consists of several items which are comparable with everyday menory tasks (e.g., remembering an appointment, a route, a newspaper story, a nane or where an personal object is laid aside). The variable of interest was the standard profile score (maximum score 24).

Two verbal category fluency tasks were used. In the 'animal' fluency task, the participants were asked to name as many different animals as possible in I minute. In the 'profession" Duency task, they were asked to name different professions. Variables of interest were the number of correctly named animals or professions.

Personality and mood variables. Depressive complaints were assessed with the Zung Self-Rating Depression Scale (Zung, 1965). The ZUNG consists of 20 items which reflect psychological and physiological correlates or symptoms of depression. The presence of the symptoms could be rated by the participant on a 4-point scale, ranging from "little/none of the time" (1) to "most of the time" (4). Higher scores on this scale indicate the presence of more depressive symptoms.

A Dutch version of the Trait scalle of the State-Trait Anxiety Inventory (STAI) of Spielberger was used to assess the general susceptibility to feelings of anxiety and stress (Van der Ploeg, Defares, \& Spielberger, 1981). The Trait scale consists of 20 items which can be scored on a 4-point scale. Higher scores indicate greater trait anxiety.

Neuroticism was assessed with a Dutch neuroticism questionnaire (Amsterdamse Biografische Vragenlijst-ABV; de Wilde, 1970). The ABV neuroticism scale consists of 30 items, in which the participants indicate the absence of ("no"), presence of ("yes"), or undecidedness about ("?") feelings of stress and worry (e.g., "Do you often feel guilty about something", "Do you often worry about the past"). Higher scores indicate a higher level of neuroticism.

Oher variables of interest. Data about backgnound wariables such as hours spent watching lelevision, reading books, or main social activities outside the house, were collected during a semi-structured interview. This was done because Salthouse, Kausler, \& Saults (1988) suggested that there may be an interaction between the effects of age and these background variables on cognitive competence. During the same interview the elderly participants from the high complaint or training group were asked what they thought was the main cause of their forgetfulness.

\section{Procedure}

The training participants received the memory questionnaires during an introductory meeting which took place 2 weeks before the memory training started. The memory questionnaires were filled in at home and returned at the first memory training meeting. In the next 2 weeks all training participants were visited and assessed at home. The control participants were also assessed at home. They received the questionnaires a few weeks before they were wisited and returned the questionnaires at the start of the home visit.

The training participants were recruited from 2 successive memory training programs. The 
newroticism and anxiety questionnaires were added to the study at a later stage and were only given to the participants recruted from the second memory training and their controls (28 training participants and 29 controls).

During the home visit a short semi-structured interview took place and the three memory tests, the MMSE and the remaining questionnaires were administered in the following order: MMSE, RBMT, ABV, AVLT trials 1-5, interview, AVLT delayed recall, Zung, ZBV, Fluency. All participants were paid for their participation.

\section{Results}

We conducted multivariate and additional univariate analyses of variance separately for the memory questioniaires and the memory test. Means, standard deviations, and the p-values of the univariate $F$ tests of the major variables of the study are presented in Table 8.1.

Table 8.1 Means and standard deviations of the main variables.

$$
\begin{array}{cc}
\text { High-complaine group } & \text { Low-complaint group } \\
(n=50) & (n=52)
\end{array}
$$

$M \quad S D \quad M \quad S D \quad p^{\mathrm{a}}$

Mewory quesfiomaines

\begin{tabular}{|c|c|c|c|c|c|}
\hline Frequencyb & 3.17 & 0.60 & 3.75 & 0.43 & .000 \\
\hline Comparison win others & 2.84 & 0.71 & 3.42 & 0.74 & .000 \\
\hline Comparison with optimum & 1.76 & 0.63 & 2.35 & 0.68 & .000 \\
\hline Spend of menemberime & 1.94 & 0.79 & 2.35 & 0.59 & .004 \\
\hline Conctral about themory & 2.90 & 1.09 & 3.75 & 0.99 & .000 \\
\hline
\end{tabular}

MAC-S

MAC-DG

Frequency b

Comparison with others

Comparison with optintum

Speed of nemenbering

Concern aboun nemory

$\begin{array}{ll}3.48 & 0.56 \\ 3.07 & 0.82 \\ 2.07 & 0.76 \\ 2.07 & 0.76 \\ 3.18 & 11.38\end{array}$

\subsection{0}

0.42

.000

3.84

0.52

.000

$2.71 \quad 0.59$

.000

$2.69 \quad 0.67$

.000

$4.16 \quad 0.99$

.000

Note. Mac-S = Memory Assessment Clinies Selfraing scale; MAC-F = Memory Assessment Clinics Rating Scale for Family.

U Unipuriate $F-$ test.

b A low score on this scalle means more complaints.

High-complaint group: $n=44 ;$ Lowncomplaint group: $n=45$. 
Table 8.1 Means and standard deviations of the main wariables (continued).

\begin{tabular}{|c|c|c|c|c|c|}
\hline & \multicolumn{2}{|c|}{$\begin{array}{l}\text { High complain group } \\
\qquad(n=50)\end{array}$} & \multicolumn{2}{|c|}{$\begin{array}{l}\text { Low-complaint group } \\
\qquad(n=52)\end{array}$} & \multirow[b]{2}{*}{$p^{a}$} \\
\hline & $M$ & $S D$ & $M$ & $S D$ & \\
\hline \multicolumn{6}{|l|}{ Memory questionnaires } \\
\hline \multicolumn{6}{|l|}{ MA } \\
\hline Strategy & 3.78 & 0.44 & 3.42 & 0.55 & .000 \\
\hline Task & 4.05 & 0.39 & 3.78 & 0.38 & .001 \\
\hline Capacity & 2.56 & 0.61 & 3.11 & 0.52 & .000 \\
\hline Change & 2.13 & 0.54 & 2.84 & 0.61 & .000 \\
\hline Anxiety & 3.55 & 0.69 & 2.90 & 0.60 & .000 \\
\hline Achievement & 4.14 & 0.45 & 3.75 & 0.47 & .000 \\
\hline Locus & 3.17 & 0.44 & 3.13 & 0.58 & .687 \\
\hline \multicolumn{6}{|l|}{ Memory rests } \\
\hline \multicolumn{6}{|l|}{ AVLT } \\
\hline innmediate recall trials $\Downarrow-5$ & 43.5 & 10.7 & 45.9 & 8.7 & .212 \\
\hline delayed recall & 8.8 & 3.1 & 9.4 & 2.7 & .334 \\
\hline RBMT' standard profile & 20.3 & 2.8 & 20.9 & 2.4 & .232 \\
\hline \multicolumn{6}{|l|}{ Filtency } \\
\hline animals & 19.8 & 4.2 & 23.9 & 5.5 & .000 \\
\hline professions & 14.9 & 4.3 & 17.0 & 4.4 & .016 \\
\hline \multicolumn{6}{|c|}{ Mood and personality questionnaires } \\
\hline Zung depression & 38.0 & 8.6 & 34.2 & 7.0 & .015 \\
\hline Trail Anxietyd & 40.0 & 10.4 & 38.0 & 10.3 & 468 \\
\hline Neuroticismd & 61.7 & 25.9 & 48.6 & 24.2 & .054 \\
\hline
\end{tabular}

Note. MIA = Metamemory in Adulthood questionnaire: $A$ VLT $=$ Auditory Verbal Learning Task; RBMT $=$ Rivermend Behavioral Memory Test:

d High-complaint group: $n=28$; Low-complaint group: $n=29$.

\section{Memory self-assessment}

The data for the MAC-S questionnaire showed an overall difference between the groups $(F(5,96)$ $=7.89, p<.001)$. As expected, the high complaint group reported significantly more everyday memory failures than the low-complaint group. There were also clear differences on the four global items of the MAC-S. The participants of the high-complaint group described their memory 
as being worse than that of others and that their memory had declined considerably from the best it had ever been. They were more concerned about this decline, and they also reported a significantly greater decrease in speed of remembering. The same pattern of results was found for the MAC.F questionnaire $(F(5,83)=6.70, p<.001)$, although the mean scores for both the high- and low complaint groups were higher than those for the MAC-S questionnaire. The mean scores for "Frequency" and "speed of remembering" of the high-complaint group were significantly higher on the MAC-F than on the MAC-S questionnaire. The mean scores on the MAC-F of the low-complaint group were all, with the exception of "concern about memory", significantly higher than the scores on the MAC-S $(p<.05)$.

A significant overall effect was found on the MIA $(F(7,94)=7.42, p<.001)$. Univariate tests revealed that these differences appeared on all subscales, except for the Locus subscale. The high-complaint group had a poorer perception of their memory capacity (Capacity), reported a greater decline of memory over the years (Change), reported more feelings of stress and anxiety related to memory performance in daily life (Anxiety), and had a significantly higher level of motivation to achieve well in everyday memory tasks (Achievement). The high-complaint group also had significantly more knowledge of basic memory processes (Task) and used memory strategies more frequently (Strategy) than the low-complaint group.

\section{Memory performance}

There was a significant overall effect on memory performance $(F(5,96)=3,69, p=.004)$, which could be ascribed to the significantly lower scores on both fluency tasks of the high-complaint group. No group differences were found on the RBMT and AVLT.

\section{Depression, anxiety and newroticism}

As only the Zung list was filled in by all the participants, only univariate $F$ tests could be used for the analysis. The high-complaint group had a significantly higher score on the Zung depression scale than the low-complaint group. The mean Zung scores for both groups were, however, within the normal range and were not indicative of depression (Zung, 1965). The high-complaint group had a far higher mean score on the neuroticism scale than the low-complaint group ( $p=$ .054). Compared to the neuroticism score of a normal population, the mean neuroticusm score of the high-complaint group corresponded to the seventh decile for norms for women and the eighth decile for norms for men. The mean score of the low-complaint group conresponded to the fifth decile for women and the sixth decile for men (de Wilde, 1970). No group difference was found on the trait anxiety questionnaire; the mean scores for both groups were within the normal range (fifth to sixth decile; Van der Ploeg et al, 1981)

\section{Background pariables}

Table 8.2 shows the participants" main activities outside the house. The subjects could report more than one activity. Duration of these activities in terms of hours per week or months is not taken into account. No differences were found between the groups $\left(X^{2}(4, N=220)=2.05, p=\right.$ 725). The low-complaint group spent more time watching TV daily and reading than the 
high-complaint group. These differences, however, were not statistically significant ( $\mathrm{rV}: \mathrm{t}(100)=$ $1.82, p=.071$; reading: $(100)=0.66, p=.509)$.

Table 8.2 Background variables of the high and low complaint groups.

$$
\begin{gathered}
\text { High-complain group } \\
(n=50)
\end{gathered} \quad \begin{gathered}
\text { Low-complaint group } \\
(n=52)
\end{gathered}
$$

Main acrivities out of the house $N$

$\begin{array}{lcr}\text { participating in clubs or other types of organizations } & 25 & 25 \\ \text { visiting family and friends } & 19 & 22 \\ \text { walking/sport } & 37 & 38 \\ \text { courses (no formal education) } & 14 & 9 \\ \text { volunteer work } & 13 & 18\end{array}$

\begin{tabular}{llllll} 
Wotching TV and reading & $M$ & $S D$ & $M$ & $S D$ \\
\hline Hours watching TV (daily) & 1.91 & 0.86 & 2.25 & 1.10 \\
Hours reading (daily; newspapers, books, magazines) & 1.29 & 0.84 & 1.41 & 0.94
\end{tabular}

\section{Attribution of the memory problem}

Table 8.3 shows the main causes of forgetfulness given by the participants in the high-complaint group. Aging was mentioned by 12 participants as the main cause of their everyday forget fulness. Twelve participants thought that their forgetfulness was due to emotional problems (tension, stress). If indifference or lack of interest is taken together with lack of concentration, 12 participants ascribed their memory complaints mainly to problems of attention. Six participants related their memory complaints to physical health problems.

\section{Addirional analysis}

The high-and low-complaint groups clearly differed from each other with respect to memory beliefs and behavior, as measured by the MLA. These differences were less clear with respect to memory performance, were significant differences, were found only on the fluency tasks. There was a significant but only small difference on the Zung depression scale. To examine the relative contribution of the various variables in distinguishing between the two groups, we performed at logistic regression analysis with group as dependent variable and the memory tests, Zung, and the subscales of the MIA as the independent variables. 
Tuble 8.3 Main possible couses offorgetfulness nemtioned by the high group $(n=50)$.

\begin{tabular}{lc}
\hline Cawse & \\
\hline aging & 12 \\
tensions / stress & 12 \\
indiffenence / lack of inverest & 6 \\
lack of concentration & 6 \\
physical health problems & 6 \\
fear of dementia & 3 \\
allways been forget ful & 2 \\
miscellaneous & 2 \\
unknown & 1 \\
\hline
\end{tabular}

To reduce the number of independent variables, we compressed the performance on the different memory tests into a single memory index score. For each memory measure the median score for all participants was taken as a cuttoff. If the individuall test score was below the median, the memory score was set to 0 ; if the test score was equal or above the median, the memory score was set to 1 . All 5 memory scores were then condensed into a single memory index score (minimum-maximum score: $0-5$ ). The high-complaint group had a significantly lower score on the memory index than the lowacomplaint group $(2,42$ versus $3,21, t(100)=2.43, p=.017)$.

Table 8.4 Logissic Regression Analysis with group as the dependent variable and Zung depression score, memory inder, and she siascales of the MAA as independent variables.

\begin{tabular}{|c|c|c|c|c|}
\hline & $B$ & $\$ E$ & $p$ & $R$ \\
\hline Memory index & .12 & .18 & .467 & .00 \\
\hline Zung depression score & $=01$ & .04 & .808 & .00 \\
\hline MIA-Memory Self-Efficacy & .72 & .23 & .002 & .25 \\
\hline MiA-Memory Task & -.96 & .84 & .250 & .00 \\
\hline MIA-Memory Strategy & -.82 & .61 & .180 & .00 \\
\hline MA-Memory Achievement &. .53 & .64 & .410 & .00 \\
\hline MIA-Memory Locus & .04 & .57 & .948 & .00 \\
\hline
\end{tabular}

Note. $B=$ estimated logistic regression coefficients; $S E=$ standard errors of the coefficients $p=$ significance level for the Wald statistic for testing the bypothesis that the coefficient is different from $0 ; R=$ partial correlation between the dependent variable and each of the independent variables (if the Wald statistic is less than 2, R is set to $0)$.

a The subscales Capacity, Stability, and Anxiety were combined into a Memory Self-Efficacy score. 
As suggested by Herzog et al. (1989), the MIA subscales Capacity, Change, and Anxiety were put together to form one Memory Self-Efficacy factor (MSE). The data from the neuroticism and anxiety questionnaires were not taken into the analysis. This reduced the number of participants for the analysis to 57 , about 15 participants per independent wariable are needed for a reliable regression equation. The memory index score and the $Z$ ZUNG were entered first into the regression analysis, followed by the MSE and the MIA subscales Task, Strategy, Achievement, and Locus. The results of the regression analysis are shown in Table 8.4. Overall, 73.5\% of the participants were correctly classified according to the logistic regression model. Only the MSE of the MIA had a significant contribution in this model. Contributions of the memory index score, the $Z$ UNG, and the remaining MIA subscales were nonsignificant.

To further examine the relation between the mood and personality variables, memory performance and MSE, we computed correlations for these variables (Table 8.5). As expected, the mood and personality variables were highly correlated. MSE beliefs were positively correlated with memory performance, although this correlation was modest. Negatiwe correlations were found between depression, anxiety and neuroticism and MSE, but only depression showed a negative correlation with test performance.

Table 8.5 Pearson Product-Monent correlations.

I

2

3

4

5

$\begin{array}{ll}\text { 1. } & \text { MIAwMSEa } \\ \text { 2. } & \text { Memory index } \\ \text { 3. } & \text { Zung depression } \\ \text { 4. } & \text { Trait Anxiety } \\ \text { 5. } & \text { Neuroticism }\end{array}$

Note. Correlations between MIA-MSE, Memory index and the Zung are based on 102 subjects; correlations for Trail Arxiety and Neuroticism are based on 57 subjects.

a Memory self-efficacy score of the MIA; see text for explanation.

b Memory index score "see text for explanation.

$* p<05$. * $p<01$.

\section{Discussion}

Two remarks must be made about the generalizability of the findings in this study. Firstly, the participants attending a memory training program were taken as model for elderly people with memory complaints. However, attendance of such program suggests that the person has an active and efforfful way of coping with his or her memory problems. This way of dealing with memory problems may not be shared by all elderly people with memory problems. Secondly, there may have selection bias. Of a group of 74 training participants, 52 were willing to participate in the 
study. All invited participants knew that they would be given memory tests. It is thus conceivable that participants with memory deficits were too anxious to undergo the memory tests and did not paricipate for that reason.

The results show that the presence of memory complaints in a group of normal healthy community-dwelling older persons is not direclly rellated to a clear decline in memory, as measured with standard and ecological memory tests. This is in line with the results of Scogin et al.(1985). As expected, the most important difference between the high-and low-complaint groups seems to be memory self-efficacy beliefs. This was the only factor of the MIA that clearly distinguished between the two groups. All other variables in the logistic regression model (memory index score, depression score, MLA-subscales Strategy, Task and Achievement) showed significant group differences, with the exception of the Locus subscale, but did not clearly distinguish between the two groups.

Of the three memory tasks, only the fluency category discriminated the high-complaint group from the low-complaint group. It is interesting that fluency tasks have been shown to be very sensitive discriminators between normal healthy controls and mildly impaired patients with dementia of the Alzheimer type (Monsch, Bondi, Butters, Salmon, Katzman, \& Thal, 1992). Most studies that focus on the relation between complaints and memory performance in elderly persons have only used tasks that involve encoding and retrieval of new information from Jong-term memory. These studies have shown there to be no or only modest correlations between complaints and memory performance. Studies need to be performed to determine whether fluency tasks are superior to encoding tasks in detecting people with memory complaints in a healthy population of elderly persons. Theoretically, this could mean that the earliest effect of aging on the memory system is a deterioration of or a decreased access to the semantic knowledge system. This, in turn, would affect the encoding of new information.

Close relatives of the elderly participants in the high-complaint group also noticed that their relatives had daily memory problems more than did the relatives of the low-complaint participarns. This finding is less plausible than it seems. An alternative explanation would be that the elderly participants in the high-complaint group overestimated their normal age-related daily memory failures because they were anxious about incipient dementia. For example, Commissaris, Verhey, Ponds, Jolles, \& Kok (1994) found that $50 \%$ of the people who attended a public information meeting on the subject of age-related forgetfulness were worried about their memory and more than hatf of this group was also afrad of dementia. About $10 \%$ of the people were even convinced that forgetfulness in people aged 65 years and older is a prodrome of dementia. In this study, however, fear of dementia was only mentioned by 3 of the 50 participants in the high-complaint grotip.

Personality measures were assessed in the second part of the study only. The high-complaint group not only thad higher neuroticism scores than the control group, but also higher scores than a normal population. However, the depression and anxiety scores of the high-complaint group were within the normal range. Summarizing the literature on neuroticism, aging and cognitive performance, Gold and Arbuckle concluded that greater neuroticism is in general associated with a poorer outcome on measures of cognitive functioning, although the effects are usually small (Gold \& Arbuckle, 1990). In a large sample of elderly persons, Arbuckje et al. (1986) found that neuroticism was negatively related to memory performance, but unrelated to subjective memory rating. In our study, however, the opposite was found. Neuroticism was significantly correlated 
to memory-self efficacy, whereas no correlation was found with memory performance.

Several researchers (Ryan, 1992; Levy \& Langer, 1994) assume that age-related decline in memory and low self-evaluation of memory are not solelly determined by biological factors, but also by the widespread negative stereotypes about the inevitable decline of memory in old age. On the basis of this assumption, we expected that aging would be mentioned by most subjects in the high-complaint group as the main cause of their forgetfulness. However, anging was mentioned by fewer than a quarter of the subjects, with both emotional problems and problems of insufficient attention both being mentioned as often as aging. This finding suggests that the contribution of negative social expectations in age-related memory decline, either objective or subjective, may be smaller than assumed.

Our findings suggesi that memory self-efficacy beliets are more important for explaining daily memory problems in elderly people than memory competence or abilities themselves, with effort being the possible mediating factor (Bandura, 1989; Cavanaugh \& Green, 1990). If people have low memory self-efficacy beliefs, they may spend less effort in everyday situations that make demands on their memory (or even avoid them). This in turn may lead to an increase in everyday memory failures and further lowering of memory self-efficacy beliefs. However, some of our findings are not in line with this explanation. The high-complaint group used memory strategies more frequently than the low-complaint group and sought help for their memory problems by attending a memory training program, which suggests that these subjects took an active approach to cope with their memory problems. The data about daily activities in and out of the house are not consistent with the implicit assumption that the elderly people in the high-complaint group could be characterized by an avoidance of cognitively challenging social activities (e.g., participating clubs) on cognitive activities (e.g., reading). It is also questionable whether it is neccesary to hypothesize about a causal relationship between memory self-efficacy beliefs and aged people's everyday memory problems. Could it not be that complaining about memory is just an example of a general attitude to complain because of a neurotic personality structure, given the strong correlation between memory self-efficacy and neuroticism in this study? It would be interesting to see whether differences in memory self-efficacy beliefs between high- and low-complaint groups would still be found if the participants were also marched for neuroticism.

Given that memory tests make demands on memory, one might also ask why the low memory-efficacy beliefs of the high-complaint group did not have a more detrimental effect on their memory performance. An explanation might be that the test situation is very different from the memory situation in daily life, in that during testing the subjects were not only reassured but also encouraged to do their best, which led to the full use of their potential memory abilities. In other words, in a face-to-face test situation memory competence rather than memory confidence is measured.

Although this study was not designed to evaluate memory training for elderly people, its findings are relevant to the further development of memory trainings programs. Most of these programs focus explicitly on the learning of memory strategies. This is based on the mostly implicit assumption that memory functioning of the elderly with memory complaints is declined and this decline can be compensated by the use of memory strategies. The results of this study support the notion that memory training programs should focus more on restoring the control over the intact memory skills of elderly persons by paying more attention to changing negative attitudes and expectations about memory (e.g., Lachman. Weaver, Bandura, Elliot, \& Lewkowicz, 1992). 


\section{References}

Arbuckle, T: Y.. Gold, D., \& Andres, D. (1986). Cognitive functioning of older people in relation to social and personatiy variables. Journal of psychology and aging, $1,55-62$.

Bandtua, A. (1989). Regulation of cogritive processes through perceived self-efficacy. Dewelopmental Psychology, $25,729.735$.

Bolla, K. I, Lindgren, K. N., Bonaccorsy, C. \& Bleecker, M. L. (1991). Memory complatints in older adults. Fact or hecion? Archives of Newrology, 48, 61.64.

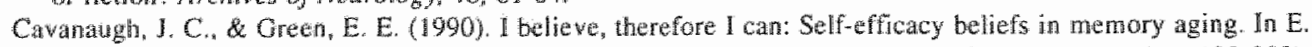
A. Lovelace (Ed. A. Aging ard cogninion: Mental processes, selfawareness and intententions (pp. 189-229). Ansterdam, the Netherlands: Elsevier Science Publishers.

Commissaris, C. J. A. M., Verhey, F. R. J., Ponds, R. W. H. M., Jolles, J., \& Kok, G. 1. (1994). Public education about nomal forgetfulness and dementia: importance and effects. Patient Edwcation and Comseling. 24. $109-115$

Craik, F. I. M., Jennings, J. M. (1992). Human memory. In F. L. M. Craik \& T. A. Salthouse (Eds), Hondbook of aging and cognwion (pp. 51-110). Hillsdale: Lawrence Erlbaum Associates.

Culler, S. J., \& Grams, A. E. (1988). Comelates of self-reported everyday memory problems. Jaurnal of Gerontology: Social Sciences, 43,82-90.

Dixon, R. A., Hulsch, D. F, \& Hertzog, C. (1988). The metamemory in adulthood (MLA) questionnaire. prychopharmacology Bullewin. 24,671-688.

Folstein, M. F., Folstein, S. E., \& McHugh, P. R. (1975). Miri-mental State: A practical memod for grading the cognitive state of patients for the clinictan. Jowmal of Psychiatic Research, $12,189-198$.

Gilewski, M. J., \& Zalinski, E. M. (1986), Questionraire assessment of memory complaints. In L. W. Poon (Ed.). Handbook for clinical memory assessmem of older aduls (pp. 93-107). Washington: American Psychological Association.

Giold, D. P. \& Arbuckle, T. Y. (1990). Interactions between personality and cognition and their implications for theories of aging. In E. A. Lovelace (Ed.). Aging and cognition: Mental processes, self awareness and interventions (Pp. 351-377). Amsterdam, the Netherlands: Elsevier Science Publishers.

Hertzog, C. Hultsch, D. F. \& Dixon, R. A. (1989). Evidence for the convergent validity of wwo selfareport metamenory questionnaires. Developsnental Psychology, 25, 687.700.

Hultsch, D. F.. Hertzog, C., Dixon, R.A., \& Davidson, H. (1988). Memory self-knowledge and selfefficacy in the aged. In N. L. Lowe \& C. J. Brainerd (Eds.), Cognitive development in adulthood: Progress in cognitive developmental research (pp. 65-92). New York: Springer Verlag.

Kausler, D. H. (1989). Comments on aging memory and its everyday operations, In $L_{\text {. W. Poon }}$ D. C. Rubin, \& B. Wilson (Eds), Everyday cognition in adulthood and late life (pp. 483-495). Cambridge: Cambridge University Press.

Lachman, M. E., Weaver, S. L., Bandura, M., Elliot, E ${ }_{4}$ \& Lewkowicz, C. J. (1992). Improving memory and control belliets through cogmitive restructuring and self-genernted strategies. Joumal of Geromology: Psychologicat Sciences, 47, 293-299.

Levy, B., Langer, B. L. (1994), Aging free fron negative stereotypes: Successful memory in China and among the Anerican deaf. Joumal of Persomality and Social Psychology, 66, 989-997.

Lezak. M. D. (1983). Nenropsychological Assessmenu (Second edition). New York: Oxford University Press.

Lovelace, E. A. (1990). Aging and metacognitions concerning memory function. In E. A Lovelace (Ed.), Aging and cognition: Mental processes, self awarewess and intervemions (pp. 157-188). Ansterdam, the Netherlands: Elsevier Science Publishers.

Monsch, A. U., Bondi. M. W., Butters, N., Samon, D. P., Katzman, R., That, L. J. (1992). Comparisons of werbal thency tasks in the desection of dementia of the Alzheimer Type. Archives of Nearolog\%, 49, 12531258.

Ryan, E. B. (1992). Belliefs about memory changes across the adult life span. Joumal of Gerontogy, 47, 41.46.

Salthouse, T. A. Kauster, D., \& Saults, J. S. (1988). Investigation of studentit status, background variables, and foasibility of standard tasks in cognitive aging research. Psychology and Aging, 3, 29-37.

Scogin, F., Storandt, M.. \& Lott, L. (1985). Memory-skills training, memory complaints, and depression in older adulis. Nowmat of Gerontology, $40,562-568$.

Van der Ploeg. H. M.n Defares, P. B., \& Spielberger, C. D. (1981). Handleiding bij de Zelf-BeoordelingsVrogentijsi (Manual for the Siate-Trait Anxiecy Inventory). Lisse, the Netherlands: Swets \& Zeitlinger.

Verhage. F. (1964). Mrelligentie en teefitid (Intelligence and age). Assen, The Netherlands: Van Gorkum. 
Wilde de, G. J. S. (1970). Neurorische labiliteif gemeten volgens de wragenlijsmethode (Neurotic instability measured with the questionnaire method). Amsterdarn: F. van Rossen.

Wilson, B. A., Cockburn, J., \& Baddeley, A. D. (1985). The Rivermead Behavional Menory Test. Reading: Thames Valley Tesr Company.

Winterling, D., Crook, T., Salama, M., \& Gobert, J. (1986). A self-rating seale for assessing memory loss. In A. Bes, J. Cahn, S. Hoyer, J. P. Marc-Vergnes, \& H. M. Wisniewski (Eds.), Swhle denentias: Early detecrion (pp. 482-486). London: John Libbey Eurotext.

Zung. W. K. (1965). A self-rating depression scale. Archives of General Psychiatry, 12, 63-70. 



\title{
Relation between Memory Self-Efficacy, performance prediction, and performance feedback in elderly adults
}

\begin{abstract}
The present study was designed to examine whether performance feedback would differentially affect memory predictions in a group of older adults with either high or low memory self-efficacy beliefs. Participants were asked to predict their memory performance in four consecutive trials of a name-face memory task. Before participants predicted performance in the second, third, and fourth trials, they were given false feedback (either neutral, positive, or negative) about their performance in the previous trial. We expected that negative feedback would lower predictions for individuals with low memory self-efficacy beliefs, but not or to a lesser extent for individuals with high memory self-efficacy beliefs. Positive feedback was expected to heighten predictions for individuals with high memory self-efficacy beliefs, but not or only marginally for individuals with low memory self-efficacy beliefs. Individuals that received positive feedback made somewhat higher predictions compared to those that received neutral feedback, and this effect could be ascribed mainly to the upgrading of predictions by especially individuals with low memory selfefficacy beliefs. However, the expected group $x$ feedback interactions were not found. At the first trial (no feedback) individuals with low memory self-efficacy beliefs made significantly lower predictions about their performance than those with high memory self-efficacy beliefs.
\end{abstract}




\section{Introduction}

Older adults frequently complain about their memory (Cutler \& Grams, 1988; Ponds, Commissaris \& Jolles, 1997 ) and perform less well than younger adults on a broad range of memory tasks (Craik \& Jennings, 1992). There are two general perspectives on the nature of this memory impaiment (Light, 1991). The first view holds that the decline in memory abilities of the elderly people is the consequence of irreversible age-related changes in basic mechanisms underlying cognition (for example, diminishing processing resources). The second view holds that the pooter memory of elderly people arises from the ineffective use of intact memory encoding and retrieval strategies (disuse perspective). For example, elderly adults become less efficient or trained in applying memory-enhancing strategies because they are no longer working and the memory demands of everyday life are greatly reduced. It is also possible that elderly people have strong negative beliefs in their memory capabilities and for that reason do no longer use memory strategies, which in turn may undermine memory performance (Lovelace, 1990). This study was designed to examine the relation between subjective memory beliefs, termed memory self-efficacy, and memory-related behavior in a sample of old middle-aged people.

The concept of memory self-eficacy is based on the more general definition of self-efficacy of Bandura (1977, 1989), who defined self-efficacy as the degree of belief one has in this or her ability to mobilize the motivation, cognitive resources, and courses of action needed to exercise control over task demands (e.g. memory tasks). Self-efficicay judgments affect activities or task selection and the effort and persistence put into that specific activity or task. While an older person"s perceptions and beliefs about his or her memory might not necessarily reflect their true potential memory capacity, they do have a substantial impact in determining which activities a person will engage in or how he or she performs (daily) memory tasks. For example, if memory self-efficacy beliefs are low, less effort (or inefficient allocation of effort) than necessary will be invested in memory tasks, which might lead to low memory performance. This in turn strengthens the subject's beliefs about his or her inadequate menory functioning. So, poor memory performance becomes more a function of self-doubt than actual lack of ability (Lovelace, 1990).

Self-efficacy judgments are believed to be based on four sources of information (Bandura, 1989): mastery experience, vicarious observations, social persuasion, and state of arousal. Mastery experience is based on the results of past and present performance of a given activity and provides the individual with the information of which task he or she is capable of doing. Vicarious observations refer to what other people of a relevant reference group are capable of doing. Social persuasion refers to the general social beliefs of what a person is capable of doing. State of arousal, finally, may provide information about the controllability of a situation or task. With regard to menry and aging, older people may get negative information from all four sources (Berry West, 1993; Cavanaugh \& Green, 1990): they may perceive that their memory performance was better when they were younger or avoid memory-clemanding situations (less mastery experiences); they meet other people of their age who complain of the same memory problems as they experience themselves; they are easy "victims" of the widespread societal belief" that memory inevitably declines with age; and finally heightened or lowered arousal (anxiety. depression) may adversely affect their memory performance.

Cavanaugh $(1990,1996)$ has proposed a complex conceptual model of memory performance 
and evaluation which takes into accoun the reciprocal influence of and the intertationships among cognitiwe capacity, personality, situational factors, general memory knowledge, task experience, performance evaluation and feedback, and memory self-efficacy. Self-efficacy evaluations are central in this model, because they are thought to strongly influence the amount and effectiveness of effort allocation and memory strategy selection, which in furn determine the level of performance. Memory self-efficacy evaluations are not static because they are based on prior memory knowledge and beliefs and the specific characteristics of the memory task an hand and the experience one has with that task (for example feedback on prior performance). Therefore both memory self-efficacy judgments and performanoe may vary over different memory task or may change within one memory task after prior experience.

The relation between memory beliefs and memory performance can be investigated in memory performance prediction studies. In such studies, individuals are asked to predict the number of items they will remember on a subsequent memory task and the correlation or accuracy between prediction and performance is taken as a measure of memory self-efficacy. Prediction of performance in additional trials of the same memory task is used to examine changes in prediction accuracy due to task experience. The findings of several studies on age differences in memory predictions lasks (Cavenaugh, 1996; Devolder, Brigham \& Pressley, 1990; Hertzog, Dixon \& Hultsch, 1990; Hertzog, Saylor, Fleece \& Dixon, 1994; Lovelace, 1990; McDonald-Miszczak, Hunter \& Hultsch, 1994; West, Dennehey-Basile \& Norris, 1996) may be summarized as follows. First predictions seem to be closely related to global measures of memory self-efficacy. as measured with metamemory questionnaires. Prediction accuracy improves on subsequent trials in both young and old adults and this improvement is only weakly correlated with global memory self-efficacy measures. Younger adults tend to be more accurate on first prediction than older adults: older adults generally overestimate their performance on first prediction. This tendency to overpredict performance disappears when the elderly subjects are shown age-graded normative data before they make their preclictions which suggests that this phenomenon represents a calibration problem in which the older adults underestimate the difficulty of the lask. Performance predictions are thus based on global memory self-efficacy judgments and on task-specific menory self-efficacy judgments, which are based on pror task experience or feedback about performance.

Performance feedback is the most direct way 10 inform individuals aboul their "mastery" or control of the task and it is believed to be the most powerful source of information for self-efficacy judgments (Bandura, 1977). While one might expect that subjects receiving positive feedback would likely upgrade their performance predictions on subsequent trials and those receiving negative feedback would lower their performance predictions, the siluation might not be this straightforward. As put forward by Dweck and Leggett (1988), what one believes about the way one's cognitive system operates strongly influences performance and self-evaluation of abilities. They termed these beliefs as the implicit theory of cognition, and differentiated between an entity and a skill implicit theory. Individuals holding an entity view believe ability is fixed and cannot to be altered by effort or practice. Those individuals holding a skil. wiew believe that ability can be improved through effort and practice. These implicit theories of cognition are closely related to the concept of cognitive or memory self-efficicay of Bandura (1989): individuals with high self-efficacy believe that memory can be improved by, for example, increased affort (skill theory), whereas individuals with low self-efficacy do not believe that memory performance can be altered by increasing effort or using alternative strategies (entity theory). The effects of 
pertormance feedback on subsequent performance predictions will be determined largely by these pervasive individual beliefs about the controllability of cognitive functions. For example, individuals with strong negative memory self-efficacy beliefs may have low expectations of their subsequent task performance in spite of positive feedback, because they betieve that their cognitive abilities cannot be altered by experience. In contrast, individuals with high self-efficacy beliefs, might have higher expectations after positive feedback, because such information fits into their beliefs about the controllability of cognitive ability. Negative feedback might have the opposite effect: people with low self-efficacy will probably lower their expectations, whereas people with high self-efficacy might keep up with their previous expectations and probably increase their effort to reach a higher level of performance. Put another way, people with low memory self-efficacy beliefs will heve a strong attentional bias towards negative feedback as this fits into their perceived decreased controllability of memory, whereas those with high memory self-efficacy will focus their attention more on positive feedback.

The present study was designed to examine the possibility of such an attentional bias toward performance feedback in a group of old adults with high memory self-efficacy beliefs and a group of old adults with low memory self-efficacy beliefs. All participants in this study were nomal community-dwelling adults with nomal objective memory functioning. We asked the participants to predict their memory performance in four consecutive trials of a name-face memory task. Before they predicted their performance in the second, third, and fourth trials of the task, they were giwe false feedback about their performance in the previous trial. There were three feedback conditions: false positive, false negative, or false neutral feedback. We expected that negative feedback would lower predictions of performance in the group with low memory self-efficacy, but not or to a lesser extent in the group with high memory self-efficacy. Positive feedback, on the other hand, was expected to heighten predictions in the group with high memory self-efficacy, but not or only marginally in the group with low memory self-efficacy. For the first prediction (no feedback), we expected that the group with high memory self-efficacy would predict a better memory performance than the group with low memory self-efficacy.

We were also interested in possible differences in attributions of successful performance (false positive feedback) and unsuccessful performance (negative leedback) between the groups. According to Bandura's theory of self-efficacy $(1977,1989)$, success will probably entance self-efficacy if performance is perceived as resulting from internal factors (for example, ability or effort) but not if performance is attributed to external factors (for example, task ease or luck). Failures, on the other hand, may lower self-efficacy, especially if performance is atributed to internal factors (for example, decreased ability) but less when it is attributed to external factors (for example, task difficulty). We expected that individuals with low memory selfefficacy would attribute successful performance more to the specific task used (external attribution) and unsuccessful performance to memory ability (internal attribution), whereas the opposite attribution pattern was expected for the individuals with high memory self-efficacy.

We also examined differences in depression, anxiety, neuroticism, and achievement motivation between the two groups. Based on the theory of cognitive self-efficacy of Bandura (1989), as well as on prewious aging research on the relation between subjective memory in elderly people and personality and mood (Arbuckle, Gold \& Andres, 1986; Arbuckle, Gold, Andres, Schwartzman \& Chaikelson, 1992; Bolla, Lindgren, Bonaccorsy \& Bleecker, 1991; Cipolli et al, 1996; Collins \& Abeles, 1996; Deptula, Singh \& Pomara, 1993; Deronesné et al., 
1989; Gillewski \& Zelinski, 1986; Häminen et al, 1994; Hood, MacLachlan \& Fisher, 1987; Ponds \& Jolles, 1996b; Smith, Petersen, Ivnik, Malec \& Tangalos, 1996), we expected that people with low memory self-efficacy beliefs would have more complaints about depression and anxiety, more neurotic symptomatology, and lower achievement motivation than the people with high memory selfefficacy beliets.

\section{Method}

\section{Selection of the participants}

Participants in this study were recruited from the first panel of 468 adults who had participated in a large cross-sectional study into the determinants of nornal cognitive aging (the Maastrich Aging Study; Jolles, Houx, van Boxtel \& Ponds, 1995). The data from this study were used fon the selection and matching of the participants.

Participants had to be at least 50 years of age and must have performed within the age-adjusted normal range (above 1 standard deviation below the age-corrected mean) on the Visual Verbal Learning Test (VVLT; Lezak, 1995). The VVLT is a widely used standand clinical memory test which measures the storage and retrieval of verbal information in episodic memory it consists of 15 monosyllabic meaningful words which are visually presented to the subject five times. After each presentation or trial the subject is requested to recall as many words as possible with no restriction concerning the order of recall. The variable of interest is the total number of correctly recalled words on the five trials (maximum is 75 ).

Participants were further selected on the basis of their memory self-efficacy score as measured with the Metamemory in Adulthood questionnaire (MIA; Dixon, Hultsch \& Hertzog, 1988; Ponds \& Jolles, 1996a). The MIA asks respondents to rate, on a 5-point Likert scale, 108 statements describing their own memory functioning and their general knowledge of memory processes. There are seven subscales: Strategy (use of memory strategies to improve memory performance), Task (knowledge of basic memory processes). Capacity (beliefs about personal memory capacity), Change (perceived change in memory fumctioning), Anxiety (feelings of stress and anxiety related to memory performance), Achievement (personal motivation to perform well in memory situations), and Locus (perceived sense of control over memory abilities). Hertzog, Hultsch and Dixon (1989) found evidence for a higher order factor called Memory Self-Efficacy (MSE) that consisted of the subseales Capacity, Change, and Anxiety. This MSE factor is thought to reflect beliefs about personal competence in various memory situations. The MSE scone in this study was taken as being the sum of the scores for Capacity, Change, and Anxiety (this scale is reversed before summing). Low MSE scores cortespond to low perceived memory capacity. perceived strong decline in memory functioning, and heightened feelings of stress and anxiety in relation to memory performance. We calculated the MSE scores of all participants who passed the first selection screen, and selected subjects with the lowest and highest MSE scores (low and high MSE group). Subjects from the high and low MSE groups were assigned to one of three experimental conditions (neutral, positive, or negative feedback, see below) so that six groups were formed. These groups were matched for age, sex, and education. 
Demographic characteristics of each group are presented in Table 9.1. The mean age was about 65 years. All groups contained more women than men. Educational level was measured with an 8-point Dutch scoring system (de Bie, 1987) ranging from unfinished primary education (level il) to university education (level 8). Matching was successful as no statistical differences were found between the groups with respect to age, male/female ratio, and educational level. Data on the AVLT and the Raven Standard Progressive Matrices test (RSPM; Raven, Court \& Raven, 1992) are allso presented. The RSPM is a test that measures general (non-verbal) intelligence. The shortened version of this test ( 36 items) was administered to control for possible differences in intelligence between the groups. No intergroup differences were found on the AVLT and the RSPM. Transformation of the mean scores of the RSPM in each group (22 to 25) into intelligence scores showed that the mean intelligence of the participants was abowe average (IQ $=117-119)$.

Table 9.1 Means (M) and standard deviations (SD) of demographe wariables, MUA Menory Self-Efficacy (MAMSE), Raven Srandard Progressive Matrices (RSPM), chad the total score for trials 1 -5 on the Afuditory Verbal Leaming Task (AWT) for ach experimental group.

\begin{tabular}{|c|c|c|c|c|c|c|}
\hline Group & $\begin{array}{c}\text { Low MSE } \\
\text { posFB }\end{array}$ & $\begin{array}{c}\text { HuW MSE } \\
\text { nCgF-B }\end{array}$ & $\begin{array}{c}\text { Low MSE } \\
\text { neufB }\end{array}$ & $\begin{array}{c}\text { High MSE } \\
\text { posFB }\end{array}$ & $\begin{array}{c}\text { High MSE } \\
\text { negFB }\end{array}$ & $\begin{array}{c}\text { High MSE } \\
\text { neutFB }\end{array}$ \\
\hline Nof subjects & 13 & 13 & 14 & 13 & 14 & 14 \\
\hline \multirow[t]{2}{*}{ Men/wonen } & $5 / 8$ & 617 & $6 / 8$ & $6 / 8$ & $6 / 8$ & $6 / 3$ \\
\hline & $S D$ & $S D$ & $S D$ & $S D$ & $S D$ & $S D$ \\
\hline
\end{tabular}

\begin{tabular}{|c|c|c|c|c|c|c|c|c|c|c|c|c|}
\hline Age & 65.2 & 9.3 & 66.5 & 7.9 & 63.1 & 7.7 & 62.5 & 11.3 & 65.3 & 7.0 & 65.1 & 7.8 \\
\hline Education & 2.8 & 1.8 & 2.2 & 1.5 & 3.2 & 2.1 & 3.1 & 1.1 & 3.11 & 2.7 & 3.3 & 1.7 \\
\hline RS SPM & 24.2 & 7.0 & 23.7 & 4.4 & 22.8 & 6.5 & 24.6 & 4.0 & 22.0 & 5.4 & 23.6 & 6.1 \\
\hline MLA-MSE & 7.1 & 0.8 & 6.8 & 1.3 & 7.0 & 1.2 & 10.8 & 1.1 & 11.1 & 1.0 & 107 & 1. I. \\
\hline AVLT trials $\|-5$ & 44.3 & 9.2 & 41.4 & 7.9 & 42.1 & 7.6 & 45.5 & 9.2 & 42.4 & 6.4 & 42.9 & 6.3 \\
\hline
\end{tabular}

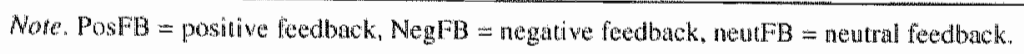

\section{Measures of personaliny and nood}

Depression. Depressive complaints were assessed with the Zung Self-Rating Depression Scale (Zung, 1965). The ZUNG consists of 20 items which reflect psychological and physiological correlates or symptoms of depression. Higher scores indicate the presence of more depressive symptoms. 
Neuroticism. Neuroticism was assessed with a Dutch neuroticism questionnire (Amsiendams. Biografische Vragenlijst-ABV; de Wilde, 1970). Two subscales were wised in this sudy: the $A B V-N$ scale (30 items), which measures neurotic instability as manifested by the presence of psychoneurotic complaints (for example, instability of mood, feelings of gult, irritablut, nervousness, worrying), and the ABV-NS scale (17 items), which measures newrotic instabuly as manifested by the presence of functional somatic complaints (for example, sleeping problents, tiredness, transpiration). Higher scores indicate more complaints.

Trait anxiety. A Dutch version of the Trait scale (20 items) of the State-Trait Anxiety Inventory (STAI) of Spielberger was used to assess general susceptibility to feelings of anxiety and stress (Van der Ploeg, Defares \& Spielberger, 1981). Higher scores indicate greater trait anxiety.

Achievement motwation. Achievement motivation was assessed with the Dutch "Prestutie Motivatie Test' (Achievement Motivation Test; Hermans, 1976), which consists of 90 items divided over three subscales. One subscale measures achievement motivation, and the other two subscales measure negative and positive performance anxiety. Negative anxiety adversely affects performance, whereas positive anxiety facilitates performance. A person with high negative performance anxiety may function well in a structured and well-know situation, but less well in relatively new and unstructured situation. A person with high positive performance anxiety is more likely to improve his or her performance in new and unstructured situations.

\section{Memory prediction fask and feedback procedure}

Memory prediction task. The memory prediction task was a name-face encoding task. This task was chosen for its high face validity because forgetting names is one of the most frequently reported daily memory failures, especially in old age. Fourteen photos of faces (taken from the Recognition Memory for Faces test of the Rivermead Behavioral Memory Test; Wilson, Cockburn \& Baddeley, 1985) were presented in three consecutive trials. At each presentation the experimenter said the corresponding first names. After all the photos were presented, they were shown again and the participants were asked to recall the relevant first name (immediate recall). At each presentation and recall, the photos were presented in a different order (similar for all participants) to prevent list learning. Twenty minutes after the third trial, the 14 photos were presented again and participants were requested to recall the relevant first names (delayed recall).

Memory prediction. Before each immediate recall trial, participants were asked to predict the number of names they thought they would be able to remember correctly. They also predicted their performance in the delayed recall triall. The participants were told that the photos and corresponding first names would not be presented before this trial and that the trial would take place 20 minutes later. Before the first prediction for trial $\mathbb{1}$, participants were given verbal description of the name-face task and they practiced on a short and easy version of the task (three photos) to get acquainted with the task. Before subjects predicted their performance in the next trial, they were told how many names they had predicted in the preceding trial (except for the prediction for trial 1), but they were not told the number of names they had correctly recalled on the preceding trial. In addition to predicting their performance, participants also rated their confidence in their ability to successfully recall the predicted number of names on a 100 point probability scale, ranging in 10-points intervals from $10 \%$ (not sure) $10100 \%$ (very sure). These confidence ratings were added to examine possible differences in expected skill level (the 
predicted number of recalled names) and skill beliefs. The distinction between estimated skill levels and skill beliefs is importan because discrepancies between the two may lead to quite different behavioral outcomes (Berry, West \& Dennehey, 1989; West \& Berry, 1994). Two subjects with identical estimated skill levels may have different confidence in their ability to actually achieve this level (for example $30 \%$ and 100\%), which could lead to differences in performance. For example, individuals with high confidence may invest more effort in recalling the names than individuals with low confidence.

Feedback. Except for trial 1, participants were given false information about their recall performance in the preceding trial before they predicted their performance in the next trial. Individuats from both the high and low MSE groups were assigned to one of three feedback conditions in with they received either neutral, positive, or negative feedback. Six experimental groups were thus formed: Low MSE - neutral feedback, low MSE - positive feedback, low MSE negative feedback, high MSE - neutral feedback, high MSE - positive feedback, high MSE negative feedback. The feedback procednre was strictly standardized. When recall was finished, the experinenter looked in fake tables to 'evaluate' performance. The individual was then shown a scale with ten report numbers from 1 to 10 . Above number 1 and 2 "very bad" was typed, above number 5 and 6 'adequate', and above number 9-10 'excellent'. In the neutral feedback condition, the experimenter pointed between the numbers 5 and 6 and said "If I transform your performance into a report number by comparing it with the performance of other people of your age "your report number would be between 5 and 6 . This is neither good nor bad". The same procedure was followed for the positive and negative feedback. In the positive feedback condition the experimenter pointed between $8-9$ and said "If 1 transform ... between 8 and 9. This is good"; in the negative feedback conditions the experimenter pointed between $2-3$ and said "If I transform .... between 2 and 3. This is bad". By using report numbers as feedback we tried to maximize the effect of the false feedback on future predictions. Individuals would have some subjective idea of the quality of their performance after recall, by comparing the number of items they had predicted with the number of items they had recalled (even though no information was provided about the correct number of names remembered). An indiwidual that had remembered more names than predicted, would perceive this as positive. An individuall with less names remembered than predicted, would perceive it as negative. By 'comparing' the performance with that of people of his or her own age, as expressed in the report number, we expected to overnule these first. impressions people made about the quality of their performance.

A schematic overview of the experinent is shown in Table 9.2.

\section{Arribution}

Atribution of test performance was measured with a visual analogue scale (200 millimeters). On the left side "memory" was printed and on the right side "this task". Directly following the feedback alter the third trial, participants were asked to indicate to what extent their performance was lypical for their memory functioning in general (ratings towards "memory", internal aturibution) or whether their performance was only related to the specific memory task and not representatiwe for their memory (ratings towards "this task", external attribution). 
Table 9.2 Overview of the experiment.

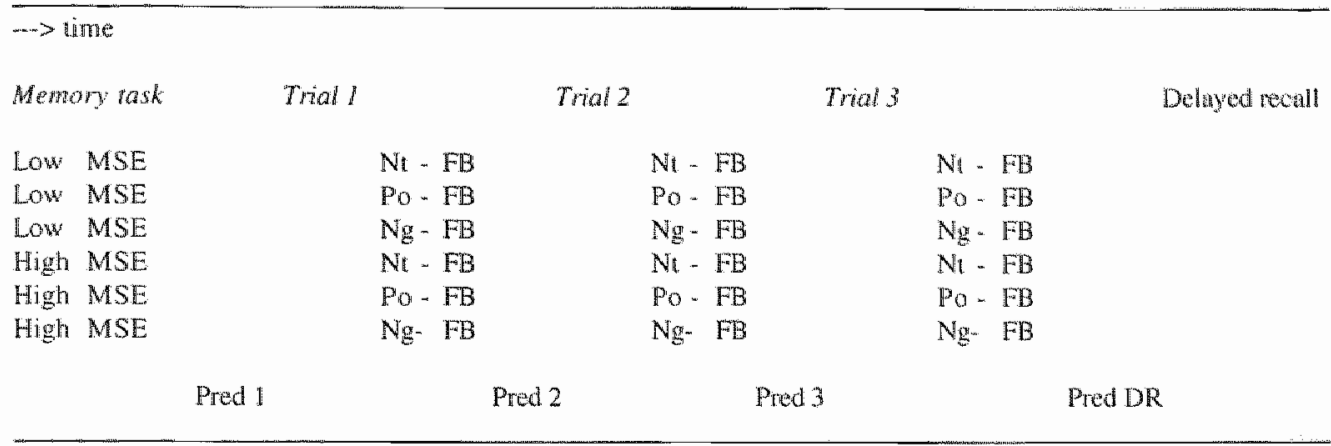

Note. $\mathrm{Nt}-\mathrm{FB}=$ neutral feedback, $\mathrm{PO} . \mathrm{FB}=$ positive feedback, $\mathrm{Ng}-\mathrm{FB}=$ negaive leedback. Pred $=$ prediction.

\section{Procedure}

All participants were tested individually at home and were paid for their participation. The personality and mood questionmaires were sent by post I week before the participants were visited. The test procedure took about 1 hour. The test procedure started with trial 1 to trial 3 of the memory prediction task. Trial 1 was preceded by a short practice trial. Between trial 3 and the delayed recall trial the Raven Standard Progressive Matrices test was administered. After the delayed recall trial, an extensive debriefing took place in which the experiment was explained. To be sure that the rationalle of the experiment was well understood afterwards (especially with respect to the false feedback), all participants had to explain the experiment in their own words directly following the explanation by the experimenter. All participants were told that they thad in fact had performed within the normal range.

\section{Siatistical analysis}

Univariate ANOVAs were performed on absolute and relative difference scores in predictions, confidence ratings, and performance to examine main effects of group (low and high MSE) and feedback (neutral and positive feedback, neutral and negative feedback) and the interaction group * feedback. For the prediction ratings and performance at prediction I (no feedback), the three Low MSE groups and the three high MSE groups were merged. The following difference scores were calculated (only prediction scores are presented, difference scores on confidence and performance are calculated in a similar way):

Absolute difference scores (aDS):

(1) aDS prediction 2 = prediction 2 - prediction 1 .

(2) aDS prediction $3=$ prediction 3 - prediction 2

(3) alDS prediction 3-1 = prediction 3 - prediction I "maximum" ffect of feedback).

(4) aDS prediction delayed recall = prediction delayed recall - prediction 3 . 
Relative difference scores (rDS):

(1) $\operatorname{rDS}$ prediction $2=($ prediction 2 -prediction $1 /$ prediction 1$) * 100$.

(2) rDS prediction $3=$ (prediction $3-$ prediction 2$)$ prediction 2$) * 100$.

(3) PDS prediction 3-1 = ((prediction 3 - prediction 1 y/prediction 1$) * 100$.

(4) $\mathrm{PDS}$ prediction delayed recall $=($ prediction delayed recall $*$ prediction 3$) /$ prediction 3$) * 100$.

Rellative difference scores were used to control for possible large individual differences in the "base rate' of the preceding predictions, confidence ratings, and performance. For example, an individual with a first prediction of two items and a second prediction of four items, shows an absolute prediction increase of two itens, but a relative increase of $100 \%$. An individual with four items on first prediction and six items on the second prediction, also has an absolute increase of two items, but relative increase of only $50 \%$. The analyses on the absolute and relative difference scores yielded by and large similar results. Results of the analysis on the relative difference scores will only be reported if they differ from the results of the analysis on the absolute difference scores.

Prediction accuracy was calculated by subtracting the number of correctly recalled names from the predicted number of names.

\section{Results}

Table 9.3 shows the means and standard deviations of the predictions, confidence ratings, performance, and prediction accuracy for each experimental group for trial 1, trial 2, trial 3, and the delayed recall trial. The standard deviations were large compared to the observed means, indicating large within-group variation on all dependent variables.

\section{No feedback (trial 1 )}

The mean prediction, confidence tating, and performance for the high MSE group $(n=41)$ for the first trial (no leedback) were 5.6 (SD 1.6), 50,6 (21.9), and 2.8 (1.8). For the low MSE group $(n$ $=40)$ the scores were $4.8(1.5), 46.4(21.8)$, and $3.0(2.1)$, respectively. The mean prediction score of the high MSE group was significantly higher than the mean prediction score of the low MSE group $(F(1,79)=6.56, p=.012)$. No statistical differences were found for confidence ratings and performance.

\section{Neural and positive feedback}

Changes in predictions, confidence ratings and performance from trial 1 to the delayed recall trial for the high and low MSE groups that reeeived either neutral or positive feedback are graphically shown in Figure 9.1 10 9.3.

Prediction. Prediction scores changed within a small range (approximately two items) (Figure 9.1). The effects of positive feedback on prediction for the high and low MSE group appeared to 
Table 9.3 Means (M) and stondard deviations (SD) of prediction, confidence, preformiance scores and prediction accuracy of the prediction memory task (Name-Faces) for wach expermental group.

\begin{tabular}{|c|c|c|c|c|c|c|c|c|c|c|c|c|}
\hline \multirow[t]{2}{*}{ Group } & \multicolumn{2}{|c|}{$\begin{array}{c}\text { Low MSE } \\
\text { posFB }\end{array}$} & \multicolumn{2}{|c|}{$\begin{array}{c}\text { Low MSE } \\
\text { negFB }\end{array}$} & \multicolumn{2}{|c|}{$\begin{array}{c}\text { Low MSE } \\
\text { newrFB }\end{array}$} & \multicolumn{2}{|c|}{$\begin{array}{c}\text { High MSE } \\
\text { posFB }\end{array}$} & \multicolumn{2}{|c|}{$\begin{array}{c}\text { High MSE } \\
\text { negFb }\end{array}$} & \multicolumn{2}{|c|}{$\begin{array}{c}\text { High MSE } \\
\text { neutFB }\end{array}$} \\
\hline & $M$ & $S D$ & $M$ & $S D$ & $M$ & $S D$ & $M$ & $S D$ & $M$ & $S D$ & $M$ & $\$ 0$ \\
\hline
\end{tabular}

Trial I

$\begin{array}{lrrrrrrrrrrrr}\text { Prediction } & 4.9 & 1.9 & 4.6 & 1.5 & 4.7 & 1.2 & 5.3 & 1.7 & 5.6 & 1.7 & 5.9 & 1.5 \\ \text { Confidence } & 51.9 & 20.4 & 38.9 & 18.6 & 48.2 & 25.2 & 60.8 & 19.0 & 43.2 & 25.5 & 48.6 & 17.9 \\ \text { Performance } & 3.7 & 2.3 & 1.8 & 1.1 & 3.5 & 2.2 & 2.4 & 1.5 & 3.3 & 2.2 & 2.7 & 1.6 \\ \text { Accuracy } & 1.3 & 2.7 & 2.8 & 1.6 & 1.2 & 2.7 & 2.9 & 2.5 & 2.4 & 2.6 & 3.2 & 2.7\end{array}$

Trial 2

$\begin{array}{lrrrrrrrrrrrl}\text { Prediction } & 5.4 & 2.0 & 4.0 & 1.8 & 4.6 & 1.3 & 5.2 & 1.5 & 4.5 & 1.8 & 4.8 & 1.8 \\ \text { Confidence } & 50.4 & 24.5 & 25.4 & 12.7 & 45.4 & 25.5 & 58.5 & 17.7 & 34.6 & 21.9 & 46.4 & 18 . \\ \text { Performance } & 6.9 & 3.3 & 5.1 & 2.4 & 6.1 & 3.3 & 5.9 & 2.8 & 6.1 & 2.4 & 5.2 & 2.3 \\ \text { Accuracy } & -1.5 & 3.0 & -1.1 & 2.1 & -1.5 & 3.0 & -0.8 & 2.5 & -1.6 & 2.6 & -0.4 & 2.4\end{array}$

Trial 3

$\begin{array}{lrrrrrrrrrrrr}\text { Prediction } & 6.7 & 2.4 & 4.2 & 1.9 & 5.0 & 3.9 & 5.8 & 2.1 & 5.0 & 2.1 & 5.2 & 2.1 \\ \text { Confictence } & 51.5 & 28.8 & 31.5 & 14.6 & 46.1 & 24.2 & 61.2 & 19.6 & 33.6 & 25.0 & 50.7 & 19.4 \\ \text { Performance } & 8.1 & 2.8 & 6.3 & 2.8 & 7.5 & 2.5 & 7.9 & 2.8 & 7.0 & 2.2 & 8.2 & 2.9 \\ \text { Accuracy } & -1.4 & 2.9 & -2.1 & 2.1 & -2.5 & 2.2 & -2.1 & 2.9 & -2.0 & 2.6 & -3.0 & 3.0\end{array}$

Delayed recall

$\begin{array}{lrrrrrrrrrrrr}\text { Prediction } & 5.6 & 2.2 & 3.6 & 1.9 & 3.9 & 1.2 & 5.1 & 1.9 & 4.1 & 1.6 & 4.8 & 1.6 \\ \text { Confidence } & 57.3 & 29.8 & 35.4 & 24.4 & 47.5 & 25.8 & 57.7 & 24.3 & 33.6 & 21.7 & 51.1 & 20.6 \\ \text { Performance } & 7.4 & 4.0 & 5.9 & 3.0 & 6.6 & 2.7 & 7.0 & 3.2 & 6.8 & 2.8 & 7.5 & 3.1 \\ \text { Accuracy } & -1.8 & 3.3 & -2.3 & 2.0 & -2.7 & 2.3 & -1.9 & 2.4 & -2.7 & 3.0 & -2.7 & 2.6\end{array}$

Note PosFB = positive feedback, $\mathrm{Neg} F \mathrm{~B}=$ negative feedback, neutFB $=$ meutral feedbick. Accouracy = prediction performance.

be opposite to what was expected. The low MSE group that received positive feedback made higher predictions than the high MSE group that received positive feedback. There was also a marked drop in the number of predicted items from the first to the second trial in the high MSE group that received neutral feedback. This drop mainly accounted for the near significant effect of group on differences in prediction (high MSE group making lower predictions) from the first to the second trial (aDS prediction 2: $F(1,50)=3.47, p=.068)$ and for the difference in prediction from the first to the third trial (aDS prediction 3-1: $F(1,50)=3.82, p=.056$ ). A. significant effect of feedback on prediction (with positive feedback leading to higher predictions) was found for the 


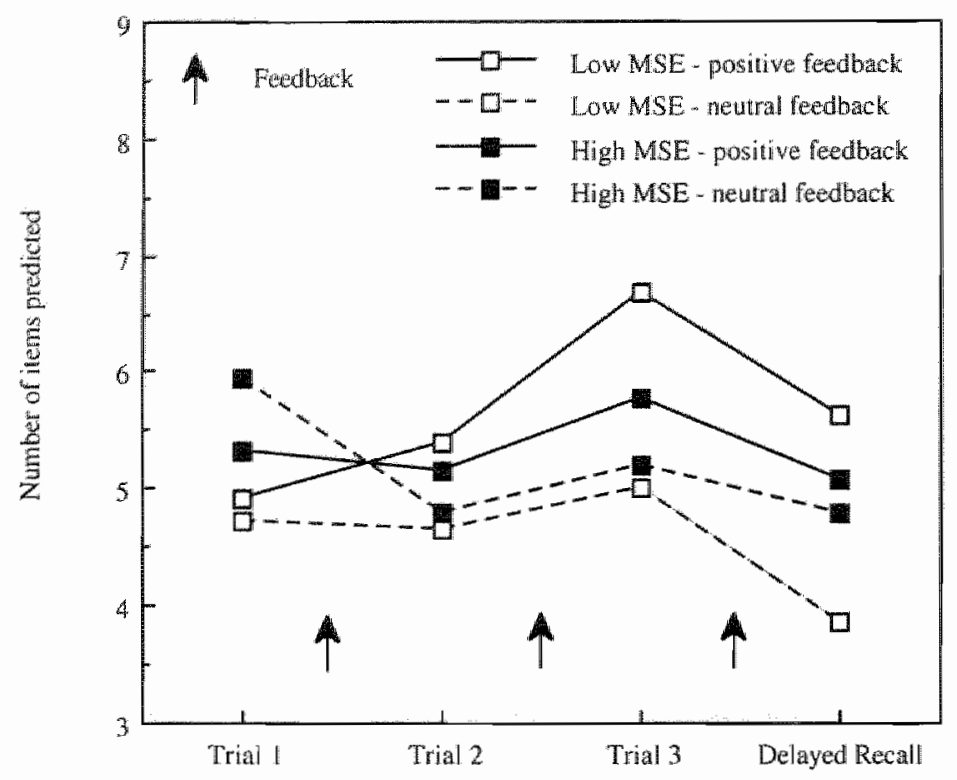

Figure 9.1 Predictions: positive and neutral feedback

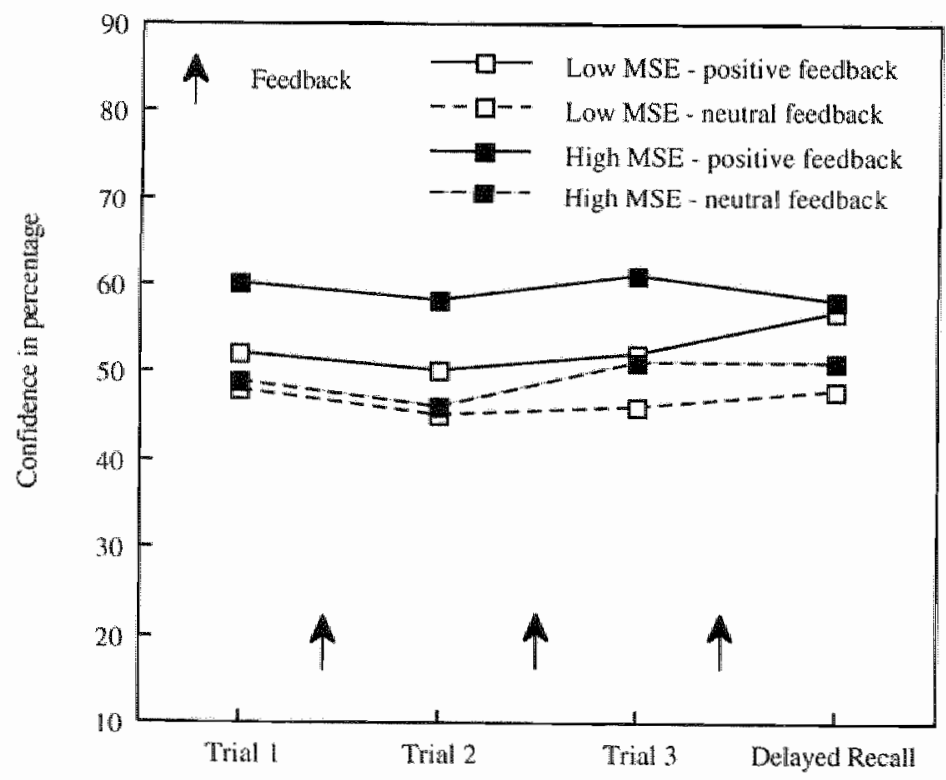

Figure 9.2 Confidence: posinive and neutral feedback 


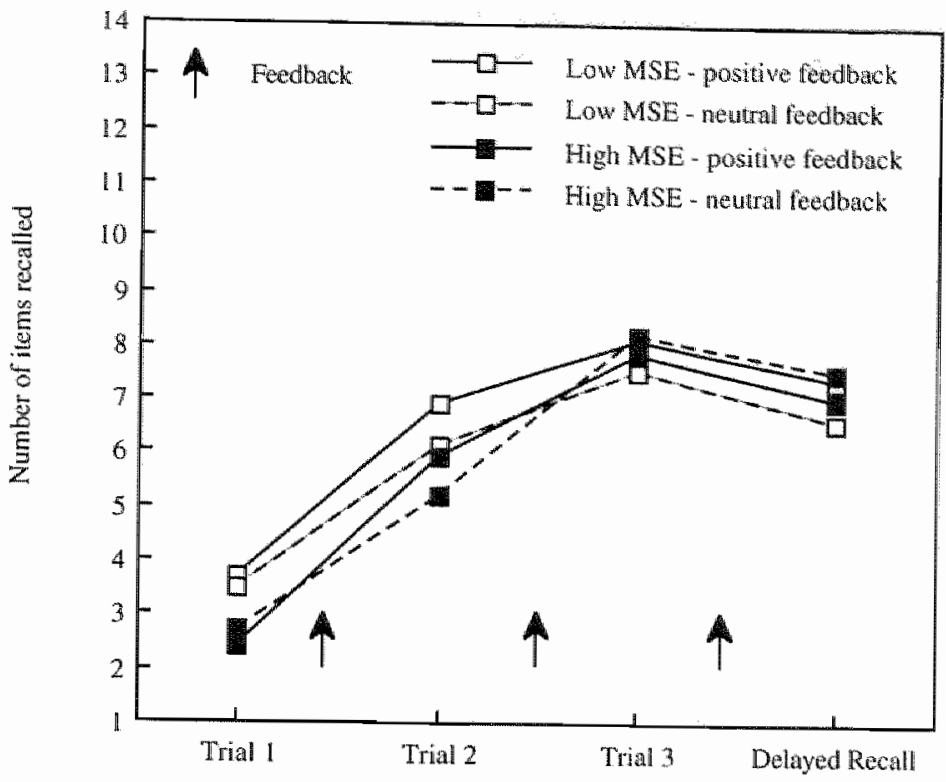

Figure 9.3 Performance: positive and neutral feedback

second to the third trial (aDS prediction $3: F(1,50)=4.50, p=.039$ ) and for the first to the third trial (aDS prediction $3-1: F(1,50)=5.12, p=.028$ ). However, the effect of leedback on the relative difference score for changes from the second to the third trial was not significant (rDS prediction $3: F(1,50)=2.87, p=.096)$. The expected group $\mathrm{x}$ feedback interactions were not found.

Confidence. As Figure 9.2 already clearly shows, no effects were found for group, feedback or group $x$ feedback.

Performance. The only significant group effect found was an greater improvement in performance from trial 2 to trial 3 for the high MSE group than for the low MSE group (aDS performance $3: F(1,50)=6.08, p=.017$ ). No effects were found for feedback or group $x$ feedback.

\section{Neutral and negative feedback}

Figure 9.4 to 9.6 shows the changes in predictions, confidence ratings and performance from trial 1 to the clelayed recall trial for the high and low MSE groups that had received either neutral or negative feedback.

Prediction. Yet again, the prediction scores changed within a small range (Figure 9.4). There was a clear drop in the number if items predicted from trial 1 to trial 2 for the high and low MSE groups that received negative feedback, and for the high MSE group that received neutral feedback (already noted before). No statistically significant effects were found.

Confidence. The mean confidence ratings for the groups that received negative feedback were 


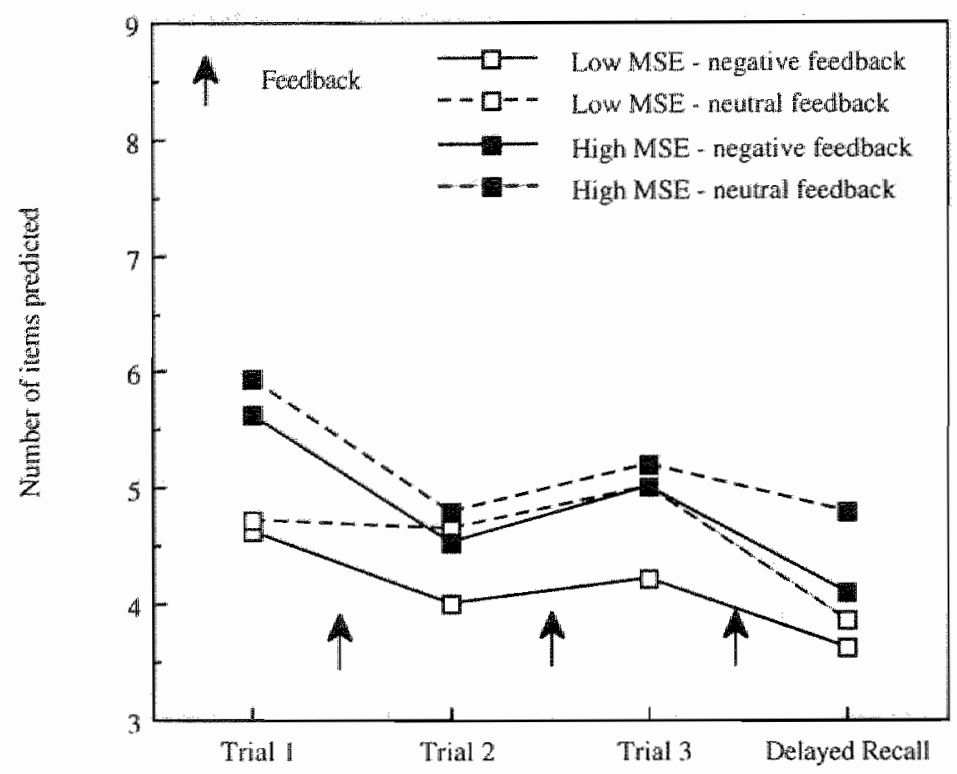

Figure 9.4 Predictions: negative and neutral feedback

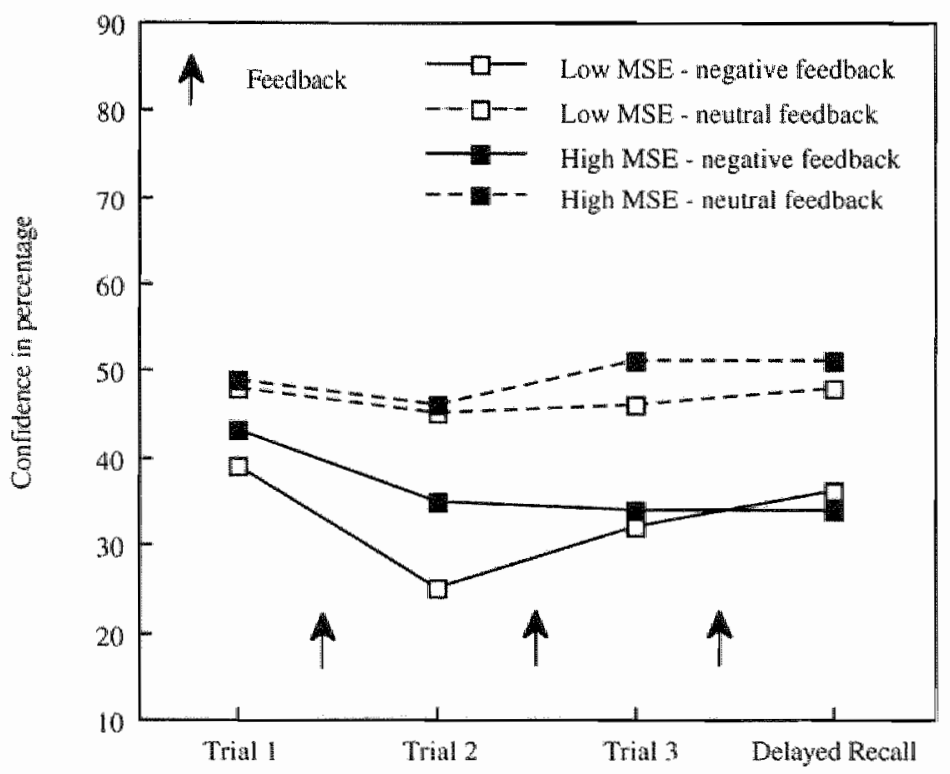

Figure 9.5 Confidence: negative and neutral feedback 


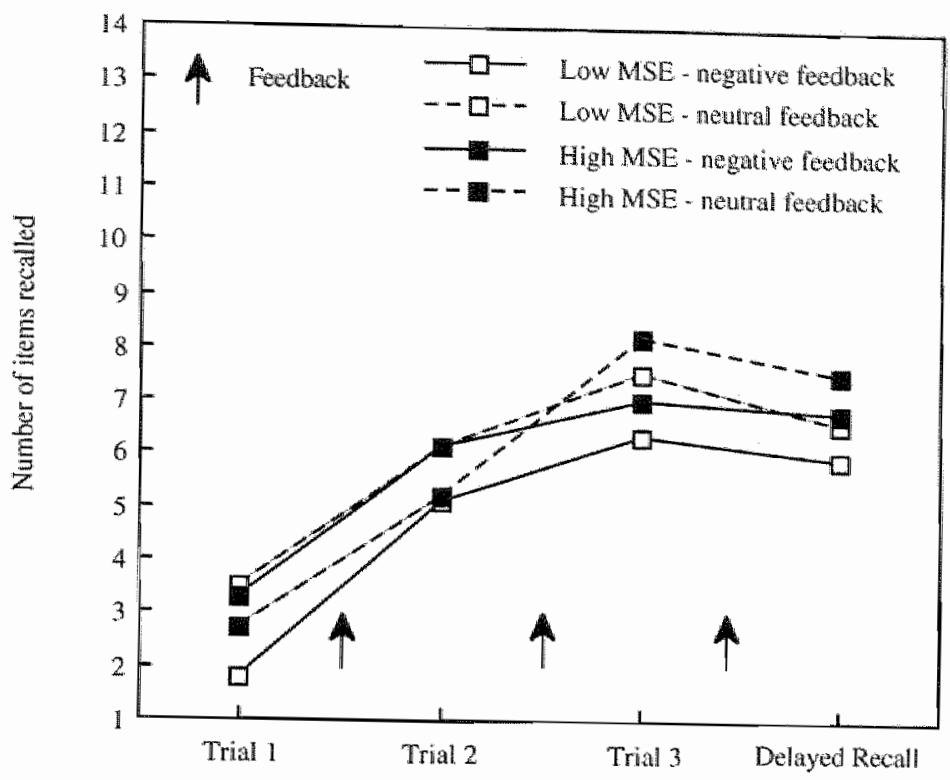

Figure 9.6 Perfonnance: megative and newral, feedback

lower than the confidence ratings of the groups that received neutral feedback (Figure 9.5). However, no statistically significant effects of feedback were found, probably due to the large within group variation. No effects were found for group or group $\mathrm{x}$ feedback.

Performance. Groups that received negative feedback showed significantly less improvement in performance from trial 2 to trial 3 than the groups that received neutral feedback (aDS performance $3: F(1,51)=5.20, p=.027)$. The group $x$ feedback interaction was nearly significant for the second to the third trial (aDS performance 3: $F(1,51)=3.97, p=.052$ ), indicating that the performance of the high MSE group was more attentated by the negative feedback than that of the low MSE group. No other effects of feedback, group or group $x$ feedback were found.

Post-hoc analyses: Effect of feedback in the high and low MSE groups

The present study was designed to examine the different effects of positive and negative feedback. in elderly people with high or low MSE. However, the expected feedback $x$ group interactions were not found. During debriefing, almost half of the individuals in the high MSE group that received neutral feedback indicated that the feedback was not perceived as neutral but rather as negative, which probably explains the large decrease in the number of items predicted in this group from trial 1 to trial 2. At the same time, some individuals from the low MSE group indicated that they perceived the neutral feedback as being positive. It maty therefore be questioned whether the neutral feedback condition was an appropriate control condition as it was intended to 
be. Furthemore, the low MSE groups seemed to be more sensitive for both negative and positive feedback than the low MSE group that received neutral feedback (see Figures 9.1 and 9.4). Finally, the confidence ratings of both the low and high MSE groups seemed to be affected more by negative feedback than by neutral feedback (Figure 9.5). For these reasons, we decided to perform additional post hoc anallyses in which we examined the effects of feedback in the high and low MSE groups. The following group comparisons (t-tests) were made on raw scores, absolute difference scores, and relative difference scores for prediction, confidence ratings, and performance: low MSE group positiwe feedback versus low MSE group neutral feedback, low MSE group negative feedback versus low MSE group neutral feedback, high MSE group positive feedback wersus high MSE group neutral teedback, high MSE group negative feedback versus high MSE group neutral feedback.

The following significant effects were found. The low MSE group that received positive feedback made significantly higher predictions at trial 3 and the delayed recall trial than the low MSE group that received neutral feedback $(p=.038$ and $p=.020$ respectively), but only the difference scores for trial $2-3$ (aDS prediction 3) and trial 1-3 (aDS prediction 3-1) were significant ( $p=.046$ and $p=.043$ ). The low MSE group that received negative feedback was significant less confident in their predictions in trial 2 than the low MSE group that received neutral feedback $(p=.017)$; the absolute difference score for trial 2 (aDS confidence 2 ) was only nearly significant $(p=.080)$. The performance in trial 1 of the low MSE group that received negative feedback was lower than that of the low MSE group that received neutral feedback $(p=$ .018 ). Confidence ratings of the high MSE group that received negative feedback were significantly lower for the delayed recall trial $(p=.038)$ than those of the high MSE group that received neutral feedback (at trial 3 the difference was near significant, $p=.054$ ); the difference scores on confidence ratings at trial 3 and the delayed recall triall were not significant. The performance of the high MSE group that received negative feedback improved less from trial 2 to trial 3 (aDS performance 3) than that of the high MSE group that received neutral feedback $(p=$ $.004)$.

\section{Prediction accuracy}

Table 9.3 shows the prediction accuracy scores from trial 1 to the delayed recall trial. All groups overpredicted their performance in the first trial (especially the high MSE groups), and consequently underpredicted their performance in the next trials. Because of the very large within-group variations, no further statistical analyses were performed.

\section{Atribution}

Table 9.4 shows the attributions made by the different experimental groups. The low MSE group that received positive feedback attributed their 'successful' performance more to the memory task (external attribution), whereas the high MSE group that received positive feedback attributed their performance more to their memory (internal attribution). The opposite was found for the groups that received negative feedback. The low MSE group now attributed their "unsuccessful" performance more to their memory and the high MSE group attributed their performance more to the memory task. Although these differences in attributions between the high and low MSE 
groups in each of the feedback conditions showed the expected pattem, no statistically significant differences were found.

Table 9.4 Atribution of performance for the high and low MSE groups.

\begin{tabular}{|c|c|c|c|c|c|}
\hline \multirow[t]{2}{*}{ group } & \multicolumn{2}{|c|}{ LOW MSE } & \multicolumn{2}{|c|}{ High MSE } & \multirow[b]{2}{*}{$p^{\text {th }}$} \\
\hline & $M$ & $S D$ & $M$ & 50 & \\
\hline Positive feedback & 108 & 53 & 84 & 42 & .217 \\
\hline Negative feedback & 86 & 64 & 121 & 51 & .123 \\
\hline Neutral feedback & 89 & 44 & 104 & 56 & .444 \\
\hline
\end{tabular}

Note. Attribution of performance expressed in millimetres on a visual analogue scale of 200 millinetres. A score of 0 would indicate attribution 10 only general memory functioning (internal attribution), a seote of 200 would indicate attribution to only the memory task (external atribution).

n T-test.

\section{Personality and mood}

Data for the different personality and mood questionnaires for the high and low MSE group are presented in Table 9.5. Statistically significant differences were found on all questionnaires.

Table 9.5 Means (M) and standard deviations: (SD) for the mood and personality questionnaires of the low MSE group $(n=40)$ and the high MSE group $(n=41)$.

\begin{tabular}{|c|c|c|c|c|c|c|}
\hline \multicolumn{2}{|l|}{ group } & \multicolumn{2}{|c|}{ Low MSE } & \multicolumn{2}{|c|}{ High MSE } & \multirow[b]{2}{*}{$p^{\text {in }}$} \\
\hline & & $M$ & $S D$ & $M$ & $S D$ & \\
\hline \multicolumn{2}{|c|}{ Zung depression } & 40.5 & 10.7 & 29.2 & 6.6 & .000 \\
\hline \multicolumn{2}{|c|}{ Trait Anxiely } & 42.8 & 11.6 & 29.8 & 6.7 & .000 \\
\hline \multirow[t]{2}{*}{ ABV } & Psychoneurotic complaints & 69.3 & 27.4 & 30.0 & 20.2 & .000 \\
\hline & Functional somatic complaints & 25.9 & 8.8 & $\| 6.1$ & 4.9 & .000 \\
\hline \multirow[t]{3}{*}{ PMT } & Achievement motivation & 21.2 & 7.7 & 24.4 & 6.1 & .037 \\
\hline & Performance anxiety negative & 15.4 & 5.7 & 6.9 & 5.6 & .000 \\
\hline & Performance anxiety positive & 5.5 & 4.3 & 11.1 & 4.6 & .000 \\
\hline
\end{tabular}

Note. $\mathrm{ABV}=$ Amsterdamse Biografische Vragenlijst, PMT = Prestatie Motivatic Test.

a $T$-test. 
Individuals from the low MSE group reported more depressive complaints. The mean score of 40.5 of this group corresponds with the lowest scote for minimal or mild depression (Zung, 1965). The low MSE group also had signiticantly higher scores for neurotic symptomatology and trait anxiety than the high MSE group. Compared to the distribution of neuroticism scores in a normal population, the mean scores for psychoneurotic complaints and functional somatic complaints of the low MSE group corresponded to the 8th and 9th decile and those of the high MSE group to the 2 th and the 5 th decile (de Wilde, 1970). The mean scores for the trait anxiety for the low and high MSE grotps corresponded with the 8 th and 3 th decilles, respectively (Van der Ploeg et al., 1981). Both groups had high scores on achievement motivation compared to the distribution in the normal population: the scores for the low MSE group were in the 8th decile and those of the high MSE group in the 9th decile (Hermans, 1976). The scores for negative and positive performance anxiety showed an inverted pattern for the two groups. The low MSE group had high scores for negative performance anxiety ( 8 th decile) and low scores for positive performance anxiety (3th decile); the high MSE group had a low mean score for negative performance anxiety (3th decile) and a normal score for positive performance anxiety (6th decile).

\section{Discussion}

The present study was designed to examine the different effects of negative and positive performance feedback on task-specific memory self-efficacy judgments in a group of elderly people with a low memory self-efficacy and in a group of elderly people with a high memory self-efficacy. On the basis of the self-efficacy theory of Bandura (1977) and the implicit theories of cognition put forward by Dweck and Leggett (1988), we expected to find that predictions about future memory performance would be strongly influenced by negative performance feedback and not or only marginally by positive feedback in the group with low memory self-efficacy beliefs. In the group with high memory self-efficacy beliefs we expected to find the reverse pattera: predictions of future memory performance would be strongly influenced by positive performance feedback, but not or only marginally by negative feedback. This, however, was not supported by the findings of the present experiment as no group $x$ feedback interactions were found. On the few statistically significant effects found, the most robust finding was that the groups that received positive feedback made somewhat higher predictions than the groups that received neutral feedback, and this effect could be ascribed mainly to the upgrading of predictions by especially the low MSE group in trials 2 and 3 (this effect was not seen for their predictions on the delayed recall trial, possibly due to the perceived difficulty of this trial). No effect of negative feedback was found on prediction, albeit that the low MSE group showed a slighty more marked decline in prediction confidence at the second trial. Negative feedback influenced performance in the high MSE group because their performance increased significantly less from the second to the third trial than that of the thigh MSE group that received neutral feedback.

Although not statistically different, the differences in attributions between the high and low MSE groups showed the expected pattern. In explaining "successful" and "unsuccessful" pertormance (as expressed by positive and negative feedback, respectively), the low MSE group tended to ascribe success to the specific memory task and failure to their memory functioning in. 
general; an attribution pattern that is likely to decrease self-efficacy strength. The high MSE group, on the other hand, tended to ascribe success more to their memory and failure to the specific memory task involved, which might lead to greater self-efficacy strength (Lachman, Steinberg \& Trotter, 1987).

All participants were nomal community-dwelling elderly people who had performed within the normal range on a standard clinical memory test. Thus although the participants were similar in their objective memory abilities, they were very different in their subjective memory beliefs. The marked differences on the personality and mood measures between the participants with at high memory self-efficacy and those with a low memory self-efficacy again underlines the inportance of taking these measures into account when studying memory beliefs and complaints in old age. Low memory self-efficay beliefs were associated with more depressive complaints, higher trait anxiety, more neurotic symptomatology, and higher negative and lower positive performance anxiety. The contrast between the high and low MSE groups is further emphasized by the fact that their scores on these measures mostly corresponded with the lower or upper limits of the normal distribution curves. An unexpected finding was encountered on achievement motivation. Although the high MSE group had a significantly higher score for achievement motivation than the low MSE group, the score of the latter group was unexpectedly high when compared with the scores of the normal population.

At the first trial, were no feedback was yet provided, the low MSE groups made significantly lower predictions than the high MSE group. This supports the notion of Hertzog ef al (1990) that performance predictions will be based on global memory self-efficacy beliefs in the absence of specific, local experience in the memory domain assessed by the task or on more specific memory self-efficacy beliefs in familiar situations. This finding is interesting when its consequences are extended to daily life. This low belief in memory abilities may probably lead the individual to avoid, unnecessarily, memory demanding situations in daily life. As a consequence, no positive change in the subject's negative memory beliefs can be established through successful or mastery experience in daily memory tasks.

Taken together, our results were disappointing, especially with respect to the marginal effects found of the feedback manipulations. At debriefing, however the participants understood and recognized the rationale of the experiment very well and especially the individuats from the low MSE group often mentioned examples from their everyday life that illustrated their bias for memory failures and their disregard of successful memory performance. Despite this, hardly any effects were found of the feedback manipulations. We think that wo methodological problems may largely have accounted for the absence of the axpected effects of feedback. The first and most important problem is that the experimental memory task was probably too difficult. We had chosen to use 14 names because in a previous study with a comparable group of older adults we detected ceiling effects on a similar task with 8 names after one presentation. In the present task, the maximum mean performance was about eight correctly recalled names in the third trial, although 16 participants $(20 \%)$ reached a score of 10 or more in this trial and three participants even reached a score of 13 correctly remembered names. At debriefing the participants were almost unanimous in their opinion that the task was wery difficult. This perceived high difficulty of the task may have made the participants cautious about changing or upgrading their predictions, which in part is illustrated by the small range of prediction change in the different feedback conditions and by the dramatic drop in prediction accuracy after the first trial. All groups 
overpredicted their performance in the furst trial, but consequently underpredicted their performance in the successive trials. In short, the difficulty of the task may have "overruled" the feedback information, as the percelved controllability of the task was too low.

A second methodological problem has to do with the feedback procedure itself. Some individuals from the high MSE group perceived the report number 5-6 as being negative, as they had expected to perform better than that. Some indiwiduals from the low MSE group, on the other hand, perceived it as being positive. Therefore the neutral condition might not have acted as the intended control condition. In a pilot study we had tried a slightly different feedback procedure in which we asked the participants to assign themselves a report number for their performance after the first triall. This report number was used as the reference point for providing feedback. Positive, neutral, and negative feedback consisted of adding 2,0, and -2 points respectively to the report number the subjects had assigned to themselves after the first trial. Although this approach has the advantage that it more directly reflects a person"s belief in his or her task competence or individual task specific MSE (and is therefore very creditable for the subject), this feedback procedure was skipped for practical and methodological reasons. Some elderly subjects in our pilot study gave themselves quite extreme report numbers (e.g., 2-3 or 8-9), which made it impossible to change the report number according to the algorithm described. Besides that, it was questionable in how far changes in report numbers from 3 to 5 (still below average) or 9 to 7 (still above average) or a an unchanged initial report number of 4 (below average) or 8 (far above average) would really be perceived as positive, negative, and neutral feedback respectively. We chose for the report numbers as feedback because we thought it would be a powerful tool to influence the participant's beliefs of their task competence. However, based on information from the participants, the indiwidual perception of the value of the report number was not as unambiguous as we thought it would be. In a following experiment a more direct (but perhaps less powerful) feedback procedure might be to tell the subject that his or her performance was below average (negative feedback), average (neutral feedback), or above average (positive feedback) compared to that of age-mates.

Despite the disappointing results, we do believe that experiments like these are important when studying determinants of age-related changes in subjective as well as objective memory in a normal aged population. Thus far, the relation between subjective and objective memory and mediating variables has been largely examined in correlational studies. Experimental studies like this are necessary to explore the possible causal mechunism by which memory self-efficacy beliefs influence behavior in memory-demanding situations.

\section{References}

Arbuckle, T. Y." Gold, D., \& Andres, D. (1986). Cognitive functioning of older people in relation to social and personality variables. Joumal of psychology and aging, 1, 55-62.

Arbuckle, I. Y.. Gold, D. P. Andres, D., Scliwartzman, A., \& Chaikelson, J. (1992). The role of psychosocial context, age, and intelligence in memory performance of older man. Psychology and Aging. 7, 25-36.

Bandura, A. (1977). Self-efficacy: toward a unifying theory of behavioral change. Psychology Review, 84, 191-215.

Bandura, A (1989). Regulation of cognitive processes through perceived seffefficacy. Developmental Psychology, 25.729 .735 .

Berry, J. M., West, R. L. (1993), Cognitive self-efficacy in relation to personal mastery and goal setting across the life span. International Joumal of Behavionat Development, 16, 351-379. 
Berry, I. M. West, R. L., Dennebey, D. M. (1989). Reliability and validity of the memory salfernoney questionnaire. Developmental Psychology, 25, 701-713.

Bolla, K. I., Lindgren, K. N., Bonaccorsy, C., Bleecker, M. L. (1991). Memory complaints in older adullis. Fact or fiction? Archives of Meurology, $48,61-64$.

Cawanaugh, J. C., \& Green, E. E. (1990). I believe, therefore I cann selfeficacy beliefs in memory aging. In E. A. Lovelace (Ed.), Aging and cognition: mental processes, selfowareness and interventions (pp. 189-229). Ansterdam, the Netherlands: Elsevier Science.

Cavenaugh, J. C. (1996). Memory self-efficacy as a moderator of memory change. In F. Blanchard-Fields \& T. H. Hess (Eds.). Perspectives on Cognitive Change in Adulhood and Aging (pp. 488-507). New York: The McGraw-Hill Compagnies.

Cipolli, C., Neri, M., De Vreese, L. P., Pinelli, M., Rubichi, s., Lalla, M. (1996). The influence of depression on memory and metamemory in the elderly. Archives of Geronology and Geriatrios, 23, 111-127.

Collins, M. W., \& Abeles, N. (1996). Subjective memory complants and depression in the able elderly. Clinical Geronirologist, 16, 29-54.

Craik, F. I. M., \& Jennings, J. M. (1992), Human memory, In F. I. M. Craik \& T. A. Salthouse (Eds.). Handbook of aging and cognirion (pp. 51-1 10). Hillsdale: Lawrence Erlbaum.

Cutier, S. J., \& Grams, A. E. (1988). Correlates of selfreported everyday menory problems. Joumat of Gerontology: Social Sciences, 43,82-90.

de Bie, S. E. (1987). Standaardwagen 1987 - Voorstellen woor waformering van waagstellingen naar achuergrondkenmerken en interviews (Toward a standardization of questions concerning dentographic uariables in populationt studies). (2nd ed.) Leiden, the Netherlands: Leiden Uniwersity Press.

de Wilde, G. J. S. (1970). Neurotische labiliteit geneten volgens de magenligstmenode - Neurotic instability measured wirh the questionnaire method. (second edition). Ansterdam: F. van Rossen.

Deptula, D., Singh, R., Pomara, N. (1993). Aging, emotional states, and memory. American Jonmat of Psychiatry, 150, 429-434.

Derouesne. C., Alperowitch, A., Arvay, N., Migeon, P., Moulin, F., Vollant, M., Rapin, J. R., \& Lee Poncin, M. (1989). Memory complaints in the elderly: as study of 367 cornmunity-dwelling individuals from 50 to 80 years old. Archives of Gerontology and Geriatrics, Suppl. 1. 151-163.

Devolder, P. A., Brigham, M. C.\& Pressley, M. (1990). Memory performance awareness in younger and older adults. Psychology and Aging, 5, 291-303.

Dixon, R. A., Hultsch, D. F., \& Hertzog, C. (1988). The metamemory in adulthood (MIA) questionnaire. Psychopharmacology Bulletin, 24,671-688.

Dweck, C. S., \& Leggett, E. L. (1988). A social-cognitive approach to motivation and personality. Psychologicol Review, 95, 256-273.

Gilewski, M. J., \& Zelinski, E. M. (1986). Questionnaire assessment of memory complaints. In L. W. Poon (Ed.), Handbook for clinical memory assessment of older adwits (pp. 93-107). Washington: American Psychological Association.

Hânninem, T., Reinikaimen, K. J., Helkala, E, Koivisto, K. Mykkänen, L. Laakso, M., Pyörailit, K., \& Riekkinen, P. I. (1994). Subjective memory complaints and personality onaits in normal elderly subjects. Journal of the American Geriatrics Socieny, 42,114.

Hermans, H. J. M. (1976). Handleiding bij de Prestafie Morivate Test (PMT). Amsierdam: Swets \& Zeittinger.

Hernog, C.. Dixon, R. A., \& Hultseh, D. F. (1990). Relationships between metanemory, memory predictions, and memory task performance in adulls. Psychology and Aging. 5, 215-227.

Herizog, C., Hultsch, D. F. \& Dixon, R. A. (1989). Evidence for the convergent validity of wo self-peport metamemory questionnaires. Developmental Psychology. $25,687.700$.

Hertzog, C., Saylor, L. L., Fleece. A. M., De Dixon, R. A. (1994). Metanemory and aging: Relations between predicted, aciual and perceived memory task performance. Aging and Cognition, 1, $203-237$.

Hood, B. M. MacLachlan, M., Eisher, S. (1987). The relationship betwen cognitive fatlures, psychoneurotic sympioms and sex. Acra Psychiarica Sicandinawica, 76, 33-35.

Jolles. J. Houx, P. J., van Boxtel, M. P. J., \& Ponds, R. W. H. M. (1995). Maastrich Aging Study: Determinants of cognitive aging. Maastricht: Neuropsych Publishers.

Lachman, M. E., Steinberg, E. S., \& Troter, S. D. (1987). Erfects of control belliefs and autubutions on memory self-assessments and performance. Psychology and Aging. 2, 266-271.

Lezak, M. D. (1995). Nearopychological Assessmen. (Third edition). New York: Oxford University Press.

Light, L. L. (1991). Memory and aging: Four hypotheses in search of data. Annual review of psychology, 42, 333376.

Lovelace, E. A. (1990). Aging and metacogntions concerning memory function. In E. A. Lovelace (Ed), Aging and cogntion: mental processes, self awareness ardintententons (pp. 157-188). Amsterdam: Elsevier Science. 
McDonald-Miszezak L. Hunter, M. A., \& Hulsch, D. F. (1994). Adull age differences in predicting memory performance: the effects of normative iniomation and task experience. Canadian Journal of Experimental Prychology, 48, 95-118.

Ponds, R.W. H. M. Commissaris, K. J. A. M., \& Jolles, I. (1997). Prewalence and covariates of subjecive forgetfuliness in a normal population. Inte rnational Jowmal of Aging and Hanan Development, 45, 207-221.

Ponds, R. W. H. M. \& Jolles, J. (1996a). The abridged Dutch Metamemory in Adulthood (MIA) questionnaire: Structure, and effects of age, sex, and education. Psychology and Aging, $11,324-332$.

Ponds, R. W. H. M, \& Jolles, J. (1996b). Memory complaints in elderly people: the role of memory abilities, metamemory, depression, and personality. Educational Gerontology, 22, 341-357.

Raven, J. C., Cour, J. H., \& Raven, J. (1992). Manual for Raven's Progressive Matrices and wocabulary scales (section 3): Standard Progressive Matrices. Oxford: Oxford Psychologist Press.

Smith, G. E, Petersen, R. C., Ivnik, R. J, Malec, J. F., Tangalos, E. G. (1996) Subjective memory complaints, psychological distress, and longitudinal change in objective memory performance. Psychology and Agifig. 11, 272-279.

Van der Ploeg, H. M., Defares. P. B., \& Spielberger, C. D. (1981). Handleiding bij de Zetf-Beoordeling,sVragenlijst. Lisse, the Netherlands: Swets \& Zeitlinger.

West, R. L. \& Berry, J. M. (1994). Age declines in memory self-efficacy: general or limited to particular tasks and measures? In J. D. Sinnot (Ed.), Handbook of Adult Lifespan Learning (pp. 426-445). New York: Greenwood Publishthing Co.

West, R. I., Dennehey-Basile, D., \& Norris, M. P. (1996). Memory self-evaluation: The effects of age and experience. Aging, Neuropsychology, and Cognition, 2, 67-83.

Wilson, B. A., Cockburn, J., \& Baddeley. A. D. (1985). The Rivermead Behavioral Memory Test. Reading: Thames Valley Test Company.

Zung, W, K. (1965). A self-rating depression scale. Archives of General Psychiatry 12, 63-70. 


\section{Concluding remarks}

The central theme of this thesis concerns age-related changes in perceived everyday memory functioning in the normal population. The prevalence, characteristics, and possible determinants of everyday memory failures or complaints were assessed in different large-scale cross-sectional studies that were conducted as part of the Maasiricht Aging Study (MAAS). The findings show that there is hardly any relation between self-appraisal of everyday memory functioning and actual memory ability, as measured with memory performance tests. Everyday memory functioning seems to be related more to factors associated with affective state, coping styles, health, worry about dementia, and personality traits than to structural changes in memory functioning per se. In line with other cognitive aging researchers (e.g., Berg, Brouwer, Deelman, Schmidt \& Sikken, 1998; Hultsch \& Dixon, 1990), we also conclude that self-appraisal of memory and objective memory performance seem to be two different and largely independent domains. The implications of these findings are discussed below.

\section{Age-related changes in subjective memory: It depends on what and how you ask}

There is a widespread belief that aging is associated with an increase in everyday memory failures. However, research on age-related changes in subjective memory has produced conflicting results. Many researchers have found that older people notice more everyday memory failures than younger people (e.g, Gilewski, Zelinski \& Schaie, 1990), but others found no differences or even found that older people reported fewer memory failures than younger people (Gilewski et al., 1990; Jackson, Bogers \& Kerstholt, 1988; Sunderland, Watts, Baddeley \& Harris, 1986). These seemingly conflicting results may in part be explained by differences in the way everyday memory functioning is assessed. Age differences become especially or only apparent when people thave to rate their present functioning in terms of their own functioning at some point in the past. The findings from several studies in this thesis confirm this. No age differences were found in the absolute number of everyday cognitive failures as measured with the Cognitive Failure Questionnaire (Chapter 4), but the older subjects indicated that these everyday failures had increased over the last few years. Only small age differences were found on the Capacity scale of the Metamemory in Adulthood Questionnaire (MIA), which asks subjects to give a general rating of present memory abilities, whereas large age differences were found on the Change scale, in which people rate the possible decline in their own memory functioning over the past 5-10 years (Chapter 5 and 6 ). It seems that if people have to rate their present memory functioning in global terms (good/bad) or in terms of frequency of everyday memory failures, they adjust their response 
to what they expect to be normal for their age, thereby masking a possible age-reiated decline in subjective memory functioning (Cavanaugh, 1987; Hultsch, Hertzog \& Dixon, 1987). This is clearly illustrated by the findings on subjective cognitive functioning reported in Chapter 3. No age differences were found when present cognivive functioning was compared to that of age mates, whereas large age differences were found when subjects had to compare their present cognitive functioning to that 5 to 10 years ago and when they were 25 years old.

It can be concluded that memory questionnaires that ask for more-or-less global ratings of present memory functioning (good/bad) or that ask for frequencies of everyday memory failure are not very suitable for the study of age-related changes in everyday memory functioning. More meaningful and reliable information on possible age-related changes in subjective memory can only be acquired if relative measurements are taken, where people judge their present memory performance relative to their performance at some defined point in their own past, as is noted eatlier by Rabbitt and Abson (1990).

\section{Characteristics of age-related differences in subjective memory}

Only a few studies have examined changes in subjective memory functioning in subjects covering the whole adult age range which is necessary in order to answer questions concerning the age at which memory changes occur, and the speed at which they progress. The findings in Chapter 3 show that a decline in subjective memory functioning is already apparent in the middle-age and that this decline is not restricted to memory but also includes other cognitive functions like mental speed, attention, planning, and decision-making. This suggests that the change or decline in cognitive functioning is rather global in nature. Scores for the MIA Change subscale also indicate that there is a steady decline in subjective memory functioning that is already apparent in young middle-aged subjects (Chapter 5). We also found a relatively high prevalence of forgetfulness (Chapter 2 ) in young and young middle-aged subjects (approximately 30\%) when compared to that of old middle-aged and old subjects ( $41 \%$ and $52 \%$ ). The conclusion must be that changes of a decline in subjective memory and cognitive functioning already occurs in the early stages of adulthood, although this clecline is more noticeable in the oldest subjects. This is a reason why cognitive aging researchers should not restrict their study samples to the older age groups, as is usually done, but should include the whole adult age range.

The findings from the MAAS samples (Chapter 2-6) show that a thigher educational level is associated with higher ratings of memory capacity and less perceived decline in memory functioning. It might be that people with a higher education are better able to compensate for an age-related decline in their memory, although they do not seem to use memory strategies more often than people with a lower level of education. We also found that the educational level of elderly people who were seeking help for their memory problems by participating in a memory training program was above average for their age group (Chapter 8 ). In Chapter 7 , the participants in a study on subjective memory were recruited from a large sample of individuals who had participated in a study on the effectiveness of an information brochure on dementia and normal forgetfulness. In this study we found that higher educationall level was associated with more perceived memory decline and lower memory capacity. This suggests that subjective memory in 
general may be better in higher-educated people, but at the same time the higher-educated persons seem to be more sensitive to perceived age-related changes or decline in their memory functioning and are consequently more motiwated to seek help or information.

Findings from the same MAAS samples showed that, overall "there are no or only small sex differences with respect to subjective memory functioning. If any relation is found, if mostly indicates that women tend to have a somewhat higher rating for present memory capacity than men. Wonen also report less decline in memory functioning. At the same time, they use memory strategies more often than men do, which perhaps explains their better everyday memory functioning.

Data on the Cognitive Failure Questionnaire (Chapter 4) showed very similar score profiles in both absolute and relative frequency across individual items for the different age groups, suggesting that there is no specific age-related pattern of functional incompetence with respect to daily cognitive performance or some unique age specific pattern of forgetting in elderly people. Moreover, older and younger individuals do not differ in the reported frequency of everyday memory failures. As in many other studies, problems in name- and word-finding, lack of concentration, and not knowing where you have put something are the most frequently reported everyday memory and cognitive failures (e.g., Cavanaugh, Grady \& Perlmutter, 1983; Strijker, Berger \& Deelman, 1994). One might have expected that elderly people would use memory strategies more often to compensate for their diminishing memory. However, data for the MlA Strategy subscales (Chapter 5) showed that there were hardly any age differences in the use of memory strategies.

In chapters 2 and 4 we explicitly asked participants to rate perceived hinder and worry about their everyday memory and cognitive functioning. Most of them did not experience much hindrance from or worry about their failing memory. No or only small effects of age were found, although we had expected to find a strong relation between worry and age. Nevertheless, approximately one to two people out of ten who considered themselves forgetful experienced considerable hindrance from their forgetfulness and, perhaps more importantly, were very worred about this forgetfulness. Worry about memory is in itself a serious problem, especially because it may potentially lead to an increase in everyday memory failures because wortied people are more anxious and therefore more error-prone in everyday memory-demanding situations.

In conclusion, there appear to be few age-specific characteristics of everyday memory functioning, besides the fact that older people in general report a greater decline in memory function. The particular memory problems older people encounter in everyday life are very similar to those encountered by younger people. No marked age differences were found with respect to perceived worry about and hinder from everyday memory failures, and young and old people made similar use of memory strategies (both type of strategy and frequency of use). There were, however, clear differences with respect to the atribution of memory problems. Older people were pessimistic in that they ascribed their forgetfulness more often to less manageable and more-orless irreversible memory-intrinsic causes, especially aging. In contrast, younger people more often mentioned more manageable and reversible memory-extrinsic causes for theit forgetfulness (e.g. tension and emotional problems, lack of interest, and poor concentration). Although older people may be more vulnerable to everyday memory failures due to the normal aging process of the brain, it is very likely that especially emotional distress is an equally important determinant of everyday memory failures, as it is in younger people. Indeed, many studies have shown a relation 
between depression and subjectwe memory complaints in older age. Ascribing increased memory fatures to emotional distress instead of 'aging' opens the way to more possibilities for intervention and relabeling of the memory problems.

\section{Relation between objective and subjective memory}

Several studies reported in this thesis examined the relation between performance on wide variety of cognitive and menory tests and measures of subjective memory. This was done within a correlational design (Chapter 3, 4, and 6) or a group-comparison design in which individuals with high and low subjective memory ratings were compared (Chapter 7 and 8 ). We found significant correlations between subjective memory measures and test performance, but these correlations in general disappeared or were substantially lowered when age in particular was partidled out. This is in line with the "implicir theory of memory and aging' (McFarland, Ross \& Giltrow, 1992), which states that the general beliefs individuals hold about the nature of memory and aging may influence the self-rating of memory functioning more than the monitoring of actual memory ability. Thus self-reported memory change or ratings of present memory capacities are primarily based on current memory self-efficacy beliefs, which in turn are strongly influenced by the widely held belief that memory inevitably declines with age. Age is thus a common factor in subjective and objective memory, but it refers to two unrelated processes, namely the norma! age-related decline in memory performance and the reported decline in memory functioning based on the widespread societal belief that memory declines with advancing age. Longitudinal data are needed to further examine the implicit theory of memory and aging, which predicts that retrospective perceived changes in memory are not related to changes in actual memory pertiormance.

It could be argued that the absence of a relation between subjective and objective memory measures may in part be due do the fact that our tests lack ecological validity. Most of the tests used were typical laboratory tasks that are not characteristic of everyday memory tasks. In the study reported in Chapter 8 a more ecological memory lest (Rivermead Behavioral Memory Test) was used together with stanclard laboratory tests, but the scores on this test were similar in the high- and low-menory complaints groups, whereas the groups had significantly different scores. lor a non-daily semantic memory task (Fluency). What might be more important than the lack of content validity of the memory tests in relation to daily memory tasks is the difference in performance conditions. In everyday memory tasks people may fail because they do several tasks at the same time, they may be stressed or distracted by noise, tired, anxious about failing, or hardly motivated to perform well. This situation is very different from testing in the laboratory, where people are examined in sound-proof rooms, have to do one task at a time, are allowed to rest between tasks, are reassured if necessary, and are encouraged to perform as well as possible. Under these circumstances, a person may perform well, but in daily life his or her memory may fail and thus the reported everyday memory decline or failures are in fact valid. Such an explanation is more-or-less in line with the functional theory of age differences in memory proposed by Craik (1986). He states that when the task or the environmental context does not support the appropriate mental operations necessary for adequate memory processing sufficiently, 
\& person must rely more on self-initiated operations for temembering. Such self-initiated mnemonic operations become more difficult to execute with increasing age, perhaps due to decreasing processing resources. Consequently, memory performance may be better in older age if there is more environmental support.

\section{Subjective memory: Non-cognitive factors}

As mentioned in the previous paragraph, self reported everyday memory functioning is hardly related to objective memory abilities. However, in all of the studies of this thesis we found substantial relations between everyday memory functioning and different non-cognitive factors that are related to affective state, coping styles, health, worry about dementia, and personality traits. These non-cognitive factors were largely age-independent, as we did not find interactions between age and any of the non-cognitive factors in the different regression andyses we performed. Although older people in general reported more memory decline, there seemed to be no tinique age-specific non-cognitive factors that could account for this decline.

If we summarize our findings, then person with low ratings of everyday memory functioning (in terms of perceived memory capacity, memory decline, or memory anxiety) is likely to have some of the following characteristics: he or she is older, has a low level of education, has health problems which he or she feels are not under his or her control, has depressive complaints, is worried about dementia or cognitive decline, has low social support, uses a passive coping style in problem situations, has a negative performance anxiety, and has more neurotic symptoms suggesting more emotional instability. It is tempting to formulate a causal chain between these non-cognitive factors. For example, one possible model would be that health problems and depressive complaints make a person more vulnerable to everyday memory failures as these problems "consume" cognitive and attentional resources. A more anxiety-prone or neurotic older person may easily interpret these everyday memory failures as signs of memory decline (or dementia) and this perceived decline is seen as a problem that is more-or-less out of personal control. Because they are anxious about this possible decline, people may develop a attentional bias toward everyday memory fallures which in itself may lower memory self-efficacy beliefs and consequently reinforce the perceived memory decline. Another simpler and rather banal model would be that complaining about memory is just one example of a general attitude to complain because of a neurotic personality structure, for which reason a person also complains about his or her health or reports more depressive symptoms. At this moment we can only speculate about these causal models because the cross-sectional nature of the data we collected do not permit straightforward inferences about cause-and-effect relations. Only longitudinal data from follow-up measurements would allow us to examine the potential causal relations between the non-cognitive factors mentioned and perceived memory decline. Such follow-up measurements are presently being undertaken in MAAS. 


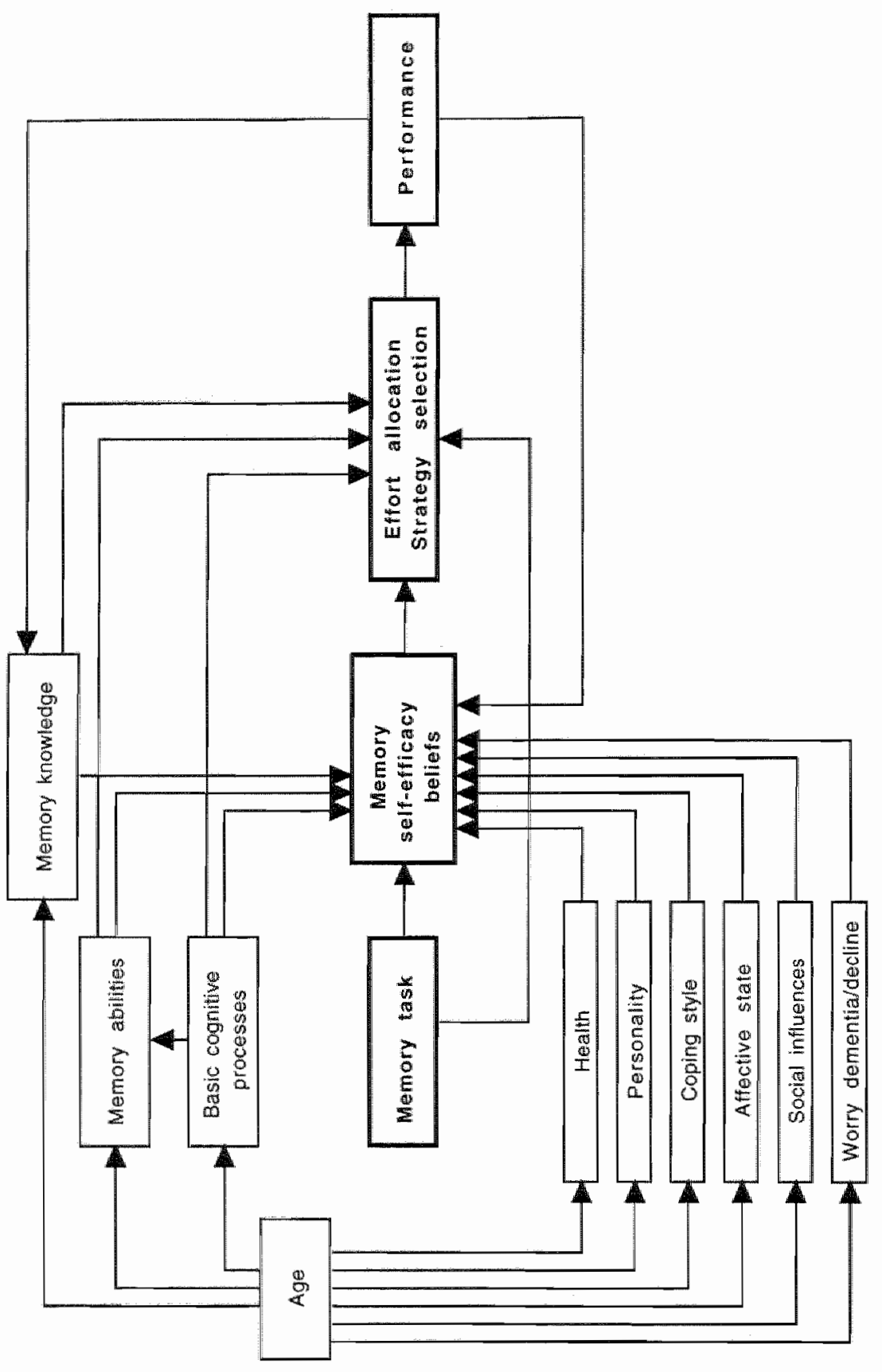

Figure 10.1 Conceptual model of she relations between menory selfefficacy, memory perfornance, and cognitive and non-cognitine determinans. 


\section{Memory self-efficacy and aging: A working model}

The central theme of this thesis is that while many people, especially the elderly, notice a decline in daily memory functioning, this perceived decline is hardly related to actual memory abilities. Although these perceptions of changes in memory function may not represent actual change in memory function, they are important because they determine to a large extent what people do when confronted with everyday memory tasks (Cavanaugh \& Green, 1990; Lovelace, 1990). The key construct central to understanding the relation between memory perceptions and everyday memory performance is memory self-efficacy. Memory self-efficacy refers to an individual's beliefs about his or her memory abilities in a wariety of memory tasks. In the Introduction, a simple model of self-efficacy was applied to memory and aging. Different sounces of self-efficacy information (e.g.x mastery experience) and the way in which self-efficacy judgments may determine task-engagement behaviors (e.g., amount of effort allocated to a task) were described.

Figure 10.1 shows a preliminary and undoubtedly incomplete model that clescribes a network of hypothesized causal and reciprocal relations among different constructs related to (everyday) memory performance. This model is based in part on the findings described in this thesis and is derived from the more complex conceptual models of self-evaluations of memory presented by Cavenaugh and colleagues (1985, 1990). Its main purpose here is to illustrate how we may proceed in examining age-related determinants of everyday memory performance within a testable framework of hypotheses. The key point is that how a person uses memory strategies and how much effort he or she allocates to a memory task is determined, in a complex way, by memory self-efficacy beliefs. These beliefs determine the amount, effectiveness and persistence of effort allocation and the choice and use of memory strategies for encoding and retriewal. In turn, efficacy beliefs are based on information from multiple sources such as general knowledge of memory processes and memory strategies, actual memory abilities, basic cognitive processes like mental speed and attention, the characteristics of the memory task itself, and a variety of non-cognitive factors like affective state, personality, and health.

To date, only a few studies have examined how memory sell-efficacy and related concepts operate across adulthood (e.g., McDonald-Miszczak, Hertzog \& Hultsch, 1995 ; Smith, Petersen, Iwnik, Malec \& Tangalos, 1996). Models, like the one presented here, can be tested within longitudinal designs, using structural equation modeling (e.g., LISREL, Jöreskog \& Sớbom, 1996), so that we can infer causal relations within a set of correlation data. Studies like the one performed by Albert, Jones, Savage, Berkman and Seeman (1995) are excellen examples of how we should set about this. They investigated, in a longitudinal study, an impressive number of predictors of cognitive change in older people using a linear structural relations modeling technique. Predictors were 18 lifestyle (e.g., alcohol use, level of strenuous activity in cveryday life), psychosocial (e.g., emotional support, life satisfaction), and physiologic measures (e.g., cortisol, body mass index). Education, strenuous activity, peak pulmonary expiratory flow rate, and selfefficacy were found to be reliable predictors of cognitive change over a 2 - to 2 .5-year period in adults aged 70-79 at initial evaluation.

Hardly any studies have been published that directly examined the nature of the relations. between memory self-efficacy, strategy selection, and effort allocation and memory performance, especially in relation to age. Such relations might be that elderly persons who are concerned about 
their memory may become trapped in a vicious circle in which a strong attentional bias to memory faitures and the misinterpretation of normal everyday memory failures on the one hand, and insufficient or ineffective allocation of effort or inappropriate strategy selection in everyday memory task on the other hand, could create an increasing number of memory failures and, as at consequence, an increasing concem about memory, which leads to a further lowering of memory self-efficacy beliefs. Experimental studies offer us the opportunity to directly examine the effects of memory self-efficacy on memory performance. The experimental study presented in Chapter 9 , for example, examined in how far low memory self-efficacy beliefs are related to an attentional bias for memory failures within a menory performance prediction paradigm. Other future topics for experimental studies could be atribution patterns or psychophysiological studies on effort in relation to memory self efficacy beliefs.

\section{Designing memory training programs}

Many elderly people take part in memory training programs to improve their everyday memory functioning. Most of these programs focus primarily on teaching mnemonic techniques. This may be useful in the sense that it provides older" people with a form of 'mastery experience' that may heighten their memory self-efficacy beliefs. However, the underlying implicit assumption of teaching mnemonic techniques is that elderly people do have some sort of memory deficit, which can be compensated for by using specific memory strategies. As such, it reinforces the layman's view that memory complaints or perceived memory decline in older age reflect an actual decline in memory function due to the biological aging of the brain. The finding that almost half of all forgetful people are interested in treatment with memory-enhancing nuedication (Chapter 2) indirectly reflects this far too simple biological explanation of everyday memory failures. Our findings, however, show that perceived everyday memory functioning is largely independent of actual memory ability, which is opposite to what would be expected from the 'biological view' of " memory and aging. Everyday memory problems in older age may be better explained within a psychological instead of a biological framework, and memory intervention programs for elderly people should put more emphasis on modifying beliefs about memory competence and controllabihty in addition to teaching mnemonic strategies, as has been noted earlier by other cognitive researchers (e.g., Cavenaugh, 1996; Lachman, Weaver, Bandura, Elliott \& Lewkowicz, $1992)$.

In cooperation with the home-care organization in Maastricht (Stichting Groene Kruis Heuvellandy, we recently developed a new memory training course for community-dwelling elderly people that explicitly focusses on improving participants" attitudes and beliefs towards their memory functioning (Ponds Bouwens, 1997). The course is also being provided by other Dutch home-care organizations. The course provides extensive information about normal age-related forgetfulness and the differences batween forgetfulness and dementia, the effects of emotional states and health on memory, and the role of memory self-efficacy beliefs on everyday memory performance. Peoples' attitudes and opinions lowards memory and aging are discussed in depth. Also memory strategies are teached, with an emphasis on external strategies. To gain a better insight into the 'dynamics' of their everyday memory functioning, the participants have to 
keep a memory diary troughout the 8 -wweek course in which they note their memory failures and the most plausible cause they can think of (e.g., lack of concentration, being too busy), their emotional reactions (e.g., anxiety", shame), their thoughts (e.g., example of "pathological" decline), and possible solutions for preventing recurrence of these memory failures (e.g., doing one thing at a time, making notes). At the moment, we are awaiting for the first evaluative data for the memory course. We expect that an adapted version of this course will also be applicable to patients with relatively minor brain disorders (e.g., minor head trauma), because we have found earlier that memory self-efficacy beliefs are at least as important determinants of everyday memory problems in these patient groups as the abjective cognitive disturbances themselves (Commissaris, Verhey \& Jolles, 1996).

\section{Conclusion}

From its start in 1991, the Maastricht Aging Study has studied both objective memory and subjective memory in relation to age. Objective memory is measured with standard. laboratory and clinical memory tasks, whereas subjective memory, being one's self-appraisal of everyday memory functioning, is mainly measured with memory questionnaires. The research described in this thesis emphasizes the importance of considering aspects from both domains. At the moment, it seems as if we are speaking of two different 'worlds', but we expect that as the Maastricht Aging Study contimues in its longitudinal phase, the two 'worlds' will unite. Everyday memory functioning in older age will probably prove to be determined in part by the observed age-related decline in memory abilities, but probably more important will be the psychological or noncognitive factors which determine the way in which older people compensate for their memory decline in everyday life. Close study of especially individuals who appear to age successfully and who have no complaints about everyday memory functioning may further provide us with tools for designing memory interventions or public education programs that may contribute to the autonomy and well-being of the older individuals in society.

\section{References}

Albert, M. S., Jones, K., Savage, C. R., Berkman, L., Seeman, T, et al. (1995). Predictors of cognitive change in older persons: MacArthur studies of succesful aging. Psychology and Aging, 10.578-589.

Berg, I. I. Brouwer W. H. Deelman, B. G., Schmid, I. W. \& Sikken, J. A. (1998). Geheugen en deservermogen in het dagelijks leven wan ouderen. Tijdschriff woor Geronologie en Geriarrie, 29, 130-140.

Cavanaugh. J. C. (1987). Age differences in adults' self-reports of memory ability: It depends on how and what you ask. International Journal of Aging and Human Development, 24, 271-277.

Cawanaugh, J. C., Grady. I. G., \& Perlmutter, M. (1983). Forgetting and use of memory aids in 20 to 70 ycar olds everyday life. International journal of aging and human developmen. $17,113-122$.

Cavanaugh, J. C, \&reen, E. E. (1990). I believe, therefore I can: Selfefficacy beliefs in memory aging. In E. A. Lovelace (Ed.), Aging and cogrition: mental processes, selfrawareness and intenentions (pp. 189-229). Amsterdan, the Netherlands: Elsewier Science.

Cavanaugh, J. C., Kramer, D. A., Sinnott, J. D., Camp, C. 1., \& Markley, R. P. (1985). On missing links and such: Interfaces between cognitive research and everyday problem-solving. Human Development, 28.146-168. 
Cavenaugh, J. C. (1996). Memory self-efficacy as a moderator of memory change. In F. Blanchard-Fields a T. H. Hess (Eds). Perspectives on Cogninve Change in Aduhood and Aging (pp. 488-507). New York. The MeGrata Hill Compúanies.

Commisaris, K., Verhey, F. R. J. \& Jolles, J (1996). A controlled sudy inlo the effects of psychoeducation for patients with cogniture distubances. Joumal of Neuropsychiary, $8,429-435$.

Craik, F. I. M. (1986). A functional account of age differences in memory. In F. Klix \& H. Hagendorf (Eds.) Human Memory and Cogninve Capabilnes: Mechanisms and Performances (pp. 409-422). Amsterdam: Elsevier Science Publishers.

Gilewski, M. I., Zelinsk, E. M., \& Schaie, K. W. (1990). The memory functioning questionnaire for assersment of memory complaints in adulthood and old age. Psychology and Aging, 5, 482-490.

Hulsch, D. F, \& Dixon, R. A. (1990), Learning and memory in aging. In J. E. Birren \& J. W. Schate (Eds.J, Handbook of the pisycholagy of aging (third edition ed, pp. 258-274). San Diego: Academic Press.

Hultsch, D. P., Hertzog, C., Dixon, R. A. (1987). Age differences in metamemory: Resolving the inconsistencies. Canadian Joumal of Psychology, 11 , 193-208.

Jackson, J. L., Bogers, H., \& Kersthol, J. (1988). Do memory aids ald the elderly in their day to day remembering? In M. M. Gruneberg, R. E. Morris, \& R. N. Sykes (Edic.). Practic aspects of memory: Currext research and issues. Clinical and edwcanonal implications (pp 137-142). Chichester: John Wiley \& Sons.

Jöreskog, K. Co., \& Sörbon, D. (1996). LISREL 8: User's reference guide. Chicago: Scientific Software International.

Lachman, M. E., Weaver, S. L., Bandura, M. Eillioti, E., \& Lewkowic, , C. J. (1992). Improving memory and control beliefs through cognitive restructuring and self-generated stratlegies. Jowmal of Geromology: Psychological Siciences, $47,293-299$.

Lovelace, E. A. (1990). Aging and metacognitions concerning memory function. In E. A. Lovelace (Ed..), Aghing and cognision: Mental processes, self awareness and interventions (pp. 157-188). Amsterdant, the Netherlands: Elsevier Seience.

McDonald-Miszczak, L., Hertzog, C. \& Hultsch, D. F. (1995), Stability and accuracy of metamemory in aduthood and aging. A longitudinal analysis. Psychology and Aging, 10,553.564.

McFarland, C. Ross, M. \& Giltrow, M. (1992). Biases recollections in older adults: The role of implicit theories of aging. Jowrual of Personality and Social Pyschology, 62.837-850.

Ponds, R. W. H. M. Bouwens, M. R. J. (1997) .Gehewgencursus woor ouderen. Den Bosch: Gezondheid Service Nedertend.

Rabbitt, P., \& Abson, V. (1990). "Lost and Found': Some logical and methodological limitations of self-report questionnaires as tools to study cognitive ageing. British Journal of Pychology, $81,1-16$.

Smith, G. E. Petersen, R. C., Ivnik, R. J., Malec. J. F. \& Tangalos, E. G. (1996). Subjective memory complaints, psychological distress, and longitudinal change in objective memory performance. Psychohgy and Aging, $11,272-279$.

Sirijker, H. A. J., Berger, H., Deelman, B. G. (1994), Hel geheugendagboek bij jongeren en ouderen (Memory diary in young and old adulis). De Psycholoog, 29, 416-420.

Sundertand, A., Watts, K., Baddeley, A. D. \& Hartis, J. E. (1986). Subjective mamory assessment and test performance in elderly adults. Joumal of Gerontology.41, 376-384. 


\section{Summary}

Many middle-aged and old people have memory complaints. They notice that their memory function declines as they grow older. At first sight, this perceived decline in everyday memory seems to parallel the observed age-related decline in memory functioning found on a broad array of clinical and laboratory memory tests. However, there is no straightforward relation between perception of memory function and memory ability as measured with such tests. Many cognitive aging studies have found no or only very modest correlations between memory test performance and scores for everyday memory questionnaires. People may have serious complaints about their everyday memory functioning whereas their performance on memory tests is normal and wice versa.

The main theme of this thesis is perceived everyday memory functioning in relation to age. The prevalence, characteristics, and possible determinants of everyday memory failures and complaints are described largely on the basis of the findings of the Maastricht Aging Study (MAAS). MAAS is a large cross-sectional population-based study on normal cognitive aging that includes individuals whose ages cover the entire adult age range.

Chapter $I$ introduces the subjects of this thesis. Some methodological and theoretical problems of the use of self-report memory questionnaires in cognitive aging studies are described (e.g., the memory introspection paradox, the influence of stereotype societal beliefs about memory and aging, the fact that people can only give relative and not absolute ratings of their memory). It is argued that memory complaints, or a perceived decline in memory functioning, in old age are especially related to non-cognitive factors like demographic variables, personality traits, affective state, health, worry about incipient dementia, and an individual's self-knowledge and beliefs about memory (metamemory). Special attention is paid to one aspect of metamemory, namely the concept of memory self-efficacy. This is defined as the degree of belief a person has in his or her ability to mobilize the motivation, cognitive resources, and courses of action needed to exercise control over task demands. Memory self-efficacy is believed to be one of the most important moderators of memory changes in older age.

Chapter 2 describes the results of a study into the prevalence and covariates of forgetfulness. "The study included 1971 people in the age range 24 to 86 years. Nearly $40 \%$ of the participants considered themselves to be forgetful, and the prevalence increased with age: $29 \%$ for the young age group ( 24 to 36 years of age), $34 \%$ for the young middle-aged group (39 to 51 years of age), $41 \%$ for the old middle-aged group (54 to 66 years of age), and 52\% for the old group (69 to 86 years of age). Forgetfulness was not considered to be a serious problem in terms of perceived hindrance and worry by most subjects, irrespective of their age. Nevertheless, approximately $15 \%-20 \%$ of all forgetful individuals experienced much to very much hinder from their forgetfulness. Of these subjects, $5 \%-12 \%$ were very worried about their forgetfulness, which was especially the case for subjects in the older age groups. Age, depression, and subjective health (especially complaints about vitality) acted as covariates of forgetfulness. Sex and education had 
no effect on the prevalence of forgetfulness. More than $25 \%$ of the forgetful subjects could not think of a possible cause for their forgetfulness. The younger adults ascribed their forgetfulness to potentially reversible and manageable memory-extrinsic causes, such as tension and emotional problems, whereas the older adults mentioned fewer manageable and more, more-or-less, irreversible memory-intrinsic causes, such as aging. Eleven percent of all forgetful subjects had considered treatment for their memory problems or had actually done so. In this group, education (37\%) and memory training (29\%) were the preferred interventions. Almost $50 \%$ of the forgetful subjects were interested in participating in future treatment programs with memory wenhancing medication. Eleven percent of the forgetful subjects had used over-the-counter medications to improve memory, elderly subjects more often that younger subjects.

Chapter 3 describes a study in which age-related changes in self wevaluation of cognitive functioning were examined in the domains of memory, attention, mental speed, planning, and decision-making. Although a decline in memory functioning is probably the most prominent change when one grows older, other cognitive functions, such as attention or mental speed, are also vulnerable to aging. In this study we examined to what extent older subjects experience subjective decline in these ather cognitive functions. We also looked at the changes in selfreported cognitive functioning when different reference points were used. A group of 1958 people in the age range 24 to 86 years rated their present cognitive functioning relative to that at three different reference points, namely, to that of their age-mates, to their functioning 5 to 10 years ago, and to their functioning when they were 25 years old. An age-stratified group of 420 participants also completed a series of cognitive tests. Factor analysis showed that perceived change or decline in memory functioning was accompanied by a similar change in attention, mental speed, planning, and decision-making (one-factor solution). The age-related decline in subjective cognitive functioning started at the age of 50 and steadily increased thereafter. This effect was only found when individuals had to rate their present functioning relative to their own functioning in the past. When participants had to compare their present cognitive functioning with that of their peers, no age effects were found. This is probably due to adaptive responding on the part of the older subjects because they adjusted their present cognitive functioning to what they thought was normal for their age. Subjective health and depression were both related to a subjective decline in cognitive functioning. No relation was found between subjective cognitive functioning and performance on cognitive tests in a subsample of 420 individuals.

The study presented in Chapter 4 was designed to examine the factor structure of the Cognitive Failure Questionnaire (CFQ), the effects of age, sex, and education on CFQ scores, and the relation between the $\mathrm{CFQ}$ and objective cogntive functioning (compound scores of cognitive speed, semantic memory, and episodic memory) and several psychosocial measures (distress, subjective health, worry about dementia, and life events) in a sample of 1358 people aged 24 to 81 years. The CFQ is a well-known 25 -item self-report questionnaire that measures individual differences in cognitive efficiency or competence by asking the respondents to rate the frequency of failures or lapses in perception., memory, attention, and motor functioning in everyday life, Factor analyses on the 25 items of the CFQ suggested that a one-factor solution fitted the data well. A four-factor solution was found for a limited set of 17 items. These four factors were termed 'Absentmindedness', "Absentmindedness in social interactions", 'Names and Words', and 
'Orientation'. The different age groups (young, young middle-aged, old middle-aged, and old persons) showed very similar profiles of scores across individual $\mathrm{CFQ}$ items, both in absolute and relative frequency. This suggests that there are no marked overall differences in the frequency with which young and old people encounter particular scenarios in their everyday lives, as tapped by the CFQ questions, and does not support the notion that there is a specific age-reluted pattern of functional incompetence with respect to daily cognitive performance. Effects of sex and education were found on the overall CFQ score but these effects were negligibly small. No substantial relations were found between several cognitive compound performance measures (mental speed, episodic memory, and semantic memory) and scores on the overall $\mathrm{CFQ}$ or $\mathrm{CFQ}$ subscales, but psychological distress, worry about dementia, and subjective health were reliable predictors of CFQ scores.

Chapter 5 reports on a psychometric sudy on the factor structure, reliability, and discriminant validity of the Metamemory in Adulthood (MIA) questionnaire. The MIA is the best-validated and most frequently used metamemory questionnaire in cognitive aging research, despite its considerable length. The MIA asks individuals to rate on a 5-point Likert scale 108 statements describing their own memory functioning and their knowledge of general memory processes. The questionnaire consists of seven factors or subscales. These are reported use of various memory strategies (Strategy), knowledge of basic memory processes (Task), perceived memory capacity (Capacity), perceived change in memory functioning (Change), perceived feelings of stress and anxiety related to memory performance (Anxiety), perceived importance of having a good memory and performing well on memory tasks (Achievement), and perceived control over memory (Locus). Findings for the Dutch version of the MLA used with a sample of 1899 normal and healthy respondents aged 24 to 86 years are reported. The factor structure of the Dutch MIA corresponded with that of the original MIA. The Strategy scale could be divided into two subscales: external and internal memory strategies. The test-retest stability of the complete MIA as well as that of the abridged MIA was satisfactory. The discriminant validity of the MIA was supported by the observation that almost no relation was fond between depression and anxiety and the MLA scores when we controlled for the possible confounding variables of age, sex, and education. The number of itens of the MIA could be reduced by $34 \%$ without loss of the factor structure or lowering of the internal consistency of the subscales. This substantial shortening of the MIA makes the questionnaire more practical to use in large-scale population studies. Substantial age effects were found on four of the seven subscales: Change, Capacity, Anxicly, and Achievement. Older subjects reported less memory capacity, more decline in memory functioning, more feelings of anxiety in everyday memory tasks, and were more motivated to achieve well in everyday memory tasks. Only few and small effects of sex were found. Lower education was strongly associated (independent of age) with a greater subjective decline in memory, greater anxiety in memory-demanding situations, and a higher level of motivation to achieve well on every memory tasks. The present study supports the cross-national use of the (abridged) MIA as a multidimensional research and clinical instrument for measuring the selifappraisal of memory.

Chapter 6 presents the frndings of a study on the relation between subject background variables. (age, sex, and education), three compound cognitive measures (mental speed, episodic memory. 
and semantic memory), four psychosocial measures (distress, health locus of control, subjective health, and wory of dementia) and four subscales of the abridged Dutch ML (Capacity, Change, Anxiety, and Locus) in a sample of more than 1300 normal adults aged 24 to 83 years. Different hierarchical regression models (with the MIA subscales as dependent variables) were compared in which the order of entry of the predictor variables (subject background variables, cognitive compound measures, and psychological measures) was systematically changed to examine the wnique contribution of each of the predictor variables. Scores on MIA-Capacity, MA-Change, and MIA-Anxiety were mainly predicted by the different psychological measures, especially subjective health and worry about dementia. Health locus of control was the only reliable predictor for MIA-Locus. The common variance of the cognitive performance variables with the scores on the MIA subscales was mainly shared with age and to a lesser extent with sex and educational level, suggesting that selfappraisal of everyday memory functioning is not, or at best only marginally, based on actual cognitive abilities. Age uniquely contributed to perceived change in subjective memory and perceiwed memory capacity, a finding which provides some support for the 'implicit theory of memory and aging'. This theory states that the general (stereotype) beliefs individuals hold about changes in memory and aging (namely that aging is inevitably accompanied with memory decline) influence self-ratings of daily memory functioning.

Chapter 7 describes a study that examimed the relation between psychosocial measures and three subscales of the Metamemory in Adulthood questionnaire (Capacity, Change, and Anxiety). The set of psychosocial measures was broader than in the study described in Chapter 6 and included personality traits (neuroticism, extraversion, and rigidity), coping style (active problem solving), depression, subjective health, social support, and environmental stress (daily hassles). Participants $(n=319$ ) were recruited from a pool of mainly middle-aged and old community-dwelling people aged 40 to 90 years who had participated in an earlier study on the quality and effectiveness of an information brochure about normal forgetfulness and dementia. A lower memory capacity (MIA-Capacity) was related to a less active coping style, a higher educational level, more subjective health complaints, and less social support. Higher ratings of memory decline (MLA-Change) were associated with greater neuroticism, older age, higher education, a less active coping style, and more subjective health complaints. Memory anxiety (MIA-Anxiety) was related to greater neuroticism and a less active coping style. A group of participants $(n=27)$ who considered themselves as being seriously forgetful were matched for age, sex, and educational level with a group of participants $(n=31)$ who did not consideted themselves to be forgetful. These two groups were selected from the questionnaire samplle to evaluate the relation between objective and subjective memory. The forgetfull group had low memory capacity scores (MIA-Capacity), had noticed a substantial decline in memory (MIA. Change), and had high memory anxiety scores (MIA-Anxiety). The non-forgetful group, on the other hand, had high scores for memory capacity, had not noticed a decline in memory, and had low memory anxiety scores. No differences were found berween the two groups on neuropsychological tests that focused on memory, speed, and attention. However, the oldest people in the forgetul group had a significantly lower performance on an episodic memory test than the oldest people in the non-forgetful group. The main conclusion of this study is that subjective memory is primarily related to psychosocial variables and is not based on actual memory or cognitive abilities 
The study described in Chapter 8 examined the relation between memory complaints, memory performance, and metamemory variables by comparing a group of elderly participants $(n=50$ ) with memory complaints with a group of participants without memory complaints $(n=52)$. The groups were matched for age (mean age was 63 years), sex, and education. Data were also collected for personality variables (trait anxiety, neuroticism) and affective state. Metamemory was measured with the Metamenory in Adulthood (MIA) questionnaire. The memory tests used ware the Auditory Verbal Learning Test, the Rivermead Behavioral Memory test, and two category thency tasks. Significant group differences were found for all subscales of the MIA (except Locus) and for verbal fluency and depression. Logistic regression analysis with depression. memory performance, and the MIA as independent variables showed that only the higher-order memory self-efficacy factor of the MIA (subscales Capacity, Change and Anxiety) could discriminate between the groups. Furthermore, subjects in the memory complants group had higher scores for neuroticism than did subjects in the no-complaints group, whereas no differences were found with respect to trait anxiety. The two groups were not different with respect to their main outdoor social activities. Only $25 \%$ of the subjects in the memory complaints group mentioned aging as the possible cause of their memory problems. A further $25 \%$ mentioned emotional tension or stress, and another $25 \%$ mentioned insufficient attention as the main cause of their daily memory problems. The findings of this study suggest that concern and complaints about memory in old age reflect memory self-efficacy beliefs rather than declining memory ability.

The studies reported in Chapters 2 to 8 were primarily based on correlational data. Chapter 9 presents an experimental study in which we examined the way in which memory self-efficacy beliefs influence future memory predictions and performance. We looked at the different effects of positive and negative performance feedback on the performance of a memory prediction task by older people (mean age 65 years) with high or low memory selfofficacy beliefs $(n=41$ and $n=$ 40, respectively). We expected that older persons with low memory self-efficacy beliefs would have a strong attentional bias toward negative feedback, whereas those with high memory selfefficacy beliefs would focus their attention more on positive feedback. Participants were asked to predict their memory performance in four consecutive trials of a name face memory lask. Before participants predicted performance in the second, third, and fourth trials, they were given false feedback (either neutral, positive, or negative) about their performance in the previous trial. We expected that negative feedback would cause individuals with low memory selfefficacy beliefs to make lower predictions of performance, but would not affect or to a lesser extent the predictions made by individuals with high memory self-efficacy beliefs. The reverse pattern was expected with positive feedback: individuals with high memory self-efficacy would raise their predictions, whereas individuals with low memory self-efficacy beliefs would not change their predictions. However, the expected group $x$ feedback interactions were not found, which in part could be explained by some methodological flaws in the experiment. Individuals who received positive feedback made somewhat higher predictions than did individuals who received neutral feedback, but this effect could be ascribed mainly to the upgrading of predictions by especially individuals with low memory self-efficacy beliefs. In the first trial (no feedback) individuals with low memory self-efficacy beliefs made significantly lower predictions about their performance than did individuals with high memory self-efficacy beliefs. There were marked differences on several personality and mood measures between the participants with a high memory self-efficacy and 
those with a low menory self-efricacy. Individuals with low memory self-efficacy beliefs had nore depressive complaints, higher trait anxiety, more newrotic symptomatology, and higher negative and lower positive performance anxiety than the individuals with high memory selfefficacy beliefs.

The various findings and main conclusions of this thesis are discussed in Chapter 10. Older people in general report more memory decline than younger people, but there are few age-specific characteristics in weryday memory functioning in terms of type and frequency of memory failures, memory strategy use and possible non-cognitive determinants of perceived memory decline (e.g., personality, affective state, health). Older people, however have a more pessimistic view becauge they ascribe their forgetfulness more often to less manageable and more or less irreversible memory-intrinsic causes, especially aging, than do younger people. Self-reported everyday memory functioning is related to different non-cognitive factors such as, affective state, coping styles, health, worry about dementia, and personality traits, but is largely unrelated to actual memory ability. A working model is proposed that describes a network of hypothesized causal and reciprocal relations among different constructs related to (everyday) memory performance. The key point of the model is that the use of memory strategies and the amount of effort allocated to a memory task constitute a complexly determined behavior that is mainly moderated by memory self-efficacy beliefs. These efficacy beliefs in tum are based on information from multiple sources, such as general knowledge of memory processes and memory strategies, actual memory abilities, basic cognitive processes like mental speed and attention, the characteristics of the memory task itself, and a variety of non-cognitive factors like affective state, personality, societal beliefs about memory and aging, and health. 


\section{Samenvatting}

Veel mensen klagen over vergeetachtigheid. Met name ouderen merken dat hun geheugen met het klimmen der jaren achteruitgat. Bij eerste beschouwing lijkt deze achteruitgang van het alledaagse geheugen parallel te lopen aan de leefijdsgerelateerde achtenitgang in prestaties op geheugentesten. Zo eenwoudig ligt het echter niet. Er is nawweliks een verband tussen hoe mensen presteren op geheugentests en hun oordeel over hun eigen alledaagse geheugen. Sommige mensen hebben veel geheugenklachten, maar presteren goed op geheugentaken. Omgekeerd zijn er mensen met zeer zwakke prestaties op geheugentests, die evenwel geen klachten hebben over hun gehengen. Nadere bestudering van deze schijnbare tegenstelling is het hoofdonderwerp van dit proefschrift. Verschillende onderzoeken worden beschreven waarin de prevalentie, kemmerken en mogelijke determinanten van alledaagse geheugenproblemen en -klachten is onderzocht bij normale en gezonde personen in de leeftijd wan 24 tot 86 jaar. Deze personen werden onderzocht in het kader van de Maastricht Aging Study (MAAS). MAAS is een grootschalig longitudinazl onderzoeksprogramma naar determinanten van cognitiewe veroudering. De onderzoeken beschreven in dit proefschrift zijn overwegend gebaseerd op de eerste cross-sectionele onderzoeken van MAAS zoals die zijn uitgevoerd in de periode 1992-1996.

Hoofdstuk I geeft een inleiding op het onderwerp van dit proefschrift. Diverse methodologische problemen die kleven aan het gebruik van geheugenvragenlijsten worden besproken. Daumaast wordt uiteengezet dat het oordeel dat personen geven over hun alledaags geheugen maar zeer ten dele afhangt van feitelijke geheugenkwaliteiten zoals die met geheugentests worden gemeten. Dit oordeel lijkt veeleer samen te hangen met diverse niet-cognitieve factoren als demografische variabelen , persoonlijkheid, stemming, gezondheid, bezorgdheid over mogelijke dementie en aspecten van het metageheugen, in het bijzonder memory self-efficacy.

In hoofdstuk 2 worden de resultaten beschreven van een onderzoek naar de prevalentie en covariaten van vergeetachtigheid bij 1971 normale en gezonde personen in de leefijd van 2410186 jaar. Circa $40 \%$ van alle personen vonden zichzelf vergeetachig en dit percentage nam toe tinet do leeftijd: $29 \%$ in de leeftijd $24-36$ jaar, $34 \%$ in de leeftijd $39-51$ jarar, $41 \%$ in de leefijd wan $54-66$ jaar en $52 \%$ in de leeftijd $69-86$ jaar. De meeste mensen die zichzelf vergeetachlig vonden waren hiver weinig bezorgd over: Ook ondervonden de meesten slechts in geringe mate hinder wan hun vergeetachtigheid. De erwaren hinder en zorg verschilde nagenoeg niet tussen de diverse leeftijdsgroepen. Naast leefijd bleek vergeetachtigheid vooral samen te hangen met subjectieve gezondheid en stemming. Personen die ouder waren, meer gezondheidsproblemen angaven en meer depressieve klachten hadden, vonden zichzelf vaker vergeetachtig. Er werd geen verband gevonden met geslacht en opleiding. Een kwart van alle personen dat zichzell vergeetachtig vond kon hiervoor geen oorzaak aanwijzen. Ouderen noemden leeftijd het vaakst als belangrijkste oorzaak van de wergeetachtigheid, terwijl personen die jonger waren dan 50 jaar vaak omkeerbare oorzaken noemden zoals spanningen, emotionele problemen en onvoldoende concentratic. Ell procent van alle vergeetachtige mensen had wel eens overwogen hulp of behandeling te zoeken voor hun vergeetachtigheid (of had dit feitelijk gedaan). Hierbij ging de voorkeur vooral uit naar 
voothchting en geheugentraining. De helft van alle vergeetachtige personen zou overwegen deel te nemen aan onderzoek naar medicinen die het geheugen zou kumen verbeteren. Elf procent van alle vergeetachtige personen had wel eens wrij verkrijgbare medicatie gekocht ter ondersteuning van het geheugen, ouderen vaker dan jongeren.

In hoofdstuk 3 wordt een onderzoek beschreven warin werd gekelken of mensen uit dezelfde steekproef als beschreven in hoofidstuk 2 , nast een leeftijdsgerelateerde achteruitgang van het geheugen, ook een achteruitgang bemerkten op andere aspecten van het cognitief functioneren zoals mentale snellieid, concentratie, verdeelde aandacht en planning. Uit factor-analytisch onderzoek bleek dat dit duidelijk het geval was. Personen die een vermindering van het geheugen rapporteerden, ervoeren eveneens een vertraging van het denken, een bemoeilijkte concentratie en een verminderd vermogen tol plannen. Verder werd nagegaan wat de verschillen zijn in het subjectief cognitief functioneren zijn alls werschillende vergelijkingskaders worden gebruikt. Aan de mensen werd gevragd om hun huidig cognitief functioneren op drie manieren te beoordelen: in vergelijking tot leeftijdgenoten, in vergelijking tot hun eigen functioneren 5 tot 10 jaar geleden en in vergelijking tot het eigen functioneren toen men 25 jaar oud was. Een leeftijdsgenelateerde achteruitgang werd gerapporteerd vanaf ongeveer 50 jaar en deze nam toe met de leeftijd. Deze achteruitgang werd alleen aangegeven wanneer men het huidige cognitieve functioneren moest vergelijken met het eigen functioneren op jongere leeftijd (5-10 jaar geleden of op 25-jarige leeftijd) en hing opnieuw vooral samen met stemming en ervaren gezondheid. Geen leeftijdseffect werd gewonden wanneer men zichzelf moest vergelijken met leeftijdgenoten. Dit is mogelijk het gevolg van adaptief responderen in de zin dat mensen hun huidig cognitief functioneren aanpassen aan wat men verwacht dat normaal is gezien de leeftijd. Bij 420 personen uit de steekproef werden tevens cognitieve testen afgenomen. Er werd geen verband gevonden tussen testprestaties en de gerapporteerde cognitieve achteruitigang.

In het onderzoek beschreven in hoofdstuk 4 is de factorstructuur van de Cognitive Failure Questionnaire (CFQ) onderzocht in een steekproef van 1358 personen in de leeftijd van 24 tot 81 jatr. De CFQ is een vragenlijst bestaande wit 25 items waarin wordt gevragd naar de frequentie van alledwagse cognitieve fouten of problemen op het gebied van geheugen, aandacht, perceptie en motoriek. De CFQ had duidelijk een én-factorstructuur. Alleen bij weglating van 8 items, konden op berrouwbare wijze 4 subschalen worden onderscheiden ('Geheugen/Nerstrooidheid", "Geheugen/verstrooidheid in cen sociale context", 'Namen en Woorden' en 'Oriëntatie'). Zowel in absolute als relatieve zin was het scoreprofiel op de CFQ nagenoeg gelijk voor verschillende leeftijdsgroepen (jong, jong-vollwassen, oud-volwassen en oud), hetgeen impliceert dat er geen leeftijsgebonden verschillen bestaan in het voorkomen van cognitief belastende alledaagse situaties en evenmin leefijdsgebonden functionele verschillen zijn in cognitieve competentie. Er werd opnieuw geen verband gevonden tussen de CFQ score en cognitieve testprestaties (mentale snelheid, cpisodisch geheugen en semantisch geheugen). Evenmin werden effecten gevonden wan geslacht en leeftijd. Wel bleken de scores op de CFQ positief samen te hangen met angst depressia, bezorgdheid over dementie en ervaren subjectieve gezondheid.

In hoofdstuk 5 wordt een overwegend psychometrisch onderzoek beschreven naar de Nederlandse vertaling van de intemational veel gebruikte Metamemory in Adulthood 
questionnaire (MLA). Metamemory of metageheugen verwijst naar de kenmis en verwachingen die mensen hebben over het functioneren, de ontwikkeling en de capaciteit van her eigen gehengan, alsmede het geheugen in het algemeen. De oorspronkelijke MIA bestatuit 108 vragen die kunnen worden onderverdeeld in 7 subschalen: gebruik van geheugenstrategieen (Strategie), algemene kennis over de werking van het geheugen (Kennis), geheugencapaciteit (Capaciteit), ervaren achteruitgang van het geheugen (Stabiliteit), geheugenangst (Angst), motivatie om goed te presteren op alledaagse geheugentaken (Motivatie) en ervaren controle over het geheugen (Controle). De Nederlandse vertaling van de MIA is onderzocht in een steekproef van 1899 personen in de leeftijd van 24 tot 86 jaar. De factorstructuur van de Nederlandse MIA kwam goed overeen met die van de Engelstalige MIA. De strategieschaal kon verder worden onderverdeeld in een externe - en interne strategieschaal. De discriminant validiteit en de test-hertest betrouwbaarheid waren voldoende. Verder kon de MLA met 34 vragen worden ingekort zonder dat dit ten koste ging van de factorstructur of de interne consistentie van de subschalen. Op 4 van de subschalen werden duidelijke leeftijdseffecten gevonden: Stabiliteit, Capaciteit, Motivatie en Angst. Ouderen rapporteren een geringere gehengencapaciteit, erwoeren meer achteruilgang van het geheugen, waren meer gespannen op momenten dat ea" een beroep wordt gedaan op het geheugen en waren meer gemotiveerd om goed te presteren op alledaagse geheugentaken. Mensen met een lagere opleiding ervoeren in het algemeen meer achteruitgang van het geheugen, meer geheugenangst en waren meer gemotiveerd om goed te presteren.

In hoofdstuk 6 worden de resultaten beschieven van een onderzoek naar de relatie tussen demografische variabelen (leeftijd, opleiding, geslacht), cognitieve prestatiematen (mentale snelheid, episodisch - en semantisch geheugen), psychosociale variabelen (angst/clepressie, ervaren gezondheid, bezorgdheid over dementie en ervaren controle over de eigen gezondheid) enerzijds en 4 subschalen van de verkorte Nederlandse Metamemory in Adulthood (MIA) questionnaire (Capaciteit, Stabiliteit, Angst, Locus) anderzijds. De steekproef betrof meer dan 1300 gezonde volwassen in de leeftijd van 24 tot 83 jaar. In verschillende regressiemodellen met de MIA subschalen als afhankelijke variabelen werd de volgorde waarin de predictoren (demografie, cognitieve maten, psychosociale maten) werden ingevoerd in bet model systematisch gevarieerd, teneinde de unieke bijdrage van elk van de variabelen te kunnen vaststellen. De scones. op de MIA-schalen Capaciteit, Stabiliteit en Angst werden het best voorspeld door de verschillende psychosociale variabelen, in het bijzonder subjectiewe gezondheid en bezorgdheid over dementie. De gemeenschappelijk wariantie tussen de scores op de MLA-subschalen Capaciteit en Stabiliteit en de cognitieve prestatiematen werd overwegend gedeeld met leeftijd en in mindere mate met geslacht en opleiding. Leeftija bleef echter uniek gecorreleerd aan Capaciteit en Stabiliteit nadat alle overige predictoren reeds in het regressiemodel waren ingevoend. Dit ondersteunt enigszins de "impliciete theorie over geheugen en veroudering", die stelt dat de perceptie van het eigen alledaagse geheugenfunctioneren bij het ouder worden vooral bepaald word door negatieve stereotiepe opvattingen over het geheugen en veroudering en niet of slechts in zeer geringe fuate door feitelijke alledaagse geheugenprestaties.

In hoofdsiuk 7 wordt opnieuw een onderzoek beschreven nat de relatie tussen diverse psychosociale variabelen en scores op een drietal MLA-subschalen (Capaciteit, Stabiliteit, Angst). Het aantal psychologische en psychosociale variabelen is echter onvangrijker dan die beschreven 
in hoofdstuk 6: persoonlijkheid (neuroticisme, extraversie, rigiditeit), copingstijl (actief/passief), depressieve klachten, subjectieve gezondheid, sociale steun en dagelijkse stress. De steekproef bestond uit 319 personen in de leeftijd van 40 tot 90 jaar. Lagere scores op de MIA subschaal Capaciteil waren gerelateerd aan een meer passieve copingstijl, hogere opleiding, meer gezondheidsklachten en geringe sociale steun. Meer achteruitgang van het geheugen (MIA subschaal Stabiliteit) was gerelateerd aan hogere leeftijd, hogere opleiding, hogere neuroticisme scores, een meer passieve copingstijl en geringere sociale steun. Hogere scores op de MIA subschaal angst hingen vooral samen met hogere scores voor neuroticisme. Om na te gaan of en in hoeverre er een verband bestond tussen de scores op de MLA subschalen en feitelijk cognitief functioneren, werden twee, op leeftijd, opleiding en geslacht gematchte, groepen geselecteerd uit de steekproef. De eerste groep van 27 personen beschouwde zichzelf als zeer vergeetachtig en was hierover ook zeer bezorgd. Deze groep had zeer lage scores op de MIA subschaal Capaciteit, hoge scores op de MIA subschaal Angst en had een sterke achteruitgang ervaren in het geheugen (MIA subschaal Stabiliteit). De tweede groep van 31 personen beschouwde zich niet als vergeetachtig. Deze groep had hoge scores op Capaciteit, lage scores op Angst en rapporteerden nagenoeg geen achteruitgang in het geheugen (Stabiliteit). Hoewel deze twee groepen sterk verschilden in hun subjectieve oordeel over het eigen geheugen, waren hun prestaties op een aantal neuropsychologische testen gericht op het geheugen, mentale snelheid en aandacht, niet verschillend. Evenals in de voorgaande onderzoeken bleek opnieuw dat het oordeel dat mensen geven over hun eigen alledaagse geheugenfunctioneren vooral werband houdt met psychologische en psychosociale variabelen en niet of nauwelijks gebaseerd is op de feitelijke kwaliteit van het geheugen en/of cognitief functioneren zoals gemeten met behulp van tests.

In hoofdstuk 8 wordt een onderzoek beschreven waarin een groep van 50 onderen met geheugenklachten wordt vergeleken met op leeftijd, opleiding en geslacht, gematchte groep van 52 ouderen zonder geheugenklachten. De gemiddelde leeftijd bedroeg 63 jaar. Met uitzondering van de Locus subschaal, werden op alle subschalen van de MIA significante verschillen gevonden in de verwachte richting. Op diverse geheugentaken werd alleen een significant verschil gevonden op een verbale fluency taak, waarbij ouderen met geheugenklachten lagere scores behaalden. Ouderen met geheugenklachten hadden tevens hogere scores voor neuroticisme en rapporteerden meer depressieve klachten. Uit een logistische regressie bleek dat alleen een wit de MIA afgeleide memory self-efficacy score ('zelfvertrouwen' in het eigen geheugen; zjjnde een samenvoeging van de subschalen Capaciteit, Stabiliteit en Angst) beide groepen van elkaar kon discrimineren. Er werden geen verschillen gevonden tussen beide groepen wat betreft alledaagse cognitief belastende activiteiten (bijvoorbeeld lezen) en sociale contacten en activiteiten. Een kwart van de ouderen met geheugenklachten noemde leeftijd als belangrijkste oorzaak van de achteruitgang van het geheugen, een kwart noemde emotionele spanningen en nog een kwart weet de achteruitgang vooral aan een gebrek aan concentratie. De conclusie is dat geheugenklachten op oudere leeftijd vooral een weerspiegeling zijn van een gering zelfvertrouwen in het eigen geheugen.

In hoofdstuk 9 wordt een experimenteel onderzoek beschreven waarin de hypothese werd getoetst dat ouderen met een gering zelfvertrouwen in het eigen geheugen (lage memory self-efficacy of MSE) relatief ongevoelig zouden zijn voor positieve geheugenervaringen en daarentegen 'overgevoelig' voor negatieve geheugenervaringen, hetgeen het. negatieve zelfbeeld in stand 
houdt. Dit in tegenstelling tot ouderen met een groot zelfwertrouwen in het eigen geheugen (hoge MSE) die positieve geheugenervaringen meer zonden waarderen en daarentegen relatief "resistent" zouden zijn woor negatieve geheugenervaringen. In een experimentele opzet is dit onderzocht door een groep van 40 oudere proefpersonen met lage MSE te vergelijken met een groep wan 4 ll oudere proefpersonen met een hoge MSE op een geheugen predictietaak warbij gebruk werd gemakt van valse positieve en negatieve feedback. De geheugentaak bestond uit een drietal herhaalde aanbiedingen van serie foto's van gezichten met de daarbij behorende voonam, waarbij de taak van de proefpersoon bestond wit het onthouden van de juiste nam bij het juiste gezicht. Voor elke aanbieding werd aan de proefpersonen gevmagd een predictie te geven van het aantal namen dat hij of zij correct zou weten te onthouden. Behalve bij de eerste aanbieding, werd elke predictie voorafgegaan door (valse) positieve, neutrale of negatieve feedback over de aigen prestatie bij de voorgaande aanbieding. Verwacht werd dat de negatieve feedback vooral bij de proefpersonen met

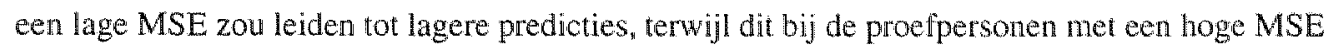
niet of slechts in geringe mate zou gebewren. Het omgekeerde patroon werd verwach bij positieve feedback: bij proefpersonen met een hoge MSE zou dit leiden tot hogere predicties, terwijl de proefpersonen met een lage MSE zich in hun predicties niet of weinig zouden laten beinvloeden door de positieve feedback. Deze verwachte groep $x$ feedback-interacthe werd echter niet gevonden, hetgeen deels verklaard kon worden door een aantal achteraf gebleken methodologische tekortkomingen van het experiment. Wel bleek dat bij de eerste aanbieding, waarbij nog geen feedback kon worden gegeven, de proefpersonen met een lage MSE al sigmificant lagere predicties gaven dan de proefpersonen mell een hoge MSE terwijl beide groepen gelijke prestaties behaalden op de geheugentaak. Aanvullend onderzoek naar mogelijke verschillen tussen beide groepen ten aanzien wan enkele persoonlijkheidskenmerken liet zien dat de ouderen met een lage MSE in vergelijking tot de ouderen met een hoge MSE aanmerkelijk hogere scores hadden voor neuroticisme, meer depressieve klachten hadden, een hogere angstdispositie kenden en tevens sterk negatief faalangstig waren.

In hoofdstuk 10 worden de belangrijkste bevindingen en conclusies van de verschillende onderzoken samenvattend besproken. Betoogd wordt dat ouderen in het algemeen, zoals verwacht, meer achteruitgang wan het geheugen rapporteren, maar dat en vender weinig leeftijdsspecifieke kenmerken of verschilen zijn wat beireft de adrd an de mogelijke determinanten van de gerapporteerde alledaagse geheugenproblemen. Er wordt een werkmodel voor alledaags geheugenfunctioneren beschreven warbij een centrale rol. wordt toegekend aan het concept memory self-efficacy (MSE). MSE bepaalt hierbij in belangrijke mate de keuze van geheugenstrategieen en de mate wan inspanning die iemand zich getroost om een geheugentak tot een goed einde te brengen. MSE wordt hierbij beinvloed door verschillende cognitiewe en niet-cognitieve factoren, die elk op zich ook weer beinvloed kunnen worden door leeftijd. De longitudinale dalt zoals die thans in de Mastricht Aging Study worden verzameld lenen zich bij uitstek woot de verdere toetsing en uitbouw van het geschetste model. 



\section{Dankwoord}

Het proefschrift dat woor a ligt is weliswar door én persoon geschreven, matr is tot stand gekomen door de inzet van wele personen en instanties over een periode van inmiddels bijna 6 jaar. Dit maakt het schrijven van een dankwoord tot een enigszins riskante aangelegenheid. De feilbaarheid van ons geheugen inmiddels goed kennende, is het bijna onvemijdelijk dat ik bepaalde personen zal vergeten te noemen. Deze onvolledigheid kan ik slechts compenseren door mijn welgemeende dank uit te spreken aan iedereen die op welke wijze dan ook heeft bijgedragen aan dit proefschrift. Een aantal personen en instanties wil ik in het bijzonder vernoemen.

Allereerst dank ik de vele deelnemers aan het MAAS onderzoek die geheel belangeloos hun medewerking verleenden. Mijn aanvankelijke ergemis over elke door hen niet ingevulde vaag op de - psychologen vaak zo eigen - ellenlange vragenlijsten over geheugen en gezondheid, sloeg al snel om in bewondering woor het grote aantal wragen dat men wél had ingevuld en op basis waarvan dit proefschrift uiteindelijk kon worden geschreven.

Ik wil vervolgens bedanken mijn promotor Jelle Jolles. Vele kwalificaties van jou zijn inmiddels all beschreven door voorgaande promovendi. Enkele daarvan worden, terecht, telkens weer genoemd: enthousiast, ideeënrijk en blijvend optimistisch over de ingeslagen onderzoekswegen. Ik wil je ook bedanken woor de ruimte die je me hebt gegeven on mijn eigen onderzoeksideeën te kunnen vormgeven. En voor de insiders: alweer een 'wagonnetje' (of parel, rib of bal) aan de inmiddels lange promotie- "trein" (of ketting, nggengraat of kerstboom).

Mijn oprechte dank ook aan Peter Houx en Martin van Boxtel, naaste collega's in MAAS en mijn beide paranimfen. Dit laatste sprak voor zich - samen uit, samen thuis. Het opzetten en dratiend houden van het MAAS-onderzoek was - en is - geen geringe klus. We hebben eindeloos veel moeten overleggen over de opzet en uitwoering van MAAS, witeenlopend van de goedkoopste manier van verzending van vragenlijsten tot de theoretische onderbouwing. Voor de vlotte samenwerking stond vooral een gezonde dosis relativeringsvermogen en humor garant.

Mijn dank ook al alle overige medewerkers van wat wij wel eens oneerbiedig onze "MAASdata-fabriek' noemen. De inzet en betrokkenheid van de medewerkers staat garant voor een hoge kwaliteit van de dataverzameling. Dat het soms routine lijkt, is ók een kenmerk wan een goede organisatie. In het bijzonder wil ik noemen Astrid Quist, Carlein Karimoen, Nico Rozendaal, Patricia Hameleers, Riet Landeweerd, Germa Wijnen, Ilse van Engelshoven en Huub Hamers. Martin Klein en Jeanette Dijkstra, die als AIO aan MAAS verbonden waren, waren voor mij zeer bepalend voor de prettige collegiale werksfeer.

Verder dank ik de verschillende medewerkers van de vakgroep Huisartsgeneeskunde en het MEMIC en de RNH-huisartsen en praktijkassistenten die hebben bijgedragen aan de opzel en dataverzameling van MAAS. Helen Bruning, Josephine Bloo, Berit van der Veen en Charlotte Kindt hebben als stagiaires een waardevolle bijdrage geleverd aan het onderzoek, warvoor ik hun erkentelijk ben. Gerard wan Breukelen van de vakgroep Methodologie en Statistiek gaf zeer wandevolle adviezen inzake de statistiek.

Verschillende personen uit diverse vakgroepen hebben verder een inhoudelijke bijdrage geleverd aan dit proefschrift: Kees Commissaris en Charlie Kaplan (Psychiatrie en Neuropsychologie), Sylvia Evers en Fred Stevens (Medische Sociologie) en Rutget Lulofs en Ton Schmidt (departement Medische, Klinische en Experimentele Psychologie). 
In de afgelopen jaren is in een gemeenschappelijk project met het Groene Kruis Heuvelland Maastricht een nieuwe geheugencursus voor ouderen ontwikkeld, een fraaie koppeling tussen theorie en praktijk. Het was een lange rit, maar uiteindelijk was er een mooi resultaat. De betrokken medewerkers van het Groene Kruis - Mirjam Bouwens, Lilian Houben en Annemarie Zeelen - wil ik bedanken voor de plezierige samenwerking.

Jane Bär-Sykes bedank ik voor haar correcties van mijn langzinnige, Nederlandse Engels.

Veel van de onderzoekswragen in dit proefschrift zijn ontstaan uit mijn klinische werkzaamheden op de Maastrichtse Geheugenpolikliniek. Hier moet tenslotte dagelijks een antwoord worden gevonden op de vraag natar de oorzaak van geheugenklachten. De multidisciplinaire discussie die hier telkens moet worden gevoerd blijkt een rijke bron voor het vormen van ideeen. De lijst van medewerkers die in de loop der tijd werkzaam zijn geweest op de geheugenpolikliniek of dit nog steeds zijn is te lang om op te sommen. Allen wil ik bedanken voor de prettige samenwerking. In het bijzonder wil ik echter noemen Frans Verhey (even enthousiast als kritisch grootgebruiker van de neuropsychologie), Jan Huynen (wijze, stille kracht) en Monique de Lugt (sempre vivace), drie collega's met wie ik in de afgelopen jaren veel heb overlegd en gediscussieerd over de betekenis van de geheugenklacht op oudere leeftijd. 


\section{Curriculum vitae}

Rudolf Ponds werd op 20 februari 1960 geboren te Lievelde. Na het voltooien van het VWO te Groenlo, studeerde hij psychologie aan de Rijksuniversiteit Groningen. Tijdens deze studie werkte hij als student-assistent ten behoeve van het merhodologie-onderwijs. In juni 1986 studeerde hij af in de klinische psychologie met als specialisatie neuropsychologie. In de periode juli 1.986 tot juni 1988 was hij aangesteld als docent bij de tussenrichting Neuro- en Revalidatiepsychologie van de Katholieke Universiteit Nijmegen. Vanaf juli 1988 is hij als staflid verbonden aan de afdeling Psychiatrie van het Academisch Zlekenhuis Maastricht in de functie van theuropsycholoog met als belangrijkste taken neuropsychologische diagnostiek en behandelling. Hier is hij vooral werkzaam op de Maastrichtse Geheugenpolikliniek welke een onderdeel vormt van de polikliniek Psychiatrie. Daarnaast is hij verbonden aan de vakgroep Psychiatrie en Neuropsychologie van de Universiteit Maastricht, sectie Neuropsychologie en Psychobiologie. Hier is hij als onderzoeker betrokken bij de Maastricht Aging Study, een longitudinaal onderzoek naar determinanten van cognitieve veroudering van het Instituut Hersenen en Gedrag. 



\section{List of publications}

\section{Articles}

Arts, B. M. G., Honig, A. Riedel, W. J., \& Ponds, R. W. H. M. (1998). Cognitieve bijwerkingen van lithium: Een meta-analyse en aanbevelingen. Tijdschrff voor Psychiarie, $40,460-468$.

Brouwer, W. H., Ponds, R. W. H. M., van Wolfelaar, P. C. \& van Zomeren, A. H. (1989). Divided Altention 5 1010 years after severe closed head injury. Cortex. $25,219.230$.

Brouwer W. H., \& Ponds R. W. H. M. (1994). Driving competence in older persons. Disabilin and Rahalitation. $16.149-161$.

Commissaris C. J. A. M., Verhey, F. R. J., Ponds, R. W. H. M.,Jolles, I., \& Kok, G. 1. (4993) Publicksvoorlichning over nomale vergeetachtigheid en dementie: Belang en effecten. Tidschriff voor Sociale Gezondheidszorg, $71,32-36$.

Commissaris, C. J. A. M., Jallies, J., Verhey, F. R. J., Ponds, R. W. H. M., Damoiseanx, V., d. Kok, G. J. (1993). Vergetachtig of dement? Wie maakt zich zorgen en wasom? Tijdschrift wor Gerontologiv wn Geriatrie, 24, 144-149.

Commissaris, C. J. A. M. Ponds, R. W. H. M., Verhey, F. R. J., Damoisenux, V., Kok, G, J., dolles, J. (1993). Publiaksvoorlichting over noumale vergee tachligheid en dementie: Elfectivitai van een planmatig. ontwikkelde voorlichtingsbrochure. Tijdschrift vor Geromolagie en Gerhatie, 24, 184-192.

Commissaris, C. J. A. M.. Verhey, Fx. R. J., Ponds, R. W. H. M. Jolles, I. \& Kok, Gi. J. (1994). Public education about normal forgetfulness and dementia: Importance and eflects. Patent education and Commselng, $24,109-115$.

Commissaris, C. J. A. M., Ponds, R. W. H. M., Verhey, F. R. J., Damoiseaux, V., Kok, G., Jolles, J. (1995). Public education about nomal forgetfulness and dememtia: Effectiveness of a systematically developed information brochure. Edwcarional Geronology, 21,763-777.

Commissaris, C. J. A. M., Jolles, I., Verhey, F. R. J., Ponds, R. W. H. M., Danoiseaux, V., \& Kok, G. J. (1996). Forgatfulness of dementia? Who is worried and why? European Jourmal of Public Healin, 6, $297-299$.

Conmissaris, C. J. A. M., Ponds, R. W. H. M. \& Jolles, J. (1998). Subjective forget lulness in a normal Dutch population and possibilites for health education and other interventoms. Patien Education and Counseing, 34 , $25-32$.

Evers, S. M. A. A.., Stevens, F. C. F. J. Diederiks, I. P. M., Ponds, R. W. H. M., Drop, M. J., Metsemakers J. H. M. \& Jolles, J, (1998). Age-related differences in cognition; lifestyle, perceived beath status, and sociodemographic factors. European Joumal of Public Heath. 8, 133-139.

Honig, A., Hofman, A., Hilwig, M., Noorthoorn, E.y \& Ponds, R. (1995). Psychoeducation and expressed emolion in bipolar disorder: Preliminary findings. Psycharry Research, 56, 299-301.

Jolles, J., van Boxlel, M. P. J, Ponds, K. W. H. M. Melsemakers, J. F. M. B. Houx, P. J. (1998). Do

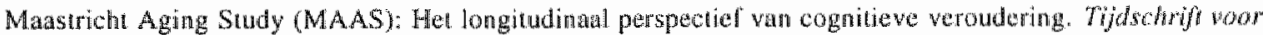
Geronologie en Geriatrie, 29, 120-129.

Klein, M., Ponds, R. W. H. M. Houx, P. J., dolles, 1. (1997). Elfect of test duration on agerelated dnflerences in Stroop Interference. Journal of Clinical and Experimental Nenopsychology, $19,77-82$.

Nicolson, N., Stoms, C., Ponds, R., B Sulon, J. (1997). Salivary contisol levals and stress reactivity in human anging. Journal of Gerontology, Medical Sctences, 52, M68-M75.

Peeters, F. P. M. L., Ponds, R. W. H. M. \& Verneeren, M. T. G. (1996). Aflectiviteit en zelfoeordicling van depressie en angst. Tijdschrift voor Psychiarie, $38,240-250$.

Ponds, R. W.H. M., \& Deeman, B. G. (1988), Kantekeningen bij de behandeling van geheugenstoormissen. Nederlands Tijdschift woor de Psychologie, 43, 299-309.

Ponds, R.W. H. M. Brouwer, W. H., \& war Wollelar, P. C. (1988). Differences in divided attention in an simulated driving task. Jownal of Geromology, 43,151-156.

Ponds, R. W. H. M., \& Eling. P. A. T. M. (1988). Behandeling wan aandachtsstoornissen. Tojdschrof voor Revalidatie Wetenschappen, $1,110,118$.

Ponds, R. W. H. M. \& Deelman, B. G. (1989). Differend approaches to the rehabilitation of menory disorders. Joumal of Rehabilitonion Sciences, $2,16-18$. 
Ponds, R. W. H. M., Browwer, W. H. \& wan Wolfelaar, P.C. (1989). Verdeelde aandacht en veroudering. Nederlawds Tijdschrift vaor Gerontologie en Geriatrie, 6, 257-258.

Ponds R. W. H. M. Verhey F. R. J., Roxendaal N., Jolles J., Deelman B. G. (1992). Dementiescreening: Validicit van de cognitieve screeningtest (CST) en de mini-menial state examination (MMSE). Tijdschrift woor Gerontologh en Geriatrie, 23, 94-99.

Ponds R. W. H. M. Bruning. H. \& Jolles, J. (1992). Ouderen en wergeetachtigheid: Een onderzoek naar zelfkennis over het gehtugen, depressie en geheugenprestates. Tijdschrift vaor Gerontologie en Geriatrie, 23, 188-194.

Ponds, R. W. H. M., Schmid, A. J. M, de Lugt, M., Lulofs, R., Verhey, F. R. J., \& Jolles, J. (1995). De angst onn te vergeten: Behandeling van functionele geheugenklachen. Tijdschrift woor Psychiatrie, 37, 62-68.

Ponds, R. W. H. M. de Lugt, M. Verthey, F. R. J., \& Jolles, J. (1995). Malingeren bij het neuropsychologisch onderzoek. De Psycholoog. 30,357-362.

Ponds, R.W. H. M., \& Jolles, J. (1996). Memory complaints in elderly people: The role of memory abilities, metamemory, depression, and personality. Edscational Gerontology, 22. 341-357.

Ponds, R. W. H. M. \& Jolles, J. (1996). The abridged Dutch Metamemory in Adulthood (MIA) questionnaire: Structure, and effects of age, sex, and education. Psychology and Aging, 11, 324-332.

Ponds, R. W. H. M., Commissaris, K. J. A. M. \& Jolles, J. (1997) Prevalence and covariates of subjective forgetfulness in at mornal population. Insernational Joumal of Aging and Haman Development. 45, 207-221.

Ponds, R. W. H. M. \& Jolles, J. Psychosocial predictors of metamemory in middle-aged and old people. Submitted for publication.

Ponds, R. W. H. M. Rozendaal, N., \& Jolles, J. The Cognitive Failure Questionnaire: Factor structure, effects of age, sex, and education and the relation with cognitive performance and psychosocial variables. Submitted for publication.

Ponds, R. W. H. M.. Rozendaal, N., \& Jolles, J. Predictors of subjective memory as measured with the Metamemory in Adulthood questionnaire. Submitted for publication.

Ponds, R. W. H. M., van Boxtel, M. P. J., \& Jolles, J. Age-related changes in subjective cognitive functioning. Submitted for publication.

Stevens, F. C. F., Kaplan, C. D., Ponds, R. W. H. M., Diederiks, J. P. M. \& Jolles, J. (in press), How ageing and social factors affect memory. Age \& Ageing.

Stevens, F. C. F., Kaplan, C. D., Ponds, R. W. H. M. \& Jolles, J. (in press). The importance of an active lifestyle for objective memory performance and metamemory. Basic and Applied Social Psychology.

Verhey, F. R. J., Ponds, R. W. H. M., Jolles, J., \& van der Lugt, P. J. M (1991). Een nieuw psychogeriatrisch syndroom: De wergeetrobie. Medisch Contact, 46, 575-576.

Verhey, F. R. J., Jolles, J., Ponds, R. W. H. M., Rozendaal N., Plugge L. A., de Vet, H. C. W. Vreeling, F. \& van der Lugt, P. J. M. (1993). Diagnosing dementia: Comparison between a monodisciplinary and a multidisciplinary approach. Joumal of Nesropsychiatry and Clinicat Neurosciences, 5, 78-85.

Verhey, F. R. J., Jolles, J., Ponds, R. W. H. M. \&Vreeling, F. (1993). Psychiatrische stoornissen bij patienten van een geheugenpolikliniek. Nederlands Tijdschrift voor Geweeskumde, 137, 1054-1058.

Verhey, F. R. J., Rozendalal, N., Ponds, R. W. H. M., \& Jolles, J. (1993). Dementia, awareness and depression. Intemational Journal of Geriatric Psychiatry, $8,851-856$.

Verhey, F, R. J. Ponds, R. W. H. M., Roozendaal, N. \& Jolles, J. (1995). Depression, insight, and personality changes in Alzheimer's disease and vascular dementia. Joumal of Geriatric Psychiary and Neurology, 8. 23-27.

Verhey, F. R. J., Jolles, J., Ponds, R. W. H. M., de Lugt, M., Vreeling. F. (1995). Psychiatric disonders in patients attending an outpatient memory clinic. Intenational Jownal of Geriatric Psycharry, 10,899.

\section{Book sections}

Aalders H., Ponds R., Eling P., Derks K., \& Hermans D. (1990). Neurotest: An interactive computer course in neuropsychological examination. In Mulder L. J. M. Maarse F. J., Sjouw W. P. B., \& Akkerman, A.E. (Eds.), Computers and Psychology - application in education, research and psychodiagnostics Voll IIL, (pp. 36-40). Lisse: Swetz \& Zeillinger.

Brouwer, W. H., Ickenroth, J., Ponds, R. W. H. M., \& van Wolffelanr, P. C. (1990). Divided attention in old age: Difficulty in integrating skills. In P. J. D. Drenth, J. A. Sergeant, \& R. J. Takens (Eds.), European Perspectives in Psychology, Vol 2 (pp. 235-348). Chichester John Wiley \& Sons.

Commissaris, C. J. A. M., Ponds, R. W. H. M., \& Jolles, J. (1995). Subjective memory problems and people's need for education and intervention. In J. Jolles, P. J. Houx, M. P. J. van Boxtel, \& R. W. H. M. Ponds 


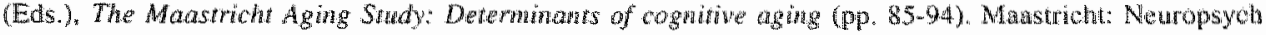
Publishers.

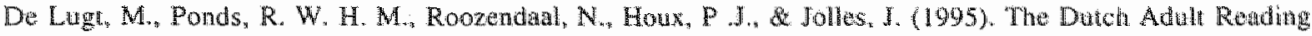
Test (DART): A measure of (premorbid) intelligence?. In J. Jolles, P. J. Houx, M. P. J. van Hoxtet, R. W.

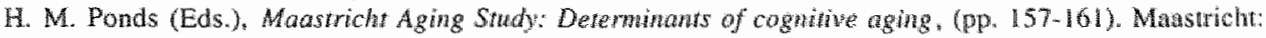
Nerropsych Publishers.

Evers, S. M. A. A., Stevens, F. C. F. J., Diederiks, J. P. M, Drop, M. J., Ponds, R. W. H. M., Iolles, J. (1995). Live styles and cognitive aging. In 1. Jolles, P. J. Houx, M. P. J. wan Boxtel. \& R. W. H. M. Ponds

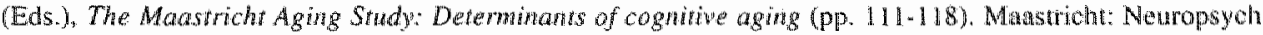
Publishers.

Jolles, J., Houx, P. J., war Boxtel, M. P. J. \& Ponds, R. W. H. M. (Eds.) (1995) The Magrrich Aging Swat Deteminants of cognitive aging. Mastricht: Neuropsych Publishers.

Jolles, I., van Boxfel, M. P. J., Ponds, R. W. H. M., \& Houx, P.J. (1996). Veroudering van hersenfunotie en geheugen. In M. van Sanvoom, \& M. Spanger (Eds.), Onder worden, ge zond en wel (pp. 87-95). Utrectur NIO.

Kovacs, F., \& Ponds, R. W. H. M. (1995). Behandeling var andactrsstoomissen. In P. Eling, \& W. H. Brouwer (Eds.), Aandachtsstoomissen. Een newropsychologisch handboek (pp. 269-280). Lisse: Swets Zeillinger.

Ponds, R. W. H. M. (1990). Behandeling wan geheugen- en aundachsstoornissen. In B. wan Cranenbungh, J. B.

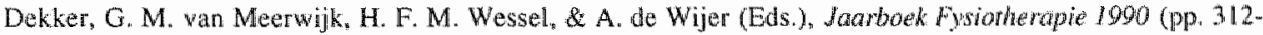
324). Utrech: Bohn, Scheltema \& Holkena.

Ponds R. W. H. M, Verhey F. R. J., Rozendaal N., Jolles J. \& Deelman, B.G. (1992), Brief cogrublive screening tests for dementia: Comparison of the minimental state examination and the cognitive sereening tests. In $\mathrm{H}$. Bouma, \&.A.M. Graafmans (Eds), Geronechnology, Volume 3 (pp. 261-264). Amsterdam: IOS Press.

Ponds, R. W. H. M. Psychologische determinanten wan geheugenklachnen bij gezonde ouderen. In M. M. Blom, Y. Kuin, H. F. J. Hendriks (Eds.), Onder worden 93 (pp. 232-237). Urrecht Nedderlands Insfituut voor Zorg on Wielzujn (NLW),

Ponds, R. W. H. M. \& Jolles, J. (1995), Metamemory and cognitive aging: The Metamemory in Adulthood (MIA) questionnaire. In J. Jolles, P. J. Holx, M. P. J. van Boxtel, \&. R. W. H. M. Ponds (Eds.). The Maastricht Aging Study: Deterninants of cognitue agung (pp. 79.84). Maastricht: Neuropsych Publishers.

Ponds, R. W. H. M. (1997). Vergeetachtigheid, metageheugen en de angst voor dementie. In J. P. Bayens (Ed.). Procedings 19 de Winter Meeting Oostende van de Belgische Vereniging woor Gerontologie en Gericurie (pp. 175-1.79), Leuven: Garant.

Ponds, R. W. H. M. (1998). Cognitiewe veroudering: De inwloed van psychologiseline factoren. Ln P. W. Hujjers, \&. M. M. van Santwoort (Eds.), Onder worden 98 (Chapter 36.135). Utrecht: Nederlands Instituut voor Gerontologie (NlOi).

Schmand, B. \& Ponds, R. W. H. M. (1997). Malingeren: Simuleren en aggraveren. In B. O. Deelman, P. A. T. M. Eling, E. H. F. de Haan, A. Jenmekens-Schinkel, \& A. H. van Zomeren (Eds.) Klinische neuropsychologie (pp. 426\%36). Ansterdam: Boom Uitgeverij.

Verhey, F. R. J., Rozendeal, N. Ponds, R. W. H. M., \& Jolles, J. (1993). Depression and insight in Alzheiner diseass and vascular dementia. In M. Nicoloni, P. F. Zatta, \& B. Corain (Eds.), Algheiner's disease and related disorders (pp. 83-84) Oxford: Pergamon Press.

Vorhey, F.R. J., Rozendal, N. Houx, P. J, de Lugh, M., Ponds, R. W. H. M., de Jolles, J. (1995) Incidence of dementia in subjects attendirg a memory clinic: Resulls of a twa-year follow-up. In J. Jollos, P. J. Houx. M. P.J. van Boxke, \& R. W. H. M. Ponds (Eds.), The Madrich Agmg Study: Deseminants of cogntive agmg (pp.163-170). Massiricht: Neuropsych Publishers.

\section{Selected abstracts: Paper and poster presentations}

Brouwer, W. H., van Zomenen, A. H., Ponds, R. W. H. M. \& wan Wolfelar, P.C. (1989) Divided Athention 5

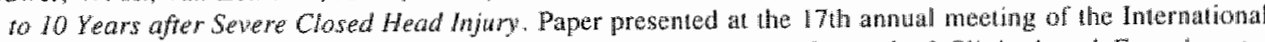
Neuropsychological Society (INS), Vancouver (8-11 February). Jownal of Clinical and Experimental Neuropsychology, 11,34

Brouwer, W. H., Ickenroth, J., Ponds, R. W. H. M., \& van Wolfelatr, P.C. (1989). Divided antentom in old age. Paper presented at the 115 European Congress of Psychology Amstrudam (2-7 July

Eling, P. A. T. M., \& Ponds, R.W.H.M. (1986). Revalidate van dandachistoowissen. Paper presented at the Voorjarsconferentie Nederlandse Vereniging voor Neuropsychologie, Rolterdam (27 May. 


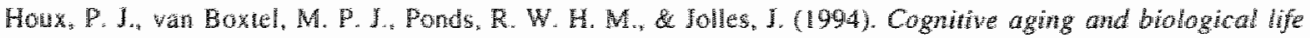
event. Poster presented at heit Intermational Workshop on the borderland berwern normal and patthological

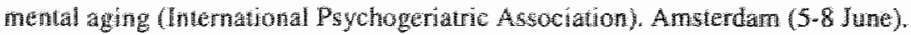

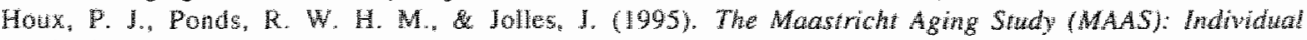
backgroud warwales and cognition. Paper presented al hel IIIrd European congress of Gerontology, Amsterdam (30. Atugust-2 Sephember?.

Houx, P. J., Ponds, R. W. I. M. wan Boxtel, M. P. J., Jolles, J. (1996). The Waastricht Aging Siudy (MAAS): Five yearg follow-up of the first cross-sectional study. Poster presented at the sixh Cognivive Aging Conference, Allanda, OA (25.28 April).

Ponds, R. W. H. M. L Deeman, B. G. (1988). Differen approaches to the rehabilitation of memory disorders. Paper presented the Third European Conference on Research in Rehabilitation, Rotterdam (8-10 June).

Ponds, R. W. H. M., Eling. P.A.T.M. (1988). Atrention traning: Fashions and questoms. Paper presented at the Third European Conterence on Research in Rehabilitation, Roterdam (8-110 June).

Ponds R. W. H. M. Bruning H. A. Jolles J. (1992). Memory training, memory complaints, memory perlormance and depreasion in older adults. Paper presented at the XXWth International Congress of Psychology, Brussels (19-24 July). Mternational Joumal of Psychology, $27,106$.

Ponds, R. W. H. M. Pychologische en psychosaciale deterninamen von geheugenklachten bij ouderen. Paper presented at 'De Gienatrische Revizen', retrate NWO-dwarsverband Gerontologien Gertatrie / Nestor, Amerstoor (ll-2 April).

Ponds, P. W. H. M. (1993) Netropsychologie van hef whiplashsymdroom. Paper presented an the sumposium "Fysiotherapis en het Whiplashtelsel" Apeldoorn (7 May).

Ponds, R. W. H. M. (1994). Malingeren bijneuropsychologisch onderzoek. Paper presented at Voorjaarsconferentie Nederandse Vereniging woor Neuropsychologie ('Neuropsychologische expertise bij letselschade: Mogelijkheden en beperkingen"). Rotherdarn (10 June).

Ponds, R. W. H. M. \& Jolles, J. (1994). Age differences on the Metamemory in Adwhood (MIA) questionnaire in a Duth sample of 2000 subjects. Poster presented at the International Workshop on the borderland between normal and pahological mental aging (International. Psychogeriatric Association), Amsterdam (5-8 June).

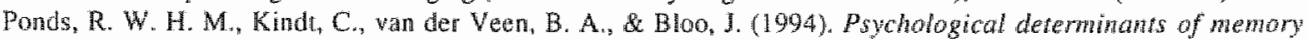

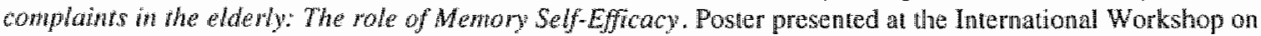
the bordertand between nomal and pathological mental aging (lnternational Psychogeriatric Association), Ansterdam $(5-8$ June $)$.

Ponds, R. W. H. M. Kind, $\mathrm{C}$. \& Jolles, J. (1995). Memony complaints, mentory functioning and contextad factors in elderly. Paper presented at het IIrd European congress of Gerontology Amsterdam (30 Augusil- 2 September).

Ponds, R. W. H. M. (1996). Hoe beoordelen ouderen hum geheugen? Papel presented at the Woorgarscongres Nedemlandse Vereniging van Psychiatrie, Amsterdam (28-29 May).

Ponds, R. W. H. M., \& Jolles, J. (1996). Age-related changes in subjective cognitive funtioning Poster presented at the $24 \mathrm{l}$ andual meeting of the International Neuropsychological Society (INS), Chicago (14-17 February). Jountrit of the Interwationat Newopsychological Society (JNS), 2, 50.

Ponds, R. W. H. M., Jolles, I. (1996). Deteminants of memory complaints in the elderly: The rote of menory

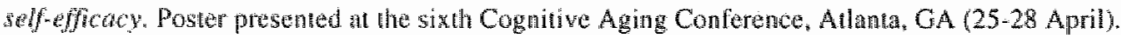

Ponds, R. W. H. M. (1998). Methg wan het subjectewe gehengen. Paper presented at the Voorjatsconferentie Nedenlandse Voreniging voor Neuropsychologie ("Geheugen"), Utrectu (5 June).

Ponds, R. W. H. M. \& J. Jolles (1998). The influence of age, woad, and personality on subjective menomy funcrioning: Results from the Manstrich Aging Sindy. Paper presented at the 9uh European Conference on Petsonality (ECP9), Universily of Surtey, Guildford, UK (7-11 July).

Siaper, S.Z. "konds, R. W. H. M. (1998). Klimische newropsychologische diagnostiek bij het whiplash-lensed. Paper presented al 'De kliniek wan het whiplashtrauma', Ede (12 June).

Verhey, F. R. J., Ponds, R. W. H. M., Reyersen-var Butren, E. J., Vreeling, F. W., \& Jolles, J. (1990), Application of research criteria for dememia in common clinical practice. Poster preserted al the Second Intomational Conference on Alzheiner Disease \& related disorders, Toronto (15-20 July). Nerabobiology of Aging, 1]. 298-299.

Ventey F. R. I. Rozendal N. Ponds R. W. H. M. \& Jolles J (1992). Might and depression in Alzheimer"s discase and wasular dewewta. Paper presented at the Third Intermational Conference on Alzheimer Disease 2 related disonders. Padua, Italy (13-17 July). Newrobiology of Aging. 13, 1 .

Verhey. F. R. J., Rozendaal, N., Ponds, R. W. H. M., de Lugt, M., Houx, P. J." Re Jolles, I. (1994). The

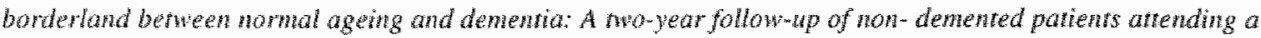


memory dinic. Poster presented at the International Workshop on the borderland between normal and pathological mental aging (International Psyctogeriatric Association), Amsterdim (5-8 June).

Verhey, F. R. J., Wisser, P. J., Ponds, R. W. H. M., Jolles, J. (1997), Prodronen wan de ziekre wan Alzheimer. Paper presented at the Voorjaarscongres Nederlandse Verenging wan Psychiatrie. Noordwitk, the Netherlands (17.18 April).

Verhey, F. R. J., Ponds, R. W. H. M., Visser, P. J., Jolles, J. (1997). Aims, methods and experiences of the Maastrich Memory Clinic (MMC). Paper presented at the Eight congress of the fnternational Psychogeriatric Association (IPA), Jerusalem (17-22 August).

Wekking, E. M., Ponds, R. W. H. M., \& Vingerhoets, A. I. I. M. (1996). Self-reported daily stressors, neuroticism and subjective health in the elderly. Poster presented at the Annual meeting of the American Psychosomatic Society. Williansburg, USA (8-10 March).

\section{Book reviews}

Bijsterveld, K., Ponds R. W. H. M. (1991). Book review 'Alzheimer's Disease. The concept of disease and the construction of medical knowledge by R. Dillmann (thesis). Psychologie en Maatschappij. 15, 298-300.

Ponds, R. W. H. M. (1990). Book review 'Grijze cellen, wijze cellen' by W. H. Brouwer et. al. De Psychoog. $25,183-184$.

Ponds, R. W. H. M. (1990). Book review 'Geheugenboek voor ouderen' by M. Vink. De Psycholoog, 25, 409 410.

Ponds, R. W. H. M. (1991). Book review 'Dat weet ik niet meer. Diagnostiek van dementie' by F. Gilson et al. De Psycholoog, 26, 184-185.

Ponds, R. W. H. M. (1992). Book review 'Traumatic Brain Injury' by B. G. Deelman et al. De Psycholoog, 27. $122-123$.

Ponds, R. W. H. M. (1993). Book review "Memory Functioning in Dementia" by L. Blickman (Ed). Tijdschrift voor Gerontologie en Geriarrie, 24, 255-256.

Ponds, R. W. H. M. Book review 'Memory Rehabilitation for closed head-injured patients' by 1. J. Berg (thesis). De Psycholoog, 1994, 247-248.

\section{Miscellaneous}

Ponds R. W. H. M., \& Aalders, H. (1989). NEUROTEST: An computer-based interactive video-course in neuropsychological exanvination. Nijmegen: Katholieke Universiteit.

Ponds, R. W. H .M. (1997). Memory complaints in the elderly: Prevalence validity and treatment. Seminar presented at the 20 h annual mid-year meeting of the Intermational Neuropsychological Sociery (INS), Bergen, Norway (25-28 June)

Ponds, R. W. H. M., \& Bouwens, M. R. J. (1997). Geheugencursus wor ouderen, Den Bosch: Gezondheid Service Nederland.

Verhey F. R. J., Ponds, R. W. H. M., Jolles, J., \& Commissaris C. J. A. M. (1994). Informatiebrochure "Vergeefachrig?" of dement? Bunnik: Alzheimer Stichting. 